The Evolution of Electricity Markets in Europe 


\section{THE LOYOLA DE PALACIO SERIES ON EUROPEAN ENERGY POLICY}

Series Editor: Jean-Michel Glachant, Holder of the Loyola de Palacio Chair on EU Energy Policy and Director of the Florence School of Regulation, European University Institute, Italy, and Professor of Economics, Université Paris-Sud, France

The Loyola de Palacio Series on European Energy Policy honours Loyola de Palacio (1950-2006), former Vice-President of the European Commission and EU Commissioner for Energy and Transport (1999-2004), a pioneer in the creation of an EU Energy Policy.

This series aims to promote energy policy research, develop academic knowledge and nurture the 'market for ideas' in the field of energy policy making. It will offer informed and up-to-date analysis on key European energy policy issues (from market building to security of supply; from climate change to a low carbon economy and society). It will engage in a fruitful dialogue between academics (including economists, lawyers, engineers and political scientists), practitioners and decision-makers. The series will complement the large range of activities performed at the Loyola de Palacio Chair currently held by Professor Jean-Michel Glachant (Robert Schuman Center for Advanced Studies at European University Institute in Florence, Italy, and University Paris-Sud 11).

Titles in the series include:

Security of Energy Supply in Europe

Natural Gas, Nuclear and Hydrogen

Edited by François Lévêque, Jean-Michel Glachant, Julián Barquín, Christian von Hirschhausen, Franziska Holz and William J. Nuttall

Competition, Contracts and Electricity Markets

A New Perspective

Edited by Jean-Michel Glachant, Dominique Finon and Adrien de Hauteclocque

The Economics of Electricity Markets

Theory and Policy

Edited by Pippo Ranci and Guido Cervigni

Building Competitive Gas Markets in the EU

Regulation, Supply and Demand

Jean-Michel Glachant, Michelle Hallack and Miguel Vazquez

Market Building through Antitrust

Long-term Contract Regulation in EU Electricity Markets

Adrien de Hauteclocque

Electricity Network Regulation in the EU

The Challenges Ahead for Transmission and Distribution

Edited by Leonardo Meeus and Jean-Michel Glachant

The Evolution of Electricity Markets in Europe

Leonardo Meeus 


\section{The Evolution of Electricity Markets in Europe}

Leonardo Meeus

Florence School of Regulation, European University Institute, Italy and Vlerick Business School, Belgium

\section{A. Edward Elgar}

Cheltenham, UK • Northampton, MA, USA 
Leonardo Meeus 2020

All rights reserved. No part of this publication may be reproduced, stored in a retrieval system or transmitted in any form or by any means, electronic, mechanical or photocopying, recording, or otherwise without the prior permission of the publisher.

Published by

Edward Elgar Publishing Limited

The Lypiatts

15 Lansdown Road

Cheltenham

Glos GL50 2JA

UK

Edward Elgar Publishing, Inc.

William Pratt House

9 Dewey Court

Northampton

Massachusetts 01060

USA

A catalogue record for this book

is available from the British Library

Library of Congress Control Number: 2020944718

This book is available electronically in the Elgaronline

Economics subject collection

http://dx.doi.org/10.4337/9781789905472

ISBN 9781789905465 (cased)

ISBN 9781789905472 (eBook) 


\section{Contents}

List of figures

viii

List of tables

ix

List of boxes

List of authors

Acknowledgements

List of abbreviations

Introduction

Structure of this book

$\mathrm{x}$

xi

xiii

$\mathrm{XV}$

$\mathrm{xx}$

xxiii

\section{PART I HOW TO TRADE AND TRANSPORT ELECTRICITY ACROSS NATIONAL BORDERS?}

$1 \quad$ Why did we start with electricity markets in Europe?

Leonardo Meeus with Valerie Reif

1.1 What was the political process that led to electricity markets in Europe?

1.2 What were the technical drivers for creating a European power system?

1.3 What do we know about the benefits of integrating electricity markets in Europe?

1.4 Conclusion

1A.1 Annex: Regulatory Guide

$2 \quad$ Who gets the rights to trade across borders?

Leonardo Meeus with Tim Schittekatte

2.1 How to deal with historical privileges?

2.2 How to implement market-based allocation of transmission rights? 26

2.3 How to implement market coupling in the day-ahead timeframe? 28

2.4 What about the timeframes before day-ahead? 31

2.5 What about the timeframes after day-ahead? 33

2.6 Conclusion 34

2A.1 Annex: The evolution of the role of power exchanges in Europe 38

2A.2 Annex: A simple numerical example of market coupling $\quad 40$

2A.3 Annex: Regulatory guide $\quad 42$ 
$3 \quad$ How to calculate border trade constraints?

Leonardo Meeus with Tim Schittekatte

3.1 Why do we focus so much on constraints?

3.2 Why do we calculate trade constraints on virtual borders? 50

3.3 Who is best placed to do virtual border calculations? 51

3.4 How to organize the data exchange in support of the calculations? 52

3.5 Why are there still open issues?

3.6 Conclusion $\quad 57$

3A.1 Annex: Flow-based market coupling (FBMC) $\quad 60$

3A.2 Annex: Transit flows and loop flows $\quad 61$

3A.3 Annex: Regulatory guide $\quad 62$

$4 \quad$ Who pays for the network when trade is international? $\quad 68$

Leonardo Meeus with Tim Schittekatte

$\begin{array}{ll}4.1 & \text { Who pays for the network? }\end{array}$

4.2 Why did national network tariffs start to be harmonized? 69

4.3 Why was there a move away from transit charges? 71

4.4 How to share network investment costs between countries? 72

$\begin{array}{ll}4.5 \text { Conclusion } & 74\end{array}$

4A.1 Annex: Congestion rent under market coupling: a numerical example $\quad 78$

4A.2 Annex: Regulatory guide $\quad 79$

PART II HOW TO COMBINE ELECTRICITY TRADE WITH SYSTEM SECURITY TO KEEP THE LIGHTS ON?

5 Who is responsible for balancing the system?

Leonardo Meeus with Tim Schittekatte and Valerie Reif

5.1 How to share responsibility between system operators? 84

5.2 How to incentivize market parties to be balanced? 88

5.3 How to ensure that reserves are available? $\quad 89$

5.4 How to integrate balancing markets across borders? 92

5.5 Conclusion 95

5A.1 Annex: Regulatory guide 100 
$6 \quad$ How to organize system operation and connection requirements?

Leonardo Meeus with Valerie Reif

6.1 Why pay attention to detailed technicalities?

6.2 How to organize regional system operation?

6.3 How to introduce minimum technical standards?

6.4 How to proceed with the implementation of technical standards?

6.5 Conclusion

6A.1 Annex: Types of grid users in the RfG and DC NC

6A.2 Annex: Regulatory guide

$7 \quad$ How to ensure adequate investment in power plants?

Leonardo Meeus with Athir Nouicer

7.1 Why did some countries introduce a capacity mechanism?

135

7.2 What is the best capacity mechanism?

7.3 How to limit the (ab)use of capacity mechanisms?

7.4 Conclusion

7A.1 Annex: Taxonomy of capacity mechanisms

7A.2 Annex: Regulatory guide

\section{PART III HOW TO PUT THE CITIZEN AT THE CENTRE OF THE ENERGY TRANSITION?}

8 How to put the citizen at the centre of the energy transition?

Leonardo Meeus with Athir Nouicer

8.1 Why did we start this new paradigm?

8.2 How is this change of paradigm being implemented?

8.3 Conclusion

8A.1 Annex: Regulatory guide

9 Conclusion

164

Leonardo Meeus 


\section{Figures}

$0.1 \quad$ The sequence of electricity markets in Europe $\quad \mathrm{xx}$

1.1 The main steps in the evolution of European electricity markets 3

1.2 The development of TSOs at the national and European levels and a selection of their tasks

1.3 The development of regulatory authorities at the national and European $\begin{array}{ll}\text { levels and a selection of their tasks } & 7\end{array}$

1.4 A basic representation of the power system using a tandem bicycle 10

2.1 Implementation of different allocation methods for cross-border transmission rights in Europe in 2004

2.2 Explicit cross-zonal allocation: hourly price difference between Germany and the Netherlands (x-axis) versus the hourly sum of nominated net flows from Germany to the Netherlands in 2004 (y-axis)

2A.1 European power exchange mergers and acquisitions (non-exhaustive)

3.1 Bidding zones in Europe as of November 2019

3.2 Left: the five regional security coordinators (RSCs) as of 1 January 2019; right: the ten capacity calculation regions (CCRs)

3.3 The common grid model (CGM) merging process

3A.1 Scheduled flows (black), transit flows (white, left) and loop flows (white, right); the different rectangular areas represent bidding zones

4.1 The Norway-Sweden case (left) and the Italy-Greece case (right)

6.1 Capacities lost at the frequencies reached in the three areas during the split of the Continental European system on 4 November 2006

6.2 Evolution of RSCIs into RSCs and then RCCs and a selection of their tasks 114

6.3 Timelines from publication to entry into application of RfG NC and DC NC 117

6A.1 Illustration of the terms 'demand facility', 'distribution facility' and 'distribution system' as used in the DC NC 


\section{Tables}

1A.1 Regulatory guide 16

2.1 Different design choices for the implementation of market coupling 29

2A.1 Regulatory guide $\quad 42$

3A.1 Regulatory guide $\quad 62$

4.1 Maximum annual average transmission charges paid by producers $\begin{array}{ll}\text { according to Regulation (EU) No 838/2010 } & 70\end{array}$

4A.1 A numerical example of congestion rent calculation 78

$\begin{array}{lll}\text { 4A.2 Regulatory guide } & 79\end{array}$

$\begin{array}{lll}5.1 & \text { Terminology for reserve products } & 85\end{array}$

5.2 Market shares of the largest BSP for FRR between 2003 and 2005

$\begin{array}{lll}\text { 5A.1 Regulatory guide } & 100\end{array}$

6.1 Limits for thresholds for different types of power-generating modules $\quad 117$

6.2 Frequency ranges and duration of connection requirements by synchronous area for PGMs of all types and transmission-connected demand facilities, transmission-connected distribution facilities, distribution systems and demand units providing demand response services $\quad 119$

6.3 Compliance of different types of power-generating modules with a selection of technical requirements as described in the RfG NC

$\begin{array}{lll}6 \text { A.1 Regulatory guide } & 127\end{array}$

7A.1 Taxonomy of capacity mechanisms 145

$\begin{array}{lll}\text { 7A.2 Regulatory guide } & 146\end{array}$

$\begin{array}{llr}\text { 8A.1 Regulatory guide } & 158\end{array}$ 


\section{Boxes}

$1.1 \quad$ Nicknaming EU legislation 4

1.2 The EU Clean Energy Package 5

1.3 The first generation of EU electricity network codes and guidelines 8

1.4 Implications of the EU Clean Energy Package for EU network codes and guidelines 9

3.1 The Italian blackout of 28 September 2003

$\begin{array}{lll}4.1 & \text { Two examples of innovative CBCA practices } & 73\end{array}$

5.1 Primary frequency control in UCTE and frequency-controlled reserves in NORDEL $\quad 86$

6.1 RfG NC and DC NC timelines and national implementation processes $\quad 117$

$\begin{array}{lll}7.1 & \text { Rationing or load-shedding plans and controversies } & 136\end{array}$

$\begin{array}{lll}7.2 & \text { The Tempus case } & 138\end{array}$ 


\section{List of authors}

Leonardo Meeus is Professor of Strategy and Corporate Affairs at Vlerick Business School. $\mathrm{He}$ is the Director of the Vlerick Energy Centre. He is also a Professor in the Florence School of Regulation at the European University Institute. In Florence, he is Course Director of online courses on the latest regulatory trends in the energy sector, such as the EU Clean Energy Package and the EU electricity network codes. He is a member of the International Association for Energy Economics. Leonardo graduated from KU Leuven as a business engineer. He later obtained a $\mathrm{PhD}$ in electrical engineering from the same university. He works as an expert for EU institutions, regulatory agencies and companies on research contracts and in advisory roles.

\section{CHAPTER CO-AUTHORS}

Athir Nouicer has been working as a research associate at the Florence School of Regulation (FSR) since 2017, where he is part of the electricity regulation research team. His main research interests are the EU Clean Energy Package and the use of flexibility in distribution grids. He is currently also a $\mathrm{PhD}$ researcher at KU Leuven. Before joining FSR, Athir worked at the Deutsche Gesellschaft für Internationale Zusammenarbeit (GIZ) as an energy expert for the German-Tunisian Energy Partnership. He graduated as a mechanical engineer from the National Engineering School of Tunis and holds two master's degrees under the EMIN programme: in the Digital Economy and Network Industries from Université Paris Sud XI and in the Electric Power Industry from Universidad Pontificia Comillas.

Valerie Reif has been working as a research associate at the Florence School of Regulation (FSR) since 2018, where she is part of the electricity regulation research team. Her main research interests are currently the EU electricity network codes and the management and exchange of electricity network, market and consumer data. Before joining FSR in 2018, she worked at the technology platform Smart Grids Austria, and gathered valuable experience at Austrian Power Grid and at the EU Representation Office of Oesterreichs Energie. Valerie holds both a BSc and an MSc degree in Renewable Energy Engineering from the University of Applied Sciences Technikum Wien in Austria and a BA in European Studies from the University of Passau in Germany.

Tim Schittekatte has been a research associate at the Florence School of Regulation since 2016, where he is part of the electricity regulation research team. His main research interests are currently EU electricity network codes, flexibility markets and distribution network tariff design. He is also affiliated with the Vlerick Energy Centre in Brussels. Before joining FSR, he was a visiting researcher at the Grid Integration Group at the Lawrence Berkeley National 
Lab and a junior economist at Microeconomix in Paris. He graduated as an engineer from Ghent University, Belgium and completed an international master's in economics (the EMIN programme). He holds a $\mathrm{PhD}$ in energy economics from Université Paris-Sud XI. 


\section{Acknowledgements}

Like all scientific work, this book stands on the shoulders of giants. Some have been mentors and colleagues at KU Leuven, the Florence School of Regulation or Vlerick Business School. Others have been partners in executive education, research projects or studies for EU institutions, regulatory authorities and companies. Equally important are those who need their work to be confirmed or challenged by academic research. We share a passion for electricity markets and for the European integration process.

You will find the following electricity market giants in the reference lists and the endnotes, and I also want to warmly thank them here: Carlos Batlle, Ronnie Belmans, Anna Creti, Erik Delarue, Adrien de Hauteclocque, William D'haeseleer, Daniel Dobbeni, Christophe Gence-Creux, Jean-Michel Glachant, Tomás Gómez San Román, Leigh Hancher, Peter Kaderjak, Christopher Jones, François Lévêque, Karsten Neuhoff, Ignacio Perez-Arriaga, Andris Piebalgs, Michael Pollitt, Joe Perkins, Alberto Pototschnig, Konrad Purchala, Pippo Ranci, Vincent Rious, Fabien Roques, Marcelo Saguan, Matti Supponen, Frauke Thies, Leen Vandezande, Jorge Vasconcelos, Jean-Arnold Vinois, Niels-Henrik von der Fehr and Christian von Hirschhausen.

This book has also benefited greatly from the online learning community at the Florence School of Regulation. Thanks go to the directors and founders of this unique school: Jean-Michel Glachant, Pippo Ranci, Ignacio Pérez-Arriaga and Jorge Vasconcelos. Thanks also go to Klaus-Dieter Borchardt, Susanne Nies, Alberto Pototschnig and Laurent Schmitt for supporting the training collaboration between the European Commission, ACER, ENTSO-E and the Florence School of Regulation on the evolution of electricity markets with the EU electricity network codes and the EU Clean Energy Package.

I thank the experts and colleagues who contributed to the online training sessions: Olivier Aine, Daniela Bernardo, Klaus-Dieter Borchardt, Chiara Canestrini, Victor Charbonnier, Anna Colucci, Paul de Wit, Ellen Diskin, Christian Dobelke, Edwin Edelenbos, Uros Gabrijel, Ilaria Galimberti, Christophe Gence-Creux, Paul Giesbertz, Sotiris Georgiopolous, Leigh Hancher, Christopher Jones, Anne-Marie Kehoe, Oliver Koch, Mathilde Lallemand, Christine Lyon, Maria Eugenia Leoz Martin-Casallo, Claudio Marcantonini, Rafael Muruais Garcia, Rickard Nilson, Martin Povh, Konrad Purchala, Mario Ragwitz, Ariana Ramos, Ioannis Retsoulis, Hélène Robaye, Josh Roberts, Julius Rumpf, Manuel Sanchez-Jimenez, Peter Schell, Laurent Schmitt, Salla Sissonen, Markela Stamati, Matti Supponen, Frauke Thies, Ernst Tremmel, Sonya Twohig, Mark van Stiphout, Chara Vlachou, Kirsten Wilkeshuis and Annika Zorn.

I also thank the alumni and colleagues who helped us improve the course texts that have inspired this book: Erik Ahlström, Olivier Aine, Eblerta Ajeti, Alia Al-Hathloul, Elena Alonso, Christopher Andrey, Carlos Arsuaga, Adrien Atayi, Guénolé Aumont, Ross Baldick, Pradyumna Bhagwat, Irina Boiarchuk, Joanna Bolesta, Anatolie Boscaneanu, Basile Bouquet, Marco Campagna, Zaza Chikhradze, Daniel Daví-Arderius, Anne de Geeter, Miguel Manuel 
de Villena, Francis Dike, Ellen Diskin, Piero Dos Reis, Žilvinas Dragūnas, Alexander Dusolt, Gianluca Flego, Marco Foresti, Lars Olav Fosse, Mathieu Fransen, Eivind Gamme, Stamatia Gkiala Fikari, Samson Hadush, Bastian Henze, Lenka Jancova, Tata Katamadze, Nico Keyaerts, Mathias Katz, Vrahimis Koutsoloukas, Randi Kristiansen, Ketevan Kukava, Mariam Kukava, Patrícia Lages, Mathilde Lallemand, Olivier Lamquet, Sam Lansink, Mathias Lorenz, Dijana Martinčić, Emilie Milin, Matteo Moraschi, Nadine Mounir, Frank Nobel, Louise Nørring, Marco Savino Pasquadibisceglie, Marco Pavesi, Konstantinos Petsinis, Ralph Pfeiffer, Martin Pistora, Marta Poncela, Lorenz Rentsch, Ioannis Retsoulis, Martin Roach, Nicolò Rossetto, Ali Sefear, Susana Serôdio, Ioannis Theologitis, Athanasios Troupakis, Per Arne Vada, Mihai Valcan, Ellen Valkenborgs, Waldo Vandendriessche, Marco Vilardo, Michael Wilch, Steve Wilkin, Nynke Willemsen, Peter Willis, Cherry Yuen and David Ziegler.

I would also like to thank the hundreds of participants who interacted with us in these online training sessions and motivated us to write this book.

Finally, I thank Athir Nouicer, Valerie Reif and Tim Schittekatte. We co-teach in the online training sessions and we also co-authored this book. They are the next generation of giants in the field of electricity markets. We enjoyed writing this book and we hope you will enjoy reading it. 


\section{List of abbreviations}

\begin{tabular}{|c|c|}
\hline 4MMC & 4M Market Coupling \\
\hline $\mathrm{AC}$ & Alternating Current \\
\hline ACER & $\begin{array}{l}\text { (European Union) Agency for the Cooperation of Energy } \\
\text { Regulators }\end{array}$ \\
\hline aFRP & Automatic Frequency Restoration Process \\
\hline aFRR & Automatic Frequency Restoration Reserves \\
\hline $\mathrm{AM}$ & Available Margin \\
\hline APX & Amsterdam Power Exchange \\
\hline Belpex & Belgian Power Exchange \\
\hline BRP & Balance Responsible Party \\
\hline BSP & Balancing Service Provider \\
\hline CACM GL & Capacity Allocation and Congestion Management Guideline \\
\hline CBA & Cost-Benefit Analysis \\
\hline CBCA & Cross-Border Cost Allocation \\
\hline CCGT & Combined Cycle Gas Turbine \\
\hline C-component & Consumer component \\
\hline CCR & Capacity Calculation Region \\
\hline $\mathrm{CE}$ & Continental Europe \\
\hline CEC & Citizen Energy Community \\
\hline CEE & Central Eastern Europe \\
\hline CEER & Council for European Energy Regulators \\
\hline $\mathrm{CEF}$ & Connecting Europe Facility \\
\hline CEP & Clean Energy for all Europeans Package (Clean Energy Package) \\
\hline CGM & Common Grid Model \\
\hline CGS & Critical Grid Situation \\
\hline CHP & Combined Heat and Power \\
\hline $\mathrm{CNC}$ & Connection Network Code \\
\hline $\mathrm{CNE}$ & Critical Network Element \\
\hline $\mathrm{CO} 2$ & Carbon Dioxide \\
\hline CoBA & Coordinated Balancing Area \\
\hline
\end{tabular}




\begin{tabular}{|c|c|}
\hline CWE & Central Western Europe \\
\hline $\mathrm{DC}$ & Direct Current \\
\hline $\mathrm{DC} \mathrm{NC}$ & Demand Connection Network Code \\
\hline $\mathrm{DE}$ & Germany \\
\hline DER & Distributed Energy Resource \\
\hline DG COMP & Directorate-General for Competition \\
\hline DLMP & Distribution Locational Marginal Pricing \\
\hline DSO & Distribution System Operator \\
\hline EB GL & Electricity Balancing Guideline \\
\hline $\mathrm{EC}$ & European Commission \\
\hline ECJ & European Court of Justice \\
\hline EENS & Expected Energy Not Served \\
\hline EEX & European Energy Exchange \\
\hline ENTSO-E & $\begin{array}{l}\text { European Network of Transmission System Operators for } \\
\text { Electricity }\end{array}$ \\
\hline ENTSOG & European Network of Transmission System Operators for Gas \\
\hline EPAD & Electricity Price Area Differential \\
\hline ER NC & Emergency and Restoration Network Code \\
\hline ERGEG & European Regulators' Group for Electricity and Gas \\
\hline ETSO & European Transmission System Operators \\
\hline EU & European Union \\
\hline EUPHEMIA & Pan-European Hybrid Electricity Market Integration Algorithm \\
\hline EXPLORE & $\begin{array}{l}\text { European X-border Project for LOng-term Real-time balancing } \\
\text { Electricity market design }\end{array}$ \\
\hline FBMC & Flow-Based Market Coupling \\
\hline FCA GL & Forward Capacity Allocation Guideline \\
\hline FCR & Frequency Containment Reserves \\
\hline FERC & Federal Energy Regulatory Commission \\
\hline FRCE & Frequency Restoration Control Error \\
\hline FRP & Frequency Restoration Process \\
\hline FRR & Frequency Restoration Reserves \\
\hline FTR & Financial Transmission Right \\
\hline $\mathrm{g}$ & gram \\
\hline GB & Great Britain \\
\hline G-component & Generator component \\
\hline GCT & Gate Closure Time \\
\hline
\end{tabular}


GLDPM

GLIP

GSK

HVDC

HVDC NC

$\mathrm{Hz}$

IGCC

IGD

IGM

ISO

ISP

ITC

JAO

$\mathrm{kg}$

KORRR

$\mathrm{kWe}$

$\mathrm{kWh}$

LFC

LOLE

LPX

LSK

MARI

MCO

mFRR

$\mathrm{mHz}$

MNA

MRC

MW

MWh

NEMO

NORDEL

NRA

NTC

OPDE
Generation and Load Data Provision Methodology

Gas Interconnection Poland-Lithuania

Generation Shift Key

High Voltage Direct Current

Requirements for Grid Connection of High Voltage Direct

Current Systems and Direct Current-Connected Power Park

Modules Network Code

Hertz

International Grid Control Cooperation

Implementation Guidance Document

Individual Grid Model

Independent System Operator

Imbalance Settlement Period

Inter-TSO compensation

Joint Allocation Office

kilogram

Key Organizational Requirements, Roles and Responsibilities

kilowatt-electric

kilowatt-hour

Load Frequency Control

Loss of Load Expectation

Leipzig Power Exchange

Load Shift Key

Manually Activated Reserves Initiative

Market Coupling Operator

Manual Frequency Restoration Reserves

millihertz

Multi-NEMO Arrangement

Multi-Regional Coupling

Megawatt

Megawatt-hour

Nominated Electricity Market Operator

Nordic Cooperation of Electricity Utilities

National Regulatory Authority

Net Transfer Capacity

Operational Planning Data Environment 


\begin{tabular}{|c|c|}
\hline OPPM & Offshore Power Park Module \\
\hline ORDC & Operating Reserve Demand Curves \\
\hline OTC & Over the Counter \\
\hline PCI & Projects of Common Interest \\
\hline PCN & Physical Communication Network \\
\hline PGM & Power-Generating Module \\
\hline PICASSO & $\begin{array}{l}\text { Platform for the International Coordination of Automated } \\
\text { Frequency Restoration and Stable System Operation }\end{array}$ \\
\hline PPM & Power Park Module \\
\hline PTDF & Power Transfer Distribution Factor \\
\hline PTR & Physical Transmission Right \\
\hline PUN & Prezzo Unico Nazionale \\
\hline PV & Photovoltaic \\
\hline RAM & Remaining Available Margin \\
\hline RCC & Regional Coordination Centre \\
\hline REC & Renewable Energy Community \\
\hline RED II & $\begin{array}{l}\text { Directive (EU) } 2018 / 2001 \text { on the promotion of the use of energy } \\
\text { from renewable sources }\end{array}$ \\
\hline RfG NC & Requirements for Grid Connection of Generators Network Code \\
\hline $\mathrm{RoCoF}$ & Rate of Change of Frequency \\
\hline RR & Replacement Reserves \\
\hline RSC & Regional Security Coordinator \\
\hline RSCI & Regional Security Coordination Initiative \\
\hline SCC & Security Coordination Centre \\
\hline SDAC & Single Day-Ahead Coupling \\
\hline SEE & South-Eastern Europe \\
\hline SGU & Significant Grid User \\
\hline SIDC & Single Intraday Coupling \\
\hline SMM & Serbia, Macedonia and Montenegro \\
\hline SO GL & System Operation Guideline \\
\hline SOR & System Operation Region \\
\hline SPGM & Synchronous Power-Generating Module \\
\hline SvK & Svenska Kraftnät \\
\hline TCM & Terms and Conditions or Methodologies \\
\hline TEN-E & Trans-European Energy Networks \\
\hline TERRE & Trans-European Restoration Reserves Exchange \\
\hline
\end{tabular}


TSO

TYNDP

UCTE

UIOSI

UK

US

VoLL

XBID
Transmission System Operator

Ten-Year Network Development Plan

Union for the Coordination of the Transmission of Electricity

Use-It-Or-Sell-It

United Kingdom

United States

Value of Lost Load

Cross-Border Intraday 


\section{Introduction}

In Europe, there is a sequence of electricity markets that starts years before the actual delivery takes place and continues up to real time. Thanks to a regulatory process driven by European Union institutions, most countries now have a very similar sequence of electricity markets. Some of these markets have already evolved from national markets into European markets, while others remain national or regional.

Figure 0.1 illustrates the sequence of electricity markets in Europe. There are wholesale markets to price the electric energy commodity. They include forward markets as well as day-ahead and intraday markets. There are also markets to put prices on transmission capacity. These markets are integrated with the commodity markets for the short term, but not for the longer term (Chapter 2). There are also separate markets for reserves or balancing services, from year-ahead balancing capacity markets to close to real-time balancing energy markets (Chapter 5). Finally, there are markets to correct the outcomes of the wholesale and balancing markets.

Corrections are needed because wholesale and balancing markets do not yet fully consider transmission and distribution network constraints. The corrective markets are referred to as redispatching markets in the context of transmission networks (Chapter 3 and Chapter 5) and flexibility markets in the context of distribution networks (Chapter 5 and Chapter 8). They

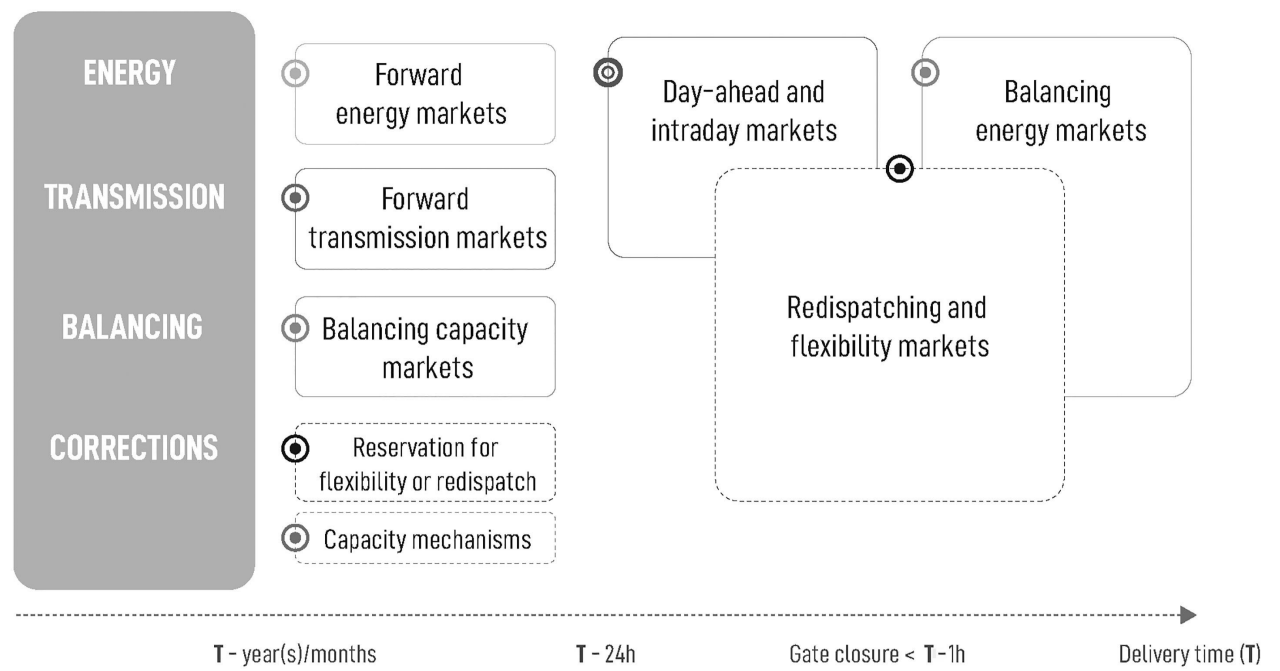

Figure $0.1 \quad$ The sequence of electricity markets in Europe 
can be separate markets or integrated into balancing markets or intraday markets. Corrections are also needed if wholesale and balancing markets do not result in adequate investment in generation capacity, demand-side flexibility or energy storage assets, and these corrections are called capacity mechanisms. They price resource adequacy (Chapter 7).

Day-ahead markets were the first to be integrated into a European market, and were followed by intraday and balancing energy markets. Forward transmission markets are centralized in one European platform (Chapter 2). Balancing capacity markets are still mainly national or regional with only some aspects Europeanized. There is little effort to integrate capacity mechanisms, and we do not yet know what will happen to redispatching markets and flexibility markets. Finally, transit charges for transporting electricity over borders have been abolished, and this happened long before roaming charges for mobile phones were abolished (Chapter 4).

The benefits of electricity market integration were not clear at the start of the process. Only after the markets developed at the national level with increasing transparency could the benefits of integration at the European scale be assessed. Today, we have the evidence, and it confirms that the benefits are significant (Chapter 1).

In this book, we tell the story of how Europeans have experienced the evolution of electricity markets since the end of the 1990s. As far as we know, this experiment has not yet been bundled into a book that bridges theory and practice. This has motivated us to document this unique European creation.

Defining moments in the process include the four waves of European legislative packages (Chapter 1), a landmark court case and a software bug (Chapter 2), an Italian blackout (Chapter 3), delayed clocks (Chapter 5), a cruise ship (Chapter 6), the financial crisis (Chapter 7) and school strikes and climate marches (Chapter 8).

In each chapter we will also refer to both issues that have been settled and issues that are still open and we continue to face today. There are too many to list them all here, but here are a few examples. Settled issues include explicit versus implicit auctions (Chapter 2), flow-based market coupling (Chapter 3), the inter-TSO compensation mechanism (Chapter 4), single versus dual pricing and regional versus European platforms in balancing markets (Chapter 5), and the connection requirements for wind and solar units (Chapter 6). Open issues include product definitions in forward transmission markets and transmission allocation in the intraday market (Chapter 2), the configuration of bidding zones (Chapter 3), creating a level playing field for all grid users to access electricity markets (Chapter 4), the filtering of balancing bids by system operators and transmission capacity reservation for balancing (Chapter 5), the connection requirements for storage units (Chapter 6), the role of capacity mechanisms (Chapter 7 ), and a new paradigm to put the citizen at the centre of the energy transition (Chapter 8).

Looking back, most of the market integration process so far required horizontal coordination between transmission system operators from different countries. Looking forward, vertical coordination between transmission and distribution system operators is becoming more important, and this coordination process has only just started. We no longer talk about completing the integration of electricity markets in Europe; instead, we embrace the process and go with the flow. We hope you will do the same after reading this book.

If you are a European academic or practitioner, this book will provide you with the necessary background to the debates that you are involved in. You will learn the language used in the world of electricity markets in Europe. In each chapter, we include endnotes with the 
main references and an annex with a regulatory guide to the legislative texts and regulatory decisions that are driving the market integration process. A few key technical concepts are also explained in the annexes.

If you are a non-European involved in the development of an international or multi-region electricity market, the book gives you a list of issues you will face, together with the European solutions. Your context is different, so you might need different solutions, but you can still learn from the trial and error process we have gone through in Europe.

In combination with this European tour, you might like a global tour and a more in-depth discussion of electricity market theory. We warmly recommend that you read the Handbook on Electricity Markets by Jean-Michel Glachant, Paul Joskow and Michael Pollitt, which together with this book is published by Edward Elgar. 


\title{
Structure of this book
}

\author{
- PART I: HOW TO TRADE AND TRANSPORT ELECTRICITY ACROSS NATIONAL \\ BORDERS? \\ - Chapter 1: Why did we start with electricity markets in Europe? \\ - Chapter 2: Who gets the rights to trade across borders? \\ - Chapter 3: How do you calculate border trade constraints? \\ - Chapter 4: Who pays for the network when trade is international?
}

Electricity is not transported in trucks or by rail as it cannot easily be stored. It is delivered instantly when we need it through the cables that connect our homes to a system that includes many power plants that jointly produce the electricity we need when we use it. It is one of the engineering wonders of our time. To allow electricity markets to function, we need many rules and regulations that clarify the roles and responsibilities of all involved. European countries have only been willing to harmonize these rules when it has been necessary to capture the benefits from integrating markets across national borders. We have often only done the right thing after trying everything else. In this first part of the book, we highlight the issues that we have faced since the start of the integration of electricity markets in Europe.

\section{- PART II: HOW TO COMBINE ELECTRICITY TRADING WITH SYSTEM SECURITY TO KEEP THE LIGHTS ON? \\ - Chapter 5: Who is responsible for balancing the system? \\ - Chapter 6: How to organize system operation and connection requirements? \\ - Chapter 7: How to ensure adequate investment in power plants?}

For other products and services, markets produce price signals that limit shortages. If a shortage seems to be on the horizon, prices go up and investment follows. If shortages do occur, the users of the product or service who are last in line have to wait. In the case of electricity, if there are shortages there is rationing, so we share the pain. Candles at home can be cosy for a few hours but they provide little consolation when you are trapped in a lift or a metro. Without electricity, nothing in our society works. All kinds of safeguards have therefore been put in place to intervene in electricity markets when needed. These interventions tend to be more national than European, but some progress has been made in cross-border collaboration in Europe to reduce costs and to limit market distortions. In the second part of the book, we discuss how this works.

- PART III: HOW TO PUT THE CITIZEN AT THE CENTRE OF THE ENERGY TRANSITION?

- Chapter 8: How to put the citizen at the centre of the energy transition? 
We used to think of citizens as electricity consumers. When electricity markets were introduced to replace the national monopolies that dominated the sector, the promise was that it would result in cheaper prices and better service. Soon after markets were introduced, Europe also started to decarbonize its electricity sector by subsidizing renewable energy and energy efficiency. The energy transition made the system more sustainable but drove up prices, as about a third of an electricity bill is made up with taxes and levies to recuperate costs from subsidies that have been granted. To keep them on board, citizens have now been offered a new deal. Instead of remaining passive consumers, they can become active by producing their own electricity with smart buildings, by engaging in peer-to-peer trade or by joining energy communities. In the third part of the book, we discuss these recent developments and their impact on electricity markets. 


\section{PART I}

How to trade and transport electricity across national borders? 


\section{Why did we start with electricity markets in Europe?}

\section{Leonardo Meeus with Valerie Reif}

In this chapter we answer three questions. First, what was the political process that led to electricity markets in Europe? Second, what were the technical drivers for creating a European power system? Third, what do we know about the benefits of integrating electricity markets in Europe?

\subsection{WHAT WAS THE POLITICAL PROCESS THAT LED TO ELECTRICITY MARKETS IN EUROPE?}

From a political perspective, the integration of electricity markets followed three main steps, with increasing levels of detail: European treaties, EU legislative energy packages and more detailed market rules that have been developed in the process of creating EU electricity network codes and guidelines.

First are the European treaties. The aim to create a common market to eliminate trade barriers between Member States dates back to the founding Treaty of Rome in 1957. Twenty-nine years later, the Single European Act of 1986 was adopted as the first major revision of the Treaty of Rome. It paved the way for what was to become one of the main achievements of the European project: the Single European Act required the adoption of measures with the aim of establishing an internal market by 31 December $1992 .{ }^{1}$ Later that year, the Council (1986) adopted energy policy objectives for the European Community, among which was that of ' $g r e a t e r$ integration, free from barriers to trade, of the internal energy market with a view to improving security of supply, reducing costs and improving economic competitiveness'. In 1988, the Commission of the European Communities published the first document on the internal energy market, which assessed that there were still considerable barriers to trade in energy products within the Community (EC 1988). On 1 January 1993, the European Single Market became a reality for the 12 Member States at that time. However, integrating the energy sector into the European Single Market alongside other goods proved lengthier and more complex than had originally been anticipated. The year 1993 turned out to be only the starting point of a long, and still ongoing, process to build an EU internal market for electricity, as we will show in this book. One reason was the legacy structure of the energy sector and the non-existence of markets at the national level. Up to the mid-1990s, the electricity sector was still dominated by state-owned or state-controlled vertically integrated utilities with regional or national monopolies. Cross-border trade was limited due to a lack of infrastructure and rules to organize this trade. 


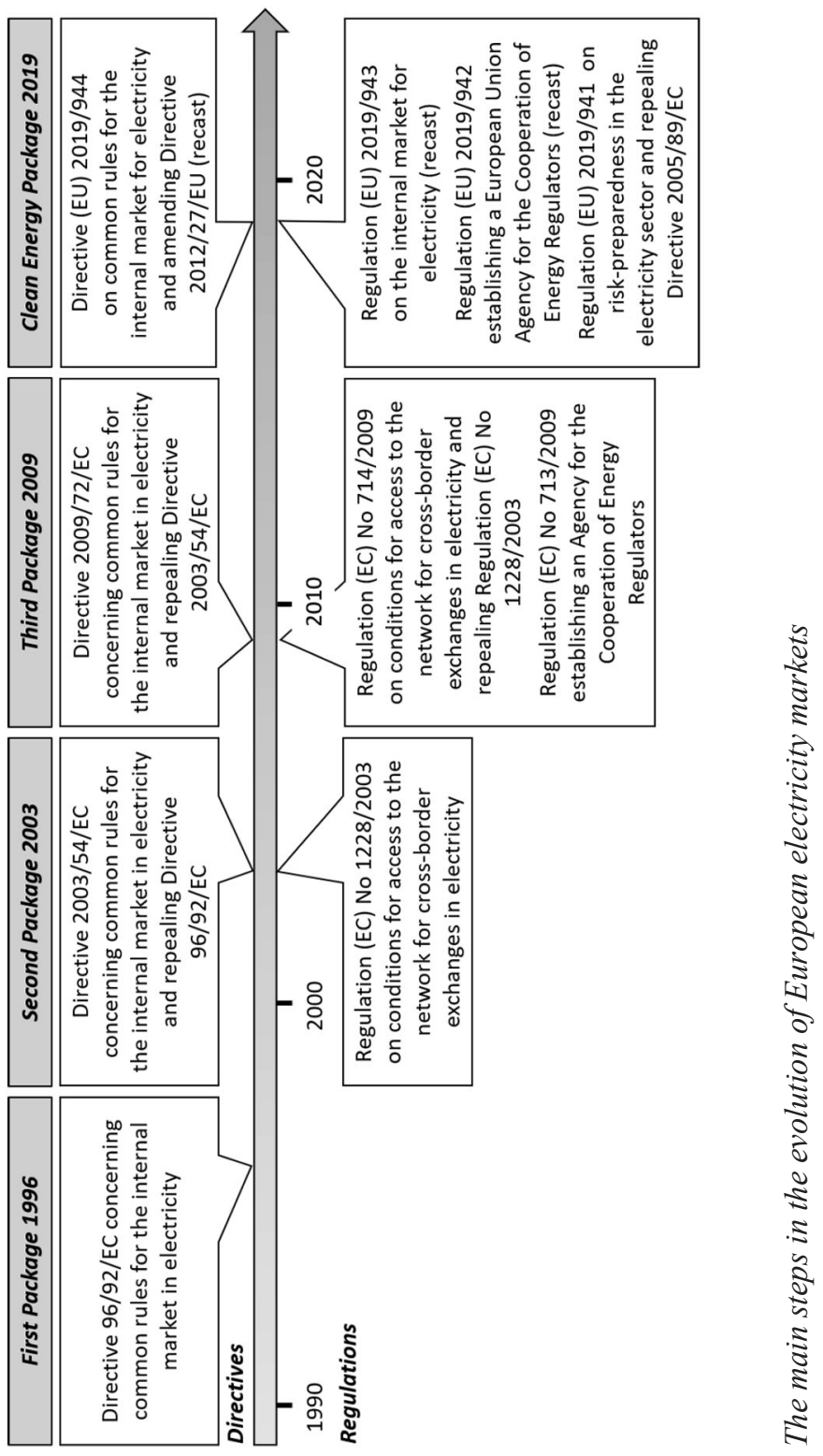

-1
0
01
010 
Second are the EU legislative energy packages. Profound changes were introduced to the national electricity sectors in three Electricity Market Directives in 1996, 2003 and 2009, as is shown in Figure 1.1. More recently, a fourth directive was adopted in 2019. All the directives are part of a so-called energy package. While the first three packages included one directive each for the electricity and the gas sectors plus a varying number of regulations for both sectors, the Clean Energy for All Europeans Package (Clean Energy Package, CEP) did not address the gas sector directly. Curiously enough, the naming of these packages follows its own logic, as is described in Box 1.1.

\section{BOX 1.1 NICKNAMING EU LEGISLATION}

Over the years, we have made an interesting observation regarding the naming of EU directives and regulations in the electricity sector.

Almost all the pieces of legislation have received nicknames that are widely applied. As a result of this practice, nobody remembers any of the official numbers of the regulations. In other words, Directive 96/92/EC is known as the First Directive, Directive 2003/54/EC as the Second Directive and so forth. One exception is Regulation 1228, where the number became the nickname.

It should also be noted that the development of nicknames lacked consistency and logic. Prior to the third package becoming the Third Package, it was called the Two Plus Package for a short while. This was to imply that the resulting package would merely consist of light amendments to the Second Package rather than a new package, which it turned out to be in the end. In the case of the latest package, several nicknames existed, such as Fourth Package, 2030 Package and Jumbo Package. After a brief period of Winter Package, the winner that finally emerged was Clean Energy Package.

Perhaps you are wondering why we even mention these nicknames. The reason is that if you want to become part of the industry the importance of speaking its language should not be underestimated.

The First Package and Directive 96/92/EC (First Directive) kicked off the liberalization process by introducing a distinction between the regulated part of the sector (network) and the competitive parts (generation and supply). However, it left a large margin of choice for the Member States as to how to introduce more competition into their electricity markets, resulting in significant differences in the level of market opening. Despite its failure to deliver the degree of liberalization originally intended, the First Directive gave the Member States and their national utility champions a taste of what was to come. ${ }^{2}$ In the following decades, national markets were gradually opened with the Second, the Third and the Clean Energy Package entering into force. As we will refer to the changes brought by the CEP throughout this book, Box 1.2 provides an introduction to it. 


\section{BOX 1.2 THE EU CLEAN ENERGY PACKAGE}

The Clean Energy Package is the latest of four packages that have been introducing fundamental changes to national electricity sectors since the 1990s. The CEP development process aimed to push forward the energy transition that started with the publication of draft legislative texts by the European Commission in November 2016. In June 2019, the adoption process was completed following the publication of the final legislative texts in the Official Journal of the European Union. The CEP consists of four directives and four regulations, which are listed below.

The regulations are Regulation (EU) 2018/1999 or 'Regulation on the Governance of the Energy Union', published on 21 December 2018; Regulation (EU) 2019/941 or 'Regulation on Risk-Preparedness', published on 14 June 2019; Regulation (EU) 2019/942 or the '(Recast of the) ACER Regulation', published on 14 June 2019; and Regulation (EU) 2019/943 or the '(Recast of the) Electricity Regulation', published on 14 June 2019.

The directives are Directive (EU) 2018/844 or the 'Energy Performance in Buildings Directive', published on 19 June 2018; Directive (EU) 2018/2001 or the 'Renewable Energy Directive (RED II)', published on 21 December 2018; Directive (EU) 2018/2002 or the 'Energy Efficiency Directive', published on 21 December 2018; and Directive (EU) 2019/944 or the '(Recast of the) Electricity Directive', published on 14 June 2019.

Regulation (EU) 2019/943 and Directive (EU) 2019/944 are the ones of most importance in the developments described in this book. The date of application of Regulation (EU) 2019/943 is 1 January 2020. Member States have 18 months to transpose Directive (EU) 2019/944 into national law. The European Commission will review the implementation of Directive (EU) 2019/944 and Regulation (EU) 2019/943 by 31 December 2025 and 31 December 2030 respectively. The Commission will submit a report to the European Parliament and the Council, accompanied by legislative proposals where appropriate.

Note that a major part of the early legislation focused on setting the conditions and creating the institutions necessary for electricity markets to function, but not on the actual market design or detailed market rules. In what follows, we illustrate this for transmission system operators (TSOs) and national regulatory authorities (NRAs).

As is illustrated in Figure 1.2, TSOs have been gradually made more independent from generation, which is referred to as the unbundling process. The First Package only required management and accounting unbundling. The Second Package took unbundling a step further in requiring transmission and distribution companies to apply legal unbundling from 1 July 2004 and 1 July 2007 respectively. The Third Package finally provided that as of 3 March 2012 TSOs had to be certified by the competent NRA under one of the three unbundling models: full Ownership Unbundling; Independent System Operator; and Independent Transmission Operator. Ownership unbundling emerged as the dominant model in Europe. ${ }^{3}$ The Third Package also required all the TSOs to create the European Network of Transmission System Operators for Electricity (ENTSO-E) and to cooperate through this new institution at the European level. Figure 1.2 lists some of the TSOs' and ENTSO-E's tasks, which have clearly been increasing with each legislative package that has been adopted. We do not discuss them here, as they will be covered in the various chapters of this book. The Clean Energy Package also requires the establishment of an entity of distribution system operators in the Union (EU 


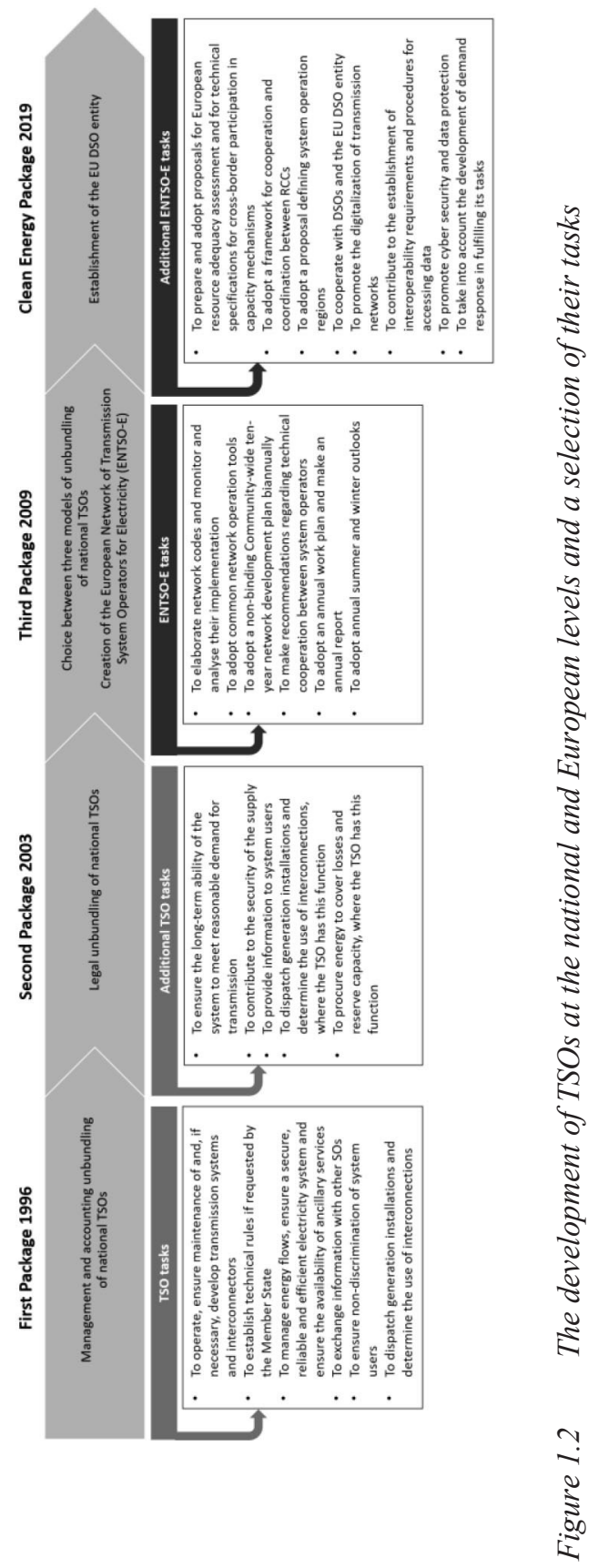




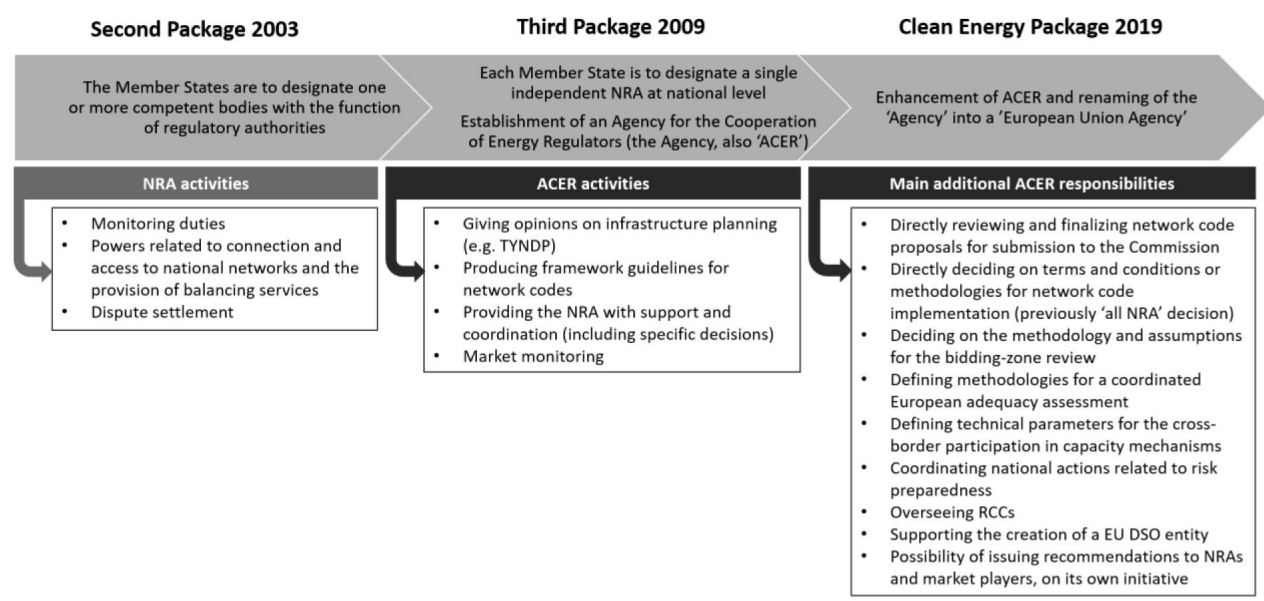

Figure 1.3 The development of regulatory authorities at the national and European levels and a selection of their tasks

DSO entity) to increase efficiencies in the electricity distribution networks and to ensure close cooperation with TSOs and ENTSO-E. ${ }^{4}$

As is illustrated in Figure 1.3, NRAs have gradually been made more independent of the industry and national governments. Initially, some countries like Germany did not see the need for an energy regulator but relied on combinations of self-regulation and competition authorities. The Second Package eventually put an end to such arrangements by requiring Member States to create national regulatory bodies that are independent of the electricity industry. The Third Package increased the independence of NRAs from national governments and also mandated the establishment of the Agency for the Cooperation of Energy Regulators (ACER). ${ }^{5}$ Figure 1.3 lists some of the NRAs' and ACER's tasks, which have clearly been increasing with each legislative package that has been adopted. We do not discuss them here, as they will be covered in the various chapters of this book.

Third are the more detailed market rules that have been developed through the process of creating EU network codes and guidelines. The first generation of network codes and guidelines were adopted after a lengthy co-creation process involving the European institutions, ENTSO-E, ACER and many stakeholders from across the electricity sector. This first generation consisted of eight legislative acts that entered into force between 2015 and the end of 2017. As we will refer to these network codes and guidelines throughout the book, Box 1.3 provides an introduction to the eight network codes and guidelines, their scope, and the related development, implementation and amendment processes. 


\section{BOX 1.3 THE FIRST GENERATION OF EU ELECTRICITY NETWORK CODES AND GUIDELINES}

The network codes and guidelines of the first generation can be subdivided into three groups or 'code families' as listed below.

- Market codes: the capacity allocation and congestion management guideline (CACM GL), published on 25 July 2015; the forward capacity allocation guideline (FCA GL), published on 27 September 2016; the electricity balancing guideline (EB GL), published on 23 November 2017.

- Connection network codes (CNCs): the network code on requirements for grid connection of generators (RfG NC), published on 14 April 2016; the network code on demand connection (DC NC), published on 18 August 2016; the network code on requirements for grid connection of high voltage direct current systems and direct current-connected power park modules (HVDC NC), published on 8 September 2016.

- Operation codes: the electricity transmission system operation guideline (SO GL), published on 25 August 2017; the electricity emergency and restoration network code (ER NC), published on 24 November 2017.

These are commonly referred to as 'the network codes', but not all of them are legally defined as network codes. Four of the eight are guidelines (CACM GL, FCA GL, EB GL and SO GL) and the other four are network codes (ER NC, RfG NC, DC NC and HVDC NC). Initially, all eight were planned to be developed as network codes, yet some became guidelines in the development process. In theory, network codes and guidelines can cover the same topics. In practice, however, it is observed that some topics lend themselves better to guidelines than to network codes and others vice versa.

Both similarities and differences between network codes and guidelines exist. Network codes and guidelines are similar in that they carry the same legal weight (both are Commission regulations and are legally binding), are directly applicable (they do not need to be transposed into national law) and are subject to the same formal adoption procedure ('old' comitology procedure). Network codes and guidelines differ from each other regarding their legal basis, the stakeholder involvement, their amendment process, topics and scope, and the adoption of further rules during the implementation phase. Indeed, the main difference is the work to be done during the implementation phase, which we explain in the following.

In general, network codes are more detailed than guidelines. Guidelines shift a larger share of the further development to the implementation phase, which can allow for more flexibility but can also slow down or complicate the overall process. Guidelines include processes whereby TSOs or Nominated Electricity Market Operators (NEMOs, see also Chapter 2) must develop so-called 'Terms and Conditions or Methodologies (TCM)'. TCMs are comprehensive (legal) texts that are often referred to as 'methodologies'. In most cases, methodologies have to be jointly developed by all TSOs or all NEMOs at the pan-European level or by the relevant TSOs/NEMOs at the regional or national levels. Depending on the scope of the methodologies, the Third Package foresaw their approval either by all NRAs (pan-European methodologies) or by the relevant subset of NRAs (regional and national 
methodologies). In certain cases, a decision is to be referred to ACER. ENTSO-E, ACER and the European Commission have monitoring, reporting and stakeholder involvement responsibilities related to methodologies. The implementation of the TCMs foreseen in the first generation of network codes and guidelines will continue until around 2025. We will refer to some of these methodologies in this book where relevant.

The regulatory guide in Annex 1A.1 provides detailed references to the relevant legislation.

Note: $\quad$ Our colleagues Hancher et al. (2020) published a research report which provides more details on the legal technicalities of the EU electricity network codes and guidelines.

For the first generation of network codes and guidelines, TSOs were placed in the position of drafting network codes through ENTSO-E with regulatory oversight. You may wonder why regulators have not been put in the position to develop these market rules. The typical answer given to this question in the European context is that the level of detail and technical complexity was such that the industry was asked to develop solutions that were then challenged by the regulators rather than vice versa. However, the perception has been that TSOs have not always developed solutions fast enough and that stakeholder involvement in the process has been insufficient. Following the Clean Energy Package, significant changes including shifts in roles and responsibilities have been introduced for both existing and future generations of EU network codes and guidelines, as is shown in Box 1.4.

\section{BOX 1.4 IMPLICATIONS OF THE EU CLEAN ENERGY PACKAGE FOR EU NETWORK CODES AND GUIDELINES}

In 2019, the adoption of the Clean Energy Package brought significant changes for both existing and future generations of EU network codes and guidelines. First, the development process saw a shift in roles and responsibilities. The strong role of ENTSO-E in drafting the network codes was reduced. The CEP also mandates the establishment of an EU DSO entity to involve distribution system operators (DSOs) in the network code and guideline drafting process. The role of ACER in the development phase is expected to increase. Another change concerns the time interval in which the European Commission is required to compile a priority list for new network codes.

Second, changes were introduced to the adoption process for both the TCM and new network codes and guidelines. Regarding TCMs, ACER now directly decides on the methodologies with a pan-European scale (former 'all NRA' decisions). Regarding network codes and guidelines, the Clean Energy Package distinguishes between the adoption of network codes and guidelines as implementing or delegated acts. Depending on the type of act, the European institutions and stakeholders have different rights and possibilities to intervene in the adoption process.

In other words, the story of EU network codes and guidelines as a way to push forward the market integration process in Europe continues. The scope of areas in which detailed market rules can be developed has increased and the process has been fine-tuned. How it will work in detail remains to be seen and can be reported in a future edition of this book. 
Note that we now have thousands of pages filled with detailed market rules, but they do not prescribe a standard market design that everybody needs to follow. In fact, the new rules simply reduce the degree of freedom that countries have in designing their markets. This is why it is difficult to read the European market rules. They do not explicitly explain the design; the resulting design is implicit. In this book, we will make it explicit.

\subsection{WHAT WERE THE TECHNICAL DRIVERS FOR CREATING A EUROPEAN POWER SYSTEM?}

In this section we will see that there are technical advantages of scale. ${ }^{6}$ For example, a larger power system is more stable as it has a higher level of inertia, which makes it easier for system operators to keep the lights on. Another technical advantage of integration in this context was the development of a solidarity mechanism between European countries that pre-dated the creation of markets. To better understand these technical issues, we will use a tandem bicycle analogy that is often used to explain power systems to non-engineers. Note that we are not exhaustive in our description and only refer to certain elements of this analogy. ${ }^{7}$

Imagine a tandem bicycle moving at a constant speed as illustrated in Figure 1.4. The task of the dark grey cyclists (power stations) is to generate the electrical energy that keeps the entire system going. The light grey figures (loads) are not generating any of this energy, but the aim of the overall system is to keep them moving nevertheless. The chain connecting all the elements in the system represents the electrical transmission network. To maintain the same velocity the chain must turn the wheels at a constant rate. In addition, constant physical tension is required in the upper part of the chain. These two features can be respectively translated into a need for a fixed constant frequency to guarantee a well-functioning system and a need for a fixed voltage level for grid connections in an electricity network.

To transmit the pedalling movement (energy) to the chain, different connections between the cyclists and the chain exist. A first type of dark grey cyclist (large thermal and nuclear power stations connected to the grid with transformers) have their pedals directly connected to the chain with one gear, which means they have to constantly pedal at the right speed and with the right amount of power. A second type of dark grey cyclist (e.g. hydropower stations with

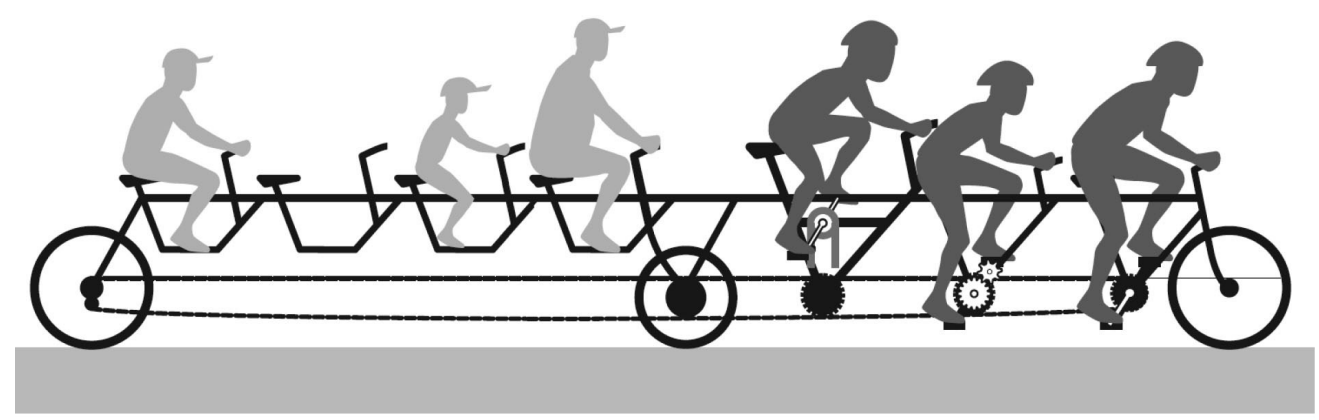

Note: Load is light grey and generation is dark grey.

Figure 1.4 A basic representation of the power system using a tandem bicycle 
their turbines connected to generators) may prefer to cycle more slowly and have their force transformed to the right speed with a gear system. A third type (e.g. wind turbines connected with a frequency inverter) is connected through a belt and a gear system, allowing them to pedal at varying speed. There are also different types of loads, but we will not explain them in detail here.

The complex task of power system management requires both the speed (frequency) and the tension of the chain (voltage level) to remain steady, even in the event of unexpected imbalances between load and generation. One of the technical advantages of scale is that the more synchronously connected rotating machines a power system has (dark grey cyclists types one and two), the more stable it is as it has a higher level of inertia. Inertia represents the ability of synchronously connected rotating machines to store and inject their kinetic energy into the system. Inertia slows down a frequency drop/spike immediately after a sudden mismatch between supply and demand (e.g. a power station outage or an unexpected change in the load connected to the network). If the system inertia is low, a small sudden difference between load and generation causes a high-frequency deviation. It is important to note that inertia only supports frequency in nearly instantaneous situations where an imbalance is caused by a sudden disconnection of large units or a nearly instantaneous change in production or load. Inertia does not support frequency under 'normal' imbalance conditions when the imbalance is caused by a prognosis error and resulting differences between production and consumption plans. System inertia is typically higher for larger synchronous power systems as the kinetic energy available and therefore the system's inertia increases with the number of generators and motors that are coupled to the grid.

However, system inertia can only slow down frequency deviations; it is not able to restore the power balance between generation and load. Therefore, some of the dark grey cyclists (power stations) do not pedal at full power. Instead, they conserve some of their energy to be able to provide extra or replacement force (reserves) when it is needed. TSOs, which are responsible for safeguarding system security within their control areas, must ensure that there are enough reserves to regulate frequency and respond to possible emergency situations. In a stand-alone system, such reserves must typically be large enough to cope with the most severe incident, which usually corresponds to a loss of the largest generator in one TSO's control area. A clear advantage of interconnecting control zones to form a large synchronous area is that reserves can be pooled and the relative importance of the most severe incident decreases as system size increases. Such solidarity schemes for reserve sharing in which each TSO can draw on the reserves in other TSOs' control zones whenever needed were implemented in synchronous areas long before markets were introduced. We will come back to the balancing mechanism that is in place today in Chapter 5. We will also come back to the technical requirements that different types of assets that are connected to the power system need to comply with in Chapter 6.

\subsection{WHAT DO WE KNOW ABOUT THE BENEFITS OF INTEGRATING ELECTRICITY MARKETS IN EUROPE?}

The initial focus of cross-border cooperation was on system stability as mentioned in the previous section and sharing of reserves as we will explain in the following. Sharing of reserves aimed at a more effective use of energy resources and optimal operation of electric power 
plants enabled by the interconnection of electricity networks. For example, by exporting electricity across borders, countries with large hydropower resources could prevent surplus production in their own country while at the same time allowing for savings in coal consumption in the neighbouring country. Similar qualitative reasoning is still valid in Europe today, as a single energy market is believed to take better advantage of the differences in industrial policy, available natural resources, weather conditions and load patterns across countries. For example, France is dominated by nuclear, Germany still has a large share of coal and Norway has significant hydro capacities, while the UK, Spain and Italy have higher relative shares of gas in their electricity mix. Countries with a large share of electrical heating such as France and Norway have larger differences between summer and winter consumption levels than countries with other heating sources. Time differences between countries can also be a source of differences in demand peaks. More recently, an important aspect of integration has been a better use of renewable resources due to uneven wind and solar conditions across Member States. Trade between European countries came only later, which was also due to the structure of the energy sector dominated by vertically integrated monopolies. However, already in the pre-liberalization period, long-term cross-border power purchase agreements with neighbouring utilities were sometimes preferred to authorizing the construction of new domestic power plants.

In the early 2000 s the new competitive environment was slowly manifesting itself as a result of the first two energy packages. At that time, questions were raised on how large the benefits of liberalization were, how these benefits could be reaped, and who could reap these benefits. The European Commission published several benchmarking reports to evaluate the implementation of electricity (and gas) directives in the early 2000s. These reports put forward indicators to check the health of particular markets. Competitive activity was measured with market development indicators related to concentration and new entries (e.g. the share of the three biggest generators, the share of the three biggest suppliers, the main retail supplier entrant type), switching estimates for different types of customers, price development (price convergence between Member States, price levels for different customer groups) and trade between Member States (the level of cross-border electricity exchange, use of interconnector capacity). None of the reports, however, included a quantification of the benefits of integrating national electricity markets to create an EU internal market for electricity. Only around 2012 did the European Commission task consultants with assessing the benefits of an integrated European electricity market. They concluded that the benefit was several billions of euros a year, an order of magnitude that was later confirmed by ACER. In its annual market monitoring report, ACER has been gradually improving its methodology to estimate these benefits and has also gone a long way in making the information that goes into the calculation more readily available. The ACER annual market monitoring report is a must-read for everybody reading this book. As it is highly technical, this book will give you the necessary background to be able to read it. ${ }^{8}$

More recently, the political developments around Brexit have led academics to estimate the potential cost of disruptions in electricity trade if the UK were to leave the European Union without a suitable trade deal. The electricity market in Great Britain, that is England, Scotland and Wales, is currently a single bidding zone, which is connected to Belgium, France and the Netherlands, and also to Northern Ireland and the Republic of Ireland. At the time of writing, uncertainty remains as to whether the political Brexit includes an 'Elecxit' (the UK leaving 
the EU internal energy market) and what longer-term consequences such a loss of a relatively small piece of the European electricity markets and the halting of interconnector expansion between Great Britain and neighbouring EU Member States would have. Academics have found that the 2030 cost to Britain of a hard electricity Brexit with little interconnector expansion and decoupled markets would amount to several hundreds of million euros a year. ${ }^{9}$

\subsection{CONCLUSION}

In this first chapter on why we started with electricity markets, we have answered three questions. First, what was the political process that led to electricity markets in Europe? The aim of creating a European internal energy market had been on the agenda of the European institutions since the 1980s. Over the period 1996 to 2019, four EU legislative energy packages were adopted that aimed to integrate and harmonize national electricity markets and mandated the creation of ENTSO-E and ACER to drive the process. EU network codes and guidelines were created that set out more detailed market rules. The Clean Energy Package introduced significant changes to the processes of developing, adopting, amending and implementing existing and future generations of network codes and guidelines.

Second, what were the technical drivers for creating a European power system? A clear advantage of larger power systems is their greater stability as they typically have larger numbers of synchronously connected rotating machines which increases the level of system inertia. Another technical advantage of scale is that the relative importance of the most severe incident decreases as system size increases and reserves to cope with such incidents can be pooled across TSO control zones. Such technical cooperation and reserve sharing among TSOs for mutual support through interconnections in case of emergencies pre-dated markets.

Third, what do we know about the benefits of integrating electricity markets in Europe? The qualitative benefits of exchanging electricity across borders to take advantage of the differences in generation mixes, weather conditions and load patterns have long been acknowledged by European countries. A more recent motivation has been to make better use of renewable resources due to uneven wind and solar conditions across Member States. The economics of market integration became clearer when information became available to assess the benefits. In 2013, an initial study found that the benefit of implementing an integrated EU electricity market was several billions of euros a year, an order of magnitude that was later confirmed by ACER. More recently, the potential cost to Great Britain of leaving the internal energy market as a part of the political Brexit has been estimated to be in the order of several hundred million euros a year by 2030 .

\section{NOTES}

1. It can be confusing to keep up with the varying terminology used for the European Single Market project, that is, common, internal and single market. The original treaties used the term 'common market' without providing a definition. Legal literature suggests that the concept of the common market went beyond the four freedoms and also included various policy areas such as agriculture, competition and state aid. Later, the term 'common market' was replaced with 'internal market' in the treaties, referring to an area without internal frontiers in which the free movements of goods, persons, services and capital are ensured. While the objectives remained the same, the procedures to adopt related legislation changed from unanimity (common market) to qualified majority voting 
(internal market). The term 'single market' can be considered an informal synonym of 'internal market'. Note that in some languages, only one word exists (e.g. 'Binnenmarkt' in German).

2. Hancher (2002) discusses the successes and failures of the First Electricity Directive of 1996 in introducing a competitive environment in national electricity sectors. Vasconcelos (2005), the founder of the Council for European Energy Regulators (CEER) in 2000, explains that the First Energy Directive provided little guidance as regards cross-border energy trade, the development of regional markets, interaction with non-EU markets, the development of interconnectors, the supra-national integration of energy markets and so on. Hence, a 'regulatory gap' between national markets and the EU internal energy market emerged. He elaborates on how Regulation (EC) No 1228/2003, which we will discuss in Chapter 2, represented the Commission's attempt to close the 'regulatory gap', which was shown to be not possible on a voluntary basis.

3. CEER (2016) provides an overview and explanation of the different unbundling models applied across European Member States. TSOs also continue to change, as is seen in the example of the Greek TSO. ADMIE moved from the Independent Transmission Operator model to the Ownership Unbundling model as a consequence of changes in the ownership and share structure (CEER 2019).

4. We do not cover the EU DSO entity in this book as there are still many open issues at the time of writing. In the future, the EU DSO entity is expected to play a significant role for example as regards the preparation and implementation of new network codes, where relevant for distribution networks. We might therefore include its tasks and responsibilities in a future edition of this book.

5. Glachant et al. (2008) analyse the institutional mechanisms of the German self-regulation arrangement that lasted from 1998 to 2005. Pototschnig (2019) provides a comprehensive overview of developments from the creation of ACER to its future as foreseen in the Clean Energy Package. Jones (2016) provides a full overview of the Third Energy Package, including the topics discussed here of common electricity wholesale markets, the unbundling of TSOs, NRAs and the coming into existence of ACER, and the regulation of cross-border electricity exchanges.

6. Many of the technical, economic and regulatory fundamentals we touch on in this book are discussed in depth in Pérez-Arriaga (2013), which is a must-read for anybody entering the sector or wanting to refresh their knowledge of some of the basic concepts the electricity sector deals with on a daily basis.

7. We do not know who came up with this analogy, but were inspired by Söder (2002) and Fassbinder and De Wachter (2005). Many thanks to our colleague Daniela Bernardo, who produced the drawing in Figure 1.4, which is an enhanced version of a drawing in Söder (2002).

8. DG TREN (2001) was the first of four benchmarking reports published by the Commission of the European Communities. Booz \& Company (2013) is the consultancy study. ACER and CEER (2019) is the annual market monitoring report. Newbery et al. (2016) provide an academic discussion of the methodology that is used in these reports.

9. This paragraph is based on the work of Geske et al. (2020), who calculate the estimated 2030 cost of Great Britain leaving the EU internal market for electricity based on a microeconomic model of decoupled markets between Great Britain and France. Newbery (2020) discusses their results in a brief review for Nature Energy.

\section{REFERENCES}

ACER and CEER (2019), 'Annual Report on the Results of Monitoring the Internal Electricity and Natural Gas Markets in 2018 - Electricity Wholesale Markets Volume'.

Booz \& Company (2013), 'Benefits of an Integrated European Energy Market', Final Report prepared for Directorate-General Energy European Commission.

CEER (2016), 'Status Review on the Implementation of Transmission System Operators' Unbundling Provisions of the 3rd Energy Package', CEER Status Review Ref: C15-LTF-43-04.

CEER (2019), 'Implementation of TSO and DSO Unbundling Provisions - Update and Clean Energy Package Outlook', CEER Status Review Ref: C18-LAC-02-08.

Council (1986), 'Council Resolution of 16 September 1986 Concerning New Community Energy Policy Objectives for 1995 and Convergence of the Policies of the Member States (86/C 241/01)'. 
DG TREN (2001), 'First benchmarking report on the implementation of the internal electricity and gas market. SEC (2001) 1957', Commission Staff Working Paper.

EC (1988), 'The internal energy market', Commission Working Document COM(88) 238 Final.

Fassbinder, S. and B. De Wachter (2005), 'The electrical system as a tandem bicycle', accessed at www .gonder.org.tr/wp-content/uploads/2015/04/ElectricityTandem.pdf\%0A\%0A.

Geske, J., R. Green and I. Staffell (2020), 'Elecxit: The cost of bilaterally uncoupling British-EU electricity trade', Energy Economics, 85, 104599.

Glachant, J.-M., U. Dubois and Y. Perez (2008), 'Deregulating with no regulator: Is the German electricity transmission regime institutionally correct?', Energy Policy, 36 (5), 1600-10.

Hancher, L. (2002), 'Slow and not so sure: Europe's long march to electricity market liberalization', Electricity Journal, 10 (9), 92-101.

Hancher, L., A.-M. Kehoe and J.Rumpf (2020), 'The EU Electricity Network Codes and Guidelines: A Legal Perspective', Research Report, European University Institute.

Jones, C. (ed.) (2016), EU Energy Law Volume I: The Internal Energy Market, 4th ed., Deventer, Netherlands and Leuven, Belgium: Claeys \& Casteels.

Newbery, D. M. (2020), 'The cost of uncoupling', Nature Energy, 5 (3), 187-8.

Newbery, D., G. Strbac and I. Viehoff (2016), 'The benefits of integrating European electricity markets', Energy Policy, 94, 253-63.

Pérez-Arriaga, I. J. (ed.) (2013), Regulation of the Power Sector, Springer-Verlag London.

Pototschnig, A. (2019), 'The ACER experience', in S. Nies (ed.), The European Energy Transition: Actors, Factors, Sectors, Deventer, Netherlands and Leuven, Belgium: Claeys \& Casteels, pp. 175-211.

Söder, L. (2002), 'Explaining power system operation to non-engineers', IEEE Power Engineering Review, 22 (4), 25-7.

Vasconcelos, J. (2005), 'Towards the internal energy market, how to bridge a regulatory gap and build a regulatory framework', European Review of Energy Markets, 1 (1). 


\section{A.1 ANNEX: REGULATORY GUIDE}

\section{Table 1A.1 Regulatory guide}

\author{
Section of this chapter, topic and relevant regulation \\ Section 1.1 \\ The aim to create a common market to eliminate trade barriers \\ between Member States dates back to the founding Treaty of \\ Rome in 1957.
}

The Single European Act of 1986 required the adoption of measures with the aim of establishing an internal market by 31 December 1992.

The Council (1986) adopted energy objectives for the European Community.

In 1988, the Commission of the European Communities published the first document on the internal energy market, which assessed that there were still considerable barriers to trade in energy products within the Community.

Directive 96/92/EC kicked off the liberalization process by introducing a distinction between the regulated part of the sector and competitive parts.
Relevant articles

Art. 2 of the Treaty of Rome states that 'The Community shall have as its task, by establishing a common market and progressively approximating the economic policies of Member States, to promote throughout the Community a harmonious development of economic activities, a continuous and balanced expansion, an increase in stability, an accelerated raising of the standard of living and closer relations between the States belonging to it.'

The Treaty includes, among many other things, provisions on the free movement of goods (Title I) and the free movement of persons, services and capital (Title III).

Art. 13 of the Single European Act states that '... the Community shall adopt measures with the aim of progressively establishing the internal market over a period expiring on 31 December 1992 ... The internal market shall comprise an area without internal frontiers in which the free movement of goods, persons, services and capital is ensured ...'

In the Council Resolution of 16 September 1986, the Council of the European Communities ' ... 5. considers that the energy policy of the Community and of the Member States must endeavour to achieve the following horizontal objectives: ... (d) greater integration, free from barriers to trade, of the internal energy market with a view to improving security of supply, reducing costs and improving economic competitiveness.' The Commission Working Document COM(88) 238 final on the internal energy market of 2 May 1988 states in its Part Two on the suggested priorities regarding the obstacles related to the establishment of a single energy market that the 'barriers are very diverse in type and significance... Most of them are the end-product of domestic rules and regulations originating in an often distant past predating European ideas: this applies for example to all the potential obstacles arising from purely domestic monopolies. ...'

As illustrations, recital 22 of Directive 96/92/EC states that it is ... necessary to establish common rules for the production of electricity and the operation of electricity transmission and distribution systems'; and recital 30 states that 'in order to ensure transparency and non-discrimination, the transmission function of vertically integrated undertakings should be operated independently from the other activities.' 
Section of this chapter, topic and relevant regulation

However, Directive 96/92/EC left a large margin of choice for the Member States as to how to introduce more competition into their electricity markets.

The First Package only required management and accounting unbundling.

The Second Package required transmission and distribution companies to apply legal unbundling.

The Third Package required TSOs to be certified by the competent NRA under one of three unbundling models.
Relevant articles

Art. 7(5) and Art. 11(2) state for TSOs and DSOs respectively that they shall not 'discriminate between system users or classes of system users, particularly in favour of [their] subsidiaries or shareholders.'

Recital 11 of Directive 96/92/EC states that 'in accordance with the principle of subsidiarity, general principles providing for a framework must be established at Community level, but their detailed implementation should be left to Member States, thus allowing each Member State to choose the regime which corresponds best to its particular situation'; and recital 12 states further that ' whatever the nature of the prevailing market organisation, access to the system must be open in accordance with this Directive and must lead to equivalent economic results in the States and hence to a directly comparable level of opening-up of markets and to a directly comparable degree of access to electricity markets.'

Art. 14(3) of Directive 96/92/EC states that 'Integrated electricity undertakings shall, in their internal accounting, keep separate accounts for their generation, transmission and distribution activities, and, where appropriate, consolidated accounts for other, non-electricity activities, as they would be required to do if the activities in question were carried out by separate undertakings, with a view to avoiding discrimination, cross-subsidization and distortion of competition.'

Art. 10 and Art. 15 of Directive 2003/54/EC state for TSOs and DSOs respectively that 'Where the [TSO,DSO] is part of a vertically integrated undertaking, it shall be independent at least in terms of its legal form, organisation and decision making from other activities not relating to [transmission, distribution]. These rules shall not create an obligation to separate the ownership of assets of the [TSO, DSO] from the vertically integrated undertaking.'

Art. 9 of Directive 2009/72/EC specifies rules on the unbundling of transmission systems and TSOs. While Art. 9(1) implies that the preferred model is ownership unbundling, Art. 9(8) gives Member States the possibility not to apply Art. 9(1) where 'on 3 September 2009, the transmission system belongs to a vertically integrated undertaking'. In such cases, Member States are given a choice between ownership unbundling and setting up a system operator or transmission operator which is independent from supply and generation interests.

Art. 10 of Directive 2009/72/EC lays down the rules for the designation and certification of transmission system operators. 


\begin{tabular}{l}
\hline Section of this chapter, topic and relevant regulation \\
The Third Package also required all the TSOs to create and \\
cooperate via ENTSO-E.
\end{tabular}
cooperate via ENTSO-E.

The selection of TSO and ENTSO-E tasks according to the First, Second, Third and Clean Energy Package listed in Figure 1.2 .

The Clean Energy Package also requires the establishment of an entity of distribution system operators in the Union (EU DSO entity).

The Second Package required Member States to create national regulatory bodies that are independent of the electricity industry.

The Third Package increased the independence of NRAs from national governments and mandated the establishment of ACER.

The selection of NRA and ACER tasks according to the Second, Third and Clean Energy Package listed in Figure 1.3.
Relevant articles

Art. 4 of Regulation (EC) No 714/2009 requires all TSOs to 'cooperate at Community level through the ENTSO for Electricity, in order to promote the completion and functioning of the internal market in electricity and cross-border trade and to ensure the optimal management, coordinated operation and sound technical evolution of the European electricity transmission network.'

Art. 5 of the same Regulation lays down the process of establishing ENTSO-E.

The tasks of TSOs described are laid out in Art. 7 and Art. 8 of Directive 96/92/EC and Art. 9 and Art. 11 of Directive 2003/54/EC.

The tasks of ENTSO-E described are laid out in Art. 8 of Regulation (EC) No 714/2009 and Art. 30 of Regulation (EU) 2019/943.

Arts. 52 to 57 of Regulation (EU) 2019/943 lay down provisions for the EU DSO entity.

Art. 23(1) of Directive 2003/54/EC states that 'Member States shall designate one or more competent bodies with the function of regulatory authorities. These authorities shall be wholly independent from the interests of the electricity industry. They shall ... at least be responsible for ensuring non-discrimination, effective competition and the efficient functioning of the market ...'

Art. 35 of Directive 2009/72/EC lays out the rules on the designation and independence of regulatory authorities. Art. 35(1) says that 'Each Member State shall designate a single national regulatory authority at national level.' Art. 35(5.a) specifies that 'In order to protect the independence of the regulatory authority, Member States shall in particular ensure that: (a) the regulatory authority can take autonomous decisions, independently from any political body, and has separate annual budget allocations ...'

Regulation (EC) No 713/2009 establishes ACER and puts forward the following motivation in recital 3: 'it is widely recognised by the sector ... that voluntary cooperation between national regulatory authorities should now take place within a Community structure with clear competences and with the power to adopt individual regulatory decisions in a number of specific cases.'

The tasks of NRAs described are laid out in Art. 23 of Directive 2003/54/EC.

The tasks of ACER described are laid out in Chapter II, Arts. 5-11 of Regulation (EC) No 713/2009 and Arts. 3-15 of Regulation (EU) 2019/942. 


Section of this chapter, topic and relevant regulation
Network codes and guidelines are adopted in a lengthy
co-creation process involving the European institutions,
ENTSO-E, ACER and many stakeholders from across the
electricity sector.
Network codes and guidelines carry the same legal weight,
are directly applicable, and are subject to the same adoption
procedure.
Network codes and guidelines differ from each other with
regard to their legal basis (Art. 6 of Regulation (EC) No
$714 / 2009$ for network codes and Art. 8 of the same regulation
for guidelines), development process, amendment process and
implementation process.

implementation process.
Relevant articles

Development of network codes: Under the Third Package, the network code development process includes multiple steps as specified in Art. 6 of Regulation (EC) No 714/2009 and simplified in the following.

First, after having consulted ACER, ENTSO-E and other relevant stakeholders, the European Commission establishes an annual priority list for possible network code areas. Second, at the request of the European Commission, ACER develops a non-binding framework guideline setting out principles for the development of such network codes and consults with ENTSO-E and other relevant stakeholders. If the European Commission considers that the framework guideline does not contribute to non-discrimination, effective competition and the efficient functioning of the market, it may request ACER to review and resubmit the framework guideline. If ACER fails to submit a framework guideline, the European Commission itself elaborates the framework guideline. Third, the European Commission requests ENTSO-E to develop and submit to ACER a network code based on the ACER framework guideline. Fourth, ACER consults relevant stakeholders and provides ENTSO-E with a reasoned opinion on the network code. Fifth, ENTSO-E may amend the network code in the light of the ACER opinion and resubmit it to ACER. Sixth, when satisfied that the network code is in line with the framework guideline, ACER submits the network code to the European Commission and may recommend its adoption. Adoption of network codes is in the hands of the European Commission. The European Commission provides reasons in the case where it does not adopt the network code. Where ENTSO-E has failed to develop the network code, the European Commission may request ACER to prepare a draft network code. On its own initiative or on the failure of ENTSO-E (ACER) to develop a (draft) network code or on recommendation by ACER, the European Commission may also adopt one or more network codes. Where the European Commission proposes to adopt a network code on its own initiative, it consults ACER, ENTSO-E and the relevant stakeholders.

Amendment of network codes: Amendments to network codes under the Third Package may be proposed to ACER by any person who is likely to have an interest in that network code, including ENTSO-E, TSOs, system users and consumers. ACER may also propose amendments on its own initiative. ACER consults stakeholders and may make a reasoned proposal for amendment to the European Commission. Taking account of the ACER proposals, the European Commission may adopt amendments to any network code. 
Section of this chapter, topic and relevant regulation

In theory, network codes and guidelines can cover the same topics.

Depending on the scope of the respective methodology, the Third Package foresaw its approval either by all NRAs or the relevant subset of NRAs.

Under the Third Package, in certain cases a decision is to be referred to ACER.

\section{Relevant articles}

Development and amendment of guidelines: Under the Third Package, the procedural requirements for guidelines in accordance with Art. 18 of Regulation (EC) No 714/2009 are less far-reaching. Art. 18(3) states that, where appropriate, the Commission can also develop guidelines for areas that are covered by network codes according to Art. 8(6). Art. 18(3) states further that the Commission shall consult the Agency and ENTSO-E for this purpose. When adopting or amending guidelines, the Commission must, among other things, ensure that the guideline provides the minimum degree of harmonization necessary to achieve the goals of the regulation and does not go beyond what is necessary for this purpose. Adoption of network codes and guidelines: Under the Third Package and in accordance with Art. 23 of Regulation (EC) No 714/2009, network codes and guidelines were adopted as implementing acts under the 'old' comitology procedure, following the regulatory procedure with scrutiny. Implementation of network codes and guidelines: As is described in Box 1.3 of Section 1.1, guidelines include processes whereby TSOs or NEMOs must develop so-called 'Terms and Conditions or Methodologies' in the implementation phase.

Under the Third Package, Art. 18(6) of Regulation (EC) No $714 / 2009$ states that 'Where appropriate, Guidelines providing the minimum degree of harmonisation required to achieve the aim of this Regulation shall also specify: ... (d) details of the areas listed in Article 8(6).'Art. 8(6) of the same regulation lists the areas that network codes shall cover, taking into account, if appropriate, regional specificities.

Under the Clean Energy Package, in accordance with Art. 61(2) of Regulation (EU) 2019/943, the 'Commission is empowered to adopt guidelines in the areas where such acts could also be developed under the network code procedure pursuant to Article 59(1) and (2). Those guidelines shall be adopted in the form of delegated or implementing acts, depending on the relevant empowerment provided for in this Regulation.'

As is set out in Art. 9 of the CACM GL, Art. 4 of the FCA GL, Art. 5 of the EB GL and Art. 6 of the SO GL.

In accordance with Art. 8(1) of Regulation (EC) No 713/2009, in certain cases a decision should be referred to ACER, namely (a) when the competent NRAs are not able to reach an agreement within a period of six months from the point in time when the case was referred to the last of those NRAs or (b) on a joint request from the competent NRAs. 


Section of this chapter, topic and relevant regulation

ENTSO-E, ACER and the European Commission have monitoring, reporting and stakeholder involvement responsibilities related to methodologies.

For the first generation of network codes and guidelines, through ENTSO-E, TSOs were placed in the position of drafting network codes with regulatory oversight.

Following the CEP, the strong role of ENTSO-E in drafting the network codes was reduced.

The CEP also mandates the establishment of an EU DSO entity to involve DSOs in the network code and guideline drafting process.
Relevant articles

Under the Third Package, relevant provisions, apart from the dedicated articles on network codes and guidelines, include Regulation (EC) No 714/2009: Art. 8 on the tasks of ENTSO-E, Art. 9 on monitoring by ACER and Art. 10 on consultations; and Regulation (EC) No 713/2009: Art. 6 on the tasks of ACER as regards the cooperation of TSOs, Art. 8 on the tasks of ACER as regards terms and conditions for access to and the operational security of cross-border infrastructure, Art. 10 on consultations and transparency, and Art. 11 on monitoring and reporting on the electricity and natural gas sectors.

Under the Clean Energy Package, relevant provisions, apart from the dedicated articles on network codes and guidelines, include Regulation (EU) 2019/943: Art. 30 on the tasks of ENTSO-E, Art. 31 on consultations, Art. 32 on monitoring by ACER, Art. 41 on transparency, Art. 56 on consultations in the network code development process, Art. 69 on Commission reviews and reports; Regulation (EU) 2019/942 Art. 5 on the tasks of ACER as regards the development and implementation of network codes and guidelines, Art. 8 on the tasks of ACER as regards nominated electricity market operators, Art. 24 on consultations, transparency and procedural safeguards, and Art. 15 on monitoring and reporting on the electricity and natural gas sectors.

Art. 8(1) of Regulation (EC) No 714/2009 states that 'The ENTSO for Electricity shall elaborate network codes in the areas referred to in paragraph 6 of this Article upon a request addressed to it by the Commission ....

Art. 59(10) of Regulation (EU) 2019/943 specifies that in the third step of the network code development process described above, ENTSO-E now drafts the network code based on an ACER framework guideline guided by a drafting committee that consists of representatives of ACER, ENTSO-E, where appropriate the EU DSO entity and NEMOs, and a limited number of relevant stakeholders.

Art. 52(1) of Regulation (EU) 2019/943 states that 'Distribution system operators shall cooperate at Union level through the EU DSO entity, in order to promote the completion and functioning of the internal market for electricity, and to promote optimal management and a coordinated operation of distribution and transmission systems. ...' Arts. 52-57 lay down rules on distribution system operation, including the establishment of the EU DSO entity, relevant principal rules and procedures, and the tasks of the EU DSO entity. 
Section of this chapter, topic and relevant regulation

With the adoption of the CEP, the role of ACER in the development phase is expected to increase.

Another change concerns the time interval in which the European Commission is required to compile a priority list for new network codes.

ACER now directly decides on the methodologies with a pan-European scale.
Relevant articles

Art. 59(3) of the same regulation states that '... If the subject matter of the network code is directly related to the operation of the distribution system and not primarily relevant to the transmission system, the Commission may require the EU DSO entity, in cooperation with the ENTSO for Electricity, to convene a drafting committee and submit a proposal for a network code to ACER.'

In the network code development process following the Third Package, as laid down in Art. 6(6-9) of Regulation (EC) No $714 / 2009$ and as described above, ACER is required to provide a reasoned opinion on the network code submitted to it by ENTSO-E, after which ENTSO-E may amend the network code in the light of this opinion and resubmit it to the Agency. Under the Clean Energy Package, Art. 59(11) of Regulation (EU) 2019/943 states that, in the fourth step of the network code development process described above, ACER will henceforth directly revise and consolidate the network code and submit the final product to the European Commission: 'ACER shall revise the proposed network code ... and, submit the revised network code to the Commission within six months of receipt of the proposal.'ACER must take into account the views provided by all the parties involved in the drafting of the proposal and consult the relevant stakeholders on the version to be submitted to the Commission. Details are also provided in Art. 5(1.c) of Regulation (EU) 2019/942.

Under the Third Package, Art. 6(1) of Regulation (EC) No $714 / 2009$ states that 'The Commission shall, after consulting the Agency, the ENTSO for Electricity and the other relevant stakeholders, establish an annual priority list identifying the areas set out in Article 8(6) to be included in the development of network codes.'

Under the Clean Energy Package, Art. 59(3) of Regulation (EU) 2019/943 states that 'The Commission shall, after consulting ACER, the ENTSO for Electricity, the EU DSO entity and the other relevant stakeholders, establish a priority list every three years, identifying the areas ... to be included in the development of network codes.'

Under the Third Package and in accordance with Art. 8(1), decisions are only referred to ACER when (a) the competent NRAs are not able to reach an agreement within a period of six months from the point in time when the case was referred to the last of those NRAs or (b) on a joint request from the competent NRAs. 
Section of this chapter, topic and relevant regulation

The Clean Energy Package distinguishes between the adoption of network codes and guidelines as implementing or delegated acts. Depending on the type of act, the European institutions and stakeholders have different rights and possibilities to intervene in the adoption process.
Relevant articles

Under the Clean Energy Package, proposals for common

'Terms and Conditions or Methodologies' for the implementation of network codes and guidelines which require the approval of all regulatory authorities shall be submitted to ACER for revision and approval in accordance with Art. 5(2) of Regulation (EU) 2019/942.

Under the Third Package and in accordance with Art. 23 of Regulation (EC) No 714/2009, network codes and guidelines were adopted as implementing acts under the 'old' comitology procedure, following the regulatory procedure with scrutiny. The Clean Energy Package distinguishes between the adoption of network codes and guidelines as implementing or delegated acts in accordance with Art. 58 of Regulation (EU) 2019/943. Network Codes as implementing acts: Art. 59(1) of Regulation (EU) 2019/943 lists the areas in which the Commission is empowered to adopt network codes as implementing acts. Adoption of network codes as implementing acts is divided into two main phases. During the pre-comitology process, the European Commission undertakes legal and impact assessment of the implementing act, among other things. During the comitology phase, the Commission submits draft implementing acts to a committee composed of Member State representatives. The committee votes on the draft with three possible outcomes. In the first case, a qualified majority of Member States votes in favour of the act resulting in an obligation on the European Commission to adopt the act. In the second case, a qualified majority votes against the act, which prohibits the European Commission from adopting it. In the third case, no qualified majority for or against exists, which means the European Commission may adopt the draft.

The CEP empowers the European Commission to adopt new network codes as implementing acts in the areas of: (existing, covered by SO GL) network security and reliability rules; (existing, covered by CACM GL and FCA GL) capacity-allocation and congestion-management rules; (existing, covered by EB GL) rules on trading related to the technical and operational provision of network access services and system balancing; (new) rules for the non-discriminatory transparent provision of non-frequency ancillary services; and (new) rules on demand response, including aggregation, energy storage and demand curtailment. 
Section of this chapter, topic and relevant regulation

Relevant articles

Network codes as delegated acts: Art. 59(2) of Regulation

(EU) 2019/943 lists the areas in which the Commission is empowered to adopt network codes as delegated acts. Adoption as a delegated act can be seen as a fast-track adoption process, as comitology committees do not exist. The European Commission prepares and adopts delegated acts after consulting national expert groups composed of representatives from each Member State. Citizens and other stakeholders can provide feedback on the draft of the delegated act. The European Commission then presents its draft delegated act simultaneously to both the European Parliament and the Council without consulting a committee. In the case that the Parliament and Council do not formulate any objections, the delegated act enters into force.

The CEP empowers the Commission to adopt new network codes as delegated acts in the areas of: (existing, covered by RfG NC, DC NC, HVDC NC) network connection rules; (existing, covered by ER NC) operational emergency and restoration procedures in an emergency; (covered partly by SO GL and Transparency Regulation (EU) No 543/2013) data exchange, settlement and transparency rules; third-party access rules (set out in Regulation (EC) No 714/2009 as an area but not yet covered by a network code); and (new) sector-specific rules for cyber security aspects of cross-border electricity flows.

Guidelines: In accordance with Art. 61(2) of Regulation (EU) 2019/943, the Commission can adopt guidelines in the network code areas in the form of delegated or implementing acts. Art. 61 of the same regulation specifies that the adoption and amendment procedure for guidelines now includes the obligation for the European Commission to consult ACER, ENTSO-E, the EU DSO entity and, where relevant, other stakeholders. 


\section{Who gets the rights to trade across borders? Leonardo Meeus with Tim Schittekatte}

In this chapter we answer five questions. First, how to deal with historical privileges? Second, how to implement market-based allocation of transmission rights? Third, how to implement market coupling in the day-ahead timeframe? Fourth, what about the timeframes before day-ahead? Fifth, what about the timeframes after day-ahead?

\subsection{HOW TO DEAL WITH HISTORICAL PRIVILEGES?}

Historically, the rights to trade across borders were granted to utilities, often state-owned vertically integrated utilities. The First Directive 96/92/EC already stated that the newly established transmission system operators (TSOs) had to provide different network users with non-discriminatory access to their networks. Despite this provision, the historical privileges of the utilities were maintained. They had long-term contracts with neighbouring utilities that included transmission rights. These contracts, which pre-dated the market integration process, had not yet expired and were kept in place.

This led to a landmark court case. In that case, VEMW, the organization representing the interests of large energy consumers in the Netherlands, the Amsterdam Power Exchange (APX) and ENECO, a large Dutch utility, challenged the decision of DTE, the Dutch regulator, to reserve a significant proportion of the rights to trade across the border for SEP, the former national vertically integrated utility. SEP used these so-called transmission rights to execute its existing long-term contracts with utilities across the border. In 2000, $1500 \mathrm{MW}$ of the available $3200 \mathrm{MW}$ of the rights were reserved for SEP contracts, which would reduce to $900 \mathrm{MW}$ in 2001 and to $750 \mathrm{MW}$ from 2005 to 2009. The European Court of Justice (ECJ) decided that this undermined potential access to the market by new players and protected the position of the incumbent. The Dutch regulator's decision was found to be incompatible with the First Directive and so annulled. Although the First Directive allowed Member States to request a transitional exemption from the relevant article in the legislation, this had not been done by the Netherlands. Other national regulatory authorities (NRAs) used the ECJ decision to take steps to remove transmission right privileges. ${ }^{1}$

The next challenge was to allocate the freed-up transmission rights in a non-discriminatory way. Figure 2.1 gives an overview of the transmission right allocation methods applied in the EU in 2004. Priority lists were said to give priority to whoever made it onto the list, often incumbent utilities and large industrial consumers. Pro-rata rationing implied that whoever asked for more got more. Explicit auctions and market splitting were the first market-based approaches to allocate transmission rights. They will be discussed in more detail in the next 


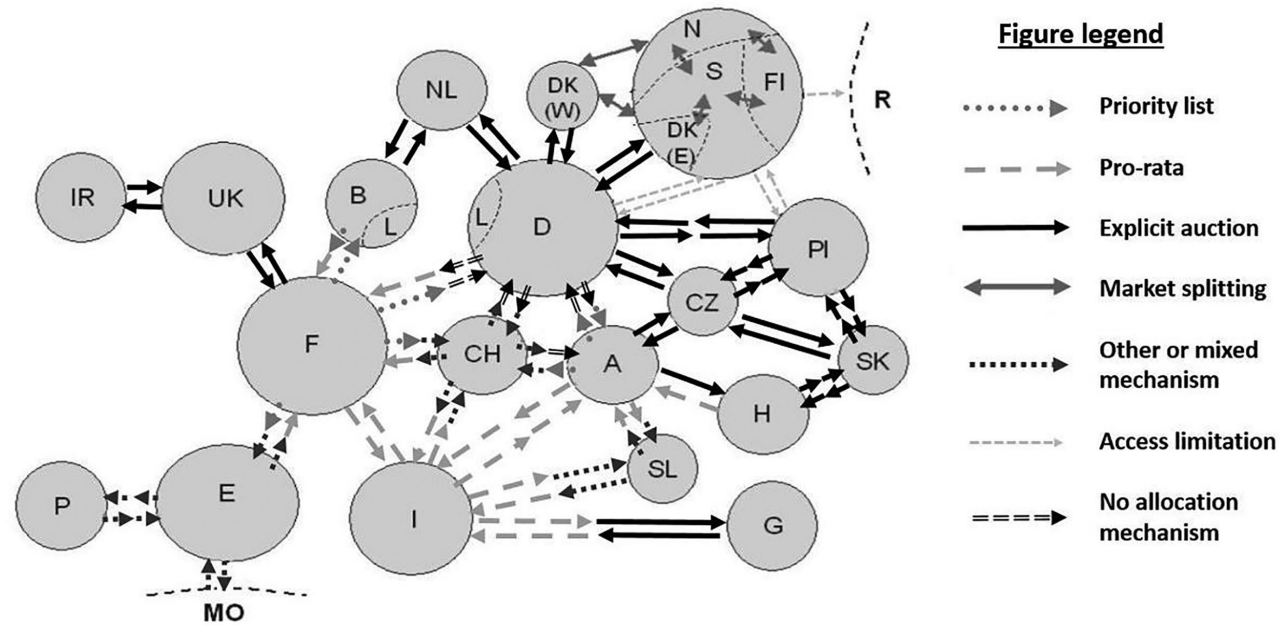

Two arrows appearing in the same flow sense in a certain interconnection, mean that, for that interconnection in that flow sense, there is not a unique capacity allocation method or congestion management mechanism jointly applied by the two TSOs involved.

Note: $\quad$ The acronyms used stand for the following. MO: Morocco (non-EU); P: Portugal; E: Spain; I: Italy; F: France; CH: Switzerland (non-EU); A: Austria; SL: Slovenia; G: Greece; H: Hungary; SK: Slovakia; CZ: Czech Republic; Pl: Poland; D: Germany; L: Luxembourg; R: Russia (non-EU); DK (E): East Denmark; DK (W): West Denmark; FI: Finland; S: Sweden; N: Norway (non-EU); B: Belgium; NL: Netherlands; UK: United Kingdom; IR: Ireland.

Source: $\quad$ Based on European Transmission System Operators (ETSO) (2004).

Figure 2.1 Implementation of different allocation methods for cross-border transmission rights in Europe in 2004

sections. Finally, please note that on several borders there is not a unique capacity allocation method or congestion management mechanism jointly applied by the two TSOs involved.

\subsection{HOW TO IMPLEMENT MARKET-BASED ALLOCATION OF TRANSMISSION RIGHTS?}

Regulation (EC) No 1228/2003 was included in the Second Package and required a market-based approach to the allocation of transmission rights. In what follows we describe the evolution from explicit auctions to implicit auctions - or market coupling - in Europe.

First, explicit auctions. Under this approach, TSOs auction transmission rights to the highest bidders separately from the trading of energy. Several auctions are held, from the year-ahead to the day-ahead timeframe. A few years after the adoption of Regulation (EC) No 1228/2003, explicit auctions became the dominant model for allocating transmission rights in Europe. Due to the separation of the auctions of transmission rights and energy trading, coordination issues arose. More precisely, to be able to bid for transmission rights, traders had to predict hourly price differences in different countries, which turned out to be very difficult. The 2007 Sector Inquiry estimated that the lost opportunities to trade across the German-Dutch border in 2004 were as high as $€ 50$ million, or half the total value. ${ }^{2}$ Figure 2.2 shows the details. Each dot 


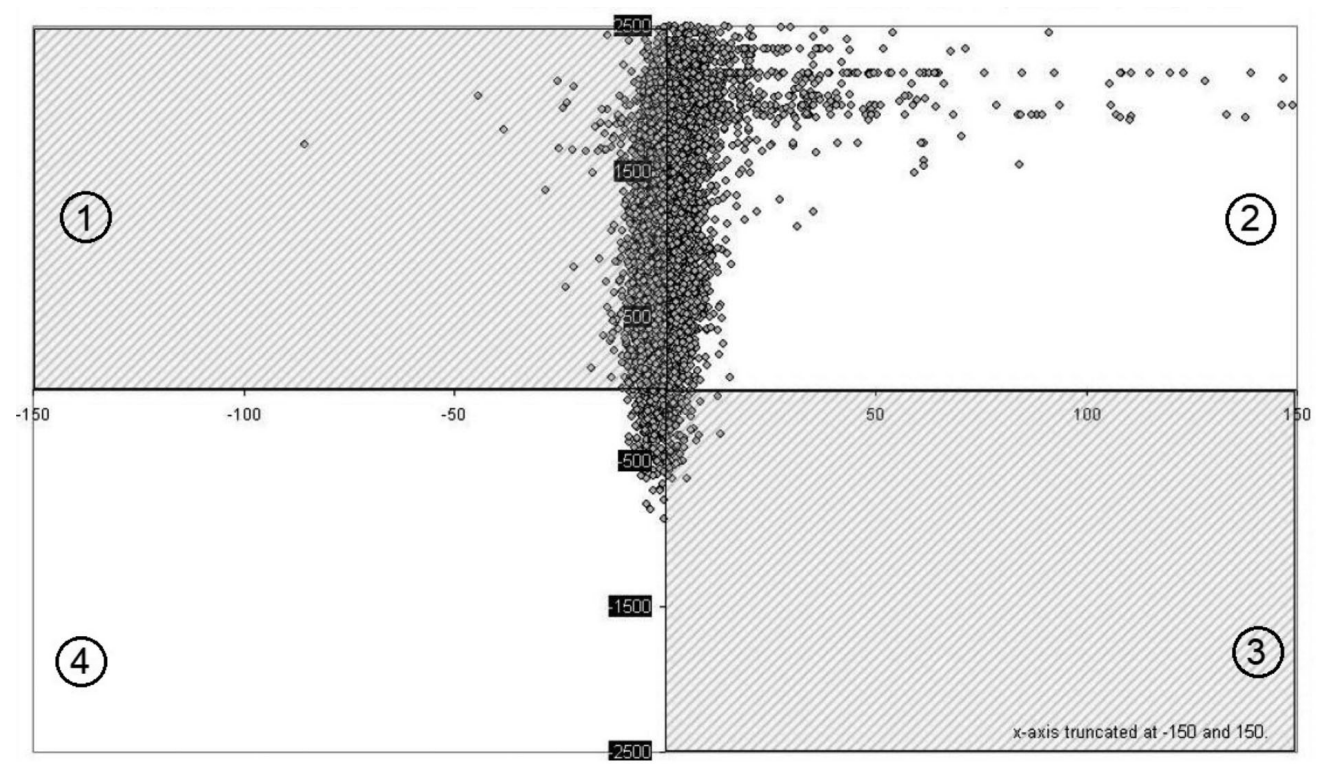

Source: European Commission (2007).

Figure 2.2 Explicit cross-zonal allocation: hourly price difference between Germany and the Netherlands (x-axis) versus the hourly sum of nominated net flows from Germany to the Netherlands in 2004 (y-axis)

represents the situation in the market at a certain hour. Two main problems can be observed. First, quadrant 2 and quadrant 4 show hours in which traders moved energy across the border earning the price spread, but they often did not capture all the opportunities. There are many hours in which not all the transmission rights were used although there was still a positive price spread. Second, quadrants 1 and 3 show hours in which traders paid for transmission rights and then moved energy across the border in the wrong direction, losing money. In this example, for about 40 per cent of the hours the electricity price in Germany was higher than in the Netherlands but the electricity was flowing towards the Netherlands (quadrant 1). The opposite also happened, with electricity flowing towards Germany when the price in the Netherlands was higher (quadrant 3).

Second, there was an evolution towards implicit auctions, or market coupling. The solution that emerged was to give the transmission rights to power exchanges. Instead of allocating them in a separate auction to cross-border traders, they were integrated into the clearing of the day-ahead auction organized by power exchanges. The name that was initially given to this solution was 'implicit auctions', but it then changed to 'market coupling' because the solution implied that the power exchange day-auctions became coupled, as we will discuss further in the next section. 


\subsection{HOW TO IMPLEMENT MARKET COUPLING IN THE DAY-AHEAD TIMEFRAME?}

This section is divided in two subsections. We first describe the evolution from regional initiatives to so-called single day-ahead coupling (SDAC). We then discuss the issues that this solution left open. Power exchanges are key actors with regard to market coupling; a description of the evolution of power exchanges in Europe can be found in Annex 2A.1. ${ }^{3}$

\subsubsection{From Regional Initiatives to Single Day-ahead Coupling}

In this subsection, we first discuss three regional initiatives that led to SDAC: market splitting, trilateral market coupling and volume coupling. As Table 2.1 summarizes, we discuss the number of power exchanges that were involved in the initiative, whether they share their order books and by whom the optimization algorithm is run. We conclude with a description of the current status of SDAC implementation.

First, market splitting. Nord Pool's approach was called market splitting because the algorithm worked in two steps. In the first step, the Nordic system price was calculated. The system price is the price that would apply in the whole region if the resulting cross-border flows were feasible. If there were not enough cross-border transmission capacity available to accommodate all trades, the second step was to split the Nordic market into smaller markets with different prices, hence 'market splitting'. It all started with Nordic market splitting. In this approach, there was one power exchange - Nord Pool - with one order book and one optimization algorithm to calculate prices for the whole Nordic region.

Second, trilateral market coupling. The starting point for this project was three power exchanges (APX, Belpex and Powernext) and three TSOs (TenneT, Elia and RTE) which wanted to implement market coupling without consolidating the exchanges into one exchange. Instead of sharing all the information in their order books, they wanted to run an optimization algorithm based on net export curves, which was a way to aggregate their order book information. The algorithm would then decide the trade volumes and directions across the borders, and once these were fixed the exchanges would continue to calculate their own set of prices for their order books. It was a very elegant idea, and we did research to help develop the concept, but our research also showed that the approach had its limitations. ${ }^{4}$ We were therefore not surprised that after a piloting phase with detailed simulations the project partners decided to abandon the approach and went for a slightly more centralized version of market coupling. This was approved by the regulators and went live in 2006. The exchanges did not consolidate into one exchange, but they did agree to share their full order books and to let one optimization algorithm calculate the prices. The compromise was that they would take turns to run the algorithm or they would run it in parallel to build some resilience into the procedure.

Third, volume coupling. Two years after the approach based on net export curves in the trilateral market project was abandoned, it resurfaced in an initiative between Nord Pool (East Denmark) and EEX (Germany). Their approach was called volume coupling, as opposed to price coupling. It was short-lived because the problems that had been anticipated in trilateral market coupling and were analysed in our research unfortunately were realized. After several attempts to fix it, the project was stopped. For a full account of what happened, with an analysis of the performance of volume coupling in each step of the way, see our research on 
Table 2.1 Different design choices for the implementation of market coupling

\begin{tabular}{lllll}
\hline & $\begin{array}{l}\text { Market } \\
\text { splitting }\end{array}$ & $\begin{array}{l}\text { Trilateral market } \\
\text { coupling }\end{array}$ & Volume coupling & Single day-ahead coupling \\
\hline $\begin{array}{l}\text { Number of power } \\
\text { exchanges involved }\end{array}$ & $\begin{array}{l}\text { One (Nord } \\
\text { Pool) }\end{array}$ & $\begin{array}{l}\text { Three (Belpex, APX } \\
\text { and Powernext) }\end{array}$ & $\begin{array}{l}\text { Two } \\
\text { (EEX and Nord } \\
\text { Pool) }\end{array}$ & Many, now certified as NEMOs \\
Order books shared & $\begin{array}{l}\text { Only one } \\
\text { order book }\end{array}$ & Yes & No & Yes \\
$\begin{array}{l}\text { Optimization } \\
\text { algorithm run by }\end{array}$ & $\begin{array}{l}\text { Rotational - To validate } \\
\text { the others do parallel } \\
\text { runs }\end{array}$ & Both & $\begin{array}{l}\text { One NEMO runs the algorithm on } \\
\text { a rotational basis. The other NEMOs } \\
\text { have the right to do parallel runs to } \\
\text { validate the results }\end{array}$ \\
\hline
\end{tabular}

the topic. ${ }^{5}$ This short-lived experiment settled the competition between different market coupling implementations in favour of trilateral market coupling, which developed into SDAC. A simple numerical example showing how prices are set and cross-border capacity is allocated between two market-coupled countries can be found in Annex 2A.2.

Fourth, the status of SDAC. The Capacity Allocation and Congestion Management Guideline (CACM GL), which was adopted in 2015, made day-ahead market coupling binding for all. Trilateral market coupling has been growing, and at the time of writing 22 countries representing close to 90 per cent of European electricity consumption are already coupled. More are expected to join in 2020: Greece, the Czech Republic, Slovakia, Hungary and Romania. ${ }^{6}$ The optimization algorithm that is used is called the Pan-European Hybrid Electricity Market Integration Algorithm (EUPHEMIA), and it originated in the trilateral market coupling project. The operation of the algorithm is called the market coupling operator (MCO) function in the CACM GL. The MCO function is jointly operated by all the participating power exchanges. To be able to participate, exchanges have to be certified as Nominated Electricity Market Operators (NEMOs).

\subsubsection{Open Issues}

In this subsection, we discuss three open issues: the governance of NEMOs and the MCO function, cost sharing and the functioning of the optimization algorithm EUPHEMIA.

The first open issue is governance. The default option described in the CACM GL is to have competing power exchanges in each Member State. However, if a national legal monopoly for day-ahead and intraday trading services existed in a Member State at the time of entry into force of the CACM GL, the Member State could decide to continue with a monopolistic power exchange. At the time of writing, Greece, Ireland, Italy, Spain, Portugal, Hungary, Bulgaria, Slovakia, the Czech Republic and Romania have designated one monopolistic NEMO and all the other Member States allow multiple NEMOs to compete in their markets. Competitive NEMOs designated in one Member State also have the right to offer trading services with delivery in another Member State where a competitive model is implemented, unless an exception is justified. Recently, multi-NEMO arrangements (MNAs) have been set up, enabling market coupling with more than one power exchange per country. 
From the operational perspective, currently eight NEMOs are running the MCO function on a rotational basis. Each day one NEMO runs the system (acting as the 'operator'), one acts as the formal 'coordinator' (e.g. announcing official results and calling the incident committee when issues arise) and another acts as 'hot backup'. The remaining NEMOs have the right to compute the same results in parallel. This has put power exchanges in a position in which they must collaborate while they are also competing. The governance of NEMOs and the MCO function was on the agenda of the Florence Forum in 2018. The European Network of Transmission System Operators for Electricity (ENTSO-E) called for a stronger separation of the MCO function and the competitive business activities of NEMOs, preferably with more TSO involvement in the control of the MCO function. The Agency for the Cooperation of Energy Regulators (ACER) acknowledged the issues and hinted at the possibility of having a single independent MCO entity. The solution suggested by ACER was included in the CACM GL as a possible option if the current option does not work well. Finally, in a report published just after the Florence Forum, the Commission decided that it was too early for action. $^{7}$

The governance issue has a history. During the development of the CACM GL, the question arose of whether power exchanges need to be regulated as monopolies now that they have a monopoly on cross-border trade in the day-ahead timeframe. Our research concluded that the competitive model for market infrastructure has its merits. Some of the activities of a power exchange, such as the provision of the interface between traders and the market and all sorts of settlement arrangements, are not necessarily monopolistic activities. Competing means they can differentiate and innovate in their services and also in their membership fees and trade commissions. We also wrote that it is necessary to avoid market coupling becoming a cartel of power exchanges, which did not make us very popular at the time. In 2014, the European Commission imposed fines of about $€ 6$ million on the two leading European power exchanges, EPEX SPOT and Nord Pool. They had agreed not to compete in the spot market (day-ahead and intraday) and to divide the European territory between them. In other words, the governance of NEMOs and the MCO function is an important issue to continue to monitor. ${ }^{8}$

The second open issue is cost sharing. The costs of operating and developing the MCO function are shared by the NEMOs. The CACM GL states that TSOs may contribute to the MCO-function-related costs of the NEMOs concerned but they are not obliged to. In the case that a TSO does not contribute to the costs or does not cover all the costs, the NEMOs are entitled to recover residual MCO-function costs by means of regulated fees or other appropriate mechanisms unless the costs are unreasonable. In short, the sharing keys between NEMOs and TSOs for MCO-function-related costs are national, while NEMOs can cover multiple Member States. As not necessarily the same NEMOs are competing in each Member State, due to the non-harmonized national sharing keys some NEMOs might need to top up their fees more than others because of the costs of MCO-related activities.

The third open issue is the algorithm. Technical issues came high on the agenda after the first major incident on 7 June 2019. Due to a software bug at EPEX SPOT - the biggest power exchange in central Europe, operating in countries such as Austria, Belgium, France, Germany and the Netherlands - its order books were not included in the market coupling algorithm EUPHEMIA. This meant that trade could not be scheduled across the borders of these countries. The fall-back solution was to organize local markets without cross-border trade. As a result, prices were unusually low in some countries and extremely high in others. ${ }^{9}$ 
At the time of writing, EUPHEMIA only has ten minutes to perform its market coupling calculations. Even though the incident on 7 June 2019 was said to have been caused by a software bug at EPEX SPOT, there are also technical issues with the algorithm itself. These issues are attracting more attention because the single-market-coupling approach in Europe relies on this one algorithm. As more countries have been added to the market coupling initiative, insufficient efforts have been made to reduce the complexity of the market that has to be handled by the algorithm. The CACM GL required NEMOs to submit a joint proposal for the bidding formats they will continue to use. In their proposal, which was accepted, they simply listed all the bidding formats that are currently used. These are a mix of multi-part orders with bids that correspond to the technical constraints of thermal power plants, including start-up costs and ramping constraints, and block orders, which allow traders to make their bids indivisible and to link them across periods. Multi-part orders are typical of power-pool type markets, while block orders are typical of power exchanges. EUPHEMIA currently has to deal with both complexities. In power-pool markets, complex bidding formats are typically combined with complex pricing, which means that side payments are used to balance supply and demand in the market on top of the clearing price. This implies that some market players get an additional side payment to avoid losing money, while the others pay or receive the clearing price corrected with an uplift to recover the money paid in side payments. Power exchanges do not do side payments; they instead allow their markets to reject block bids that are in-the-money at the prevailing clearing price (so-called paradoxically rejected blocks). Side payments would require a change in the CACM GL, but they would simplify the algorithm. Our research and that of colleagues has indeed demonstrated that complex pricing can reduce the complexity of the algorithm, but we have come to different conclusions on whether it should be done or not. Our colleagues argued in favour of complex pricing while we argued that the gains in terms of trade would be relatively small in comparison to the side payments that would need to be administered. ${ }^{10}$

Stakeholders are under pressure to come up with solutions because the complexity is only expected to increase. More countries will be added to SDAC, and the Clean Energy Package includes provisions that will increase the granularity of day-ahead markets from hourly to half-hourly or even 15 minutes.

Note finally that more progress has been made on another technical issue: the minimum and maximum clearing prices that are used by the different power exchanges have been harmonized. Following the CACM GL, all NEMOs were first asked to come up with a joint proposal which the NRAs had to unanimously approve. The NRAs could not reach an agreement and therefore requested ACER to adopt a decision. ACER decided that the harmonized maximum price in the day-ahead market should be $€ 3000 / \mathrm{MWh}$ and the minimum price $-€ 500 / \mathrm{MWh}$. ACER avoided the maximum clearing price being able to act as a price cap by making it dynamic. In the event that the clearing price exceeds a value of 60 per cent of the previously set maximum clearing price, the maximum clearing price is increased by $€ 1000 / \mathrm{MWh}$.

\subsection{WHAT ABOUT THE TIMEFRAMES BEFORE DAY-AHEAD?}

The timeframes before day-ahead are referred to as forward and futures markets. These mainly involve bilateral deals or over-the-counter (OTC) trading. Power exchanges also play a role, but not by organizing auctions as they do in the day-ahead timeframe. Instead, they offer 
platforms that enable continuous trade in standardized future contracts, for example one-year and three-year contracts. This means that there are no power exchange auctions that can be coupled in the timeframes before day-ahead. Cross-border long-term transmission rights can only be allocated in explicit auctions, the market-based solution that was abandoned in the day-ahead timeframe. Indeed, TSOs organize explicit auctions for at least monthly and yearly transmission right contracts. They have also started to collaborate via the Joint Allocation Office (JAO). JAO is a joint service company of currently 20 TSOs from 17 countries with harmonized auction rules and timings, which helps traders reduce their transaction costs in procuring transmission rights. With the Forward Capacity Allocation Guideline (FCA GL), which entered into force in 2016, this bottom-up voluntary initiative became the European platform. Following the FCA GL, in 2017 all the NRAs approved a methodology that proposed JAO becoming the single allocation platform for the whole of Europe. In what follows, we discuss the two main open issues regarding long-term transmission rights: the length and the types of contracts.

The first open issue is the length of contracts. To split the available transmission rights over the different long-term timeframes and contract lengths, the FCA GL foresees the need to develop methodologies at the regional level. At the time of writing, these methodologies are being discussed and have not yet been approved. Traders have made it clear that they prefer to have capacity offered year-ahead or more. Most TSOs propose a somewhat gradual offering by dividing the capacity over the different timeframes. The incentives for TSOs depend on the compensation they have to pay to market parties if they have to curtail long-term transmission rights because they face problems in their networks, and on whether NRAs allow TSOs to recover these payments through their grid tariffs. No compensation payments is not an option because then market parties would have a hedge that they could not rely on because it can be curtailed without any consequences for the TSO that issued the hedging product. This has been an issue in the past and has been addressed in the FCA GL. In the FCA GL, two causes for the curtailment of long-term transmission rights are distinguished. If what happens is considered force majeure, the price of the right in the original auction is refunded. The determination of whether an event classifies as force majeure is, however, still done at the national level. More precisely, the national regulatory authority of the TSO invoking a force majeure event has to assess whether the event qualifies as force majeure. If it is not force majeure, that is, the TSO curtails long-term transmission rights to ensure that all flows remain within the operational security limits, the compensation is the lost opportunity, which is the day-ahead price spread. In this case, the TSOs concerned might propose introducing a cap on the total compensation, which is further specified in the FCA GL.

The second open issue is the type of contract. Most TSOs started by auctioning so-called physical transmission rights (PTRs). A trader that buys such a right can trade across the border and nominate that trade to the TSO, which then subtracts this capacity from the overall volume of transmission rights that remain for the other timeframes. If the trader decides not to use the right, it is compensated for the value of the right in a day-ahead auction, where other traders might be willing to pay for it (use-it-or-sell-it, UIOSI). If the day-ahead stage applies market coupling, the price difference across the border is the implicit price for the transmission right. Most TSOs have already converted or are converting to another type of long-term transmission right referred to as a financial transmission right (FTR). With FTRs, use-it-or-sell-it becomes sell-it-without-the-possibility-of-using-it. Traders still hedge against the day-ahead price 
differences between countries, but they cannot nominate a cross-border flow ahead of the day-ahead timeframe. Hence the name financial, because the physical element is no longer there. At the time of writing, FTRs are in place on nine borders in the EU and implementation of FTRs is planned on an additional eight borders. ${ }^{11}$

The FCA GL leaves it open whether PTRs or FTRs are used. However, among other things, it is required that marginal pricing is applied in the auctions, that for both PTRs and FTRs harmonized allocation rules are followed, and that the two types of transmission right cannot be applied in parallel on one border. Regulators can adopt a coordinated decision not to issue PTRs or FTRs on a border when they can show that there is no need for hedging or by ensuring that there are other cross-border hedging instruments available in the market. For example, in the Nordics an instrument called electricity price area differentials (EPADs) is in place. EPAD contracts hedge the difference between the price in a certain location and the Nordic system price. The Nordic system price is the price that would have emerged if there were no congestion in the Nordic system. This system price is a legacy from the market splitting approach and does not represent an actual location in the Nordic system. Italy does something similar with an instrument that hedges the difference between the price in a certain location for supply and the 'unique' national price for demand, that is, Prezzo Unico Nazionale (PUN).

\subsection{WHAT ABOUT THE TIMEFRAMES AFTER DAY-AHEAD?}

The timeframes after day-ahead are intraday and balancing markets. Power exchanges play a role in the intraday stage by organizing continuous trading platforms, and in some cases also auctions. In the day-ahead and forward markets the debate was mainly over how to allocate transmission rights, while for the intraday stage the debate was over keeping the borders open long enough for intraday trade to become international. The CACM GL prescribes that the intraday cross-border gate closure shall be at most one hour before delivery. After the intraday cross-border gate closure, national intraday markets often remain open until even closer to real time.

Progress in the intraday stage has been slower than in the day-ahead stage. The volumes that are traded are smaller so less money can be made by organizing and participating in intraday trade, but intraday markets are important because they allow market parties to avoid imbalances. This is especially important for new players and renewable energy technologies, which would otherwise be exposed to high balancing costs. We will come back to this interaction in Chapter 5 on balancing markets. In what follows, we focus on the two intertwined open issues related to intraday markets: the transmission right allocation method and reservation.

Continuous trade became the dominant model in Europe for intraday in a context where intraday was less important and trade volumes were so low that auctions were not considered a feasible option. Now, this intraday continuous trade can also be cross-border using transmission rights. A main open issue is how to allocate these transmission rights. For most borders, the current practice is that intraday transmission rights are used free of charge by whoever is matched first on the continuous trade platform until the rights are no longer available or the border is closed (i.e. one hour before delivery). After that, the matching of traders can continue locally. However, first-come-first-served is not a market-based allocation method. Therefore, no transmission rights are reserved for the intraday stage; only the rights that have not been used in the day-ahead stage are allocated. Another option is to organize explicit auctions for 
intraday transmission rights complementing continuous trade, which at the time of writing is done on several borders. However, we know from experience in the day-ahead market that explicit allocation is not without flaws.

The CACM GL pushes continuous trade in the intraday timeframe, and auctions are tolerated as complementary regional arrangements. The cross-border intraday market project (XBID), based on continuous trading with first-come-first-served allocation of transmission rights, has been formalized as the single intraday coupling (SIDC) to be applied by all Member States. At the time of writing, XBID is composed of members from 21 European countries ("the first and second waves'). However, at the same time, the CACM GL requires a single methodology for intraday cross-zonal pricing reflecting market congestion through an implicit allocation method. Explicit allocation is only allowed as a transitional complementary arrangement. The implementation of this methodology has been challenging. The NRAs could not agree on how to do this, so ACER had to decide. Finally, in 2019 ACER decided that three pan-European auctions will be introduced on top of continuous trading in the intraday timeframe. As soon as there are auctions in the intraday timeframe, transmission rights can be allocated efficiently through market coupling and will no longer be allocated for free. The debate on reservation of transmission rights for this timeframe can even be reopened. How this will play out is very much an open issue.

\subsection{CONCLUSION}

In this second chapter, on who gets the rights to trade across borders, we have answered five questions.

First, how to deal with historical privileges? In Europe, they had remained in place for a relatively long period until they were challenged in court. Finally, the European Court of Justice found these privileges were incompatible with the First Electricity Directive. This landmark court case opened the door for other countries to also abolish them. The accepted idea was to introduce market-based allocation of transmission rights. However, we had to wait for Regulation (EC) No 1228/2003, adopted as part of the Second Energy Package, for market-based allocation of transmission rights to be made mandatory on all EU borders.

Second, how to implement market-based allocation of transmission rights? Regulation (EC) $1128 / 2003$ did not specify which market-based approach should be used. In Europe, many different approaches were tried before converging towards market coupling. Most borders started with explicit auctions for transmission rights as this solution did not require many changes to national electricity markets. However, it was quite quickly shown that explicit auctions had strong deficiencies in the day-ahead timeframe.

Third, how to implement market coupling in the day-ahead timeframe? Different implementations emerged through regional initiatives. The EU network codes and guidelines made the implementation of market coupling legally binding through the CACM GL. At the time of writing, day-ahead market coupling covers 22 European countries, representing more than 90 per cent of EU electricity consumption. The governance of the market coupling operator (MCO) function and the performance of the algorithm are the main open issues today.

Fourth, what about the timeframe before day-ahead? The network codes and guidelines, more specifically the FCA GL, also impacted cross-border long-term transmission rights. Currently, TSOs are obliged to issue transmission rights at least month-ahead and year-ahead 
on a joint allocation platform. However, there are still ongoing discussions on how to divide long-term transmission rights between the year-ahead and month-ahead auctions. Traders want to have as many rights as possible allocated far ahead of delivery, while TSOs generally propose dividing rights more equally over the timeframes. Moreover, the network codes and guidelines do not settle which kind of transmission right should be issued. Historically, on most borders physical transmission rights were in place. Currently, we are seeing a transition from physical to financial transmission rights in Europe.

Fifth, what about the timeframes after day-ahead? Historically, due to low liquidity, intraday markets were organized as continuous trading platforms with few options to trade cross-border. Important progress has been made with the ongoing implementation of XBID, the single intraday market coupling solution. ACER has decided to complement XBID with three pan-European intraday auctions. Currently, no cross-border capacity is planned to be reserved for intraday.

\section{NOTES}

1. More in-depth discussion of this case can be found in Hancher (2006).

2. The competition authority of the European Commission opened a Sector Inquiry into the functioning of the European energy markets after significant price increases in the European electricity wholesale markets (European Commission 2007). Generally, the idea was that by integrating markets competition can be fostered. In this regard, Gilbert et al. (2004) show that the way that transmission rights are allocated to generators can also have a strong impact on whether market power can be mitigated or not.

3. Annex 2A.1 is based on our own work and that of our colleagues. Boisseleau (2004) was one of the pioneers discussing the importance of power exchanges. In Meeus et al. (2005b) we discuss the early development of the EU electricity market and the role of power exchanges. In Meeus (2011b) we focus on the governance and business models of power exchanges and power pools in Europe. For market statistics, refer to ACER and CEER (2019) and DG Energy (2019).

4. EuroPex (2003) introduced the concept of net export curves. In Meeus et al. (2005a) we argue that the concept can work if we only consider simple and single-period orders. But, as discussed in Meeus (2006), the problem is block orders, which would require many iterations and the quality of the solution would suffer.

5. In Meeus (2011a) we focus on the experience with volume coupling. We show that volume coupling initially performed worse than the situation without coupling. The implementation of volume coupling was then changed, which slightly improved the performance but not enough to save the project. We also explain mathematically why what happened was to be expected.

6. More specifically, two coupling projects are in parallel operation, namely the Multi-Regional Coupling (MRC) and the 4M Market Coupling (4MMC) projects. At the end of 2019, the MRC connected 22 countries. Furthermore, Greece is also expected to be coupled through the GreeceItaly interconnector in 2020. The other coupling project, the 4MMC, covers the Czech Republic, Slovakia, Hungary and Romania. Both projects are expected to be merged in 2020 (ENTSO-E 2019a).

7. In a report published just after the Florence Forum in 2018, the European Commission (2018) wrote that 'the Commission sees a need to continue the discussion on the challenges faced so far and assess the various options for a potential change in the governance of the MCO function.' All the presentations at the Florence Forums can be accessed online through the European Commission's dedicated website.

8. In Meeus (2011b) we distinguish between merchant and cost-of-service-regulated power exchanges. We show that these models each have pros and cons by referring to experiences in financial markets. We also show that more responsibility for power exchanges comes with market coupling, which might require a governance model to be put in place. At the time of writing we have two main 
worries. First, that power exchanges may not implement market coupling properly to protect their own business, as we found in Meeus (2011a). Second, asking them to collaborate to organize market coupling should not result in a cartel. The press release on the antitrust case of power exchanges can be found in European Commission (2014).

9. For more information, consult the NEMO Committee (2019) report on the incident.

10. In Meeus et al. (2009) we use simulations based on market data from APX to compare the results of an algorithm with and without side payments. Madani et al. (2018) further develop the algorithm, which can be used for market coupling with complex pricing, arguing that it would be a simpler way of clearing markets.

11. This is reported in ENTSO-E (2019b). ACER (2019b) keeps track of the status of long-term transmission rights on its website.

\section{REFERENCES}

ACER (2017a), 'Decision No 04/2017 of the Agency for the Cooperation of Energy Regulators of 14 November 2017 on the NEMOs' Proposal for Harmonised Maximum and Minimum Clearing Prices for the SDAC'.

ACER (2017b), 'Decision No 05/2017 of the Agency for the Cooperation of Energy Regulators of 14 November 2017 on the NEMOs' Proposal for Harmonised Maximum and Minimum Clearing Prices for the SIDC'.

ACER (2019a), 'Decision No 01/2019 of the Agency for the Cooperation of Energy Regulators of 24 January 2019 on Establishing a Single Methodology for Pricing Intraday Cross-Zonal Capacity'.

ACER (2019b), 'Cross-zonal hedging status', accessed at https:/www.acer.europa.eu/en/Electricity/ MARKET-CODES/FORWARD-CAPACITY-ALLOCATION/Pub_Docs/Crosszonal hedging status.pdf.

ACER and CEER (2019), 'Annual Report on the Results of Monitoring the Internal Electricity and Natural Gas Markets in 2018 - Electricity Wholesale Markets Volume'.

All NEMOs (2017a), 'All NEMOs' Proposal for Products that Can Be Taken into Account by NEMOs in Intraday Coupling Process in Accordance with Article 53 of the CACM GL', published on 13 November 2017.

All NEMOs (2017b), 'All NEMOs' Proposal for Products that Can Be Taken into Account by NEMOs in Single Day-Ahead Process in Accordance with Article 40 of the CACM GL', published on 13 November 2017.

All NEMOs (2017c), 'All NEMOs' Proposal for the MCO Plan', published on 13 April 2017.

Boisseleau, F. (2004), 'The Role of Power Exchanges for the Creation of a Single European Electricity Market: Market Design and Market Regulation', PhD Thesis, Delft University of Technology/Paris IX Dauphine University.

DG Energy (2019), 'Quarterly Report on European Electricity Markets', Market Observatory for Energy Q2/2019, vol. 12.

ENTSO-E (2019a), 'Market Report 2019'.

ENTSO-E (2019b), 'Type of LTTRs - current status', presentation at the European Market Stakeholder Committee on 02/07/2019, accessed at https://docstore.entsoe.eu/Documents/Network codes documents/Implementation/stakeholder_committees/MESC/2019-07-02/4.1_190702_MESC_status_ LTTRs.pdf.

ETSO (2004), 'An Overview of Current Cross-Border Congestion Management Methods in Europe'.

European Commission (2007), 'DG COMP Report on Energy Sector Inquiry'.

European Commission (2014), 'Antitrust: Commission fines two power exchanges $€ 5.9$ million in cartel settlement', press release of 5 March 2014.

European Commission (2018), 'Report from the European Commission to the Council and the European Parliament on the Development of Single Day-Ahead and Intraday Coupling in the Member States and the Development of Competition between NEMOs in Accordance with Article 5(3) of Commission Regulation 2015/1222 (CACM)'.

EuroPex (2003), 'Using implicit auctions by power exchanges to manage cross exchanges: decentralized market coupling', presentation by B. Den Ouden, President of EuroPex at the Florence Forum. 
Gilbert, R., K. Neuhoff and D. Newbery (2004), 'Allocating transmission to mitigate market power in electricity networks', RAND Journal of Economics, 35 (4), 691-709.

Hancher, L. (2006), 'Case C-17/03, VEMW, APX en Eneco Nv v. DTE', Common Market Law Review, 43 (4), 1125-44.

Madani, M., C. Ruiz, S. Siddiqui and M. Van Vyve (2018), 'Convex hull, IP and European electricity pricing in a European power exchanges setting with efficient computation of convex hull prices', ArXiv Preprint ArXiv:1804.00048, accessed at https://arxiv.org/abs/1804.00048.

Meeus, L. (2006), 'Power Exchange Auction Trading Platform Design', PhD Thesis, KU Leuven.

Meeus, L. (2011a), 'Implicit auctioning on the Kontek Cable: Third time lucky?', Energy Economics, 3 (33), 413-18.

Meeus, L. (2011b), 'Why (and how) to regulate power exchanges in the EU market integration context?', Energy Policy, 39 (3), 1470-5.

Meeus, L., T. Meersseman, K. Purchala and R. Belmans (2005a), 'Implicit auctioning of network capacity by power exchanges using net export curves', EEM Conference Paper.

Meeus, L., K. Purchala and R. Belmans (2005b), 'Development of the internal electricity market in Europe', Electricity Journal, 18 (6), 25-35.

Meeus, L., K. Verhaegen and R. Belmans (2009), 'Block order restrictions in combinatorial electric energy auctions', European Journal of Operational Research, 196 (3), 1202-6.

NEMO Commitee (2019), 'SDAC Report on the "Partial Decoupling" Incident of June 7th 2019', Version: 1.0, accessed at http://www.nemo-committee.eu/assets/files/sdac-report-on-decoupling.pdf. 


\section{A.1 ANNEX: THE EVOLUTION OF THE ROLE OF POWER EXCHANGES IN EUROPE}

In this annex we describe how the role of power exchanges evolved in Europe. First, we introduce the slow start of power exchanges. Second, we explain the increased focus on them. Third, we discuss the circumstances that led to a consolidation of the number of power exchanges across Europe.

First, the slow start of power exchanges. The evolution of power exchanges in Europe started in 1993 with Statnett Marked AS in Norway. Three years later Sweden joined the initiative, which was renamed as Nord Pool ASA. After, Nord Pool extended to Finland and Denmark in 1998 and 2000 respectively. In Spain, OMEL was founded in 1998. In the Netherlands, the Amsterdam Power Exchange (APX) was launched in 1999. In 2000, Germany saw its first power exchange (APX Deutschland, APXDE) launch and then cease operation after only a couple of months without any trading. In the same year, the Leipzig Power Exchange (LPX) and later the European Energy Exchange (EEX) were created. The French exchange Powernext was launched in 2001, and many other countries followed after. Power exchanges were market infrastructure set up by market parties, financial market institutions, TSOs or a combination of private actors. Over-the-counter (OTC) markets and organized exchanges complement each other but also compete for trading volume, which helps to reduce transaction costs for traders. Power exchanges are trading platforms that facilitate anonymous trade between market parties. By acting as a counterparty in all transactions and clearing all trades either themselves or through their clearing houses, they greatly reduce the counterparty risk for market participants. Power exchanges also enhance market transparency as prices and volumes are published through the platform, while details of OTC trades remain with the negotiating parties. The closer to real time, the more specific the needs of the market participant are and the more difficult it is to find the right counterparty. Despite the early movers mentioned above, it took a long time for all the markets to have a power exchange up and running. Still today, OTC trade constitutes the bulk of electricity trade.

Second, the increased focus on power exchanges. Having a healthy and well-functioning exchange became a benchmark in national market functioning. The Sector Inquiry of 2007 used several indicators to measure the performance of power exchanges, such as the number of players, traded volumes, the price-setting frequency of certain generators and price volatility. Later, price resilience was also added as an indicator. Not surprisingly, the smaller and/or more concentrated markets found that an exchange did not work very well in their contexts. Consequently, various liquidity-supporting measures were implemented to incentivize incumbent utilities and TSOs to trade on power exchanges for the benefit of new entrants, which relied on them to survive. Note that TSOs only purchase energy to offset the losses in their transmission network. Today, day-ahead markets in Europe are generally considered to be liquid enough, while this is not yet the case for intraday markets.

Third, we discuss the circumstances that led to a consolidation of the number of power exchanges across Europe. In the early days of the EU electricity market integration process, every country wanted to have its own market infrastructure. However, after the initial sensitivities faded, the market logic led to consolidation. Often, these national power exchanges had in any case already outsourced a major part of their activities instead of developing their own trading software and/or platforms. Gradually, two large players emerged through mergers and 


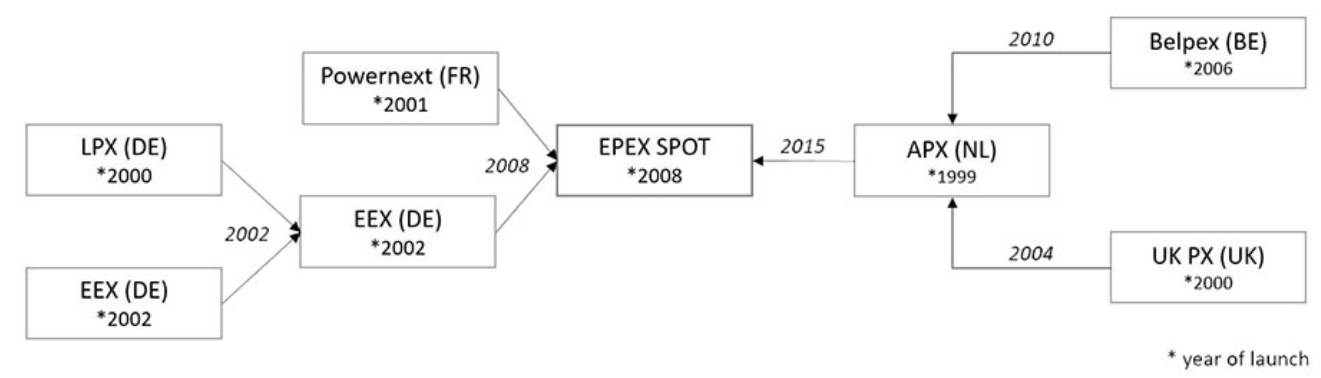

Figure 2A.1 European power exchange mergers and acquisitions (non-exhaustive)

acquisitions. One large player is Nord Pool AS, which is mentioned in Section 2.3. The other is EPEX SPOT SE, which has a long history of mergers and collaborations, as is shown in Figure 2A.1. In 2002, the Dutch power exchange APX tried to set up a Belgian subsidiary called BPX, a project which was abandoned. Instead, the Belgian TSO Elia established a Belgian power exchange called Belpex in 2006. Belpex was eventually integrated into APX in 2010. Five years later, APX itself was integrated into EPEX SPOT, which was the result of the merger of the German exchange EEX and the French Powernext. At the time of writing, EPEX SPOT and Nord Pool are active in 8 and 14 countries respectively, with more expansions planned for both power exchanges. The south-eastern European countries are still setting up new power exchanges in cooperation with one of the two big players. Examples are the Independent Bulgarian Energy Exchange (IBEX) and the Croatian power exchange (CROPEX), where Nord Pool operates the day-ahead and intraday markets. Another example is the South East European Power Exchange (SEEPEX), which was established as a joint venture between the Serbian TSO and EPEX SPOT. We also see new players coming into the market infrastructure business, and will come back to this in Chapter 8. 


\section{A.2 ANNEX: A SIMPLE NUMERICAL EXAMPLE OF MARKET COUPLING}

Imagine two countries, A and B, which each represent one bidding zone. The concept of bidding zones is discussed in more depth in Chapter 3 of this book. Basically, when a country equals one bidding zone it means that the electricity price will be the same for the whole country per market time period.

First, no later than 11.00 Central European Time (CET), available capacities on interconnectors are published. Second, until 12.00 CET market parties have the possibility to submit their buy/sell orders to the power exchange(s) in their country for the day-ahead auction covering delivery in all hours of the next day. Third, each power exchange sends its order books, that is, the collected buy and sell orders, to the market coupling operator (MCO). The following table shows an example for an order book of two countries for a specific hour. Fourth, the prices are calculated by the pan-European algorithm operated by the MCO. Fifth, under normal circumstances, at $12.55 \mathrm{CET}$ the final market coupling results are published by the power exchange(s).

\begin{tabular}{lll}
\hline Country A & Sell orders & Inelastic demand \\
\hline & Ga1: $20 \mathrm{MWh}$ at $€ 20 / \mathrm{MWh}$ & $80 \mathrm{MWh}$ \\
& Ga2: $30 \mathrm{MWh}$ at $€ 50 / \mathrm{MWh}$ & \\
& Ga3: $70 \mathrm{MWh}$ at $€ 60 / \mathrm{MWh}$ & \\
Country B & Sell orders & Inelastic demand \\
& Gb1: $130 \mathrm{MWh}$ at $€ 20 / \mathrm{MWh}$ & $100 \mathrm{MWh}$ \\
& $\mathrm{Gb} 2: 20 \mathrm{MWh}$ at $€ 30 / \mathrm{MWh}$ & \\
\hline & $\mathrm{Gb3}: 40 \mathrm{MWh}$ at $€ 40 / \mathrm{MWh}$ & \\
\hline
\end{tabular}

We can consider four cases, which differ in the amount of commercial cross-border capacity between the countries indicated by the relevant TSOs. For simplicity, an inelastic demand is considered, and the price is set by the marginal sell order unconditional on whether it is fully filled or not.

Case 1: no commercial cross-border capacity between countries $A$ and $B$

This means there are two different clearings, one for each country.

\begin{tabular}{lllll}
\hline & Price & Demand & Supply & Export to other country \\
\hline Country A & $€ 60 / \mathrm{MWh}$ & $80 \mathrm{MWh}$ & $80 \mathrm{MWh}$ & 0 \\
Country B & $€ 20 / \mathrm{MWh}$ & $100 \mathrm{MWh}$ & $100 \mathrm{MWh}$ & 0 \\
\hline
\end{tabular}

In this case, there is no cross-border trade. The spread between the two countries is $€ 40 / \mathrm{MWh}$. In country A, Ga3 sets the price. In country B, Gb1 sets the price. There is no congestion rent as there is no volume traded between the two countries.

\section{Case 2: unlimited commercial cross-border capacity between countries $A$ and $B$}

This means there is one joint clearing for both countries, that is, the supply (and demand) curves of the two countries are aggregated. 


\begin{tabular}{lllll}
\hline & Price & Demand & Supply & Export to other country \\
\hline Country A & $€ 40 / \mathrm{MWh}$ & $80 \mathrm{MWh}$ & $20 \mathrm{MWh}$ & $-60 \mathrm{MWh}$ \\
Country B & $€ 40 / \mathrm{MWh}$ & $100 \mathrm{MWh}$ & $160 \mathrm{MWh}$ & $+60 \mathrm{MWh}$ \\
\hline
\end{tabular}

In this case, the price reduces in country A and increases in country B. There is cross-border trade but no price spread. Gb3 sets the price for both countries. Implicitly, $60 \mathrm{MW}$ of cross-border capacity is allocated by the MCO from country B to A for the particular hour. There is no congestion rent as there is no price spread between the two countries.

Case 3: $100 \mathrm{MW} / \mathrm{h}$ commercial cross-border capacity is available in both directions between countries $A$ and $B$

This means there is one joint clearing for both countries, that is, the supply (and demand) curves of the two countries are aggregated unless the exchange exceeds the commercial capacity available.

\begin{tabular}{lllll}
\hline & Price & Demand & Supply & Export to other country \\
\hline Country A & $€ 40 / \mathrm{MWh}$ & $80 \mathrm{MWh}$ & $20 \mathrm{MWh}$ & $-60 \mathrm{MWh}$ \\
Country B & $€ 40 / \mathrm{MWh}$ & $100 \mathrm{MWh}$ & $160 \mathrm{MWh}$ & $+60 \mathrm{MWh}$ \\
\hline
\end{tabular}

This case is no different to case 2 as the exchange between the two countries is not limited by the commercial cross-border capacity available.

Case 4: $40 \mathrm{MW} / \mathrm{h}$ commercial cross-border capacity between countries $A$ and $B$ is available in both directions

This means there is one joint clearing for both countries, that is, the supply (and demand) curves of the two countries are aggregated unless the exchange exceeds the commercial capacity available.

\begin{tabular}{lllll}
\hline & Price & Demand & Supply & Export to other country \\
\hline Country A & $€ 50 / \mathrm{MWh}$ & $80 \mathrm{MWh}$ & $40 \mathrm{MWh}$ & $-40 \mathrm{MWh}$ \\
Country B & $€ 30 / \mathrm{MWh}$ & $100 \mathrm{MWh}$ & $140 \mathrm{MWh}$ & $+40 \mathrm{MWh}$ \\
\hline
\end{tabular}

In this case, compared to case 1, the price reduces in country A (but not as much as in cases 2 and 3 ) and the price increases in country B (but not as much as in cases 2 and 3). There is cross-border trade and a price spread. The commercial exchange between the countries is limited due to the capacity available. In country A, Ga2 sets the price; in country B, Gb2 sets the price. Implicitly, $40 \mathrm{MW}$ of cross-border capacity is allocated from country B to A for the particular hour by the MCO. There is a congestion rent of $40 \mathrm{MWh} * € 20 / \mathrm{MWh}=€ 800$ for this particular hour. More information about the calculation of congestion rent can be found in Annex 4A.1 of Chapter 4. 


\section{A.3 ANNEX: REGULATORY GUIDE}

\section{Table 2A.1 Regulatory guide}

\author{
Section of this chapter, topic and relevant regulation \\ Section 2.1 \\ The First Directive 96/92/EC stated that TSOs had to provide \\ different network users with non-discriminatory access to their \\ networks.
}

The First Directive 96/92/EC allowed Member States to ask for a transitional exemption from the relevant article in the legislation.

\section{Section 2.2}

Regulation (EC) No 1228/2003 required a market-based approach for the allocation of transmission rights.

\section{Section 2.3}

The CACM GL makes day-ahead market coupling binding for all.

The operation of the algorithm is called the market coupling operator (MCO) function in the CACM GL.

According to the CACM GL, to be able to participate in market coupling, exchanges have to be certified as Nominated Electricity Market Operators (NEMOs).

According to the CACM GL, the NEMO function is jointly operated by all participating power exchanges.

The default option described in the CACM GL is to have competing power exchanges in each Member State.

\section{Relevant articles}

Art. 7(5) states that 'The system operator shall not discriminate between system users or classes of system users, particularly in favour of its subsidiaries or shareholders.'

In accordance with Art. 24, the Member States were entitled to ask the Commission to allow an exemption up to one year after the entry into force of the Directive.

The first point under 'general' in the annex to Regulation (EC) No 1228/2003 states that 'Congestion management method(s) implemented by Member States shall deal with short-run congestion in a market-based, economically efficient manner whilst simultaneously providing signals or incentives for efficient network and generation investment in the right locations.'

Art. 42(1) states that 'The day-ahead cross-zonal capacity charge shall reflect market congestion and shall amount to the difference between the corresponding day-ahead clearing prices of the relevant bidding zones.'

Art. 2(30) defines the MCO function as 'the task of matching orders from the day-ahead and intraday markets for different bidding zones and simultaneously allocating cross-zonal capacities.'

Art. 2(23) defines a NEMO as 'an entity designated by the competent authority to perform tasks related to single day-ahead or single intraday coupling.'

Art. 7(2) states that 'NEMOs shall carry out MCO functions jointly with other NEMOs'and lists the different tasks.

The competitive model is the default (preferred) arrangement. See Art. 4(1, 5). However, a monopoly is still possible according to Art. 4(6.a) and Art. 5(2). Art. 5(2) states ' a national legal monopoly is deemed to exist where national law expressly provides that no more than one entity within a Member State or Member State bidding zone can carry out day-ahead and intraday trading services.' Art. 5(3) continues 'if the Commission deems that there is no justification for the 
Section of this chapter, topic and relevant regulation

According to the CACM GL, the regulator (or other competent authority) designates the one or more power exchanges that can organize cross-border trade in the day-ahead and intraday markets.

According to the CACM GL, competitive NEMOs designated in one Member State also have the right to offer trading services with delivery in another Member State where a competitive model is implemented, unless an exception is justified.

Multi-NEMO arrangements (MNAs) in the CACM GL.

Operational MCO implementation according to the CACM GL.

Having a single independent MCO entity is a possible option according to the CACM GL.

The CACM GL states that TSOs may contribute to the MCO-function-related costs of the NEMOs concerned but are not obliged to.

The CACM GL requires NEMOs to submit a joint proposal for the bidding formats they will continue to use.
Relevant articles

continuation of national legal monopolies or for the continued refusal of a Member State to allow cross-border trading by a NEMO designated in another MS, the Commission may consider appropriate legislative or other appropriate measures to further increase competition and trade between and within Member States.'

Art. 4(3): 'Unless otherwise provided by Member States, regulatory authorities shall be the designating authority, responsible for NEMO designation, monitoring of compliance with the designation criteria and, in the case of national legal monopolies, the approval of NEMO fees or the methodology to calculate NEMO fees. Member States may provide that authorities other than the regulatory authorities be the designating authority. In these circumstances Member States shall ensure that the designating authority has the same rights and obligations as the regulatory authorities in order to effectively carry out its tasks.'

This is described in Art. 4(5). On top of not having the right to offer trading services in another Member State when the NEMO is a legal monopoly in its Member state or where a legal monopoly is in place in the Member State of delivery, two other exceptions are listed in Art. 4(6): technical obstacles and incompatible trading rules.

Arrangements concerning more than one NEMO in one bidding zone are described in Art. 45 for day-ahead and Art. 57 for intraday.

Art. 7(3) requires all NEMOs to come up with a plan that sets out how to jointly set up and perform the MCO functions. The MCO plan (All NEMOs 2017c) was approved by all NRAs on 26 June 2017.

Recital 15 states that 'The Commission, in cooperation with the ACER may create or appoint a single regulated entity to perform common MCO functions relating to the market operation of single day-ahead and intraday coupling.'

Art. 76(1) states that the costs of establishing, amending and operating the algorithms, systems and procedures for market coupling (day-ahead and intraday) are borne by all NEMOs. Art. 76(2) adds that TSOs may contribute to the costs subject to approval by the relevant regulatory authorities.

Art. 40 and Art. 53 describe the methodology for the products to be accommodated in the SDAC and SIDC respectively. For both market timeframes, the orders resulting from these products should be expressed in euros and make reference to one or multiple market time units. In January 2018, all NRAs approved the amended proposals for SDAC and SIDC products (All NEMOs 2017a, 2017b). 


Section of this chapter, topic and relevant regulation

Side payments would require a change to the $\mathrm{CACM}$ GL.

Regulation (EU) 2019/943 of the Clean Energy Package includes provisions that will increase the granularity of day-ahead markets from hourly markets to half-hourly or even 15 minutes.

Following the CACM GL, all NEMOs were asked to come up with a joint proposal for minimum and maximum prices in the SDAC and SIDC.

\section{Section 2.4}

According to the FCA GL, JAO became the European platform for long-term transmission right allocation.

To split the available transmission rights over the different long-term timeframes and contract lengths, the FCA GL foresees the need to develop methodologies at the regional level.
Relevant articles

Art. 38(1.b) states that' The price coupling algorithm shall produce the results set out in Article 39(2), in a manner which: ... (b) uses the marginal pricing principle according to which all accepted bids will have the same price per bidding zone per market time unit.'

More specifically, in Art. 8(2) of Regulation (EU) 2019/943, it is stated that 'NEMOs shall provide market participants with the opportunity to trade in energy in time intervals which are at least as short as the imbalance settlement period for both day-ahead and intraday markets.' In the same Regulation and article it is stated at point 4 that 'By 1 January 2021, the imbalance settlement period shall be 15 minutes in all scheduling areas, unless regulatory authorities have granted a derogation or an exemption. Derogations may be granted only until 31 December 2024. From 1 January 2025, the imbalance settlement period shall not exceed 30 minutes where an exemption has been granted by all the regulatory authorities within a synchronous area.'

Arts. 41 and 54 describe the methodology for the harmonized minimum and maximum prices for the SDAC and SIDC respectively. With decisions 04/2017 and 05/2017, ACER (2017a, 2017b) adopted the final version of the harmonized min-max clearing prices to be applied, respectively, to SDAC and SIDC in November 2017.

Recital 5 states that 'Harmonised long-term cross-zonal capacity allocation rules require the establishment and operation of a single allocation platform at European level. This central platform should be developed by all TSOs to facilitate the allocation of long-term transmission rights for market participants and should provide for the transfer of long-term transmission rights from one eligible market participant to another.'Arts. 48, 49 and 50 respectively describe the establishment, functional requirements and tasks of the single allocation platform.

Art. 16 describes the methodology for splitting long-term cross-zonal capacity. 


Section of this chapter, topic and relevant regulation

In the FCA GL, two causes for curtailment of long-term transmission rights are distinguished.

According to the FCA GL, if what happens is considered force majeure, the price of the right in the original auction is refunded.

If it is not a force majeure, i.e. curtailment of the right to ensure operation remains within operational security limits, the compensation is the lost opportunity, which is the day-ahead price spread. In this case, the TSOs concerned might propose introducing a cap, which is further specified in the FCA GL.

The determination of whether an event is classified as force majeure is, however, still done at the national level.
Relevant articles

First, the curtailment of transmission rights in the event of force majeure. A force majeure is defined in the CACM GL Art. 45(2) as 'any unforeseeable or unusual event or situation beyond the reasonable control of a TSO, and not due to a fault of the TSO, which cannot be avoided or overcome with reasonable foresight and diligence, which cannot be solved by measures which are from a technical, financial or economic point of view reasonably possible for the TSO, which has actually happened and is objectively verifiable, and which makes it impossible for the TSO to fulfil, temporarily or permanently, its obligations in accordance with this Regulation.' Second, long-term transmission rights can also be curtailed prior to the day-ahead firmness deadline to ensure that operation remains within operational security limits, defined in CACM GL Art. 2(7) 'as the acceptable operating boundaries for secure grid operation such as thermal limits, voltage limits, short-circuit current limits, frequency and dynamic stability limits.' Lastly, there can be a special case when bidding zone borders cease to exist. This could happen when two bidding zones are merged or bidding zone borders are redrawn.

Art. 56(3) states that in the case of force majeure, the holder of long-term transmission rights will receive compensation from the TSO which invoked the force majeure. This compensation will be equal to the amount initially paid for long-term transmission rights. Art. 27(2) states that similarly in the special case that a bidding zone border ceases to exists, the transmission right holders shall also be entitled to reimbursement by the TSOs concerned based on the initial price paid for the long-term transmission rights.

In the case of a curtailment due to operational security limits, Art. 53(2) specifies that the TSOs concerned on the bidding zone border where long-term transmission rights have been curtailed shall compensate the holders of these rights with the market spread. Furthermore, Art. 54(1) adds that the TSOs concerned on a bidding zone border may propose a cap on the total compensation to be paid to all holders of curtailed long-term transmission rights.

Art. 56(5) states that' Where a Member State has so provided, upon request by the TSO concerned, the national regulatory authority shall assess whether an event qualifies as force majeure.' 


Section of this chapter, topic and relevant regulation
The FCA GL leaves it open whether PTRs or FTRs are used.
If a trader decides not to use a PTR, the trader is compensated
for the value of the right in the day-ahead auction, where other
traders might be willing to pay for it (use-it-or-sell-it).

The FCA GL requires that marginal pricing is applied in the auctions.

The FCA GL states that the two types of transmission rights cannot be applied in parallel on one border.

Regulators can adopt a coordinated decision not to issue PTRs or FTRs on a border when they can show that there is no need for hedging or by ensuring that there are other cross-border hedging instruments available in the market.

\section{Section 2.5}

The CACM GL prescribes that the intraday cross-border gate closure shall be at most one hour before delivery. After the intraday cross-border gate closure, national intraday markets often remain open until even closer to real time.
Relevant articles

Art. 31(1) states: 'Long-term cross-zonal capacity shall be allocated to market participants by the allocation platform in the form of physical transmission rights pursuant to the UIOSI principle or in the form of FTRs - options or FTRs - obligations.' Art. 2(6) defines UIOSI as 'the principle according to which the underlying cross-zonal capacity of physical transmission rights purchased and non-nominated is automatically made available for day-ahead capacity allocation and according to which the holder of these physical transmission rights receives remuneration from the TSOs.'

Art. 28(1) states that 'The allocation of forward capacity shall take place in a way which: (a) uses the marginal pricing principle to generate results for each bidding zone border, direction of utilization and market time unit.'

Art. 51 describes the introduction of harmonized allocation rules. Art. 52 describes the requirements for the harmonized allocation rules. The revised proposal by all TSOs regarding harmonized allocation rules was not unanimously approved by all NRAs. Finally, ACER adopted a decision in August 2017. Art. 31(6) states that 'The allocation of physical transmission rights and FTRs - options in parallel at the same bidding zone border is not allowed. The allocation of physical transmission rights and FTRs - obligations in parallel at the same bidding zone border is not allowed.'

Art. 30(1) states that 'TSOs on a bidding zone border shall issue long-term transmission rights unless the competent regulatory authorities of the bidding zone border have adopted coordinated decisions not to issue long-term transmission rights on the bidding zone border. When adopting their decisions, the competent regulatory authorities of the bidding zone border shall consult the regulatory authorities of the relevant capacity calculation region and take due account of their opinions.' The remainder of Art. 30 states that an assessment needs to show that no hedging needs are unmet by ensuring that there are other cross-border hedging instruments available in the market.

Art. 59(3) states that 'one intraday cross-zonal gate closure time shall be established for each market time unit for a given bidding zone border. It shall be at most one hour before the start of the relevant market time unit and shall take into account the relevant balancing processes in relation to operational security.'The intraday cross-zonal gate closure time is defined in Art. 2(3): 'the point in time where cross-zonal capacity allocation is no longer permitted for a given market time unit.' 
Section of this chapter, topic and relevant regulation

Continuous trade is the default trading arrangement in the intraday timeframe, and auctions are tolerated as a complementary regional arrangement.

The CACM GL requires a single methodology for intraday cross-zonal pricing reflecting market congestion through an implicit allocation method.

\section{Relevant articles}

Art. 51 states that 'From the intraday cross-zonal gate opening time until the intraday cross-zonal gate closure time, the continuous trading matching algorithm shall determine which orders to select for matching.' Art. 63(1) adds that the relevant NEMOs and TSOs on bidding zone borders may jointly submit a common proposal for the design and implementation of complementary regional intraday auctions. Complementary regional intraday auctions may be implemented within or between bidding zones in addition to the single intraday coupling solution referred to in Art. 51.

Art. 55(3) states that all TSOs shall develop a proposal for a single methodology for pricing intraday cross-zonal capacity. Art. 55(1) adds that 'Once applied, the single methodology for pricing intraday cross-zonal capacity developed in accordance with Article 55(3) shall reflect market congestion and shall be based on actual orders.' The revised proposal by all TSOs regarding a single methodology for pricing intraday cross-zonal capacity was not unanimously approved by all NRAs. Finally, ACER (2019a) adopted a decision in January 2019.

According to the CACM GL, explicit allocation is only allowed as a transitional complementary arrangement.
Art. 64 states the provisions related to explicit allocation under the section title 'Transitional intraday arrangements'. In Art. 64(1) it is stated that 'Where jointly requested by the regulatory authorities of the Member States of each of the bidding zone borders concerned, the TSOs concerned shall also provide explicit allocation, in addition to implicit allocation, that is to say, capacity allocation separate from the electricity trade, via the capacity management module on bidding zone borders.' Art. 65 explains the removal of explicit allocation. 


\section{How to calculate border trade constraints? Leonardo Meeus with Tim Schittekatte}

In this chapter we answer five questions. First, why do we focus so much on constraints? Second, why do we calculate trade constraints on virtual borders? Third, who is best placed to do virtual border calculations? Fourth, how to organize the data exchange in support of the calculations? And fifth, why are there still open issues?

\subsection{WHY DO WE FOCUS SO MUCH ON CONSTRAINTS?}

In this section, we explain that transmission lines are currently the only economically viable way to transport electricity, transmission planning is challenging and transmission operation is critical to avoid blackouts.

First, transmission lines are currently the only economically viable way to transport electricity. In other industries, transport and logistics follow the rest of the value chain. There are many companies that compete to supply transport services. In those industries, transport is considered a cost rather than a constraint. Maybe in the future we will have competition to transport electricity, with market parties carrying large-scale batteries on trucks, trains or ships to transport it over long distances. However, for the moment there are no alternatives. In the EU, we have transmission system operators (TSOs), which own networks and perform the system operator tasks in a certain geographical area that is called a control area. In most countries, the control area coincides with the national territory. Germany is one of the exceptions, having four control areas. Some countries have chosen to separate the system operator role from the asset owner, in which case the system operator is referred to as an independent system operator (ISO). For example, Ireland and Great Britain follow this model, which is also the dominant one in the US. Regardless of the specific model, the transmission network is centrally planned and regulated, and therefore by definition imperfect. In economic terms, we consider the transmission network to be a natural monopoly. We discussed how incentive regulation has been used to manage these imperfections in our previous book. ${ }^{1}$

Second, transmission planning is challenging. Transmission planning by TSOs (or ISOs) under the supervision of regulators tries to anticipate the decisions of market parties on where they will invest in power plants or where they will consume electricity. Investments in the network are then planned accordingly. However, as there are many uncertainties involved and large transmission projects take longer than most power plant projects, there are typically many transmission-capacity constraints in the system. Due to these constraints, the cheapest resources cannot reach the consumers with the highest willingness to pay. This planning problem is becoming even more pressing with greater numbers of renewable energy technologies. Indeed, wind turbines and solar parks are faster to build than coal or nuclear power plants. 
Third, transmission operation is critical to avoid blackouts. If we do not account for limitations in the network, the market will result in consumption and production patterns that are not feasible. If we then force the flows through the network lines, they overheat and disconnect. The weakest link disconnects first, which redistributes the flows to other lines. This can create additional overheating, which is followed by a cascade of disconnections, ending in a blackout. The same cascade of events can take place if something unexpected happens to a transmission line. An example of such an event is the blackout that took place in Italy in 2003 after a line tripped on the Swiss-Italian border (Box 3.1). Normally, these problems are avoided by applying the $\mathrm{N}-1$ redundancy principle. There is always some reserve kept in the system to avoid a complete collapse if one of the elements fails.

\section{BOX 3.1 THE ITALIAN BLACKOUT OF 28 SEPTEMBER 2003}

On 28 September 2003 at 03.28 in the morning, a blackout affected more than 56 million people across Italy and some areas of Switzerland. The consequences were huge. For example, 30000 people were stranded on trains in the Italian railway network. Estimates of the number of fatalities directly related to the loss of power vary. Much of Italy was energized again before 08.00 , the central part around noon and the rest of the mainland at 17.00. Sicily was only fully energized at 21.40 . Some commercial and domestic users even suffered disruption in their power supplies for up to 48 hours.

The sequence of events was triggered by the $380 \mathrm{kV}$ Swiss Mettlen-Lavorgo line tripping at 03.01 as a result of a tree flashover. Tree flashovers happen when a line comes too close to trees because they have not been trimmed properly and/or when a line sags more than normal due to overheating.

Following the N-1 principle, other lines were able to take over the flows, but only for a short time. The system needed to be restored to return to a secure state. The Swiss TSO therefore asked the Italian TSO to reduce Italian imports by $300 \mathrm{MW}$. At this time, Italy was importing up to $300 \mathrm{MW}$ more than the already high import schedule, which amounted to $6400 \mathrm{MW}$ on the northern border. However, the import reduction, together with some internal countermeasures taken within the Swiss system, was insufficient to relieve the overload. At 03.25 , the Sils-Soazza line in proximity to the Mettlen-Lavorgo line also tripped after another tree flashover. Almost simultaneously and automatically the remaining lines towards Italy also tripped, and the Italian system was isolated from the European network about 12 seconds after the loss of the Sils-Soazza line.

After this separation, the Italian system had a large shortage resulting in a frequency drop and a disconnection of power plants in the north of Italy. This then accelerated the frequency drop. The Italian TSO tried to save the situation with emergency load shedding, but the frequency reached the threshold of $47.5 \mathrm{~Hz}$ and the whole system collapsed in a blackout 2 minutes and 30 seconds after the isolation of Italy from the rest of Europe. In Chapter 6 we will come back to the role of power plants and other grid connections in this kind of incident. 
Note: UCTE (2004) provides a detailed investigation of the incident. Ranci (2019), the first president of the Italian regulator and founding director of the Florence School of Regulation, describes from his point of view how he saw the blackout that happened in the last months of his mandate. He states that it was an unexpected failure, showing how limited the regulator's powers were to coordinate international relations. He also comments that the Italian regulatory authority had to learn how difficult it can be to explain a highly technical issue to the media, to the public at large and even to members of government.

\subsection{WHY DO WE CALCULATE TRADE CONSTRAINTS ON VIRTUAL BORDERS?}

In this section, we start by introducing the zonal congestion pricing approach that is currently in place in the EU. Afterwards, we discuss why the calculation of net transfer capacities between bidding zones is problematic. Last, we explain that flow-based market coupling allows moving away from net transfer capacities.

First, the zonal congestion pricing approach. When electricity trading started in Europe, the general view was that transmission constraints would not be an issue within a country. At the national level, investments had been made to avoid constraints, while internationally a more minimalistic approach had been followed. Therefore, it seemed logical to define trade borders between countries - so-called bidding zones - and allocate a limited amount of transmission rights on these borders, so-called net transfer capacities. This approach is referred to as a bidding-zone market configuration. This implies that prices are zonal, meaning that within a predefined bidding zone the wholesale electricity prices at each market time unit are the same and trade is unlimited. Of course, everybody knew that bidding zone borders were virtual because a border is an aggregation of physical lines. In some cases, there was awareness that the actual constraint was not necessarily the physical lines crossing the border but another network component deeper inside the national network that was strongly impacted by an increase in cross-border trade. However, this initially did not lead to questioning the approach. Figure 3.1 shows the bidding zone configuration in Europe in 2019. Bidding zone borders still mostly coincide with national borders. The exceptions are Sweden, Norway, Denmark and Italy, which are divided into several bidding zones, and Luxembourg, which shares a bidding zone with Germany.

Second, the calculation of net transfer capacity (NTC). TSOs had the impossible task of calculating the amount of energy that could be traded over a virtual border. First, the amount depends on how the flow will be distributed over the different border lines, which in turn depends on production and consumption patterns, which are only known after trade takes place. TSOs therefore predict the outcome of trade when deciding how much capacity to make available for trade. Second, it depends on what happens on other borders. The amount of capacity that a certain TSO can make available on one border depends on what other TSOs are doing on other borders. There are many flow paths between two points in a transmission network, and the flow will automatically distribute itself over all the paths. As a result, TSOs were very conservative in estimating NTC values to avoid getting it wrong and having to pay penalties for not delivering the capacity they had made available to the market.

Third, the evolution towards flow-based market coupling (FBMC). FBMC essentially means that now virtual border capacity and virtual flow distribution factors are calculated. By doing this, TSOs can be less conservative in the amount of capacity they make available. 


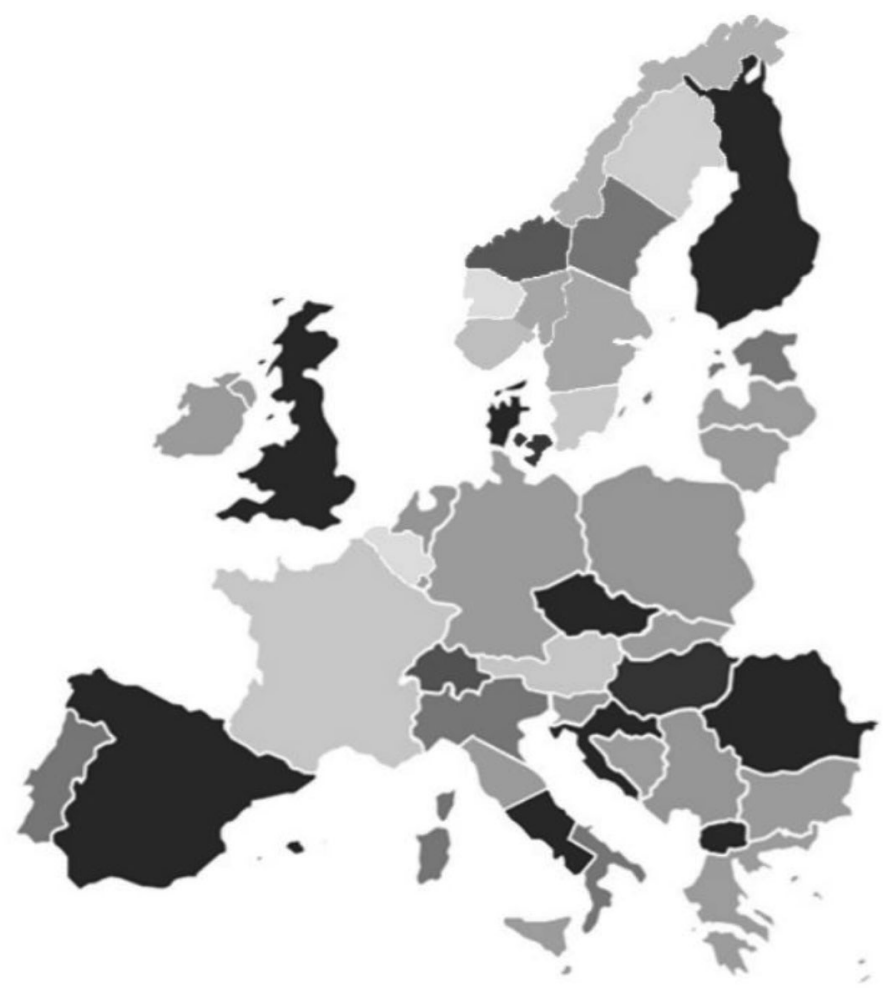

Figure 3.1 Bidding zones in Europe as of November 2019

This is because the interdependencies between different bidding zones are considered using virtual flow factors in the market coupling algorithm. The algorithm allocates the interdependent flows over the different borders to maximize welfare from cross-border trade. The Capacity Allocation and Congestion Management Guideline (CACM GL) refers to FBMC as the primary approach for day-ahead and intraday capacity calculations. Even though the NTC method is still allowed, FBMC is already the dominant model. The idea was discussed long ago in the central western Europe (CWE) regional initiative. The original launch in that region was foreseen for 2009, but due to delays and implementation issues it took until the adoption of the CACM GL in 2015 to finally implement the FBMC method. For a more detailed discussion of the FBMC concept and the key parameters that play a role, see Annex 3A.1. ${ }^{2}$

\subsection{WHO IS BEST PLACED TO DO VIRTUAL BORDER CALCULATIONS?}

Regional collaboration among TSOs started voluntarily and was then formalized. In what follows, we first discuss the steps from regional security coordination initiatives (RSCIs) to regional security coordinators (RSCs) to finally regional coordination centres (RCCs). After, 
we discuss the connection of RCCs with capacity calculation regions (CCRs), which play a key role in the implementation of FBMC.

First, the steps from RSCIs to RSCs to RCCs. Around 2008, the first RSCIs set up were CORESO (based in Brussels) and TSCNET services (based in Munich). In 2015, another RSCI was created in south-eastern Europe (SEE) in Belgrade. In 2016, Nordic and Baltic RSCIs were established. A system operation guideline (SO GL) adopted in 2017 formalized these initiatives by stating that each control area was to be covered by at least one RSC. The left-hand side of Figure 3.2 gives an overview of the geographical coverage of the five RSCs as of January 2019. RSCs are owned or controlled by TSOs and perform different tasks. The SO GL defines five core tasks for the RSCs, and the Clean Energy Package (CEP), more specifically Regulation (EU) 2019/943, has recently added additional tasks. The CEP also renamed the RSCs as regional coordination centres and enhanced their governance.

Second, the connection between RCCs and the CCRs. Within a CCR there is a high degree of interdependence of capacity calculation across borders. CCRs play a key role in the implementation of FBMC. The CACM GL includes the methodology for defining CCRs and requires a coordinated capacity calculation methodology to be developed per CCR. It is this capacity calculation methodology that specifies the implementation of FBMC using parameters, which we discuss in Annex 3A.1. The definition of the geographical scope of the CCRs was a very sensitive topic, with the Agency for the Cooperation of Energy Regulators (ACER) deciding to merge central western Europe (CWE) and central eastern Europe (CEE) into one region, referred to as the Core region. Remember that ACER can only decide on the adoption of methodologies if the national regulatory authorities (NRAs) cannot agree, which was the case for this methodology. For each CCR, the relevant RCC is appointed as coordinated capacity calculator. In the case that there is more than one established RCC active in a CCR, it is expected that one RCC will be responsible for assuming the function of the coordinated capacity calculator on a rotating basis. The right-hand side of Figure 3.2 shows the resulting map of the CCRs. Two of the ten CCRs, the Core and the Nordic CCR, agreed to implement FBMC for the day-ahead timeframe. FBMC spanning the full Core region is expected to go live on 1 December 2020. For the Nordics, the go-live is planned for 1 July 2021. The idea is that gradually CCRs will merge and as such coordinated capacity calculation can be performed over wider geographical areas.

Note finally that even though RCCs take up the role of coordinated capacity calculators, TSOs remain responsible for maintaining operational security. TSOs can decide not to implement a coordinated action proposed by the RCC, whether it is an action related to capacity calculation or grid operation, but only for security reasons, and not for economic considerations. They then need to report the detailed reason to the RCC and the TSOs of the region. This will be further investigated. The RCC may then propose a different set of actions. How this will work is an open issue. In Chapter 6, we describe the incident that led to the start of RSCIs and the tasks they and their grandchildren perform.

\subsection{HOW TO ORGANIZE THE DATA EXCHANGE IN SUPPORT OF THE CALCULATIONS?}

To understand how the data exchange supporting regional capacity calculations is organized, it is necessary to read multiple EU network codes and guidelines. The CACM GL, Forward 

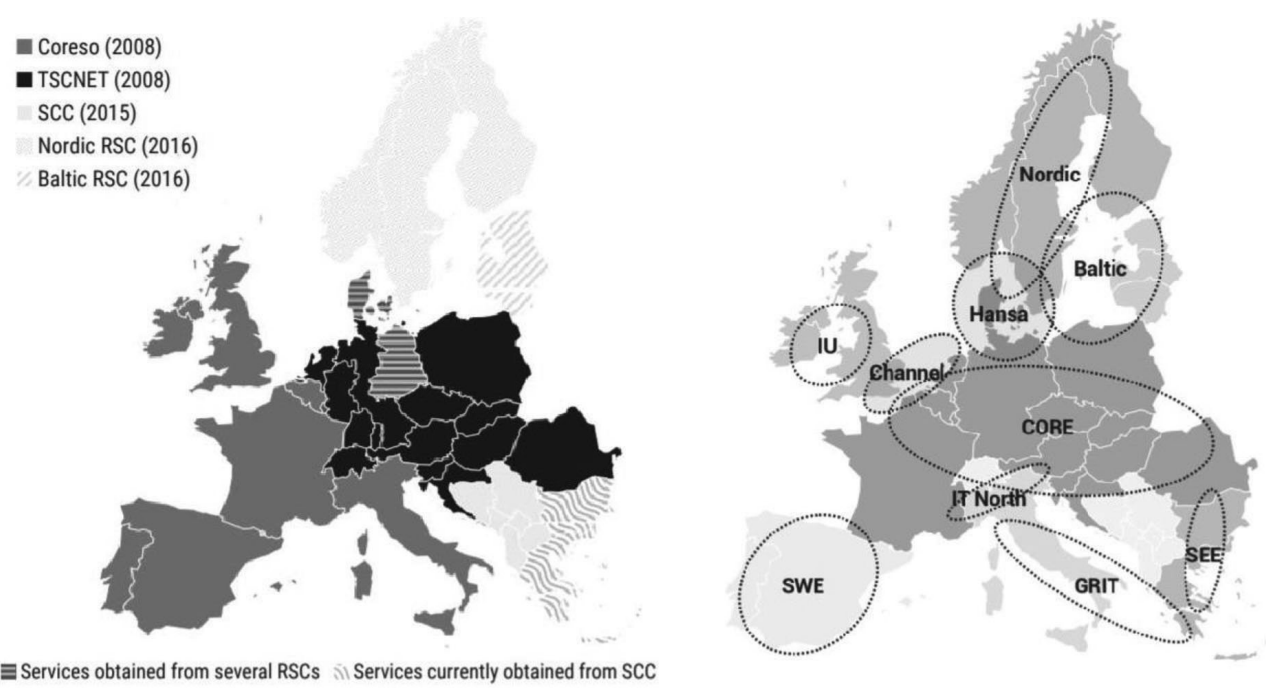

Source: Both figures are adapted from ENTSO-E (2019).

Figure 3.2 Left: the five regional security coordinators (RSCs) as of 1 January 2019; right: the ten capacity calculation regions (CCRs)

Capacity Allocation Guideline (FCA GL) and System Operation Guideline (SO GL) each contain methodologies that when combined explain how the data exchange is organized. All these methodologies have already been approved by the NRAs and adopted. In what follows, we provide an overview of who provides the input data to the TSOs, the process for integrating the data from the TSOs into a common grid model (CGM), how this CGM is used and the physical infrastructure used to exchange these data.

The first question is who provides the input data to the TSOs? The CACM GL and FCA GL each include generation and load data provision methodologies (GLDPM). These set out the generation and load data that TSOs can request from grid users. This applies mainly to the grid users connected at voltages of $220 \mathrm{kV}$ or above. It can also apply to voltages below $220 \mathrm{kV}$ if they are used in regional operational security analysis of the capacity calculation timeframe concerned. These data provisions apply regardless of whether the units are operated by the TSO or a distribution system operator (DSO), including closed distribution systems (a type of private network). TSOs can only use the GLDPM to request data if those data are not already available to them through other national or EU legislation (e.g. the ENTSO-E Transparency Platform), which can help to avoid double reporting. In addition, the TSOs can only use information received under the GLDPM for capacity calculations.

The second question is what is the process for integrating the data from the TSOs into a common grid model? Figure 3.3 summarizes the process. It starts with the TSOs' individual grid models (IGMs). The IGMs cover the power system characteristics, such as generation, load and grid topology. They are scenarios with a forecast representation of the power system for a given timeframe. The RCCs then merge the IGMs into CGMs, one for each timeframe. The merging process is a continuous cycle updating the information available on the grid situ- 


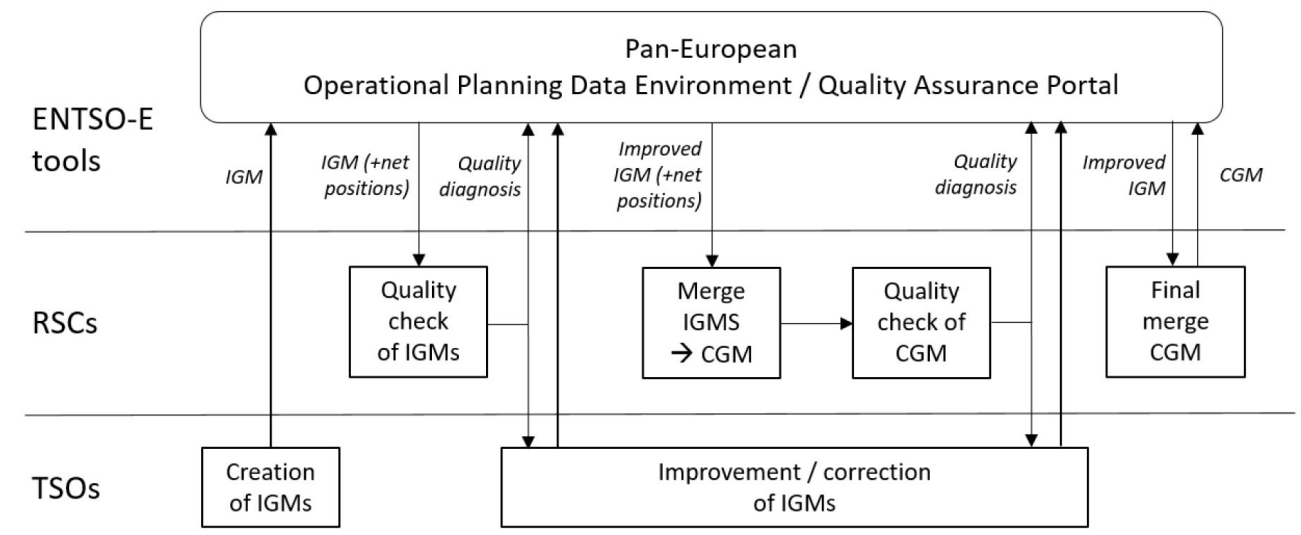

Source: $\quad$ Adapted from ENTSO-E (2018a).

\section{Figure 3.3 The common grid model (CGM) merging process}

ation to ensure that each TSO has enough information for its area and each RCC has the necessary pan-European view to do the capacity calculations for the region. Note that the CGMs are pan-European, even though the capacity calculation is done regionally. It is expected that the RCCs will take turns to merge the IGMs into CGMs. Note too that ENTSO-E stores the IGMs and the CGMs in a portal called the pan-European Operational Planning Data Environment (OPDE).

The third question is how is the CGM used? The SO GL, the CACM GL and the FCA GL each require the establishment of CGMs. The difference between these different models lies in the timeframes for which they are calculated and used. Following the CACM GL, the RCCs must use the CGMs for their capacity calculations in the day-ahead and intraday timeframes. Following the FCA GL, the RCCs can use the CGMs for their capacity calculations in the timeframes before day-ahead, but they can also opt for a statistical approach. The SO GL refers to the use of CGMs for various system operation processes.

The fourth question is what is the physical infrastructure used to exchange these data? A new physical infrastructure called the Physical Communication Network (PCN) will be built for the purpose of exchanging CGM-related data. In 2017, the TSOs decided to merge the PCN with their existing network to exchange real-time data (the Electronic Highway). Both types of data exchange are equally critical for TSOs to perform their tasks.

In conclusion, the days when each TSO was using its own grid model to perform capacity calculations are behind us. There is widespread agreement on the benefits of a common approach to reducing costs and improving performance. The organization of data exchanges to support the ongoing market integration process is a topic that is being increasingly discussed. One of several open issues is the data exchange between the TSO and DSOs and access rights to different grid users' data. In this regard, the key organizational requirements, roles and responsibilities (KORRR) methodology is relevant. The KORRR methodology, which is part of the SO GL, covers data needed beyond capacity calculation - for example, data for real-time operations - and it complements the GLDPMs. The approved version of this 
methodology states that it is to be decided at the national level whether distribution-connected significant grid users (SGUs) have to provide their data directly to the TSO or through the connecting DSOs. ${ }^{3}$

\subsection{WHY ARE THERE STILL OPEN ISSUES?}

FBMC was expected to improve the availability of transmission capacity thanks to a more sophisticated capacity calculation. To monitor if the approach delivered, ACER and the Council of European Energy Regulators (CEER) developed the concept of a benchmark capacity, which is the capacity they expect TSOs to make available on a certain border. In the first full year of FBMC in 2016, on average only 59 per cent of this capacity was made available in central western Europe. This was slightly better than what was available before the implementation of FBMC, but there was less improvement than expected. ACER also estimated that we are losing several billions of euros a year by not reaching the benchmark capacity. ${ }^{4}$

The reason is that FBMC does not address today's most pressing issue, which is that the real constraints in the network are no longer at the outdated virtual borders but within the bidding zones. In what follows, we discuss how Directorate-General for Competition (DG COMP the European competition authority), the EU network codes and guidelines, and the EU Clean Energy Package (CEP) have started to address the issue. Finally, we discuss the US approach to this problem.

First, the approach by DG COMP. This started with an antitrust case against the Swedish TSO Svenska Kraftnät (SvK) and continued with a case against the German TSO TenneT DE. The SvK case started in 2006 after a complaint by the Danish energy industry association that it suffered high prices because the Swedish TSO was blocking cheap imports from Norway to Denmark via Sweden. DG COMP concluded that SvK had indeed constrained cross-border trade to reduce internal congestion problems. This was found to be an abuse of the TSO's dominant position and discrimination against cross-border flows in favour of internal flows. SvK initially stated that it would remedy the situation by investing in the constrained internal transmission lines, but this was not enough for the Commission. To avoid being fined, in 2010 SvK agreed to split Sweden into four bidding zones. This was the best solution because traders in Sweden now compete on a level playing field with cross-border traders for the limited internal capacity that is available in Sweden. When Sweden was one bidding zone, national trade was unlimited and cross-border trade could only use the national trade's leftovers. ${ }^{5}$

The TenneT DE investigation started in 2018. In this case, the complaint was that TenneT DE limited the export of cheap renewable wind energy from Denmark to Germany. This TSO also agreed to remedies to avoid being fined by DG COMP. TenneT DE guaranteed it would make significantly more capacity available on the Danish border a few months after the agreement with DG COMP, and would further increase capacity by 2026 , when additional investment projects will have been completed. This solution is not a good one, but it currently seems to be the only politically feasible solution in Germany. Germany does not want to split up the national bidding zone into smaller bidding zones to deal with internal constraints. Its long-term solution is transmission investment, and in the meantime it has agreed to allow more cross-border trade, although it knows that it does not have enough internal transmission capacity to handle it. The German TSOs therefore intervene in the market with so-called redis- 
patching actions. Germany is basically changing the market outcome to prevent its internal lines from overloading. These interventions are costly, and they also lead to market distortions. The result is paying those that caused the problem to solve the problem. They can then create more problems and earn more money. ACER estimated that in 2017 redispatch costs in the EU had already reached 2 billion euros. ${ }^{6}$

Second is the approach followed by the CACM GL. This introduced a bidding zone review process. The first bidding zone review was requested by ACER in 2016 for the central Europe region, and ENTSO-E published the results in 2018. Four alternative bidding zone configurations were assessed using a multi-criteria analysis. Following the CACM GL, the three main criteria considered were the stability and robustness of the bidding zones, network security and overall market efficiency. No alternative bidding zone configuration was found to outperform the status quo on all the criteria. The review therefore proposed keeping the current configuration. The TSOs did not feel comfortable carrying out this politically sensitive review, and together with most observers we have been disappointed with the outcome. This explains why this issue has again been picked up in the CEP.

Third is the approach followed by the CEP. Regulation (EU) 2019/943 introduced an improved bidding zone review process. The implementation of this new process has already started with the submission of a bidding zone review methodology and alternative configurations by TSOs. All the NRAs then have three months to reach a unanimous decision on the proposal. If they fail to reach a decision, then ACER will decide within an additional three months. The TSOs will do the bidding zone review and analyse alternative configurations using the agreed-upon methodology. They will then provide the relevant Member States or their designated competent authorities with a joint proposal to amend or maintain the current bidding zone configuration. This process is similar to that described in the CACM GL. However, the end of the process is new. If Member States that opt to change the existing bidding zone configuration cannot reach a unanimous decision, as a last resort the European Commission will adopt a decision to amend or maintain it.

The European Commission had originally proposed legislation that would put it in charge of configurating bidding zones. However, the European Council (representing the Member States) opposed this and compromised with the European Parliament on what came to be known as one of the most controversial elements in the CEP. In the final version of Regulation (EU) 2019/943, the European Commission only has last resort powers when it comes to the bidding zone configuration, but Member States have to comply with a transmission capacity availability threshold. Regulation (EU) 2019/943 states that the available transmission capacity of all transmission elements possibly limiting the amount of electricity that can be exchanged between different bidding zones should be at least 70 per cent of a benchmark value. A process has been set in motion to assess the extent to which different countries already comply with this threshold and how they intend to comply by 2025. Basically, countries need to choose between the two DG COMP cases - whether to follow the Swedish or the German approach to stopping discrimination between cross-border and national trade.

Fourth is the US approach to this issue, that is, nodal pricing. If it is not possible to agree on bidding zones, they could simply be abolished or reduced to the physical nodes in the transmission network. This would mean that, instead of a simplified network with virtual borders and flow factors, the physical constraints of the transmission network are represented in the market coupling algorithm. If none of the constraints are binding and thermal losses are 
excluded, there would be a single price for the whole of Europe. If one of them is binding, the result would be a 'weather map' in which every point or node in the transmission network would have a different price depending on where it is in relation to that network constraint. The price map would change with weather conditions as the availability of wind and solar is becoming an important factor in electricity production. In addition, temperature influences electricity consumption. US markets have experience with nodal pricing in smaller-scale markets; Europe could be the first to do it on a much larger international scale. We shall see how this open issue plays out. ${ }^{7}$

\subsection{CONCLUSION}

In this chapter on the calculation of cross-border trade constraints, we have answered five questions.

First, why do we focus so much on constraints? Transmission lines are currently the only economically viable way to transport electricity. Transmission planning is challenging and transmission operation is critical to avoid blackouts. The $\mathrm{N}-1$ redundancy principle means that there is always some reserve kept in the system to avoid a complete collapse if one of the elements fails.

Second, why do we calculate trade constraints on virtual borders? It seemed natural to define virtual trade borders between countries and assign a limited capacity to these borders. The FBMC algorithm captures the interdependencies between borders and the CACM GL mandates it to be the primary approach for day-ahead and intraday capacity calculation.

Third, who is best placed to do these virtual border calculations? Collaboration among TSOs started voluntarily and evolved into being more formal. The CACM GL introduced the concepts of CCRs and RSCs and the Clean Energy Package added responsibilities for RSCs and renamed them as regional coordination centres (RCCs).

Fourth, how to organize the data exchange in support of the calculations? The SO GL, the CACM GL and the FCA GL require the establishment of CGMs. They ensure that each TSO has information to manage its area and each regional coordination centre has the pan-European view. Interestingly, a dedicated European physical communication infrastructure supporting multiple real-time and non-real-time services has been built up to support the data exchange.

And fifth, why are there still open issues? The current bidding zone configuration is outdated. Too many countries have a national bidding zone with internal congestion within it. They therefore discriminate against cross-border trade in favour of national trade. The best solution is to split bidding zones, but some countries prefer to keep their national bidding zone despite the very high cost.

\section{NOTES}

1. In Meeus and Glachant (2018) we discuss how TSOs and distribution systems operators (DSOs) are regulated as monopolies over transmission and distribution assets. We also show that the border between what is considered a market, transmission or distribution is not always clear, which is referred to as seams issues or grey areas in regulation.

2. A comprehensive comparison between the NTC approach and FBMC can be found in Van den Bergh et al. (2016).

3. A distribution-connected significant grid user (SGU) is a generator connected to a distribution network with a connected capacity higher than a certain threshold. This threshold, typically between 
several hundred kWs and $1 \mathrm{MW}$, depends on the national implementation of the Requirements for Generators Network Code (RfG NC), which is discussed in more depth in Chapter 6. In addition, distribution-connected demand facilities, directly or aggregated, which provide demand response to the TSO are considered SGUs.

4. The benchmark capacity is calculated as if the ACER (2016b) recommendation on common capacity calculation, redispatching and countertrading cost sharing methodologies is applied. This recommendation emphasizes that internal network elements should not limit available tradable cross-zonal capacity and that loop flows and other unscheduled flows should be minimized. Loop flows are explained in Annex 3A.2. Making comparisons with how much available capacity was offered in the past is not straightforward. This is first because it is not easy to compare available tradable capacity under an NTC and an FBMC approach, and second because the concept of a benchmark capacity was introduced for the first time in the ACER and CEER (2017) market monitoring report of 2016. For example, the market monitoring analysis in ACER and CEER (2016) shows that approximately 31 per cent of the interconnector's physical capacity on CWE borders was used for trading in 2015. The same report found that the ratio between NTC and thermal capacity in CWE was 27 per cent.

5. A more detailed legal discussion of the SvK case can be found in the work of our colleagues de Hauteclocque and Hancher (2011).

6. The discussion regarding the TenneT DE case is based on press releases from the European Commission (2018). The $€ 2$ billion estimate of EU-wide redispatch costs in 2017 is based on the ACER and CEER (2018) market monitoring report. Using simple cases, Stoft (1999) shows the possibility of gaming between the wholesale market and redispatching, the so-called incrementaldecremental (inc-dec) game. Purchala (2019) describes how the zonal market does not facilitate correct incentives for efficient behaviour.

7. The book Spot Pricing of Electricity by Schweppe et al. (1988) and the paper 'Contract networks for electric power transmission' by Hogan (1992) were seminal works which laid the foundations for the implementation of nodal pricing in the US. Neuhoff and many colleagues (2013) quantify the Europe-wide operational savings of nodal relative to zonal market design to be in the order of $€ 0.8-2$ billion/year (representing 1.1-3.6 per cent of operating costs). Similarly, Green (2007) calculates that moving from a uniform zonal price to optimal nodal prices for England and Wales could raise welfare by 1.3 per cent of the generators' revenues, and would be less vulnerable to market power. Both papers add that nodal pricing would send better investment signals but would also cause politically sensitive redistributions. More recently, the concept of distribution locational marginal pricing (DLMP) or nodal pricing all the way down to distribution grids is gaining attention. Caramanis et al. (2016) propose a DLMP framework in which the market and reserves are cleared simultaneously (co-optimization) with inclusion of flexible loads and distributed energy resources (DERs) and while considering line-flow constraints and distribution-bus voltage limits. Papavasiliou (2018) provides an analysis of three DLMP approaches. He discusses price formation under each approach and their strengths and limitations. MIT Energy Initiative (2016) highlights the need for advanced meters, inexpensive information and communications technology (ICT) solutions and DERs in order to make effective use of DLMP.

\section{REFERENCES}

ACER (2016a), 'Decision No 06/2016 of the Agency for the Cooperation of Energy Regulators of 17 November 2016 on the Electricity Transmission System Operators' Proposals for the Determination of Capacity Calculation Regions'.

ACER (2016b), 'Recommendation No 02/2016 of the Agency for the Cooperation of Energy Regulators of 11 November 2016 on the Common Capacity Calculation and Redispatching and Countertrading Cost Sharing Methodologies'.

ACER and CEER (2016), 'Annual Report on the Results of Monitoring the Internal Electricity and Natural Gas Markets in 2015 - Electricity Wholesale Markets Volume'.

ACER and CEER (2017), 'Annual Report on the Results of Monitoring the Internal Electricity and Natural Gas Markets in 2016 - Electricity Wholesale Markets Volume’. 
ACER and CEER (2018), 'Annual Report on the Results of Monitoring the Internal Electricity and Natural Gas Markets in 2017 - Electricity Wholesale Markets Volume'.

ACER and CEER (2019), 'Annual Report on the Results of Monitoring the Internal Electricity and Natural Gas Markets in 2018 - Electricity Wholesale Markets Volume'.

All TSOs (2016), 'All TSOs' Proposal for a Generation and Load Data Provision Methodology in Accordance with Article 16 of the CACM GL', published on 13 May 2016.

All TSOs (2018), 'All TSOs' Proposal for the Key Organisational Requirements, Roles and Responsibilities (KORRR) Relating to Data Exchange in Accordance with Article 40(6) of the SO GL', published on 1 October 2018.

Caramanis, M. C., E. Ntakou, W. W. Hogan, A. Chakrabortty and J. Schoene (2016), 'Co-optimization of power and reserves in dynamic T\&D power markets with nondispatchable renewable generation and distributed energy resources', Proceedings of the IEEE, 104 (4), 807-36.

de Hauteclocque, A. and L. Hancher (2011), 'The Svenska Kraftnät case: Introduction of bidding zones in Sweden', Network Industries Quarterly, 13 (1), 20-22.

ENTSO-E (2018a), 'ENTSO-E implementation of the CIM', presentation at CIM User Group on 7 June 2018, accessed at http://cimug.mobi/Meetings/eu2018/2018 Ljubljana Presentations/CIM Meeting Day 2/CIM ug ENTSO-E implementation of the CIM.pptx.

ENTSO-E (2018b), 'First Edition of the Bidding Zone Review: Final Report'.

ENTSO-E (2019), 'Enhanced TSO Regional Coordination for Europe'.

European Commission (2018), 'Antitrust: Commission opens investigation into German grid operator TenneT for limiting cross border electricity capacity with Denmark', press release of 19 March 2018.

Green, R. (2007), 'Nodal pricing of electricity: How much does it cost to get it wrong?', Journal of Regulatory Economics, 31 (2), 125-49.

Hogan, W. W. (1992), 'Contract networks for electric power transmission', Journal of Regulatory Economics, 4, 211-42.

Meeus, L. and J.-M. Glachant (eds) (2018), Electricity Network Regulation in the EU: The Challenges Ahead for Transmission and Distribution, Cheltenham, UK and Northampton, MA, USA: Edward Elgar Publishing.

MIT Energy Initiative (2016), 'Utility of the Future: An MIT Energy Initiative Response to an Industry in Transition'.

Neuhoff, K., J. Barquin, J. W. Bialek, R. Boyd, C. J. Dent, F. Echavarren, T. Grau, C. von Hirschhausen, B. F. Hobbs, F. Kunz, C. Nabe, G. Papaefthymiou, C. Weber and H. Weigt (2013), 'Renewable electric energy integration: Quantifying the value of design of markets for international transmission capacity', Energy Economics, 40, 760-72.

Papavasiliou, A. (2018), 'Analysis of distribution locational marginal prices', IEEE Transactions on Smart Grid, 9 (5), 4872-82.

Purchala, K. (2019), 'EU electricity market: The good, the bad and the ugly', in S. Nies (ed.), The European Energy Transition: Actors, Factors, Sectors, Deventer, Netherlands and Leuven, Belgium: Claeys \& Casteels, pp. 275-88.

Ranci, P. (2019), 'The early years of the energy regulator in Italy', Competition and Regulation in Network Industries, 20 (3), 250-7.

Schweppe, F. C., M. C. Caramanis, R. D. Tabors and R. E. Bohn (1988), Spot Pricing of Electricity, Boston, MA: Kluwer Academic Publishers.

Stoft, S. (1999), 'Using game theory to study market power in simple networks', IEEE Tutorial on Game Theory in Electric Power Markets, 33-40.

UCTE (2004), 'Final Report of the Investigation Committee on the 28 September 2003 Blackout in Italy'.

Van den Bergh, K., J. Boury and E. Delarue (2016), 'The flow-based market coupling in central western Europe: Concepts and definitions', Electricity Journal, 29 (1), 24-9. 


\section{A.1 ANNEX: FLOW-BASED MARKET COUPLING (FBMC)}

FBMC is a process, not a one-step calculation, which starts two days before real time (base case) and ends the morning one day ahead. At that moment, the coordinated capacity calculators deliver the necessary parameters to the market coupling operator (MCO) that is in charge of the day-ahead market-clearing algorithm. In FBMC, market clearing and the allocation of cross-zonal transmission capacity are done jointly. By considering interdependencies between network elements in the market clearing, the transmission capacity is allocated in a way that total welfare from trade is maximized. To arrive at a simplified network model without having to consider all the individual lines, each TSO defines critical network elements (CNEs) in its control area. In the literature, CNEs are also called critical branches. CNEs include cross-zonal lines, but they can also include internal lines or transformers that are significantly impacted by cross-zonal exchanges. By considering a CNE in the capacity calculation process, a CNE can limit the amount of power that can be exchanged. The flow-based parameters incorporated in the market-clearing algorithm are challenging to determine. We briefly introduce two of these: zonal power transfer distribution factors (PTDFs) and CNE availability margins.

First, zonal PTDFs describe the linear relationship between the physical flow in a CNE and the net exchange position of a specific bidding zone. The net exchange position is equal to the total production minus the total consumption within the zone. If production is higher than consumption, the zone will be a net exporter; vice versa, the zone would be a net importer. PTDFs are formulated in a matrix with all the bidding zones in one dimension and all the CNEs in the other dimension. With zonal pricing, nodes are grouped in zones. This implies that in order to correctly represent flows between zones, zonal PTDFs need to be approximated from what happens at the nodal level within a zone. Generation shift keys (GSKs) and load shift keys (LSKs) may also be used to 'translate' changes in generation/consumption at the nodal level to impacts on the net exchange level of a zone. GSKs are not easy to determine as they are based on predictions of the market outcome and subject to forecast errors. Each TSO calculates the GSKs for its control area.

Second, CNE available margins (AMs). The AM is the maximum flow from day-ahead trade that can be carried by CNEs. The available margin is also referred to as the remaining available margin (RAM). Determining the AM involves identifying the CNEs within a control zone and the contingencies (critical outages) to be considered for system security. More precisely, AMs are the maximum flow an element can carry corrected by three types of flows to what is left for day-ahead trade. The first correction is for the reference flow to a CNE. This is caused by transactions between or within bidding zones other than the day-ahead market, such as bilateral transactions or transactions in forward markets. The second correction is for a final adjustment value, a margin which is TSO-specific and depends on, for example, costly remedial actions such as redispatch possibilities. To determinate this value it is important to ensure that there is no discrimination between internal and cross-zonal flows. The third correction is for a flow reliability margin, a safety margin compensating for approximations made in the flow-based approach. 


\section{A.2 ANNEX: TRANSIT FLOWS AND LOOP FLOWS}

Two types of flow can 'consume' cross-zonal capacity between two bidding zones at the expense of capacity available for trade between the two bidding zones. First, transit flows. Some cross-zonal capacity of one bidding zone will be used by parallel flows resulting from trade between other bidding zones. For example, trade between Germany and France can flow through Belgium. Thus, the cross-zonal transmission capacity available for trade between Belgium and its neighbours will be impacted. Transit flows are unscheduled when the exchange causing the flow is cross-zonal and the capacity calculation is not coordinated with the zone facing the flow. A flow is called an unscheduled flow when the physical flow in the network differs from commercial exchanges between consumers and producers within a bidding zone or between two different bidding zones. If the cross-zonal capacity calculation is coordinated between the zones causing the transit flow and the zone facing it, the transit flow is scheduled, as it can be accounted for in the transmission calculation process. A transit flow is illustrated on the left-hand side of Figure 3A.1.

Second, loop flows. Transactions within a bidding zone can have an impact on the flows through adjacent bidding zones. For example, if there is a commercial transaction between the north and the south of Germany, it is possible for electricity to flow through Poland to reach its destination. Thus, the cross-zonal transmission capacity available for trade between Poland and its neighbours (mostly Germany in this case) will be impacted. By definition loop flows are always unscheduled as they occur between two nodes within the same bidding zone. A loop flow is illustrated on the right-hand side of Figure 3A.1.

Transit flows are exactly the kind of flows that can be dealt with by FBMC, but loop flows cannot. Loop flows can only be addressed by revising the bidding zone configuration.
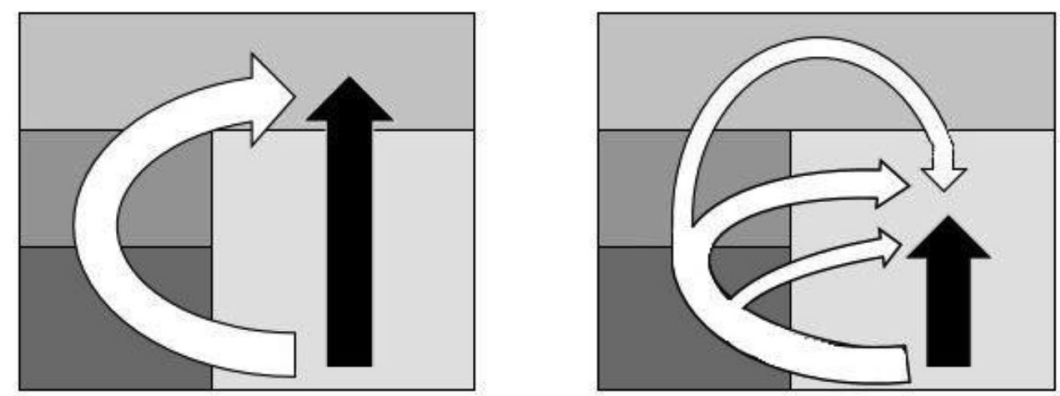

Figure 3A.1 Scheduled flows (black), transit flows (white, left) and loop flows (white, right); the different rectangular areas represent bidding zones 


\section{A.3 ANNEX: REGULATORY GUIDE}

\section{Table 3A.1 Regulatory guide}

Section of this chapter, topic and relevant regulation

\section{Section 3.2}

The CACM GL refers to FBMC as the primary approach for day-ahead and intraday capacity calculations. Even though the NTC method is still allowed, FBMC is already the dominant model.

\section{Section 3.3}

The SO GL formalizes RSCIs by stating that each control area shall be covered by at least one regional security coordinator (RSC).

Regulation (EU) 2019/943, part of the CEP, renamed RSCs as regional coordination centres (RCCs) and enhanced their governance.

The SO GL defines five core tasks of the RSCs.
Relevant article

Relevant article

Art. 20(1) states that 'For the day-ahead market time-frame and intraday market time-frame the approach used in the common capacity calculation methodologies shall be a flow-based approach, except where the requirement under paragraph 7 is met.'Art. 20(7) states that 'TSOs may jointly request the competent regulatory authorities to apply the coordinated net transmission capacity approach in regions and bidding zone borders (other than those referred to in paragraphs 2 to 4), if the TSOs concerned are able to demonstrate that the application of the capacity calculation methodology using the flow-based approach would not yet be more efficient compared to the coordinated net transmission capacity approach and assuming the same level of operational security in the concerned region.'

Art. 3(89) defines RSCs as 'the entity or entities, owned or controlled by TSOs, in one or more capacity calculation regions performing tasks related to TSO regional coordination.' Art. 77 describes the organization of regional operational security coordination. Art. 77(2.a) states that each TSO shall be covered by at least one RSC.

Art. 35 in Regulation (EU) 2019/943 describes the establishment and mission of RCCs. Art. 35(2) specifies 'Following approval by regulatory authorities of the proposal [for the establishment of regional coordination centres], the regional coordination centres shall replace the regional security coordinators established pursuant to [SO GL] and shall enter into operation by 1 July 2022.'

Art. 77(3) lists four tasks of the RSCs: (a) regional operational security coordination; (b) building a common grid model; (c) regional outage coordination; and (d) regional adequacy assessment. The fifth task, coordinated capacity calculation, is indirectly mentioned in the CACM GL. In recital 6 of the CACM GL it is stated that 'capacity calculation for the day-ahead and intraday should be coordinated at least at regional level.' Additionally, Art. 6(3) of the Emergency and Restoration Network Code (ER NC) states that RSCs will be consulted to assess the consistency of measures described in a TSO's system defence and restoration plan. Last, RSCs also provide critical grid situation support to TSOs, a responsibility that was introduced with the cold spell in the winter of 2017/2018. 


\begin{tabular}{l} 
Section of this chapter, topic and relevant \\
regulation \\
\hline Regulation (EU) 2019/943 adds more tasks for \\
RSCs, renamed as regional coordination centres.
\end{tabular}

The CACM GL includes a methodology to define capacity calculation regions (CCRs).

The CACM GL asks for the development of a coordinated capacity calculation methodology for each CCR.

TSOs remain responsible for maintaining operational security. They can decide to not implement a coordinated action proposed by the RCC. They then need to report the detailed reason to the RCC and the TSOs of the region. This will be further investigated. The RCC may then propose a different set of actions.

\section{Section 3.4}

The CACM and FCA GL each include a generation and load data provision methodology (GLDPM).

The GLDPM sets out the generation and load data that TSOs can request from grid users. This applies mainly to grid users connected at voltage levels of $220 \mathrm{kV}$ or above. It can also apply to voltage levels below $220 \mathrm{kV}$ if they are used in regional operational security analysis of the capacity calculation timeframe concerned.
Relevant article

Recital 55 of Regulation (EU) 2019/943 states that 'The tasks of regional coordination centres should cover the tasks carried out by [RSCs pursuant to SO GL] as well as additional system operation, market operation and risk preparedness tasks. The tasks carried out by regional coordination centres should not include real-time operation of the electricity system.' In Art. 37(1), all 16 tasks are listed. Annex I of the same regulation provides additional information.

Art. 15 requires CCRs to be determined. A CCR is a geographical area in which coordinated capacity calculation is applied. Each CCR comprises a set of bidding zone borders. Finally, ACER (2016a) approved the revised proposal of all the TSOs, under the condition of merging central western Europe and central eastern Europe into one Core region.

Art. 20(2) states that " $n o$ later than 10 months after the approval of the proposal for a capacity calculation region in accordance with Article 15(1), all TSOs in each capacity calculation region shall submit a proposal for a common coordinated capacity calculation methodology within the respective region.' A methodology for both day-ahead and intraday capacity calculation is to be proposed. Delayed submission was permitted for certain CCRs (CACM GL, Art. 20(3-4)). ACER and CEER (2019) report that as of June 2019 the relevant NRAs approved capacity calculation methodologies in all CCRs except Italy North.

Art. 42 of Regulation (EU) 2019/943 describes the adoption and review of coordinated actions and recommendations. This article states that TSOs shall implement the coordinated actions issued by RCCs except where the implementation would result in a violation of the operational security limits defined by each TSO in accordance with the SO GL. It adds that RCCs may propose a different set of coordinated actions in the case that TSOs decide not to implement their recommendations.

Art. 16 of the CACM specifies the GLDPM methodology. Art. 17 of the FCA GL states that the GLDPM developed under the FCA GL shall take into account and complement the GLDPM provided in Art. 16 of the CACM GL. Art. 16(2) of the CACM GL states that the proposal for the GLDPM shall specify which generation units and loads are required to provide information to their respective TSOs for the purpose of capacity calculation. Details on which grid users have to provide what data can be found in the approved versions of the respective GLDPMs, e.g. All TSOs (2016). 


Section of this chapter, topic and relevant Relevant article
regulation

TSOs can only use the GLDPM to request data if that data is not already available to them through other national or EU legislation (e.g. the ENTSO-E Transparency Platform), which can help to avoid double reporting.

According to the CACM GL, TSOs can only use the information received under the GLDPM for the purpose of capacity calculation.

The three network codes (CACM GL, FCA GL and SO GL) introduce individual grid models (IGMs).

RCCs merge the IGMs into common grid models (CGMs).

The three network codes (CACM GL, FCA GL and SO GL) describe the IGM merging process in the different CGMs. The difference between these different models lies in the timeframe in which they are calculated and used.

It is expected that the RCCs will take turns to merge the IGMs into CGMs.

ENTSO-E stores the IGMs and the CGMs in a portal that is called the pan-European Operational Planning Data Environment (OPDE)
Art. 3(1) of the GLDPM approved according to the CACM GL (All TSOs (2016)) states that 'Each TSO shall have the right but not the obligation to obtain these data from the owner of the corresponding network element or the party responsible for providing the information, as the case may be, provided that all of the following conditions are met ...' One of the conditions is that the data are not already available to the TSO through other national or EU legislation.

Art. 16(5) specifies that the information received under the GLDPM shall only be used for capacity calculation purposes.

CACM GL Art. 2(1) defines an IGM as 'a data set describing power system characteristics (generation, load and grid topology) and related rules to change these characteristics during capacity calculation, prepared by the responsible TSOs, to be merged with other individual grid model components in order to create the common grid model.' CACM GL Art. 19, FCA GL Art. 20 and SO GL Arts. 66 and 70 provide more information about the respective IGMs.

According to the CEP, more specifically Regulation (EU) 2019/943, RCCs take over the tasks of RSCs. Art. 77(3) of the SO GL states that one of the tasks of the RSCs is to build a common grid model (CGM). The CGM is defined in the CACM GL as ' $a$ Union-wide data set agreed between various TSOs describing the main characteristics of the power system (generation, loads and grid topology) and rules for changing these characteristics during the capacity calculation process.'

Art. 17 of the CACM GL describes the CGM methodology. Point b in the second paragraph specifies that this methodology shall contain a description of the process for merging IGMs to form the CGM. Art. 18 in the FCA GL introduces the CGM methodology for long-term capacity calculation. Art. 67 in the SO GL describes the year-ahead CGMs and Art. 70 in the same regulation describes the methodology for building day-ahead and intraday CGMs. The SO GL refers to the use of CGMs for various system operation processes.

Art. 28 of the CACM GL describes the creation of the common grid model. Art. 28(2) states that 'each TSO shall deliver to the TSOs responsible for merging the individual grid models into a common grid model the most reliable set of estimations practicable for each individual grid model.' Art. $77(3)$ of the SO GL states that one of the tasks of the RSC is to build the CGM. The CGM is pan-European while the capacity calculation is done for the CCRs. Therefore, it is expected that the RCCs will rotationally take the role of the 'merging agent'.

The SO GL describes the general provisions for the OPDE in Art. 114. 


Section of this chapter, topic and relevant
regulation
Following the FCA GL, the CCRs can use the
CGMs for their capacity calculations in the
timeframes before day-ahead, but they can also
opt for a statistical approach.
The SO GL requires a key organizational
requirements, roles and responsibilities
(KORRR) methodology. The approved version
of this methodology will be decided at the
national level whether distribution-connected
significant grid users (SGUs) have to provide
their data directly to the TSO or through the
connecting DSOs.

\section{Section 3.5}

The CACM GL introduced a bidding zone review process.

Following the CACM GL, the three main criteria considered are the stability and robustness of the bidding zones, network security and overall market efficiency.

Regulation (EU) 2019/943 introduces an improved bidding zone review process.

The implementation of this new process has already started with the submission of a bidding zone review methodology and alternative configurations by TSOs.
Relevant article

Long-term capacity calculation may be based on the CGM. Alternatively, CCRs may opt to use the statistical approach pursuant to Art. 10(4.b) of the FCA GL.

Art. 40(6) states that 'all TSOs shall jointly agree on key organisational requirements, roles and responsibilities in relation to data exchange. Those organisational requirements, roles and responsibilities shall take into account and complement where necessary the operational conditions of the [GLDPM developed in accordance with Article 16 of the CACM GL].' In December 2018, the revised KORRR methodology proposal by All TSOs (2018) was approved by all NRAs. Art. 3(3) in this approved methodology states that 'Subject to approval by the competent regulatory authority or by the entity designated by the Member State and according to Article 40 of the SO GL, it shall be determined at a national level whether distribution-connected SGUs in their TSO's control area shall provide the structural, scheduled and real-time data to the TSO directly or through their connecting DSOs or to both. The decision on the data exchange model may be independent for each type of information and $S G U$, if required. When the data is provided to the DSO, the DSO shall provide the required data to the TSO with a data granularity necessary to comply with the requirements of the SO GL provisions.'Art. 2 of the SO GL gives more detail on which SGUs the SO GL applies to.

Art. 32 states who can launch a bidding zone review process and how this process is performed by reviewing existing bidding zone configurations. The first bidding zone review (ENTSO-E 2018b) was initiated by a letter from ACER dated 21 December 2016 specifying central Europe as the relevant region.

The three criteria for reviewing bidding zone configurations are listed and elaborated upon in Art. 33.

Regulation (EU) 2019/943 Art. 14 describes the bidding review process.

Art. 14(5) in Regulation (EU) 2019/943 states that 'By 5 October 2019 all relevant transmission system operators shall submit a proposal for the methodology and assumptions that are to be used in the bidding zone review process and for the alternative bidding zone configurations to be considered to the relevant regulatory authorities for approval.' 


\begin{tabular}{l} 
Section of this chapter, topic and relevant \\
regulation \\
\hline According to Regulation (EU) 2019/943, if \\
Member States that have opted to change the \\
existing bidding zone configuration cannot \\
reach a unanimous decision, as a last resort the \\
European Commission shall adopt a decision \\
to amend or maintain the bidding zone \\
configuration.
\end{tabular}

Member States have to comply with a transmission capacity availability threshold. Regulation (EU) 2019/943 states that the available transmission capacity of all transmission elements possibly limiting the amount of electricity that can be exchanged between different bidding zones should be at least 70 per cent of a benchmark value.
Relevant article

Art. 14(8) states that 'For those Member States that have opted to amend the bidding zone configuration ..., the relevant Member States shall reach a unanimous decision within six months of the notification ... Other Member States may submit comments to the relevant Member States, which should take account of those comments when reaching their decision. The decision shall be reasoned and shall be notified to the Commission and ACER. In the event that the relevant Member States fail to reach a unanimous decision within those six months, they shall immediately notify the Commission thereof. As a measure of last resort, the Commission after consulting ACER shall adopt a decision whether to amend or maintain the bidding zone configuration in and between those Member States by six months after receipt of such a notification.'

Art. 16(8) states that 'Transmission system operators shall not limit the volume of interconnection capacity to be made available to market participants as a means of solving congestion inside their own bidding zone or as a means of managing flows resulting from transactions internal to bidding zones.' Art. 16(8) continues that the following minimum levels of available capacity for cross-zonal trade that have to be reached (at any market time unit) are (a) for borders using a coordinated net transmission capacity approach, the minimum capacity shall be 70 per cent of the transmission capacity respecting operational security limits after deduction of contingencies, as determined in accordance with the CACM GL; (b) for borders using a flow-based approach, the minimum capacity shall be a margin set in the capacity calculation process as available for flows induced by cross-zonal exchange. The margin shall be 70 per cent of the capacity respecting operational security limits of internal and cross-zonal critical network elements, taking into account contingencies, as determined in accordance with the CACM. Lastly, Art. 16(8) adds that a total amount of 30 per cent can be used for reliability margins, loop flows and internal flows on each critical network element.

There are three exceptions to the 70 per cent rule: (a) where structural congestion has been identified, in the case that Member States opt for a multinational action plan, the linear trajectory according to Art. 15(2) has to be reached. Compliance with the 70 per cent rule shall be reached by 31 December 2025; (b) Art. 16(9) states that at the request of TSOs in a CCR, the relevant regulatory authorities may grant a derogation from the 70 per cent rule on foreseeable grounds where necessary for maintaining operational security. This derogation shall be granted for no more than one year at a time or, provided that the extent of the derogation decreases significantly after the first year, up to a maximum of two years; (c) Art. 16(3) adds that where RCCs conclude that the available remedial actions in the capacity calculation region or between capacity calculation regions are not sufficient to reach the minimum capacities provided (or the linear trajectory) while respecting operational security limits, they may, as a measure of last resort, set out coordinated actions reducing the cross-zonal capacities accordingly. 


\begin{tabular}{l} 
Section of this chapter, topic and relevant \\
regulation \\
\hline A process has been set in motion to assess the \\
extent to which different countries already \\
comply with this threshold and how they intend \\
to comply with the threshold by 2025 .
\end{tabular}

Countries need to choose between the two DG COMP cases. They can follow the Swedish or the German approach to stop discrimination between cross-border and national trade.
Relevant article

Note that the 70 per cent minimum capacity available for trade in Regulation (EU) 2019/943 applies from January 2020, the date of entry into application of Art. 71(2). In addition, Art. 15(2) says that if a Member State opts for an action plan, the minimum capacity, as described in Art. 16(8), shall be reached by 31 December 2025 .

Art. 16(3) states that RCCs shall submit a report to the relevant regulatory authorities and to ACER on any reduction of capacity or deviation from coordinated actions due to operational security threats. The RCCs shall assess the incidences and make recommendations, if necessary, on how to avoid such deviations in the future.

ACER and CEER (2019) are also already monitoring compliance with the 70 per cent rule in their market monitoring report.

Art. 14(7) states that where structural congestion has been identified, the Member State concerned shall, in cooperation with its TSOs, decide to establish national or multinational action plans, or to review and amend its bidding zone configuration.

Structural congestion is defined in Art. 2(6) as 'congestion in the transmission system that is capable of being unambiguously defined, is predictable, is geographically stable over time, and frequently reoccurs under normal electricity system conditions.' The identification of long-term structural congestion can be done in three ways: using ENTSO-E's report on structural congestion (Art. 14(2)); using TSO assessments; or the bidding zone review itself (Art. 14(7)).

According to Art. 16(8), in the case that a Member State fails to respect the 70 per cent rule while not opting for a multinational action plan or if a Member State has opted for a multinational action plan but does not respect the linear trajectory, a bidding zone reconfiguration can result (Arts. 15(7) and 15(5)). 


\section{Who pays for the network when trade is international?}

\section{Leonardo Meeus with Tim Schittekatte}

In this chapter, we answer four questions. First, who pays for the network? Second, why did national network tariffs start to be harmonized? Third, why was there a move away from transit charges? And fourth, how to share network investment costs between countries?

\subsection{WHO PAYS FOR THE NETWORK?}

Electricity networks are important infrastructure like roads, railways and fibre networks. Such important infrastructure is typically paid for through a combination of general taxation and user tariffs. However, electricity networks in Europe are mostly paid for by network users through so-called network tariffs. In what follows, we introduce the two types of network tariffs: connection charges and access charges. ${ }^{1}$

First, connection charges. As the name indicates, these charges are for connection to the grid at the time of connecting and are typically one-off payments that in some cases can be spread over time. They are often labelled 'super-shallow', 'shallow' or 'deep' connection charges. Super-shallow means a very cheap or free connection. Shallow means you pay for the cable and other necessary equipment to connect you to the electricity network's local feeder. You are the only user of that piece of the network so the cost can easily be attributed to you. Deep means that you also pay for network reinforcements that might be needed deeper inside the network to accommodate the new connection at your location. Deep charges try to influence the location of new connections by signalling where the network can still host additional connections without reinforcement and where reinforcement would be needed. Shallow connection charges are the dominant model in Europe, but there are also a few countries with deep charges (five countries in 2018). Connection charges can also vary within a country for different voltage levels and/or different grid users. Consumers and producers are not necessarily treated in the same way.

Second, access charges. These charges are paid on a monthly or bi-annual basis. Network access charges are usually divided between transmission access charges and distribution access charges. Grid users contribute to the network cost of the voltage level that they are connected to and the voltage levels above them. This means that grid users connected to the highest transmission-level voltage only pay transmission charges for that level, while households connected to the lowest distribution-level voltage pay for all the network levels above them through both transmission and distribution access charges. The origin of this cascading principle is that electricity flows from the highest voltage all the way down to the lowest. Transmission access charges are also used to recover the costs of some of the services that are 
provided by transmission system operators (TSOs). The European Network of Transmission System Operators for Electricity (ENTSO-E) reports that on average in Europe in 2018, 59 per cent of transmission access charges covered infrastructure costs, 31 per cent system services and 10 per cent losses.

TSOs also collect congestion revenue, which can cover part of their costs and thus can reduce the need to collect money through network tariffs. This revenue results from explicit or implicit auctioning of transmission rights, as was discussed in Chapter 2. According to ENTSO-E data, on average $€ 2$ billion of congestion revenue a year was collected in the period 2011-2015. In Annex 4A.1, we provide an example of how this congestion revenue is calculated under implicit auctioning of transmission rights.

\subsection{WHY DID NATIONAL NETWORK TARIFFS START TO BE HARMONIZED?}

In this section, we first discuss the level of harmonization of transmission network tariffs and then introduce two open issues.

\subsubsection{The Harmonization of Transmission Network Tariffs}

For the moment, network tariffs have only been harmonized at the transmission level, and only access charges, not connection charges, are harmonized. Moreover, only the access charges that apply to generators have to a certain extent been harmonized (the so-called G-component), not those that apply to consumers (the C-component). Not all countries have a G-component, but those that do (15 countries in 2018) have to comply with the caps listed in Table 4.1. These caps apply to the total amount of money that is collected from producers divided by their total output per year. Connection charges, charges related to system services and losses are excluded from this calculation. These caps were introduced in Regulation (EU) No 838/2010. The development of guidelines around the harmonization of transmission tariffs was first described in Regulation (EC) No 1228/2003, which was part of the Second Energy Package.

The main argument for a G-component in transmission access charges is that it ensures that generators consider transportation costs in their decisions. Connection charges can guide generators to locate where it would be cheaper to transport what they produce. Access charges can also guide decisions to produce or consume in the period after the connection. When the network is in a critical condition, generators can be given a signal not to produce. The implementation of a geographically differentiated G-component is limited to the UK, Ireland and Sweden. The argument against a G-component is that generators in that country are at a competitive disadvantage with respect to generators that access the European electricity market via a country that does not have such a G-component. It is this distortion of the level playing field that motivated the introduction of the above-mentioned caps. Moreover, locational signals can be more effectively provided through variations in energy prices over well-defined zones (or nodes) as described in Chapter 3.

A similar logic can be applied to distribution network tariffs. Indeed, producers increasingly access the European electricity market through distribution grids. In our research, we made a first attempt to calculate the spillover effects caused by distribution tariffs and concluded that they can be significant. ${ }^{2}$ During the negotiations on the Clean Energy Package, the European 
Table 4.1 Maximum annual average transmission charges paid by producers according to Regulation (EU) No 838/2010

\begin{tabular}{ll}
\hline & $\begin{array}{l}\text { Maximum annual average transmission charge paid by } \\
\text { producers }\end{array}$ \\
\hline Great Britain, Ireland and Northern Ireland & $€ 2.5 / \mathrm{MWh}$ \\
Romania & $€ 2 / \mathrm{MWh}$ \\
Denmark, Finland and Sweden & $€ 1.2 / \mathrm{MWh}$ \\
All other EU countries & $€ 0.5 / \mathrm{MWh}$ \\
\hline
\end{tabular}

Commission proposed harmonizing distribution network tariffs through the EU network code process, but this proposal was dropped due to strong opposition on the part of stakeholders and national governments.

\subsubsection{Network Tariffs - Open Issues}

In this subsection we introduce two open issues related to network tariffs: the treatment of energy storage and the implementation of the cost-reflectivity principle. ${ }^{3}$

First, the treatment of energy storage. In some countries, energy storage is charged like generation and in other countries like consumption. There are also countries where energy storage is charged for consumption and for generation, and countries that have started to treat storage separately when it comes to network access charges. For instance, Belgium has exempted newly connected energy storage assets from transmission charges for ten years. Charges that apply to generators to access the European electricity market to create a level playing field have been harmonized so the same logic could be applied to energy storage. We expect energy storage to play an important role in the electricity system of the future, so we can expect that debate on this issue will continue.

Second, the implementation of the cost-reflectivity principle. Regulation (EU) 2019/943 mandates ACER to come up with best practice reports on transmission and distribution network tariffs. The regulation also states that these tariffs should become more cost-reflective, which can include locational and time-varying signals. Historically, distribution access charges were simple rather than cost-reflective. Consumers paid in proportion to the volume of their annual consumption in euro/kWh. With the emergence of rooftop photovoltaic (PV) panels, electric vehicles, heat pumps and home batteries, simple tariffs increasingly give distorted signals.

The best-known example is what happened with the large-scale introduction of rooftop PVs. Wealthy households used to consume more so they contributed more to distribution network costs. Today, volumetric tariffs achieve the opposite. Wealthy households can more easily invest in rooftop PVs. In some hours of the day, these households inject the output of their PV panels into the network, and in other hours they withdraw that energy back from the network. If we only measure and charge on the basis of the net effect, they no longer pay for the network they continue to use at the expense of other users who cannot afford PV panels.

Cost-reflective tariffs mean you pay for the costs you cause. This is easier said than done, and we also do not want tariffs to become too complicated. Cost-reflectivity can become politically sensitive if it implies different charges for urban and rural areas, or if it implies revisiting the allocation of network costs between households and industry. Following the 
cascading principle, households connected to distribution networks contribute to transmission network costs, while large industrial consumers connected to transmission networks do not contribute to distribution network costs, which could be challenged in an electricity system that is increasingly decentralizing.

\subsection{WHY WAS THERE A MOVE AWAY FROM TRANSIT CHARGES?}

In this section we first introduce transit charges and then discuss the inter-TSO compensation (ITC) scheme that replaced them. ${ }^{4}$

First, transit charges. Who pays for the network becomes more complicated when you introduce international trade. As discussed in the previous sections, national network tariffs mean charging producers and consumers connected to the transmission and distribution network when they connect or when they access the grid. However, what should be done with traders that use the network to transfer energy from one national network to another, possibly also crossing the networks of transit countries? Most countries introduced a so-called transit charge to apply to cross-border transactions. This meant that traders not only needed to buy transmission rights to be able to trade across borders, but they also had an extra transaction cost for trading across the border.

However, cross-border transactions only cause network costs to the extent that they cause flows. There are many more transactions than physical flows, and transactions can go both ways across a certain border so that they cancel out and do not cause any flow or cost. It is also possible to have physical flows across a network even if there are no transactions. Traders can transact via another path around a country while the flow will still go through its network. Transit charges also allowed countries to tax international trade in order to reduce their national network tariffs. Transit charges were an obstacle to trade as they were increasing transaction costs rather than charging the users of the grid. Therefore, they were finally abolished in 2014 .

The process that led to the abolishment of transit charges is interesting, as it played out over many years in the Florence Forum. Stakeholders started to meet informally in Florence and the gathering was then institutionalized by the European Commission. In 2002, the 8th Florence Forum agreed to abolish all existing transit charges while still allowing capped export charges. Initially the cap on export charges was set at $€ 1 / \mathrm{MWh}$, but was then reduced to $€ 0.5 / \mathrm{MWh}$. Finally, this led to their abolishment in 2004, long before roaming was abolished for mobile phones, which received much more attention.

Second, the inter-TSO compensation (ITC) scheme. In 2002, eight European TSOs signed a first ITC agreement. Through their associations (ETSO and later ENTSO-E), TSOs continued to develop and expand this mechanism. Under this scheme, TSOs from countries that cause international flows by importing or exporting contribute to a fund and TSOs from countries that host international flows receive money from that fund. TSOs that pay into the fund collect the money by increasing their national network tariffs and those that receive money from the fund use it to lower their national network tariffs. It is a zero-sum game that pays for the costs caused by transit flows and avoids the problems with transit charges on transactions.

Even though the principle of the ITC scheme is clear, its implementation has proven to be challenging. To determine the size of the fund, TSOs and their national regulatory authorities (NRAs) need to agree on the level of costs, and there are different cost-reporting practices. The 
definition of a transit has also been challenged. There can be transit flows that cross a country, but there can also be transit flows that enter a country to run along the border and exit again. Both would count equally as transits, but they do not cause the same level of costs. It therefore took a long time to agree on a definitive ITC methodology. Note that transit flow is a concept that is also used in the debate on flow-based market coupling (see Annex 3A.1 and Annex 3A.2 in Chapter 3), but the definition is not the same as in the debate on the ITC methodology. As with G-charges in the previous section, the ITC mechanism was already part of Regulation (EC) No 1228/2003 and it was further formalized in Regulation (EU) No 838/2010.

In other words, the ITC scheme is far from perfect but it did help to abolish transit charges, which were worse. Sensitivities related to transit charges and the ITC scheme dominated the debate for a long time, but gradually faded. In 2017, the ITC fund amounted to $€ 259.3$ million. This consisted of $€ 100$ million to compensate for infrastructure costs and $€ 159.3$ million to compensate for losses caused by transits. In comparison with the schemes we will discuss in the next section and that have received most of the attention in recent years, the money that circulates in the ITC mechanism is relatively small and not used to provide investment signals but instead to allocate sunk investments costs.

\subsection{HOW TO SHARE NETWORK INVESTMENT COSTS BETWEEN COUNTRIES?}

In this section we first introduce the process of prioritizing projects of common interest (PCI) in Europe and then discuss so-called cross-border cost allocation (CBCA) agreements for these projects, which determine how network investment costs are charged across countries.

First, projects of common interest (PCIs). Following Regulation (EC) No 714/2009, TSOs make national transmission investment plans and they are consolidated into the so-called Ten-Year Network Development Plan (TYNDP). ${ }^{5}$ The TYNDP is one of ENTSO-E's tasks, and in 2018 it argued that $€ 114$ billion of investment in power lines would be needed by 2030. Regulation (EU) No 347/2013, better known as the Trans-European Energy Networks (TEN-E) Regulation, then introduced a process in which some of these projects could become PCIs. The list of PCIs also includes third-party projects. Third-party projects can be merchant projects that have followed an exemption process or regulated projects from countries that allow third parties to compete with TSOs to develop such projects. The first PCI list was published in 2013. It is updated every two years and contains a selection of electricity transmission lines, gas and oil pipelines, gas and electricity storage projects, electricity smart grids, and carbon dioxide transport infrastructure. The total investment cost of the electricity projects on the 2017 PCI list is $€ 49.3$ billion - almost half of the TYNDP investment in 2018.

To obtain PCI status, projects need to conduct a cost-benefit analysis (CBA) following a methodology designed by ENTSO-E with supervision by ACER. They can then be ranked on the basis of their CBA and be selected in a process that is set out in the TEN-E Regulation. Projects with PCI status have advantages, such as accelerated permitting procedures, dedicated financial incentives from the NRAs involved and access to the Connecting Europe Facility (CEF). In the period 2014-2020, a total of $€ 5.35$ billion in EU funding was allocated to PCI projects via the CEF.

Second, cross-border cost allocation (CBCA) agreements. Countries used to agree on cross-border investments on the assumption that they would each pay for assets in their ter- 
ritories. If they both benefited enough to justify these costs, they would agree to go forward with the investment. If one of them had doubts, the project would be cancelled or delayed. The country that was more convinced about the project then had an incentive to compensate the neighbour. In Box 4.1 we illustrate two projects where countries started to do this on a voluntary basis.

With the CBCA process, the TEN-E Regulation mandated ACER to act as a mediator in these kinds of cases. TSOs make a CBCA proposal for PCIs, and if the NRAs cannot agree ACER can intervene. This has happened twice so far, namely the Gas Interconnection PolandLithuania (GILP) in August 2014 and the Lithuanian part of the Electricity Interconnection between Lithuania and Poland (LitPol Link) in April 2015. ACER decided that a case where the default cost allocation clearly results in a net loser, that is, a country that benefits less than the costs it is expected to incur by investing in the assets in its territory, is not a justification for applying for CEF funding. Instead, the other beneficiaries are first asked to compensate the net loser for its loss, and other beneficiaries can even be third countries which do not host any of the assets in their territory but clearly benefit from the projects. Only in the GILP case did ACER allocate costs beyond the hosting countries, according to its principle of compensating net losers. In the case of the LitPol Link, ACER decided not to allocate costs to non-hosting countries because there was no net loser.

Our research provides a more detailed discussion of these cases because we had the pleasure of advising ACER in this process. Note that the allocation of CEF funding by the European Commission remains controversial. The $\mathrm{CBA}$ and $\mathrm{CBCA}$ process tried to reduce the politics, but the impression is that this has only been partly accomplished.

\section{BOX 4.1 TWO EXAMPLES OF INNOVATIVE CBCA PRACTICES}

\section{The Norway-Sweden case}

Norway is divided into five bidding zones because it has structural congestion within the country. In dry years, the energy supply within each bidding zone can be very tight. This is the case in mid-Norway, but the situation worsened in 2005 because of new industrial consumption. The situation became critical in the following dry year. The easiest and quickest solution for Norway was to increase the interconnection capacity between mid-Norway and Sweden (line A on the left-hand side of Figure 4.1). This is a 100-km-long $420 \mathrm{kV} \mathrm{AC}$ line between Nea and Järpströmmen, which was commissioned in 2009. Seventy-five per cent of the assets are in Swedish territory. Line B, the line in Norwegian territory (on the left-hand side of Figure 4.1) was expected to increase the available capacity on line A from 200 to $750 \mathrm{MW}$ so that Sweden would also benefit from the cross-border exchange, but line B was less advanced. Norway therefore agreed to compensate Sweden for line A until line $\mathrm{B}$ was ready.

The compensation incentivized Sweden to speed up the development of line A, and also incentivized Norway to speed up the development of line B. The TSOs involved entered into a formal contract, which was approved by their NRAs. 

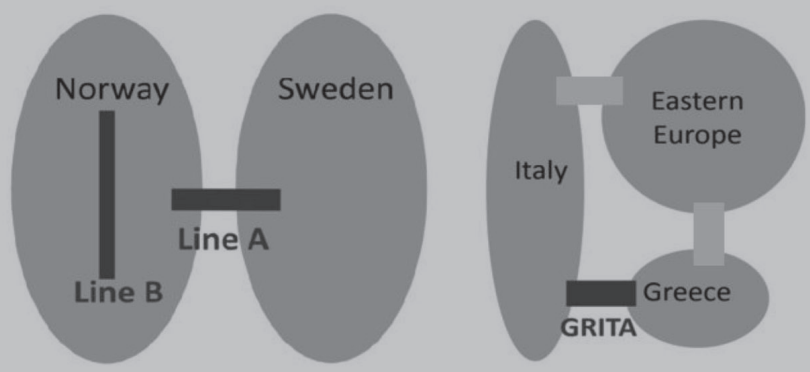

Figure 4.1 The Norway-Sweden case (left) and the Italy-Greece case (right)

\section{The Italy-Greece case}

In 2002, a 500 MW submarine high voltage direct current (HVDC) link between Greece and Italy (GRITA) was commissioned (see the right-hand side of Figure 4.1). Italy paid for and owns 75 per cent of the project and Greece the remaining 25 per cent. The project also received an EU grant, so this CBCA agreement only applied to part of the project costs. The project allows Italy to import cheaper electricity from eastern European countries, like Albania and Turkey, via Greece.

This CBCA showcases innovation, with parties deviating from the common 50:50 cost sharing for an interconnector. It is a typical case in which a transit country (Greece) is compensated to jointly develop a project with its neighbour (Italy).

\subsection{CONCLUSION}

In this chapter on network cost allocation when trade is international, we have answered four questions.

First, who pays for the network? The common practice today for electricity networks is that they are mostly paid for by the network users. There are two types of network tariffs: connection charges and network access charges.

Second, why did national network tariffs start to be harmonized? Transmission network tariffs were somewhat harmonized by Regulation (EU) No 838/2010, which introduced a cap on access charges for generators. Currently, how to apply network tariffs to storage and how to implement the cost-reflectivity principle in distribution network tariffs are open issues.

Third, why was there a move away from transit charges? Transactions do not cause network costs - only flows do; so transit charges were increasing transaction costs rather than charging the users of the grid. Under the inter-TSO compensation scheme, TSOs pay in proportion to the international flows they cause and receive money in proportion to the international flows they host.

Fourth, how to share network investment costs between countries? Each country used to pay for the assets on its territory even if it was not the main beneficiary. Following the TEN-E Regulation, projects can receive project of common interest status. PCIs have several advan- 
tages, including the cross-border cost allocation (CBCA) process in which ACER can mediate in projects to reach a better cost allocation that can help unblock them.

\section{NOTES}

1. In ENTSO-E (2018) there is an overview of transmission tariffs in Europe. This report is updated every year and the facts and figures on transmission tariffs quoted in this chapter come from this report. In Ruester et al. (2012) we provided an academic discussion on transmission tariffs and the possible role of the EU.

2. In Govaerts et al. (2019) we provided a first analysis of the spillover effects of distribution grid tariffs in the internal electricity market. A simplified numerical example is used to give insight into the order of magnitude of the spillovers and the main sensitivities that drive these effects.

3. In Schittekatte et al. (2018) and Schittekatte and Meeus (2020) we discuss why future-proof distribution tariffs need to anticipate the behaviour of households in response to price signals. We also discuss the distributional effects of tariffs by analysing their impact on active versus passive customers. Our colleagues from Comillas and MIT have also done a very interesting analysis on this topic in the 'Utility of the Future' study by the MIT Energy Initiative (2016). In CREG (2018) and Ofgem (2019), the treatment of energy storage for transmission network tariffs is discussed in detail.

4. In ACER (2018b) and ENTSO-E (2019a) there is detailed information on the ITC mechanism. These reports are updated every year with the latest statistics. For more background, refer to ERGEG (2006). Also interesting is academic work on the topic. Olmos and Pérez-Arriaga (2007), Pérez-Arriaga et al. (2002) and Daxhelet and Smeers (2007) analyse the different options that have been considered to implement the ITC scheme. In the conclusions of the 8th and 10th Florence Fora published by the European Commission $(2002,2003)$, the gradual abolishment of transit charges can be observed. The prominence of this issue on the agenda over many years can also be seen from the conclusions of the earlier Florence Fora.

5. The TYNDP is described in ENTSO-E (2019b). The TYNDP is updated every two years. ACER (2018a) reports on the two-yearly PCI list. European Commission (2018) is an example of a press release related to the Connecting Europe Facility (CEF) funding scheme. In Keyaerts et al. (2016) and Meeus et al. (2013) we gave our recommendations for the development of the cost-benefit analysis (CBA) methodology that is used for PCIs in Europe. We also supported ACER in its approach to cross-border cost allocation (CBCA) (ACER, 2015b). In Meeus and He (2014) we made recommendations to ACER when it was given the CBCA mandate. We argued that ACER could only intervene in certain cases to encourage stakeholders to come forward with innovative approaches. The examples shown in Box 4.1 originate from that policy brief. One year later, in Meeus and Keyaerts (2015) we also evaluated the first cases that were treated by the ACER. In Keyaerts and Meeus (2017) we provide case studies on countries that decided to introduce dedicated financial incentives for priority projects. In Bhagwat et al. (2019) we updated our CBA and CBCA analysis with a focus on the implications for meshed offshore transmission networks to support the development of wind power. In Schittekatte et al. (2020) we provide recommendations on how to revise the TEN-E Regulation to be aligned with the objectives of the European Green Deal. Furthermore, for a study on how the incentives of national TSOs are not necessarily aligned with the overall European welfare when deciding about building an interconnector, see the work of Matti Supponen (2011). Finally, for deeper discussions about the implications of the Trans-European Energy Networks (TEN-E) Regulation and its importance, see the book edited by Jean Arnold Vinois (2014). For more details about the two ACER decisions, please consult ACER (2014, 2015a).

\section{REFERENCES}

ACER (2014), 'Decision No 01/2014 of the Agency for the Cooperation of Energy Regulators of 11 August 2014 on the Investment Request including Cross-Border Cost Allocation for Gas Interconnection Poland-Lithuania. Project of Common Interest No 8.5'. 
ACER (2015a), 'Decision No 02/2015 of the Agency for the Cooperation of Energy Regulators of 16 April 2015 on the Investment Request Including Cross-Border Cost Allocation for the Lithuanian Part of the Interconnection between Alytus (LT) and the Lithuanian-Polish Border. Project of Common Interest No 4.5.1'.

ACER (2015b), 'Recommendation No 05/2015 of the Agency for the Cooperation of Energy Regulators of 18 December 2015 on Good Practices for the Treatment of Investment Requests, including CBCA Requests, for Electricity and Gas PCIs'.

ACER (2018a), 'Consolidated Report on the Progress of Electricity and Gas Projects of Common Interest for the Year 2017', published on 10 July 2018.

ACER (2018b), 'ITC Monitoring Report 2018', Report to the European Commission on the Implementation of the ITC Mechanism in 2017, published in October 2018.

Bhagwat, P., T. Schittekatte, L. Lind, N. Keyaerts and L. Meeus (2019), 'D7.4 Economic Framework for a Meshed Offshore Grid', Final Report PROMOTioN.

CREG (2018), 'Besluit tot vaststelling van de tariefmethodologie voor het elektriciteits-transmissienet en voor de elektriciteitsnetten met een transmissiefunctie voor de regulatoire periode 2020-2023' ['Conclusion on the Application of Tariff Methodologies for Electricity Transmission Systems and Electricity Transmission Functions for the Regulatory Period 2020-2023'], Beslissing(Z)1109/10, published on 28 June 2019.

Daxhelet, O. and Y. Smeers (2007), 'The EU regulation on cross-border trade of electricity: A two-stage equilibrium model', European Journal of Operational Research, 181 (3), 1396-412.

ENTSO-E (2018), 'Overview of Transmission Tariffs in Europe: Synthesis 2018', Annual Report, published in May 2018.

ENTSO-E (2019a), 'ITC Transit Losses Data Report 2018', Annual Report, published on 24 September 2019.

ENTSO-E (2019b), 'TYNDP 2018 - Executive Summary', Connecting Europe: Electricity 2025-2030-2040. Final Version after Consultation and ACER Opinion - October 2019.

ERGEG (2006), 'Cover note to ERGEG draft proposal on Guidelines on Inter TSO Compensation', Ref: E06-CBT-09-08a, 10 April 2006.

European Commission (2002), 'European Electricity Regulatory Forum: A significant step forward in completing the internal electricity market', MEMO/02/37. Brussels, 27 February 2002, accessed at https://ec.europa.eu/commission/presscorner/detail/en/MEMO_02_37.

European Commission (2003), 'Florence Forum gets rid of all cross border electricity charges', MEMO/03/153. Brussels, 18 July 2003, accessed at https://ec.europa.eu/commission/presscorner/ detail/en/MEMO_03_153.

European Commission (2018), 'More growth and jobs: EU invests $€ 873$ million in clean energy infrastructure', press release of 25 January 2018, accessed at https://ec.europa.eu/commission/presscorner/ detail/en/IP 18383.

Govaerts, N., K. Bruninx, H. Le Cadre, L. Meeus and E. Delarue (2019), 'Spillover effects of distribution grid tariffs in the internal electricity market: An argument for harmonization?', Energy Economics, 84, accessed at https://doi.org/10.1016/j.eneco.2019.07.019.

Keyaerts, N. and L. Meeus (2017), 'The regulatory experience of Italy and the United States with dedicated incentives for strategic electricity transmission investment', Utilities Policy, 46, 71-80.

Keyaerts, N., T. Schittekatte and L. Meeus (2016), 'Standing still is moving backward for the ABC of the CBA', FSR Policy Brief 2016/08.

Meeus, L. and X. He (2014), 'Guidance for project promoters and regulators for the cross-border cost allocation of projects of common interest', FSR Policy Brief 2014/02.

Meeus, L. and N. Keyaerts (2015), 'First series of cross-border cost allocation decisions for projects of common interest: Main lessons learned', FSR Policy Brief 2015/01.

Meeus, L., N.-H. von der Fehr, I. Azevedo, X. He, L. Olmos and J.-M. Glachant (2013), 'Cost Benefit Analysis in the Context of the Energy Infrastructure Package', Final Report. THINK Project, Topic 10, published in January 2013.

MIT Energy Initiative (2016), 'Utility of the Future: An MIT Energy Initiative Response to an Industry in Transition'. 
Ofgem (2019), 'Open letter on implications of charging reform on electricity storage', Open Letters and Correspondence, published on 24 January 2019.

Olmos, L. and I. Pérez-Arriaga (2007), 'Evaluation of three methods proposed for the computation of inter-TSO payments in the internal electricity market of the European Union', IEEE Transactions on Power Systems, 22 (4), 1507-22.

Pérez-Arriaga, I., L. Olmos and F. J. Rubio (2002), 'Report on Cost Components of Cross Border Exchanges of Electricity', Final Report. Prepared for the Directorate-General for Energy and Transport/European Commission, published in November 2002.

Ruester, S., C. von Hirschhausen, C. Marcantonini, X. He, J. Egerer and J. M. Glachant (2012), 'EU Involvement in Electricity and Natural Gas Transmission Grid Tarification', Final Report. THINK Project, Topic 6, published in January 2012.

Schittekatte, T. and L. Meeus (2020), 'Least-cost distribution network tariff design in theory and practice', Energy Journal, 41 (5), 97-133.

Schittekatte, T., I. Momber and L. Meeus (2018), 'Future-proof tariff design: Recovering sunk grid costs in a world where consumers are pushing back', Energy Economics, 70, 484-98.

Schittekatte, T., A. Pototschnig, L. Meeus, T. Jamasb and M. Llorca (2020), 'Making the TEN-E regulation compatible with the Green Deal: Eligibility, selection, and cost allocation for PCIs', FSR Policy Brief 2020/27.

Supponen, M. (2011), 'Influence of National and Company Interests on European Electricity Transmission Investments', Aalto University Publication Series Doctoral Dissertations, 77/2011.

Vinois, J. A. (ed.) (2014), EU Energy Law Volume VIII - The Energy Infrastructure Policy of the European Union, Deventer, Netherlands and Leuven, Belgium: Claeys \& Casteels. 


\section{A.1 ANNEX: CONGESTION RENT UNDER MARKET COUPLING: A NUMERICAL EXAMPLE}

Suppose that the day-ahead market auction for a certain hour results in a price in zone A of $€ 50 / \mathrm{MWh}$ and a price in zone B of $€ 60 / \mathrm{MWh}$. The satisfied demand in zone A is $100 \mathrm{MWh}$, that in zone $\mathrm{B}$ is $150 \mathrm{MWh}$ and $50 \mathrm{MW}$ of transmission rights are used to trade between the two zones in that hour. In this case, electricity flows from the low-price zone (A) to the high-price zone (B). There is a price difference, which means that the transmission rights have been fully utilized but they were not enough to create a single price zone. The rights therefore have a value and congestion rent is collected, as is illustrated in Table 4A.1.

Table 4A.1 A numerical example of congestion rent calculation

\begin{tabular}{|c|c|c|c|c|c|}
\hline & Price & Demand & Generation & Demand expense & Generation income \\
\hline Zone A & $€ 50 / \mathrm{MWh}$ & $100 \mathrm{MWh}$ & $\begin{array}{l}150 \mathrm{MWh} \\
\text { (demand zone } \mathrm{A}+ \\
\text { interconnector) }\end{array}$ & $€ 5000$ & $€ 7500$ \\
\hline \multirow[t]{2}{*}{ Zone B } & $€ 60 / \mathrm{MWh}$ & $150 \mathrm{MWh}$ & $\begin{array}{l}100 \mathrm{MWh} \\
\text { (demand zone B } \\
\text { - interconnector) }\end{array}$ & $€ 9000$ & $€ 6000$ \\
\hline & & & & $€ 14000$ & $€ 13500$ \\
\hline
\end{tabular}

The total income for generation over the two zones is $€ 13500$ while the total amount spent by demand equals $€ 14000$. The difference between the two is the congestion rent of $€ 500$, equalling the price differential between the two zones $(€ 10 / \mathrm{MWh})$ multiplied by the capacity of the line $(50 \mathrm{MW})$. This congestion rent is transferred to the TSO(s) owning the interconnector. There are strict rules around the use of congestion rent in the EU. Congestion rent should be used to invest in the network; only if the revenues cannot be used efficiently for investments can they be used to lower the national transmission network tariffs. 


\section{A.2 ANNEX: REGULATORY GUIDE}

\section{Table 4A.2 Regulatory guide}

Section of this chapter, topic and relevant regulation

\section{Section 4.1}

TSOs collect congestion revenues, which can cover part of their costs, and thus they can reduce the need to collect money through network tariffs.

\section{Section 4.2}

Caps on G-charges were introduced in Regulation (EU) No 838/2010. The development of guidelines for the harmonization of transmission tariffs was first described in Regulation (EC) No 1228/2003 in the Second Energy Package.

Regulation (EU) 2019/943 and network charges for storage.

Regulation (EU) 2019/943 mandates ACER to come up with best practice reports on transmission and distribution network tariffs.
Relevant article

Relevant article

Regulation (EC) No 714/2009 states in Art. 16(6) that any revenue resulting from the allocation of interconnection shall be used for guaranteeing the actual availability of the allocated capacity and/or maintaining or increasing interconnection capacities through network investment, in particular in new interconnectors. The article continues by stating that 'if the revenues cannot be efficiently used for these [the two above-mentioned purposes], they may be used, subject to approval by the regulatory authorities of the Member States concerned, up to a maximum amount to be decided by those regulatory authorities, as income to be taken into account by the regulatory authorities when approving the methodology for calculating network tariffs and/or fixing network tariffs.'

In Art. 8(3) of Regulation (EC) No 1228/2003 it is stated that, where appropriate, the Commission shall adopt and amend guidelines that determine appropriate rules leading to a progressive harmonization of the underlying principles for the setting of charges applied to producers and consumers (load) under national tariff systems. Regulation (EU) No 838/2010 contains in its Annex part B 'Guidelines for a Common Regulatory Approach to Transmission Charging' in which the caps on G-charges are specified.

Art. 18(1) states that network charges shall not discriminate either positively or negatively against energy storage.

Art. 18(9) states that 'By 5 October 2019 in order to mitigate the risk of market fragmentation ACER shall provide a best practice report on transmission and distribution tariff methodologies while taking account of national specificities.' Furthermore, the article lists several dimensions of network tariffs that were to be addressed, among which are time and location differentiation. It also states that ACER shall update the best practice report at least once every two years. Art. 18(10) adds that 'Regulatory authorities shall duly take the best practice report into consideration when fixing or approving transmission tariffs and distribution tariffs or their methodologies in accordance with Article 59 of Directive (EU) 2019/944.'Art. 59 of Directive (EU) $2019 / 944$ lists the duties and powers of the regulatory authorities. 


Section of this chapter, topic and relevant
regulation

Regulation (EU) 2019/943 states that these tariffs should become more cost-reflective, which can include locational and time-of-use signals.

\section{Section 4.3}

Transit charges were finally abolished in 2004.

As with G-charges in the previous section, the ITC mechanism was already part of Regulation (EC) No 1228/2003 and was further formalized in Regulation (EU) No 838/2010.

\section{Section 4.4}

Following Regulation (EC) No 714/2009, TSOs make national transmission investment plans. These are consolidated into the so-called Ten-Year Network Development Plan (TYNDP). Regulation (EU) No 347/2013, better known as the Trans-European Energy Networks (TEN-E) Regulation, introduced a process through which some of these projects could become projects of common interest (PCIs).

The PCI list also includes third-party projects. Third-party projects can be merchant projects that have followed an exemption process or regulated projects from countries that allow third parties to compete with TSOs to develop such projects.

The PCI list is updated every two years and contains a selection of electricity transmission lines, gas and oil pipelines, gas and electricity storage projects, electricity smart grids, and carbon dioxide transport infrastructure.
Art. 18(7) states that 'Distribution tariffs shall be cost-reflective taking into account the use of the distribution network by system users including active customers. Distribution tariffs may contain network connection capacity elements and may be differentiated based on system users' consumption or generation profiles. Where Member States have implemented the deployment of smart metering systems, regulatory authorities shall consider time-differentiated network tariffs when fixing or approving transmission tariffs and distribution tariffs or their methodologies in accordance with Article 59 of (EU) 2019/944 and, where appropriate, time-differentiated network tariffs may be introduced to reflect the use of the network, in a transparent, cost efficient and foreseeable way for the final customer.'

Regulation (EC) No 1228/2003, which entered into force on 1 July 2004, formalized the abolishment of transit charges in Art. 4(5) by stating that "there shall be no specific network charge on individual transactions for declared transits of electricity.'

In Art. 8(2) of Regulation (EC) No 1228/2003 it is stated that, where appropriate, the Commission shall adopt and amend guidelines that shall specify the details of the ITC mechanism. Regulation (EU) No 838/2010 contains in its Annex part A 'Guidelines on the Inter-Transmission System Operator Compensation Mechanism.'

Art. 8(3.b) states that ENTSO-E shall adopt ' $a$ non-binding Community-wide ten-year network development plan, including a European generation adequacy outlook, every two years.'

Art. 2 defines a PCI as 'a project necessary to implement the energy infrastructure priority corridors and areas set out in Annex I and which is part of the Union list of projects of common interest referred to in Article 3.' Art. 3 sets out how the Union list of PCIs will be made up. The Commission is empowered to adopt delegated acts that establish the Union list of PCIs. The Commission ensures that the Union list is established on the basis of the regional lists adopted by the decision-making bodies of the Groups. There are 12 regional groups listed in Annex I.

The definition of project promoters in Art. 2(6) of Regulation (EU) No $347 / 2013$ clarifies that a project promoter can not only be a TSO, DSO or other operator but also an investor developing a project of common interest.

Art. 3 of Regulation (EU) No 347/2013 states that the Commission shall ensure that the Union PCI list is established every two years. Annex II of this regulation sets out the energy infrastructure categories which are eligible as PCIs. 


\begin{tabular}{l} 
Section of this chapter, topic and relevant \\
regulation \\
\hline Regulation (EU) No 347/2013 states that to \\
obtain PCI status projects need to conduct \\
a cost-benefit analysis (CBA) following \\
methodology designed by ENTSO-E with \\
supervision by ACER.
\end{tabular}

PCIs can then be ranked based on their CBA and be selected via a process that is set out in the TEN-E Regulation.
Relevant article

Annex III.2(1) setting out the process for establishing regional lists states that 'for projects having reached a sufficient degree of maturity, a project-specific cost-benefit analysis in accordance with Articles 21 and 22 based on the methodologies developed by the ENTSO for electricity or the ENTSO for gas pursuant to Article 11' will be conducted. Art. 4(2) states that all 'the potential overall benefits of the project, assessed according to the respective specific criteria in paragraph 2, outweigh its costs, including in the longer term.' Art. 4(2) lists specific criteria that apply to projects of common interest depending on the specific energy infrastructure categories.

Art. 11(1) states that ENTSO-E (and ENTSOG - European Network of Transmission System Operators for Gas) shall publish and submit to the Member States, the Commission and the Agency their respective methodologies, including on network and market modelling, for a harmonized energy system-wide cost-benefit analysis at Union level for PCIs. Annex V sets out the principles to be satisfied by the methodology for a harmonized energy system-wide cost-benefit analysis for projects of common interest. Art. 11(2) specifies that within three months of the day of receipt of the methodologies, ACER shall provide an opinion to the Member States and the Commission on the methodologies and publish it.

Annex III.2(11) of Regulation (EU) No 347/2013 setting out the process for establishing regional lists states that 'The Group shall meet to examine and rank the proposed projects taking into account the assessment of the regulators, or the assessment of the Commission for oil and carbon dioxide transport projects.' Annex III.2(14) continues with 'If, based on the regional lists received, and after having taken into account the Agency opinion, the total number of proposed projects of common interest on the Union list would exceed a manageable number, the Commission shall consider, after having consulted each Group concerned, not to include in the Union list projects that were ranked lowest by the Group concerned according to the ranking established pursuant to Article 4(4).'

Art. 4(4) of Regulation (EU) No 347/2013 states that 'in order to facilitate the assessing of all projects that could be eligible as PCIs and that could be included in a regional list, each Group shall assess each project's contribution to the implementation of the same priority corridor or area in a transparent and objective manner. Each Group shall determine its assessment method on the basis of the aggregated contribution to the criteria referred to in paragraph 2; this assessment shall lead to a ranking of projects for internal use of the Group.' Art. 4(4) continues with four additional criteria to which each Group shall give due consideration when assessing projects. 


\begin{tabular}{l} 
Section of this chapter, topic and relevant \\
regulation \\
\hline Projects with PCI status have advantages, such \\
as accelerated permitting procedures, dedicated \\
financial incentives from the NRAs involved, \\
and access to the Connecting Europe Facility \\
$(\mathrm{CEF})$.
\end{tabular}

In the CBCA process, the TEN-E Regulation mandates ACER to act as a mediator in these kinds of cases. TSOs make a CBCA proposal for PCIs, and if the NRAs cannot agree, ACER can intervene.
Relevant article

Chapter III of Regulation (EU) No 347/2013 (Arts. 7-10) describes the permit-granting and public participation procedure for PCIs. Chapter IV (Arts. 11-13) describes their regulatory treatment. Lastly, Chapter V (Arts. 14-16) specifies the financing. Art. 14 describes in more detail the eligibility criteria for Union financial assistance for projects. Recital 42 states that 'Projects of common interest in the fields of electricity, gas and carbon dioxide should be eligible to receive Union financial assistance for studies and, under certain conditions, for works as soon as such funding becomes available under the relevant Regulation on a Connecting Europe Facility in the form of grants or in the form of innovative financial instruments ... A three-step logic applies to investments in projects of common interest. First, the market should have the priority to invest. Second, if investments are not made by the market, regulatory solutions should be explored, if necessary the relevant regulatory framework should be adjusted, and the correct application of the relevant regulatory framework should be ensured. Third, where the first two steps are not sufficient to deliver the necessary investments in projects of common interest, Union financial assistance could be granted if the project of common interest fulfils the applicable eligibility criteria.'

Art. 12(6) of Regulation (EU) No 347/2013 states that 'Where the national regulatory authorities concerned have not reached an agreement on the investment request within six months of the date on which the request was received by the last of the national regulatory authorities concerned, they shall inform the Agency without delay. In this case or upon a joint request from the national regulatory authorities concerned, the decision on the investment request including cross-border cost allocation referred to in paragraph 3 as well as the way the cost of the investments are reflected in the tariffs shall be taken by the Agency within three months of the date of referral to the Agency.' Paragraph 3(c) states that the investment request shall be accompanied by a substantiated proposal for cross-border cost allocation if the project promoters agree. 


\section{PART II}

How to combine electricity trade with system security to keep the lights on? 


\section{Who is responsible for balancing the system? Leonardo Meeus with Tim Schittekatte and Valerie Reif}

In this chapter, we answer four questions. First, how to share responsibility between system operators? Second, how to incentivize market parties to be balanced? Third, how to ensure that reserves are available? And fourth, how to integrate balancing markets across borders?

\subsection{HOW TO SHARE RESPONSIBILITY BETWEEN SYSTEM OPERATORS?}

In this section, we first explain why primary, secondary and tertiary control have been renamed as the frequency containment, frequency restoration and reserve replacement processes. We then discuss in more detail how the balance responsibility between system operators is shared in each of these three processes. We also refer to a clock incident that illustrates the fragility of the shared responsibility.

\subsubsection{Name Change}

The 'primary', 'secondary' and 'tertiary' control terminology is included in all power system engineering handbooks. The various synchronous areas in Europe also applied this terminology, but they had their own detailed definitions which did not align. The five synchronous areas in Europe are Continental Europe (CE), the Nordics, the Baltics, Great Britain and Ireland.

We worked as consultants for the European Commission in 2006 and were involved in Babylonian discussions between experts from the Union for the Coordination of the Transmission of Electricity (UCTE) and the Nordic Cooperation of Electricity Utilities (NORDEL), the former bodies for cooperation between transmission system operators (TSOs) in $\mathrm{CE}$ and the Nordics respectively. We did not recommend the name change, but we understand why it became part of the solution. Table 5.1 introduces the new terminology and maps it onto the historical concepts of primary, secondary and tertiary control. In the remainder of this chapter, we use the new language of frequency containment, frequency restoration and reserve replacement introduced in 2017 in the System Operation Guideline (SO GL).

Following the Electricity Balancing Guideline (EB GL), also introduced in 2017, a limited number of standard balancing energy products were defined per balancing process. There is one standard automatic frequency restoration reserves (aFRR) product, two standard manual frequency restoration reserves (mFRR) products (direct and scheduled activation), and one standard replacement reserves (RR) product. ${ }^{1}$ The Agency for the Cooperation of Energy Regulators (ACER) was in favour of limiting the number of standard balancing energy prod- 
Table $5.1 \quad$ Terminology for reserve products

\begin{tabular}{lllll}
\hline & $\begin{array}{l}\text { Frequency containment } \\
\text { process }\end{array}$ & Frequency restoration process & & $\begin{array}{l}\text { Reserve } \\
\text { replacement } \\
\text { process }\end{array}$ \\
\hline $\begin{array}{llll}\text { Operational reserves } \\
\text { defined in the SO GL }\end{array}$ & $\begin{array}{l}\text { Frequency containment } \\
\text { reserves (FCR) }\end{array}$ & $\begin{array}{l}\text { Automatic frequency } \\
\text { restoration reserves (aFRR) }\end{array}$ & $\begin{array}{l}\text { Manual frequency } \\
\text { restoration reserves } \\
\text { (mFRR) }\end{array}$ & $\begin{array}{l}\text { Replacement } \\
\text { reserves (RR) }\end{array}$ \\
UCTE & Primary control & Secondary control & Tertiary control & \\
NORDEL & $\begin{array}{l}\text { Frequency-controlled } \\
\text { reserves }\end{array}$ & Fast reserves & & \\
\hline
\end{tabular}

Note: $\quad$ The mapping of names is indicative. Due to different operational practices a perfect one-on-one mapping is not possible.

ucts during the EB GL drafting process, while the European Network of Transmission System Operators for Electricity (ENTSO-E) proposal was to keep several products. The standardized products, however, include standardized and non-standardized characteristics. A standardized characteristic of a standard mFRR product is, for example, its full activation time and an example of a non-standardized characteristic is the minimum duration between deactivation and the following activation. Countries can also choose to introduce so-called specific balancing products, which are balancing services that can be used locally, to complement the standardized European products that will be exchanged across borders. To what extent countries will use specific balancing products and to what extent the non-standardized characteristics of the standard products will diverge is an open issue.

\subsubsection{Frequency Containment and the Solidarity Mechanism}

The frequency containment process is the first response to a frequency deviation when an imbalance occurs. In each of the synchronous areas in Europe, this first response is an automatic joint reaction by all the control areas in the synchronous area.

As is discussed in Box 5.1, frequency containment reserves (FCR) are dimensioned to handle a so-called reference incident. Traditionally, this was the loss of the largest generation unit. The probability that countries lost their largest unit at the same time was very low, so they benefited from pooling their FCR requirements into a solidarity mechanism. Each synchronous area already had a solidarity mechanism, and the SO GL formalized these mechanisms. Without such a mechanism, each TSO responsible for a control area would have to procure enough FCR to be able to handle the loss of its largest generator. For France, this would imply doubling or even tripling the procured volume of FCR. For a smaller control area like Belgium, it would imply increasing FCR procurement tenfold. 


\section{BOX 5.1 PRIMARY FREQUENCY CONTROL IN UCTE AND FREQUENCY-CONTROLLED RESERVES IN NORDEL}

In UCTE, dimensioning primary control was based on a reference incident which defined the maximum instantaneous power deviation between generation and demand to be handled by primary control starting from undisturbed operation. This reference incident was defined as $3000 \mathrm{MW}$, as was the primary control reserve in both the positive and negative directions. This meant that a generation load imbalance of that size could be absorbed without frequency deviations exceeding $200 \mathrm{mHz}$. The capacity chosen corresponded to the simultaneous loss of two large units of around $1500 \mathrm{MW}$ each. The provision of primary control was a joint action involving generating units and loads spread evenly across the interconnected network. The various countries' contributions to the total primary regulation reserve were determined on an annual basis and distributed in proportion to the share of the energy generated in one year in the entire synchronous area.

In NORDEL, frequency-controlled reserves were split into normal operation reserves and disturbance reserves. At least $600 \mathrm{MW}$ of normal operation reserves needed to be available at all times. These reserves were to be fully activated if the frequency deviation from the nominal frequency exceeded $100 \mathrm{mHz}$. Contributions to the normal operation reserves of the subsystems in the synchronous system were determined based on the annual consumption in the previous year. The division was updated once a year. The volume and composition of the disturbance reserves were dimensioned in such a way that a dimensioning fault would not cause a frequency below $49.5 \mathrm{~Hz}$ in the synchronous system. The disturbance reserves were distributed among the countries in proportion to their respective dimensioning faults, for example the loss of a large generating station, and the division was updated once a week, or more often if necessary.

Note: $\quad$ Box 5.1 is based on NORDEL (2006) and UCTE (2009). The contribution of each country to the FCR solidarity mechanism can be found in Artelys (2017).

The definition of the reference incident is increasingly being questioned. Following the SO GL, the reference incident for CE was defined as $3000 \mathrm{MW}$, which is the same as the historical value shown in Box 5.1. The value is also the same for upward and downward FCR. In the decentralizing power system the biggest generation unit has not increased, but we increasingly have incidents involving new interactions between the smaller units, as will be shown in Chapter 6. Whether this will lead to the definition of a new reference incident is an open issue.

\subsubsection{Frequency Restoration and Reactive Balancing}

The frequency restoration process starts directly after the frequency containment process. This second response to a system imbalance is organized in so-called load frequency control (LFC) areas. The LFC area is generally equal to the TSOs' control area. Following the SO GL, TSOs can decide to jointly operate the frequency restoration process in an LFC block spanning more than one LFC area within a synchronous area. At the time of writing, most TSOs have not yet done this. The restoration of an imbalance is therefore typically done by the relevant TSO in the control area where the imbalance originates. 
Frequency restoration reserves (FRR) are used to restore the frequency within a predefined time. First, automatic FRR (aFRR) and later manual FRR (mFRR) are activated to relieve FCR and aFRR respectively. aFRR are automatically activated by a controller operated by the TSO; mFRR are activated upon a specific manual request by the TSO.

Reactive balancing means that the TSO relies on market parties to balance themselves through intraday markets. The TSO does not try to anticipate imbalances by activating reserves before a frequency deviation takes place and the frequency containment and frequency restoration processes kick in. This means that the balancing price can spike in periods in which market parties have not managed to balance themselves in the intraday market. This typically implies that there is much activity in the intraday market and market parties are incentivized to help the system operator to balance the system. Most residual imbalances are handled with aFRR.

\subsubsection{Reserve Replacement and Proactive Balancing}

The reserve replacement process involves the slowest type of reserves, which can need 30 minutes to be fully activated. The TSOs that have replacement reserves (RR) often rely less on aFRR and apply a proactive balancing approach. They try to anticipate imbalances by activating RR before the frequency containment and restoration processes kick in.

Proponents of proactive balancing argue that it increases system security, which is especially important in more isolated and inflexible power systems. They also argue that the cost of balancing is reduced by using cheaper RR instead of the more expensive FRR. The counter-argument is that a proactive approach does not create enough incentives for market parties to be balanced and invest in assets that can help balance the system. We will come back to this later in this chapter, and also in Chapter 7 when we discuss the missing money problem.

The EB GL and the SO GL do not explicitly rule on proactive versus reactive balancing, but they implicitly favour reactive balancing. A key concept in the codes is the balancing energy gate closure time (GCT), which has been capped at one hour before real time in Europe. Following the codes, market parties can submit balancing energy bids up to the GCT, and TSOs cannot activate balancing energy bids prior to this GCT. This seems to limit TSOs to balancing proactively, but there are exceptions. Several countries have also started to make use of these exceptions to continue with proactive balancing. How this will evolve is very much an open issue.

\subsubsection{The Clock Incident}

The fragility of the shared balance responsibility between system operators in Europe surfaced in 2018. Many clocks depend on a stable frequency of $50 \mathrm{~Hz}$ to run correctly, but the average frequency had been $49.996 \mathrm{~Hz}$ for several weeks. Clocks accumulated a delay of about six minutes, which was the first time that electricity balancing reached the mainstream media.

ENTSO-E had to face the media to explain how a dispute in south-eastern Europe could cause clock delays in the whole European continent. ${ }^{2}$ The dispute was between Serbia and Kosovo in the LFC block of Serbia, North Macedonia and Montenegro (SMM block). The system had been short, and had not been fully restored, with a total of $113 \mathrm{GWh}$ missing. 
The dispute lasted several weeks. After it was resolved the TSOs decided to catch up by maintaining a frequency of $50.01 \mathrm{~Hz}$ for some weeks. This corrected the delayed clocks, except those that had already been restored manually, which were now running several minutes ahead.

\subsection{HOW TO INCENTIVIZE MARKET PARTIES TO BE BALANCED?}

In this section, we explain balance responsible parties (BRPs) and the imbalance settlement.

\subsubsection{Balance Responsible Parties}

In principle all market parties have balance responsibility. They can take this responsibility themselves or delegate it to a third party. In what follows, we discuss exceptions and whether this responsibility applies at the unit or portfolio level.

First, exceptions to balance responsibility. Renewable energy projects have often been exempted from balance responsibility. They received feed-in tariffs so that they did not have to worry about wholesale market prices or balancing prices. They just injected whatever they could into the system and got paid for it. Forecasting was a problem for system operators, who had to handle forecasting errors. There were no incentives for these new entrants to help in that process. Following Regulation (EU) 2019/943, this is no longer possible. Only three types of grid users can still receive a derogation: demonstration projects for innovative technologies (limited in time); installations benefiting from support approved by the Commission under Union state aid rules (commissioned before 4 July 2019); and renewable generation with an installed electricity capacity of less than $400 \mathrm{~kW}$ (commissioned before 1 January 2026). For renewable generation commissioned after 1 January 2026, the derogation can only apply to installations with an installed electricity capacity of less than $200 \mathrm{~kW}$.

Second, balance responsibility at the unit or portfolio level. The decentralized market model in Europe entails that balance responsibility is defined at the portfolio level, typically within a bidding zone. This gives market parties the possibility of deciding how to dispatch their power plants. Some countries require market parties to balance their generation and consumption portfolios separately, while other countries allow mixed portfolios. There are also exceptions. A few countries still have a more centralized market model, which is often combined with central dispatch and balancing responsibility at the unit level. Note that with smaller bidding zones (see the discussion in Chapter 3), the difference between portfolio bidding and unit bidding becomes smaller. Even if there is portfolio bidding, with nodal pricing a BRP is likely to only have a single unit or a very small portfolio in a certain node. If nodal pricing were only applied to the transmission network, the portfolio would become the resources connected to the distribution grid behind the transmission node.

\subsubsection{Imbalance Settlement}

In what follows we discuss the main design parameters in the imbalance settlement mechanism: the imbalance settlement period and dual as opposed to single pricing. 
First, the imbalance settlement period (ISP). The ISP is the unit of time over which the imbalance of a BRP is calculated. The ISPs in Europe range from 15 minutes (e.g. in the Netherlands) to one hour (e.g. in Poland). This means that a BRP in Poland can be short in some quarters of an hour and long in other quarters of the same hour without paying balancing costs. In the Netherlands, the same BRP will face the costs for both imbalances. The more BRPs face the costs they cause, the more they are incentivized to be balanced. The balancing costs that cannot be allocated to BRPs are socialized by TSOs through their transmission network tariffs. The EB GL states that all EU countries shall apply an ISP of 15 minutes within three years of the entry into force of the regulation, although it leaves some room for exceptions. Regulation (EU) 2019/943 also states that the goal is a 15-minute ISP and adds that ISPs shall not exceed 30 minutes from 1 January 2025, with no exceptions.

Second, dual versus single pricing. Dual pricing implies that BRPs that are unbalanced in the direction of the system imbalance pay the costs of the balancing services that need to be activated, often plus a penalty. The argument for the penalty is that market parties that are unbalanced put the system in danger, so they need an extra incentive to avoid imbalances. Dual pricing also implies that BRPs that are unbalanced in the opposite direction to the system imbalance are not remunerated in the same way as the balancing services that are called upon by the system operator. For instance, if a BRP is helping the system operator to solve a shortage with its imbalance, its remuneration will be capped at the day-ahead price in wholesale markets. Single pricing means no penalties and the same remuneration for activated balancing services and BRPs that are unbalanced in the opposite direction to the system imbalance.

In our research we have long been advocating single pricing. Dual pricing is a legacy from the past in which balancing was a mechanism rather than a market. Dual pricing increases prices in wholesale markets because BRPs are incentivized to buy more than they need to reduce the risk of being short in balancing markets and facing penalties. BRPs will also keep reserves for themselves instead of offering them to the system operator. Dual pricing therefore favours larger players that have reserves over new entrants that rely on the balancing markets. We have also shown that dual pricing in one country can have negative consequences for a neighbouring country because it incentivizes BRPs to move their imbalances across the border to escape penalties. ${ }^{3}$

The EB GL clearly states that prices should reflect the real-time value of energy and favours single pricing over dual pricing. However, following the EB GL, dual pricing is possible as an exception. At the time of writing, some countries still use penalties, but their number has decreased. Note that in terms of the geographical dimension, the imbalance price or prices are calculated per imbalance price area. In this regard, Regulation (EU) 2019/943 states that each imbalance price area shall be equal to a bidding zone. An exception to this is the case of a central dispatching model, where an imbalance price area may constitute a part of a bidding zone.

\subsection{HOW TO ENSURE THAT RESERVES ARE AVAILABLE?}

In this section, we first discuss balancing capacity tenders, then balancing energy markets, and lastly the related issue of scarcity pricing in balancing markets. 


\subsubsection{Balancing Capacity Tenders}

In this subsection, we first discuss whether TSOs can own balancing services, and then discuss how they tender for balancing capacity.

First, TSO ownership of balancing services. TSOs have in exceptional cases been allowed to own pumped hydro plants and batteries. However, this creates a conflict of interest between the TSO as the single buyer of balancing services and the TSO as one of the players in this market. Directive (EU) 2019/944 ruled out TSO ownership of energy storage assets, with possible derogations under specific circumstances. TSO ownership of generation assets has already been addressed with the unbundling process, which we referred to in Chapter 1.

Second, TSO tenders for balancing capacity. Market parties that offer balancing services are called balancing service providers (BSPs). They used to mainly be gas-fired power plants, which preferred longer-term contracts and could provide upward and downward services in one contract. This was nicely aligned with the interests of the system operators, who like simplicity and security. Renewable energy players can more easily provide downward than upward balancing services, and for aggregators of demand flexibility the opposite applies. Both prefer separate procurements for upward and downward balancing services. They also prefer tenders closer to real time, when they have a better idea of the services they can provide. Some even prefer to offer balancing energy bids without balancing capacity reservation. In some countries this was not possible; in other countries it was not appealing because whoever won a balancing capacity tender had to provide balancing energy bids at the low price agreed upon in the tender. ${ }^{4}$

To create a level playing field between incumbent and new players in balancing markets, many changes were needed. They increased the complexity of balancing markets but also improved their competitiveness and reduced the costs. This is an ongoing process. Regulation (EU) 2019/943 contains provisions to gradually move away from yearly and monthly contracts towards shorter-term day-ahead tenders. The EB GL states that the balancing energy price should not be predetermined in the balancing capacity contract for standardized products. This rule is reiterated in Regulation (EU) 2019/943. The EB GL also states that upward and downward balancing capacity should be procured separately for FRR and RR. A temporary exception to this rule can be requested. In Chapter 8, we will come back to the specific issues related to flexible generation, demand and storage resources connected to distribution grids and their participation in balancing markets.

\subsubsection{Balancing Energy Markets}

In what follows, we introduce the main balancing energy market controversies: merit-order activation versus pro-rata activation; and marginal pricing versus pay-as-bid pricing.

First, merit-order activation versus pro-rata activation. As discussed above, many TSOs relied on balancing capacity tenders to secure reserves. They did not always have a balancing energy market to procure aFRR, mFRR or RR closer to real time. The price at which they activated reserves was often agreed upon in a balancing capacity contract. The contracted reserves also contributed to solving an imbalance in proportion to their size without distinguishing between delivery costs, that is, pro-rata activation. Under pro-rata activation, efficient pricing and enabling competition for the provision of balancing energy is an issue. Therefore, the EB 
GL prescribes the development of balancing energy markets with merit-order activation of balancing energy bids. Under merit-order activation, the cheapest balancing energy bids are selected one by one up to the required volume. As described in the previous subsection, balancing capacity tenders can still be used to make sure that there are enough balancing energy bids in the market, but not to set their price. Note that this applies to standardized balancing products, but not necessarily to specific products that might still be used at the national level.

Second, marginal pricing versus pay-as-bid pricing. The EB GL makes marginal pricing mandatory for standardized products. Pay-as-bid pricing is a legacy of pro-rata activation, which has been replaced by merit-order activation. However, if all TSOs identify inefficiencies in the application of marginal pricing, they may request an amendment and propose an alternative pricing method. Applying marginal pricing to balancing energy markets is not always straightforward. ${ }^{5}$ Several bids can be activated at different times within a certain settlement period, sometimes even in opposite directions. The EB GL did foresee the development of a methodology for the harmonized implementation of marginal pricing in balancing energy markets.

FCR is the exception. FCR continues to typically be a service that combines upward and downward balancing. These reserves receive as much energy as they give, so that only capacity needs to be remunerated. By its nature, the FCR product is indeed more about capacity than energy.

\subsubsection{Scarcity Pricing in Balancing Markets}

Here, we first introduce the 'missing money' problem related to balancing capacity tenders, and then discuss the scarcity pricing solution that has been proposed. ${ }^{6}$

First, the missing money problem. ACER and CEER's market monitoring found that in most of Europe balancing capacity is remunerated more than balancing energy, and imbalance settlement prices only recover the balancing energy costs. This means that most balancing costs are socialized through transmission network tariffs. It also means that BRPs are not adequately incentivized to be balanced, and BSPs are not adequately incentivized to invest in flexible assets. We already mentioned that this is an issue when discussing proactive balancing. Balancing capacity tenders are an additional source of missing money in balancing markets.

Second, the solution. In Chapter 7 we will show that capacity mechanisms have been proposed as a solution to compensate investors for the missing money problem. Another solution is to reform balancing markets so that there is no missing money. The reform is referred to as operating reserve demand curves (ORDC). It was proposed by academics and tested for the first time in Texas in 2014. In Europe, the GB regulator Ofgem has applied a similar concept, and the Belgian regulator CREG has started looking into it. The idea is to include an uplift in the imbalance settlement pricing mechanism. When the system is short of reserves, the uplift can increase to a very high value that represents the willingness of customers to avoid being cut off from the system. When there are enough reserves in the system, the uplift goes to zero. Note that the penalties we discussed in the previous section were also a kind of uplift. However, they often disregarded system conditions and were designed to punish BRPs for imbalances rather than to correct the scarcity price signal in balancing markets. The penalties were also often combined with asymmetric incentives to BRPs and BSPs, while the uplift in the ORDC approach applies symmetrically to BRPs and BSPs. The EB GL mentions that an 
additional settlement mechanism may be developed to allocate the costs of balancing capacity. To what extent this will be done is an open issue.

\subsection{HOW TO INTEGRATE BALANCING MARKETS ACROSS BORDERS?}

In this section, we first recall why the integration of balancing markets was started. We then discuss the ongoing integration of balancing markets with imbalance netting, the exchange of balancing energy, the exchange of balancing capacity and sharing of reserves. We end with open issues in congestion management in balancing markets.

\subsubsection{Why Was the Integration of Balancing Markets Started?}

In the previous section, we discussed how ongoing changes to national balancing markets are helping to bring new players into these markets. In this section, we discuss how the integration of balancing markets across national borders is also helping to reduce balancing costs.

In Chapter 2 we referred to the Sector Inquiry published in 2007. We also discussed how this inquiry helped to accelerate the integration of wholesale markets across borders. Table 5.2 shows why it did the same for balancing markets by revealing the alarming level of concentration in national balancing markets between 2003 and 2005. Even countries that had relatively well-functioning wholesale markets had problematic balancing markets. At the time of the inquiry, TSO unbundling was also limited. The concern was therefore that TSOs were not motivated enough to change the situation because they were in some cases part of the same holding company as the generators profiting from the situation.

The integration process for balancing started after the wholesale process, but it proceeded faster. The Nordics were the first to create a cross-border balancing market in Europe. Other European TSOs followed with several pilots, and the ambition increased further during the drafting process of the EB GL. The drafts referred to coordinated balancing areas (CoBAs). They were going to be regional initiatives that would be slowly merged over time, like the process that had been followed for wholesale markets as described in Chapter 2. ENTSO-E was also proposing a minimalistic approach to balancing market harmonization. ACER argued for harmonized products and integration through European platforms instead of CoBAs, and the final version of the EB GL leans towards ACER's view. Earlier in this chapter, we showed that we have standardized products. In what follows, we introduce the European platforms. ${ }^{7}$

\subsubsection{Imbalance Netting}

As discussed earlier in this chapter, the first response to a frequency deviation is a shared responsibility (i.e. frequency containment), but the second response (i.e. frequency restoration) is generally the responsibility of the TSO from the control area that caused the frequency deviation. This implies that one TSO might have a positive imbalance to solve while a neighbouring TSO has a negative imbalance at the same time. Until recently, both TSOs would then activate balancing services: one would balance upwards; the other downwards. Imbalance netting simply means they stop doing this and only take action to solve the net imbalance. The TSO with the residual net imbalance then still has to activate balancing services, but it 
Table 5.2 Market shares of the largest BSP for FRR between 2003 and 2005

\begin{tabular}{llll}
\hline UK & $\approx 19 \%$ & DK & $\approx 88 \%$ \\
NL & $\approx 39 \%$ & FR & $\approx 91 \%$ \\
ES & $\approx 44 \%$ & DE & $\approx 93 \%$ \\
CZ & $\approx 53 \%$ & AT & $\approx 100 \%$ \\
IT & $\approx 78 \%$ & HU & $\approx 100 \%$ \\
SI & $\approx 86 \%$ & & \\
\hline
\end{tabular}

Source: Author's own table based on a graph from the Sector Inquiry (European Commission 2007).

is cheaper than solving the gross imbalance. The other TSO does not have to do anything. Of course, netting can only take place if there is enough transmission capacity available to accommodate the associated flows.

In our research, we found that the potential for Belgium and the Netherlands was significant. The International Grid Control Cooperation (IGCC) project confirmed the benefits. The IGCC is an initiative by the four German TSOs that grew into the biggest balancing pilot for imbalance netting. More specifically, the IGCC avoids the activation of aFRR in opposite directions on different sides of a border in the case that there is interconnector capacity available in the right direction. Between 2012 and 2019, the accumulated benefit from this pilot was $€ 475$ million. And this with a cost of only $€ 20$ million for setting up the platform and an annual cost of $€ 1$ million to run it. There were also smaller pilots running in parallel that confirmed the potential of imbalance netting prior to the EB GL. However, it was later agreed that the IGCC would be used as the starting point for the implementation of a European platform for imbalance netting according to the EB GL. In January 2020, the IGCC was operational in 11 countries (13 TSOs). The initiative is quickly expanding as the EB GL mandates that the platform shall be used to perform the imbalance netting process for at least the CE synchronous area. The EB GL mandates that the platform shall be used to perform the imbalance netting process for at least the CE synchronous area. It is foreseen that TSOs in synchronous areas other than CE performing the automatic frequency restoration process (aFRP) may decide to become member TSOs of the European platform at a later point in time. Netting strongly reduces the need for balancing. As an illustration, in 2017, imbalance netting reduced Latvia's need for aFRR balancing energy by 55 per cent and the Netherlands' need by 83 per cent. ${ }^{8}$

\subsubsection{Exchange of Balancing Energy}

The Nordics TSOs have been exchanging balancing energy for mFRR since 2002. More recently, balancing pilots have also been set up by the other TSOs. The main aFRR pilot was called EXPLORE (European X-border Project for LOng-term Real-time balancing Electricity market design), and the RR pilot was called TERRE (Trans-European Restoration Reserves Exchange).

Positive experience with these pilots inspired the EB GL drafters to set up European platforms for the exchange of aFRR, mFRR and RR. The EB GL did foresee the development of detailed implementation frameworks for each of these platforms, and TSOs have already started with their establishment. The aFRR platform is called PICASSO (Platform for the International Coordination of Automated Frequency Restoration and Stable System 
Operation). It was initiated in July 2017 and involved 16 TSOs (plus 10 observers) by the end of 2019. PICASSO builds further on the work done in the EXPLORE regional project. The mFRR platform is called MARI (Manually Activated Reserves Initiative). The RR platform is called TERRE, which is the same name as the balancing pilot it is based on. TERRE is the only balancing platform that has been launched as of January 2020. At that time, 8 TSOs (plus 6 TSO observers and ENTSO-E) were involved. In January 2020, ACER also adopted decisions regarding the implementation frameworks for the other platforms.

Note that BSPs will continue to submit their balancing energy bids to the TSO of their control area. The TSOs will then submit the bids to the European platforms. This way of working is referred to as the TSO-TSO model. The EB GL states that this is the model for exchanging balancing bids, with possible exceptions where two or more TSOs on their initiative or on request by their relevant regulatory authorities develop a proposal for the application of a TSO-BSP model. The alternative TSO-BSP model means that BSPs can submit their bids to another TSO without passing through their own TSO. This then assumes that the BSPs can purchase and use transmission rights for this purpose. The EB GL only allows alternative proposals applying a TSO-BSP model as temporary solutions, except for certain circumstances related to TSOs operating the replacement reserves process.

\subsubsection{Exchange of Balancing Capacity and Sharing of Reserves}

The EB GL requires each TSO to publish a balancing report at least every two years. In this report the TSO is asked to analyse the potential for exchange of balancing capacity and sharing of reserves and to put forward explanations and justifications for the procurement of balancing capacity without the exchange of balancing capacity or sharing of reserves. This means that much more information will be available, but the initiatives remain voluntary.

The exception is sharing of reserves for FCR, which is mandatory and already exists for FCR, as was shown in Section 5.1.2. This implies that countries decide together the total amount of FCR to procure and how to share the responsibility between them. In fulfilling this responsibility, they can procure FCR locally or they can decide to exchange balancing capacity across borders. A balancing pilot was set up between the Austrian TSO and the Swiss TSO to exchange FCR capacity in 2013. This pilot was successful and currently the Belgian, Danish, Dutch, French and German TSOs are also part of the FCR cooperation project. In 2019, the project was formalized according to the EB GL.

Note that the SO GL required all the TSOs in a synchronous area to jointly develop a proposal regarding the determination of LFC blocks. In many cases, the LFC block equals the LFC area, which is equal to the control area. Exceptions are the Nordics, Ireland and Great Britain, where the LFC block equals the synchronous area. Germany, Luxembourg and West Denmark are also exceptions. They form an LFC block consisting of several LFC areas. The same applies to Slovenia, Croatia, and Bosnia and Herzegovina and to Serbia, North Macedonia and Montenegro. For these exceptions, the SO GL states that FRR has to be dimensioned per LFC block. The TSOs involved then have to agree on the volume to reserve, the ratio between aFRR and mFRR, and the sharing of responsibility. The SO GL also sets out rules for dimensioning and sharing of RR for LFC blocks in which all the TSOs make use of RR. These rules are similar to those for FCR, which apply to all TSOs. Following Regulation (EU) 2019/943, regional coordination centres (RCCs) will facilitate regional dimensioning 
and the procurement of balancing capacity. RCCs were briefly introduced in Chapter 3 and will be discussed in more depth in Chapter 6 .

\subsubsection{Congestion Management in Balancing Markets}

There are three open issues in congestion management in balancing markets: reserving available transmission capacity for balancing markets; filtering balancing bids; and the interaction with redispatching or flexibility markets.

First, the reservation of available transmission capacity for balancing markets. The EB GL requires all TSOs to use available cross-zonal capacity after the cross-zonal intraday gate closure for operating the imbalance netting process or for the exchange of balancing energy. The EB GL also foresees the possibility of reserving available transmission capacity for the exchange of balancing capacity or sharing of reserves for FRR and RR. Nothing is specified regarding imbalance netting or the exchange of balancing energy. Note that available transmission capacity is already reserved for FCR. The so-called reliability margin on transmission lines is to account for FCR. To what extent it is opportune to do additional reservation is very much an open issue.

Second, filtering balancing bids. The SO GL foresees distribution system operators (DSOs) being able to filter balancing bids from BSPs connected to distribution grids. If they fear that certain bids may cause congestion when called upon by TSOs, they can disqualify them. Whether this will result in penalties being paid to the TSO by the BSP and/or paid to the BSP or the TSO by the DSO is an open issue. The SO GL also allows TSOs to filter bids. They do not have to forward all the BSPs' bids to the European platforms. If they fear that certain bids may cause congestion when called upon by neighbouring TSOs, they can also disqualify these bids. Filtering balancing bids is a new issue that has emerged in the ongoing balancing market integration process.

Third, the interaction between balancing markets and redispatching or flexibility markets. Redispatching actions by TSOs were covered in Chapter 3. They imply that fewer resources are available for balancing. Redispatching can be done by activating an upwards balancing bid in one location and a downwards balancing bid in another location. It can also be done by countertrading in the intraday markets. The TSO then procures energy in the intraday market in one location to sell the same amount in another location. Some TSOs also procure redispatching resources in a separate market, possibly in cooperation with DSOs, which have also started to use flexibility to manage congestion in their grids. How congestion management in balancing markets, redispatching markets and flexibility markets will evolve is very much an open issue. We will come back to the topic of TSO-DSO coordination in balancing and congestion management in Chapter $8 .{ }^{9}$

\subsection{CONCLUSION}

In this fifth chapter on who is responsible for balancing the system, we have answered four questions.

First, how to share responsibility between system operators? The first response to a frequency deviation in Europe is referred to as the frequency containment process with frequency containment reserves. This first response is also a joint response with a solidarity mechanism 
in each synchronous zone. The second response is referred to as the frequency restoration process with automatic and manual frequency restoration reserves. This second response is typically per control area and performed by the TSOs in the zone with the imbalance that caused the frequency deviation. TSOs can also choose to share this responsibility by organizing themselves in so-called load frequency control areas and blocks that are bigger than one control area. TSOs can anticipate frequency deviations and resolve imbalances before they occur by activating RR, which is referred to as proactive balancing, as opposed to reactive balancing. The EB GL default is reactive balancing, but proactive balancing is still possible.

Second, how to incentivize market parties to be balanced? All market players either take on the balance responsible party role or delegate this responsibility to a third party. Renewable energy players can no longer avoid this responsibility. The only exceptions are for very small-scale and/or innovation demonstration projects. The imbalance settlement is becoming more cost-reflective with single pricing instead of dual pricing, and with smaller imbalance settlement periods.

Third, how to ensure that reserves are available? Many changes had to be made to balancing markets to create a level playing field between the traditional balancing service providers and new players. Balancing energy markets are becoming more important. At least for standard energy balancing products, these markets will apply marginal pricing and the bids will be activated following a merit order. Shorter-term balancing capacity tenders can continue. To avoid the missing money problem, the costs of these tenders can be included in a scarcity price signal through an uplift on top of the balancing energy price in periods when the system is short of reserves.

Fourth, how to integrate balancing markets across borders? Imbalance netting has proven to be very beneficial and relatively easy to implement. In line with the EB GL, TSOs have started to set up European platforms to exchange balancing energy. Their names are PICASSO (aFRR), MARI (mFRR) and TERRE (RR). Congestion management in balancing markets is also an open issue. This includes reserving available transmission capacity for balancing, filtering of balancing bids and the interaction between balancing markets and redispatching and flexibility markets.

\section{NOTES}

1. There is no standard FCR balancing energy product. FCR is paid for reserved capacity rather than activated volume.

2. More details can be found in the ENTSO-E press releases (2018a, 2018b, 2018c).

3. Saguan and Glachant (2007) were pioneers in the study of balancing market design, the negative impact of dual pricing in balancing markets on wholesale prices and the willingness of balancing service providers (BSPs) to pool reserves. In Vandezande et al. (2010) we elaborate on the negative impact of dual pricing with penalties. We argue that the impact is not only discriminatory to new entrant renewable energy players but also counterproductive in terms of the security of the system. In Vandezande et al. (2009a) we illustrate how traders can exploit differences in the imbalance settlement mechanisms of neighbouring countries. ENTSO-E (2019c) is an example of the annual balancing market survey that is conducted by TSOs and includes the penalties that are applied in countries that apply dual pricing.

4. De Vos et al. (2019) present a method for the dimensioning of operating reserves on a daily basis. They show that this dynamic dimensioning approach makes a positive business case for the Belgian system in 2020 as opposed to a static approach in which the capacity required is determined once 
a year. Based on the results of this study, Belgium decided on a gradual implementation towards 2020 of daily procurement of mFRR according to estimations of daily needs.

5. Littlechild $(2007,2015)$ provides a detailed discussion on the pricing rule for balancing energy. He favours marginal pricing but also recognizes that some characteristics of the balancing energy market make it more difficult to apply this rule in certain situations.

6. ACER first highlighted this issue in Figure 24 of its 2015 market monitoring report (ACER and CEER 2016). Since 2017 (ACER and CEER 2018, 2019), the share of balancing costs recovered through imbalance settlement has been left out of the report so it is difficult to know how it has evolved. The academic who came up with the operating reserve demand curve (ORDC) concept is William W. Hogan (Hogan 2005, 2013). Papavasiliou and Smeers (2017) study how an ORDC adder would perform in Belgium. An evaluation of the implementation of scarcity pricing in GB can be found in Ofgem (2018).

7. ENTSO-E (2019a) provides an overview of the nine balancing pilot projects in Europe. ENTSO-E (2014) included the concept of CoBAs in version 3.0 of the EB GL, which was published in 2014. Pentalateral Energy Forum (2016) includes the difference between the views of ACER and ENTSO-E on the level of harmonization required in balancing markets to enable integration during the EB GL drafting process.

8. In Vandezande et al. (2009b) we calculate the potential for netting between Belgium and the Netherlands using historical imbalance data, balancing prices and available transmission capacity. The quarterly benefits of the IGCC are available in ENTSO-E (2019b), the costs related to the IGCC in Artelys et al. (2016) and the data on Latvia and the Netherlands in ACER and CEER (2018).

9. The balancing survey in ENTSO-E (2019c) shows that in $2018 \mathrm{mFRR}$ was also used for congestion management in Great Britain and the Nordics. Balancing bids cannot be used for redispatch in the Netherlands and Germany.

\section{REFERENCES}

50Hertz, Elia, Amprion, APG, Energienet, RTE, Swissgrid, Transnet BW and TenneT (2018), 'TSOs' Proposal for the Establishment of Common and Harmonised Rules and Processes for the Exchange and Procurement of Balancing Capacity for FCR in Accordance with Article 33 of the EB GL', published on 18 October 2018.

ACER (2020a), 'Decision No 01/2020 of the European Union Agency of 24 January 2020 on the Methodology to Determine Prices for the Balancing Energy that Results from the Activation of Balancing Energy Bids'.

ACER (2020b), 'Decision No 02/2020 of the European Union Agency of 24 January 2020 on the Implementation Framework for the European Platform for the Exchange of Balancing Energy from Frequency Restoration Reserves with Automatic Activation'.

ACER (2020c), 'Decision No 03/2020 of the European Union Agency of 24 January 2020 on the Implementation Framework for a European Platform for the Exchange of Balancing Energy from Frequency Restoration Reserves with Manual Activation'.

ACER and CEER (2016), 'Annual Report on the Results of Monitoring the Internal Electricity and Natural Gas Markets in 2015 - Electricity Wholesale Markets Volume'.

ACER and CEER (2018), 'Annual Report on the Results of Monitoring the Internal Electricity and Natural Gas Markets in 2017 - Electricity Wholesale Markets Volume'.

ACER and CEER (2019), 'Annual Report on the Results of Monitoring the Internal Electricity and Natural Gas Markets in 2018 - Electricity Wholesale Markets Volume'.

All CE TSOs (2018), 'All TSOs' Proposal for the Determination of LFC Blocks for the Synchronous Area Continental Europe in Accordance with Article 141(2) of the SO GL', published on 15 July 2018 .

All Nordic TSOs (2018), 'Proposal from all TSOs of the Nordic Synchronous Area for the Determination of LFC Blocks within the Nordic Synchronous Area in Accordance with Article 141(2) of the SO GL', published on 5 July 2018. 
All TSOs (2018a), 'All TSOs' Proposal for the Implementation Framework for a European Platform for the Exchange of Balancing Energy from Frequency Restoration Reserves with Automatic Activation in Accordance with Article 21 of the EB GL', published on 18 December 2018.

All TSOs (2018b), 'All TSOs' Proposal for the Implementation Framework for a European Platform for the Exchange of Balancing Energy from Frequency Restoration Reserves with Manual Activation in Accordance with Article 20 of the EB GL', published on 18 December 2018.

All TSOs (2018c), 'All TSOs' Proposal on Methodologies for Pricing Balancing Energy and Cross-Zonal Capacity Used for the Exchange of Balancing Energy or Operating the Imbalance Netting Process Pursuant to Article 30(1) and Article 30(3) of the EB GL', published on 18 December 2018.

All TSOs (2019), 'All TSOs' Proposal for the Implementation Framework for a European Platform for the Imbalance Netting Process in Accordance with Article 22 of Commission Regulation (EU) 2017/2195 of 23 November 2017 Establishing a Guideline on Electricity Balancing', published on 10 September 2019.

All TSOs using RR (2018), 'The Proposal of all Transmission System Operators Performing the Reserve Replacement Process for the Implementation Framework for the Exchange of Balancing Energy from Replacement Reserves in Accordance with Article 19 of the EB GL', published on 18 June 2018.

Artelys (2017), 'METIS Technical Note T6 - METIS Power System Module', METIS Technical Notes, (May), accessed at https://ec.europa.eu/energy/sites/ener/files/power_system module.pdf.

Artelys, COWI and Frontier Economics (2016), 'Integration of Electricity Balancing Markets and Regional Procurement of Balancing Reserves', Final Report, carried out for the European Commission (DG ENER B1).

De Vos, K., N. Stevens, O. Devolder, A. Papavasiliou, B. Hebb and J. Matthys-Donnadieu (2019), 'Dynamic dimensioning approach for operating reserves: Proof of concept in Belgium', Energy Policy, 124, 272-85.

ENTSO-E (2014), 'ENTSO-E Network Code on Electricity Balancing Version 3.0'.

ENTSO-E (2018a), 'Continuing frequency deviation in the Continental European Power System originating in Serbia/Kosovo: Political solution urgently needed in addition to technical', press release of 6 March 2018.

ENTSO-E (2018b), 'Deviations affecting frequency in Continental Europe have ceased; ENTSO-E working on step 2', press release of 8 March 2018.

ENTSO-E (2018c), 'Frequency deviations - Continental European TSOs have restored the situation to normal', press release of 3 April 2018.

ENTSO-E (2019a), 'Cross Border Electricity Balancing Pilot Projects', accessed at https://www.entsoe .eu/network_codes/eb/.

ENTSO-E (2019b), 'IGCC Regular Report on Social Welfare Q3 2019'.

ENTSO-E (2019c), 'Survey on Ancillary Services Procurement and Balancing Market Design 2018', ENTSO-E WGAS, published in March 2019.

European Commission (2007), 'DG COMP Report on Energy Sector Inquiry'.

Hogan, W. W. (2005), 'On an "energy only" electricity market design for resource adequacy', White Paper, Harvard University.

Hogan, W. W. (2013), 'Electricity scarcity pricing through operating reserves', Economics of Energy and Environmental Policy, 2 (2), 65-86.

Littlechild, S. (2007), 'Electricity Cash Out Arrangements', accessed at https:/www.ofgem.gov.uk/ ofgem-publications/40635/19091 cashoutreviewslittlechild.pdf.

Littlechild, S. (2015), 'Reflections on cash-out arrangements', letter to Roger Witcomb, February 2015.

NORDEL (2006), 'System Operation Agreement'.

Ofgem (2018), 'Analysis of the first phase of the Electricity Balancing Significant Code Review', Working Paper, published in August 2018.

Papavasiliou, A. and Y. Smeers (2017), 'Remuneration of flexibility using operating reserve demand curves: A case study of Belgium', Energy Journal, 38 (6), 105-36.

Pentalateral Energy Forum (2016), 'Balancing', Penta Flexibility Work Stream - Penta SG3 - Technical Background Paper - Balancing.

Saguan, M. and J.-M. Glachant (2007), 'An institutional frame to compare alternative market designs in EU electricity balancing’, MIT-CEEPR Working Paper 07-001. 
UCTE (2009), 'Continental Europe Operation Handbook. P1: Load-Frequency Control and Performance'. Vandezande, L., L. Meeus, R. Belmans, M. Saguan and J. M. Glachant (2010), 'Well-functioning balancing markets: A prerequisite for wind power integration', Energy Policy, 38 (7), 3146-54.

Vandezande, L., L. Meeus, R. Belmans, M. Saguan, J. M. Glachant and V. Rious (2009a), 'Lacking balancing market harmonisation in Europe: Room for trader profits at the expense of economic efficiency?', 32nd IAEE International Conference, Jun 2009, San Francisco, United States.

Vandezande, L., M. Saguan, L. Meeus, J.-M. Glachant and R. Belmans (2009b), 'Assessment of the implementation of cross-border balancing trade between Belgium and the Netherlands', 6th International Conference on the European Energy Market, 27-29 May, Leuven, Belgium. 


\section{A.1 ANNEX: REGULATORY GUIDE}

\section{Table 5A.1 Regulatory guide}

Section of this chapter, topic and relevant regulation

\section{Section 5.1.1}

The SO GL introduces new names for old concepts: frequency containment, frequency restoration, and reserve replacement.

There is one standard automatic frequency restoration reserves product (aFRR), two standard manual frequency restoration reserves (mFRR) products (direct and scheduled activation) and one standard replacement reserves (RR) product.

According to the EB GL, the standardized products include standardized and non-standardized characteristics.
Relevant articles

Revevaticles

Art. 2(6-8) provides definitions of the terms 'frequency containment
reserves,' 'frequency restoration reserves' and 'replacement reserves'

According to the EB GL, implementation frameworks have to be proposed by all TSOs for the European aFRR, mFRR and RR balancing platforms (Arts. 21, 20, 19). One element in these implementation frameworks is proposed standard products (Art. 21(3.i), Art. 20(3.i), Art. 19(3.i)). Only the implementation framework for RR has been approved by the relevant NRAs so far - in December 2018 (All TSOs using RR 2018). This framework specifies that there is one standard RR product. The proposals for the implementation frameworks for aFRR and mFRR were referred to ACER in July 2019. In these proposals, All TSOs (2018a, 2018b) propose one standard product for aFRR and two for mFRR. The mFRR standard products differ in their activation mode, namely direct and scheduled activation. The mFRR implementation framework proposals provide for balancing energy bids to be submitted either only for scheduled activation or for scheduled and direct activation in one common merit-order list. The mFRR implementation framework defines a scheduled activatable bid in Art. 2(2.x) as ' $a$ standard mFRR balancing energy product bid that can only be activated at one specific point in time, i.e. the point of scheduled activation, with respect to the period of time for which the balancing energy bid is submitted.'A direct activatable bid is defined in Art. 2(2.e) of the same proposal as ' $a$ standard $m F R R$ balancing energy product bid that can be activated at any point of time following the point of scheduled activation of the quarter hour for which the bid is submitted and until the point of scheduled activation of the subsequent quarter hour. Every direct activatable bid is a scheduled activatable bid as well, while no scheduled activatable bid is a direct activatable bid.'

The standardized and non-standardized characteristics can be found in the implementation frameworks for the respective balancing processes (Arts. $21,20,19)$. The standardized characteristics of a product are defined in the implementation frameworks. The non-standardized characteristics are defined in the terms and conditions for balance service providers (BSPs), which are defined by each TSO individually (Art. 18(1.a)). 


\begin{tabular}{l} 
Section of this chapter, topic and relevant \\
regulation \\
\hline According to the EB GL, countries can also \\
choose to introduce so-called specific balancing \\
products, which are balancing services that can \\
be used locally, to complement the standardized \\
European products that will be exchanged across \\
borders.
\end{tabular}

\section{Section 5.1.2}

Each synchronous area already had a solidarity mechanism and the SO GL formalized these mechanisms.

Following the SO GL, the reference incident for $\mathrm{CE}$ is defined as $3000 \mathrm{MW}$. The value is the same for upward and downward FCR.

\section{Section 5.1.3}

According to the SO GL, the frequency restoration process (FRP) is organized in so-called load frequency control (LFC) areas.

Following the SO GL, TSOs can decide to jointly operate the frequency restoration process (FRP) in an LFC block spanning more than one control area in a synchronous area.
Relevant articles

Requirements for specific products are described in Art. 26. Art. 26(1.b and f) states that a TSO proposing a specific product has to demonstrate that standard products are not sufficient to ensure operational security and that the specific product does not create significant inefficiencies and distortions in the balancing market. Art. 26(3) states that 'the specific products shall be implemented in parallel to the implementation of the standard products. Following the use of the specific products, the connecting TSO may alternatively: (a) convert the balancing energy bids from specific products into balancing energy bids from standard products; (b) activate the balancing energy bids from specific products locally without exchanging them.' Art. 6(14) of Regulation (EU) 2019/943 reiterates these requirements for specific products.

Art. 153 describes the FCR dimensioning rules. Art. 153(1) states that 'All TSOs of each synchronous area shall determine, at least annually, the reserve capacity for FCR required for the synchronous area ...'

Art. 153(2.b.i) states that 'All TSOs of each synchronous area shall specify dimensioning rules in the synchronous area operational agreement in accordance with the following criteria: ... (b) the size of the reference incident shall be determined in accordance with the following conditions: (i) for the CE synchronous area, the reference incident shall be $3000 \mathrm{MW}$ in positive direction and 3000 MW in negative direction.' Art. 153(2.c) adds that 'for the CE and Nordic synchronous areas, all TSOs of the synchronous area shall have the right to define a probabilistic dimensioning approach for FCR taking into account the pattern of load, generation and inertia, including synthetic inertia as well as the available means to deploy minimum inertia in real-time ... with the aim of reducing the probability of insufficient FCR to below or equal to once in 20 years.'

Art. 141(4) states that 'All TSOs of each LFC area shall ... (b) implement and operate a FRP for the LFC area.'

Art. 145(6) states that 'In addition to the aFRP implementation in the LFC areas, all TSOs of an LFC block which consists of more than one LFC area shall have the right to appoint one TSO of the LFC block in the LFC block operational agreement to: (a) calculate and monitor the FRCE of the whole LFC block; and (b) take the FRCE of the whole LFC block into account for the calculation of the setpoint value for aFRR activation in accordance with Article 143(3) in addition to the FRCE of its LFC area.' In addition, an LFC area can consist of more than one control area. If the LFC area is defined over multiple control areas, TSOs can also jointly operate the FRP. An LFC area is defined in the SO GL Art. 3(12) as 'a part of a synchronous area or an entire synchronous area, physically demarcated by points of measurement at interconnectors to other LFC areas, operated by one or more TSOs fulfilling the obligations of load-frequency control.' 


\begin{tabular}{l} 
Section of this chapter, topic and relevant \\
regulation \\
\hline Following the SO GL, frequency restoration \\
reserves (FRR) are used to restore the frequency \\
within a predefined time.
\end{tabular}

\section{Section 5.1.4}

The replacement reserves process involves the slowest type of reserves, which can need 30 minutes to be fully activated.

The EB GL and the SO GL do not explicitly rule on proactive versus reactive balancing, but they implicitly favour reactive balancing. The balancing energy gate closure time is capped at one hour before real time in Europe. Market parties can submit balancing energy bids up to the GCT, and TSOs cannot activate balancing energy bids prior to this GCT. This seems to limit TSOs to balancing proactively, but there are exceptions.
Relevant articles

Art. 143(1.a) states that 'The control target of the FRP shall be to: (a) regulate the Frequency Restoration Control Error (FRCE) towards zero within the time to restore frequency.' The FRCE is defined in Art. 3(43) as 'the control error for the FRP which is equal to the area control error of a LFC area or equal to the frequency deviation where the LFC area geographically corresponds to the synchronous area.' Table 1 in Annex III of the SO GL indicates that the time to restore frequency is 15 minutes for each synchronous area, except for the Baltic synchronous area, for which no information is listed.

The approved implementation framework for the exchange of balancing energy from replacement reserves states that the full activation time of the RR standard product is 30 minutes. Art. 3(30) defines the full activation time as 'the period between the activation request by the connecting TSO in case of TSO-TSO model or by the contracting TSO in case of TSO-BSP model and the corresponding full delivery of the concerned product.'

There are several articles of importance with respect to this matter. Most importantly, Art. 29(2-3) of the EB GL states that '2. TSOs shall not activate balancing energy bids before the corresponding balancing energy gate closure time, except in the alert state or the emergency state when such activations help alleviate the severity of these system states and except when the bids serve purposes other than balancing pursuant to paragraph 3. 3. By one year after the entry into force of this Regulation, all TSOs shall develop a proposal for a methodology for classifying the activation purposes of balancing energy bids. This methodology shall: (a) describe all possible purposes for the activation of balancing energy bids; (b) define classification criteria for each possible activation purpose.'

Regarding the balancing energy gate closure time, two articles imply that the balancing energy GCT for standard products will be at most one hour before real time. First, with regard to the balancing energy GCT for standard products, Art. 24(1-2) of the EB GL states: '1. As part of the proposals [for the European platforms for the exchange of balancing energy], all TSOs shall harmonize the balancing energy gate closure time for standard products at the Union level, at least for each of the following processes: [RR, $m F R R$, aFRR] 2. Balancing energy gate closure times shall: (a) be as close as possible to real time; (b) not be before the intraday cross-zonal gate closure time; (c) ensure sufficient time for the necessary balancing processes.' Second, Art. 59(3) of the CACM GL concerning the intraday cross-zonal GCT states that 'One intraday cross-zonal gate closure time shall be established for each market time unit for a given bidding zone border. It shall be at most one hour before the start of the relevant market time unit and shall take into account the relevant balancing processes in relation to operational security.' Note that the balancing gate closure time is only capped at one hour for standard products of all reserve types. The timing of the gate closure for specific products is not explicitly restricted. 


\begin{tabular}{l}
\hline $\begin{array}{l}\text { Section of this chapter, topic and relevant } \\
\text { regulation }\end{array}$ \\
\hline
\end{tabular}

\section{Section 5.2.1}

Following Regulation (EU) 2019/943, all market participants are balance responsible with the exception of three types of grid users which can still receive a derogation.

The decentralized market model in Europe entails that balancing responsibility is defined at the portfolio level, typically within a bidding zone. Some countries require market parties to balance their generation and consumption portfolios separately, while other countries allow mixed portfolios. A few countries still have a more centralized market model, which is often combined with central dispatch and balancing responsibility at the unit level.
Art. 5(1) of Regulation (EU) 2019/943 states that 'All market participants shall be responsible for the imbalances they cause in the system ("balance responsibility”).' Art. 5(2) states that 'Member States may provide derogations from balance responsibility only for: (a) demonstration projects for innovative technologies, subject to approval by the regulatory authority, provided that those derogations are limited to the time and extent necessary for achieving the demonstration purposes; (b) power-generating facilities using renewable energy sources with an installed electricity capacity of less than $400 \mathrm{~kW}$; (c) installations benefitting from support approved by the Commission under Union State Aid rules pursuant to Articles 107, 108 and 109 TFEU, and commissioned before 4 July 2019.' Art. 5(4) states that 'For power-generating facilities commissioned from 1 January 2026, point (b) of paragraph 2 shall apply only to generating installations using renewable energy sources with an installed electricity capacity of less than $200 \mathrm{~kW}$.'

Art. 54(1) states that 'each TSO shall calculate within its scheduling area or scheduling areas when appropriate the final position, the allocated volume, the imbalance adjustment and the imbalance: (a) for each balance responsible party.' Art. 110(2) states that 'where a bidding zone covers only one control area, the geographical scope of the scheduling area is equal to the bidding zone. Where a control area covers several bidding zones, the geographical scope of the scheduling area is equal to the bidding zone. Where a bidding zone covers several control areas, TSOs within that bidding zone may jointly decide to operate a common scheduling process, otherwise, each control area within that bidding zone is considered a separate scheduling area.' Furthermore, Art. 54(3) of the EB GL specifies that 'Until the implementation of the [proposal to further specify and harmonize the imbalance settlement], each TSO shall calculate the final position of a balance responsible party using one of the following approaches: (a) [the] balance responsible party has one single final position equal to the sum of its external commercial trade schedules and internal commercial trade schedules; (b) [the] balance responsible party has two final positions: the first is equal to the sum of its external commercial trade schedules and internal commercial trade schedules from generation, and the second is equal to the sum of its external commercial trade schedules and internal commercial trade schedules from consumption; (c) in a central dispatching model, a balance responsible party can have several final positions per imbalance area equal to generation schedules of power generating facilities or consumption schedules of demand facilities.' The possibility of keeping a central dispatch model is elaborated upon in the following. 


\section{Section of this chapter, topic and relevant regulation \\ Relevant articles}

There are also exceptions. A few countries still have a more centralized market model, which is often combined with central dispatch and balancing responsibility at the unit level.

\section{Section 5.2.2}

Balancing costs that cannot be allocated to BRPs are socialized by TSOs through their transmission network tariffs.

The EB GL states that all EU countries shall apply an ISP of 15 minutes by three years after the entry into force of the regulation, with some room for exceptions. Regulation (EU) 2019/943 states that the goal is a 15 -minute ISP and adds that the ISP shall not exceed 30 minutes from 1 January 2025, with no exceptions. national rules.'
The self-dispatch model is more in line with the European target model and is seen as the 'default' in the EB GL, as can be deduced from Art. 14(2): 'Each TSO shall apply a self-dispatching model for determining generation schedules and consumption schedules. TSOs that apply a central dispatching model at the time of the entry into force of this Regulation shall notify to the relevant regulatory authority ... in order to continue to apply a central dispatching model for determining generation schedules and consumption schedules. The relevant regulatory authority shall verify whether the tasks and responsibilities of the TSO are consistent with the definition [of a central dispatching model] in Article 2(18).' In EB GL Art. 2(18), a central dispatching model is defined as 'a scheduling and dispatching model where the generation schedules and consumption schedules as well as dispatching of power generating facilities and demand facilities, in reference to dispatchable facilities, are determined by a TSO within the integrated scheduling process.'

Art. 44(2) of the EB GL states that 'Each relevant regulatory authority in accordance with Article 37 of Directive 2009/72/EC shall ensure that all TSOs under its competence do not incur economic gains or losses with regard to the financial outcome of the settlement pursuant to Chapters 2, 3 and 4 of this Title [Settlement], over the regulatory period as defined by the relevant regulatory authority, and shall ensure that any positive or negative financial outcome as a result of the settlement pursuant to Chapters 2, 3 and 4 of this Title shall be passed on to network users in accordance with the applicable

Art. 53 in the EB GL covers the imbalance settlement period. Art. 53(1) states that 'By three years after the entry into force of this Regulation, all TSOs shall apply the imbalance settlement period of 15 minutes in all scheduling areas while ensuring that all boundaries of market time unit [s] shall coincide with boundaries of the imbalance settlement period.' Art. 53(2-3) explains the exemptions. Art. 8(4) of Regulation (EU) 2019/943 states that 'By 1 January 2021, the imbalance settlement period shall be 15 minutes in all scheduling areas, unless regulatory authorities have granted a derogation or an exemption. Derogations may be granted only until 31 December 2024. From 1 January 2025, the imbalance settlement period shall not exceed 30 minutes where an exemption has been granted by all the regulatory authorities within a synchronous area.' 


\begin{tabular}{|c|c|}
\hline $\begin{array}{l}\text { Section of this chapter, topic and relevant } \\
\text { regulation }\end{array}$ & Relevant articles \\
\hline $\begin{array}{l}\text { The EB GL clearly states that prices should } \\
\text { reflect the real-time value of energy and favours } \\
\text { single pricing over dual pricing. Following the } \\
\text { EB GL, dual pricing is possible as an exception. }\end{array}$ & $\begin{array}{l}\text { Art. 52(2) of the EB GL states that 'By one year after entry into force } \\
\text { of this Regulation, all TSOs shall develop a proposal to further specify } \\
\text { and harmonize at least: ... (c) the use of single imbalance pricing for all } \\
\text { imbalances ... which defines a single price for positive imbalances and } \\
\text { negative imbalances for each imbalance price area within an imbalance } \\
\text { settlement period; and (d) the definition of conditions and methodology for } \\
\text { applying dual imbalance pricing for all imbalances ... which defines one } \\
\text { price for positive imbalances and one price for negative imbalances for each } \\
\text { imbalance price area within an imbalance settlement period, encompassing: } \\
\text { (i) conditions on when a TSO may propose to its relevant regulatory authority } \\
\text {... the application of dual pricing and which justification must be provided; } \\
\text { (ii) the methodology for applying dual pricing.' Additionally, Art. } 6 \text { of } \\
\text { Regulation (EU) } 2019 / 943 \text { states that 'The imbalances shall be settled at } \\
\text { a price that reflects the real-time value of energy.' }\end{array}$ \\
\hline
\end{tabular}

\section{Section 5.3.1}

Directive (EU) 2019/944 rules out TSO ownership of energy storage assets, with possible derogations under specific circumstances.

Regulation (EU) 2019/943 contains provisions to gradually move away from yearly and monthly contracts towards shorter-term day-ahead tenders.

The EB GL states that upward and downward balancing capacity should be procured separately for FRR and RR. A temporary exception to this rule can be requested.
Art. 54(1) states that 'Transmission system operators shall not own, develop, manage or operate energy storage facilities.' Art. 54(2-5) lists the circumstances under which derogations from this rule can be granted by Member States and the specific conditions that apply in such cases.

Art. 6(9) states that '... Contracts for balancing capacity shall not be concluded more than one day before the provision of the balancing capacity and the contracting period shall be no longer than one day, unless and to the extent that the regulatory authority has approved the earlier contracting or longer contracting periods to ensure the security of supply or to improve economic efficiency.' Art. 6(9-10) specifies the conditions that apply in cases where a derogation is granted. Notwithstanding such derogations, Art. 6(11) states that 'from 1 January 2026 contract periods shall not be longer than six months' and Art. 6(12) states that 'By 1 January 2028, regulatory authorities shall report to the Commission and ACER on the share of the total capacity covered by contracts with a duration or a procurement period of longer than one day.'

Art. 32(3) states that 'The procurement of upward and downward balancing capacity for at least the frequency restoration reserves and the replacement reserves shall be carried out separately. Each TSO may submit a proposal to the relevant regulatory authority ... requesting the exemption to this requirement.' The article further lists what the proposal for exemption shall include. Art. 6(9) of Regulation (EU) 2019/943 reiterates 'The procurement of upward balancing capacity and downward balancing capacity shall be carried out separately, unless the regulatory authority approves a derogation from this principle on the basis that this would result in higher economic efficiency as demonstrated by an evaluation performed by the transmission system operator ...' 


\begin{tabular}{|c|c|}
\hline $\begin{array}{l}\text { Section of this chapter, topic and relevant } \\
\text { regulation }\end{array}$ & Relevant articles \\
\hline $\begin{array}{l}\text { The EB GL states that the balancing energy price } \\
\text { should not be predetermined in the balancing } \\
\text { capacity contract for standardized products. This } \\
\text { rule is reiterated in Regulation (EU) } 2019 / 943 \text {. } \\
\text { A temporary exception to this rule can be } \\
\text { requested. }\end{array}$ & $\begin{array}{l}\text { Art. 16(6) of the EB GL states that 'The price of the balancing energy bids } \\
\text { or integrated scheduling process bids from standard and specific products ... } \\
\text { shall not be predetermined in a contract for balancing capacity. A TSO may } \\
\text { propose an exemption to this rule ... Such an exemption shall only apply to } \\
\text { specific products ... and be accompanied with a justification demonstrating } \\
\text { higher economic efficiency.' Art. 6(2) of Regulation (EU) } 2019 / 943 \text { states that } \\
\text { 'The price of balancing energy shall not be pre-determined in contracts for } \\
\text { balancing capacity.' }\end{array}$ \\
\hline
\end{tabular}

\section{Section 5.3.2}

The EB GL prescribes the development of balancing energy markets with merit-order activation of balancing energy bids.

The EB GL makes marginal pricing mandatory for standardized products.

If all TSOs identify inefficiencies in the application of marginal pricing, they may request an amendment and propose an alternative pricing method.

The EB GL did foresee the development of a methodology for the harmonized implementation of marginal pricing in balancing energy markets.

FCR is an exception. It continues to typically be a service that combines upward and downward balancing. These reserves receive as much energy as they give so that only capacity needs to be remunerated. By its nature, the FCR product is indeed more about capacity than energy.

Arts. 19(2), 20(2) and 21(2) state that the European platforms for RR, mFRR and aFRR respectively shall apply merit-order lists.

Art. 30(1) states that 'By one year after the entry into force of this Regulation, all TSOs shall develop a proposal for a methodology to determine prices for the balancing energy that results from the activation of balancing energy bids for the frequency restoration process ... and the reserve replacement process ... Such methodology shall: (a) be based on marginal pricing (pay-as-cleared ...' Art.6(4) of Regulation (EU) 2019/943 states that 'The settlement of balancing energy for standard balancing products and specific balancing products shall be based on marginal pricing (pay-as-cleared) unless all regulatory authorities approve an alternative pricing method on the basis of a joint proposal by all transmission system operators following an analysis demonstrating that that alternative pricing method is more efficient.'

Art. 30(5) of the EB GL states that 'Where all TSOs identify inefficiencies in the application of the methodology proposed pursuant to paragraph l(a), they may request an amendment and propose a pricing method alternative to the pricing method in paragraph 1(a). In such case, all TSOs shall perform a detailed analysis demonstrating that the alternative pricing method is more efficient.'

All TSOs' (2018c) proposal on methodologies for pricing balancing energy and cross-zonal capacity used for the exchange of balancing energy or operating the imbalance netting process pursuant to Art. 30(1) and Art. 30(3) was referred to ACER in July 2019. In January 2020, ACER (2020a) published its decision, which includes the implementation of a single cross-border marginal price, which ensures that a single marginal price is propagated across all areas among which there is no congestion. At least one price is established for each market time unit, which is defined to be shorter than or equal to the imbalance settlement period. The pricing methodology also differentiates between the different products and processes.

The EB GL states in Art. 32(3) that 'The procurement of upward and downward balancing capacity for at least the frequency restoration reserves and the replacement reserves shall be carried out separately.' Hence, this is not a requirement for FCR. Additionally, Art. 46(1) states that 'each connecting TSO may calculate and settle the activated volume of balancing energy for the frequency containment process with balancing service providers ...' Hence, paying BSPs for FCR is optional. 


\begin{tabular}{l}
\hline $\begin{array}{l}\text { Section of this chapter, topic and relevant } \\
\text { regulation }\end{array}$ \\
\hline
\end{tabular}

\section{Section 5.3.3}

The EB GL mentions that an additional settlement mechanism may be developed to allocate the costs of balancing capacity.

\section{Section 5.4.2}

The EB GL requires all TSOs that are performing the automatic frequency restoration process to implement and make operational the European platform for imbalance netting. The platform shall be used to perform the imbalance netting process at least for the Continental Europe synchronous area.

At the time of writing it is foreseen that TSOs of synchronous areas other than CE performing the automatic frequency restoration process may decide to become member TSOs of the European platform at a later point in time.

\section{Section 5.4.3}

The EB GL did foresee the development of detailed methodologies for European platforms for the exchange of aFRR, mFRR and RR.
Art. 44(3) states that 'Each TSO may develop a proposal for an additional settlement mechanism separate from the imbalance settlement, to settle the procurement costs of balancing capacity ... administrative costs and other costs related to balancing.'

Art. 22(1) states that 'By six months after entry into force of this Regulation, all TSOs shall develop a proposal for the implementation framework for a European platform for the imbalance netting process.' At the time of writing, the proposal by All TSOs (2019) has not yet been approved by all NRAs. All NRAs made a second request for amendment in July 2019. Furthermore, Art. 22(5) states that 'By one year after the approval of the proposal for the implementation framework for a European platform for the imbalance netting process, all TSOs performing the [aFR process] shall implement and make operational the European platform for the imbalance netting process. They shall use the European platform to perform the imbalance netting process, at least for the Continental Europe synchronous area.'

Art. 5(4) of All TSOs' revised proposal for the implementation framework for a European platform for the imbalance netting process from September 2019 states that 'TSOs of synchronous areas other than CE performing the [automatic frequency restoration] process may decide to become member TSOs of the [imbalance netting] Platform at a later point in time, after fulfilling the relevant requirements defined in this [implementation framework] and the [imbalance netting] Platform accession roadmap.'

According to the EB GL, implementation frameworks have to be proposed by all TSOs for the European aFRR, mFRR and RR balancing platforms (Arts. $21,20,19)$. The implementation framework for RR was approved by the relevant NRAs - in December 2018 (All TSOs using RR 2018). Proposals for the implementation frameworks for aFRR and mFRR were referred to ACER in July 2019. ACER (2020b, 2020c) adopted decisions on both implementation frameworks in January 2020. 


\begin{tabular}{l} 
Section of this chapter, topic and relevant \\
regulation \\
\hline The EB GL states that the TSO-TSO model is \\
the model for exchanging balancing bids, with \\
possible exceptions under certain circumstances.
\end{tabular}

The EB GL only allows alternative proposals as temporary solutions.

\section{Section 5.4.4}

The EB GL requires each TSO to publish a balancing report at least every two years. The TSO is required to analyse the potential for exchange of balancing capacity and sharing of reserves and to put forward an explanation and justification for the procurement of balancing capacity without exchanging balancing capacity or sharing reserves.

The FCR cooperation project was formalized according to the EB GL in 2019.

The SO GL requires all TSOs in a synchronous area to jointly develop a proposal regarding the determination of LFC blocks. In many cases, the LFC block equals the LFC area, which equals the control area. The Nordics, Ireland and Great Britain, where the LFC block equals the synchronous area, are exceptions. Germany, Luxembourg and West Denmark, which form an LFC block consisting of several LFC areas, are also exceptions. The same applies to Slovenia, Croatia and Bosnia and Herzegovina and to Serbia, North Macedonia and Montenegro.
Relevant articles

Arts. 21, 20, 19 all state that the European balancing platforms shall apply a multilateral TSO-TSO model with common merit-order lists to exchange all balancing energy bids from all standard products. Art. 2(21) defines the TSO-TSO model as ' $a$ model for the exchange of balancing services where the balancing service provider provides balancing services to its connecting TSO, which then provides these balancing services to the requesting TSO.' Art. 33(2) states that 'Except in cases where the TSO-BSP model is applied pursuant to Article 35, the exchange of balancing capacity shall always be performed based on a TSO-TSO model whereby two or more TSOs establish a method for the common procurement of balancing capacity taking into account the available cross-zonal capacity and the operational limits ...' Art. 35(1) states that 'Two or more TSOs may at their initiative or at the request of their relevant regulatory authorities ... develop a proposal for the application of the TSO-BSP model' and lists what such a proposal for the application needs to include.

Art. 35(7) states that 'By four years after entry into force of this Regulation, all exchanges of balancing capacity shall be based on the TSO-TSO model. This requirement shall not apply to the TSO-BSP model for replacement reserves if one of the two involved TSOs does not operate the reserve replacement process as part of the load-frequency-control structure ...'

Art. 60(1) states that 'At least once every two years, each TSO shall publish a report on balancing covering the previous two calendar years, respecting the confidentiality of information in accordance with Article 11.' Art. 60(2) specifies the information to be included in these reports, including '(e) analyse the opportunities for the exchange of balancing capacity and sharing of reserves; (f) provide an explanation and a justification for the procurement of balancing capacity without the exchange of balancing capacity or sharing of reserves.'

In 2019, all relevant NRAs approved the methodology by all TSOs from the Netherlands, Germany, France, Belgium, Austria, Denmark and Switzerland on harmonized rules and processes for the exchange and procurement of balancing capacity for FCR using one standard product according to Art. 33 of the EB GL (50Hertz et al. 2018).

Art. 141(2) of the EB GL states that 'By 4 months after entry into force of this Regulation, all TSOs of a synchronous area shall jointly develop a common proposal regarding the determination of the LFC blocks, which shall comply with the following requirements.'

The LFC block proposal by All CE TSOs (2018) was approved in August 2018. The LFC block proposal by All Nordic TSOs (2018) was approved in September 2018 by all the relevant NRAs. 


\begin{tabular}{l} 
Section of this chapter, topic and relevant \\
regulation \\
\hline The SO GL states that FRR has to be \\
dimensioned by LFC blocks. The TSOs involved \\
then have to agree on the volume to reserve, the \\
ratio between aFRR and mFRR, and the sharing \\
of responsibility.
\end{tabular}

The SO GL sets out rules for dimensioning and sharing of RR for LFC blocks in which all TSOs make use of RR.

Regulation (EU) 2019/943 tasks the regional coordination centres (RCCs) with facilitating regional dimensioning and procurement of balancing capacity.

\section{Section 5.4.5}

The EB GL requires that all TSOs shall use the available cross-zonal capacity after the cross-zonal intraday gate closure for operating the imbalance netting process or for the exchange of balancing energy.

The EB GL foresees the possibility of reserving available transmission capacity for the exchange of balancing capacity or sharing of reserves for FRR and RR. Nothing is specified regarding imbalance netting or the exchange of balancing energy.

Available transmission capacity is already reserved for FCR. The so-called reliability margin on transmission lines is to account for FCR.
Relevant articles

Art. 157 states that all TSOs of an LFC block shall set out FRR dimensioning rules in the LFC block operational agreement. The detailed requirements in terms of dimensioning are described in the article.

Art. 160 states that all TSOs of an LFC block shall have the right to implement a reserve replacement process. The detailed requirements in terms of dimensioning are set out in the article.

Art. 37(1.j and k) lists regional sizing of reserve capacity and facilitating the regional procurement of balancing capacity as tasks of RCCs. Art. 6(7) adds that 'The dimensioning of reserve capacity shall be performed by the transmission system operators and shall be facilitated at regional level.'Art. 6(8) states that 'The procurement of balancing capacity shall be performed by the transmission system operator and may be facilitated at a regional level ...'

Art. 36(1) states that 'All TSOs shall use the available cross-zonal capacity ... for the exchange of balancing energy or for operating the imbalance netting process.'Art. 37(3) specifies thatall the TSOs in a capacity calculation region shall develop a methodology for cross-zonal capacity calculation within the balancing timeframe for the exchange of balancing energy or for operating the imbalance netting process.

Art. 36(2.c) states that cross-zonal capacity for the exchange of balancing capacity or sharing of reserves can be allocated. Art. 38(4) adds that cross-zonal capacity allocated for the exchange of balancing capacity or sharing of reserves shall be used exclusively for FRR and RR. Art. 38(1) specifies three approaches allowed to reserve cross-zonal capacity for balancing: a co-optimization approach (Art. 40), a market-based approach (Art. 41) and an approach based on economic efficiency analysis (Art. 42). The capacity reserved shall be limited depending on the way it is calculated (Art. 40(1.d), 41(2) and 42(2)). It should be noted that all TSOs exchanging balancing capacity or sharing reserves shall regularly assess whether the cross-zonal capacity allocated for the exchange of balancing capacity or sharing of reserves is still needed for that purpose as it means that this capacity is no longer offered to wholesale markets (Art. 38(8)).

Art. 38(4) states that '... The reliability margin calculated pursuant to [the CACM GL] shall be used for operating and exchanging frequency containment reserves, except on Direct Current (DC) interconnectors for which cross-zonal capacity for operating and exchanging frequency containment reserves may also be allocated in accordance with paragraph 1.' Paragraph 1 states that two or more TSOs may at their initiative or at the request of their relevant regulatory authorities make a proposal for reserving capacity for the exchange of balancing capacity according to one of the three possible methods. 


\begin{tabular}{l} 
Section of this chapter, topic and relevant \\
regulation \\
\hline The SO GL foresees that DSOs can filter \\
balancing bids from BSPs connected to \\
distribution grids. If they fear that certain bids \\
may cause congestion when called upon by \\
TSOs, they can disqualify them.
\end{tabular}

Whether filtering bids for balancing by DSOs will result in penalties paid to the TSO by the BSP and/or paid to the BSP or the TSO by the DSO is an open issue.

The SO GL allows TSOs to filter bids. They do not have to forward all the bids by BSPs to the European platforms. If they fear that certain bids may cause congestion when called upon by neighbouring TSOs, they can also disqualify these bids.
Relevant articles

According to Art. 182(5), each reserve-connecting DSO and each intermediate DSO can set temporary limits to the delivery of active power reserves before their activation. Procedures need to be agreed upon with the respective TSO. Furthermore, the SO GL specifies in Art. 182(3) that the prequalification process for balancing resources connected to the distribution level shall rely on rules concerning information exchanges and the delivery of active power reserves between the TSO, the reserve-connecting DSO and the intermediate DSOs. Each reserve-connecting DSO and each intermediate DSO, in cooperation with the TSO, shall have the right to set limits to or exclude the delivery of active power reserves located in the distribution system during the prequalification process. Art. 182(4) specifies that reasons for limitations or exclusion should be technical, such as the geographical location of the reserve-providing units and reserve-providing groups.

Art. 15(3) of the EB GL states that each TSO may, together with the reserve-connecting DSOs within the TSO's control area, jointly elaborate a methodology for allocating costs resulting from the exclusion or curtailment of active reserves connected to the distribution level.

Art. 29(14) on the activation of balancing energy bids from the common merit-order list states that 'Each TSO may declare the balancing energy bids submitted to the activation optimization function unavailable for the activation by other TSOs because they are restricted due to internal congestion or due to operational security constraints within the connecting TSO scheduling area.'Additionally, Art. 29(10) states that 'Each TSO applying a self-dispatching model and operating within a scheduling area with a local intraday gate closure time after the balancing energy gate closure time pursuant to Article 24 may develop a proposal to limit the amount of bids that is forwarded to the European platforms pursuant to Articles 19 to 21. The bids forwarded to the European platforms shall always be the cheapest bids. This proposal shall include: (a) the definition of the minimum volume that shall be forwarded to the European platforms. The minimum volume of bids submitted by the TSO shall be equal to or higher than the sum of the reserve capacity requirements for its LFC block ... and the obligations arising from the exchange of balancing capacity or sharing of reserves; (b) the rules to release the bids that are not submitted to the European platforms and the definition of the point in time at which the concerned balancing service providers shall be informed of the release of its bids.'Art. 29(11) states that TSOs shall regularly assess the impact of limiting the volume of bids sent to the European platforms and the functioning of the intraday market. 


\section{How to organize system operation and connection requirements?}

\section{Leonardo Meeus with Valerie Reif}

In this chapter, we answer four questions. First, why pay attention to detailed technicalities? Second, how to organize regional system operation? Third, how to introduce minimum technical standards? Fourth, how to proceed with the implementation of technical standards?

\subsection{WHY PAY ATTENTION TO DETAILED TECHNICALITIES?}

In this section, we revisit two iconic incidents where technical requirements came to the attention of the wider public. They involve a solar eclipse and a cruise ship.

First, the solar eclipse. ${ }^{1}$ On 20 March 2015, a solar eclipse took place that affected Europe, starting at 08.01 in the western part of Portugal and ending at 11.58 in the eastern part of Romania. It was the first solar eclipse in a power system with significant amounts of solar power. Solar photovoltaic (PV) generation gradually reduces as the sun goes down in the evening and raises back up with the sunrise. For the solar eclipse the same would happen, but much faster. In anticipation of the event, regional groups of transmission system operators (TSOs) in European Network of Transmission System Operators for Electricity (ENTSO-E) had analysed the potential impact and had looked at countermeasures that could be useful during the eclipse.

In the Nordics, the TSOs had not expected to be significantly affected by the reduction in solar PV generation. The Nordic countries decided to limit exchanges with Continental Europe (CE). The idea was to protect the Nordic system from a possible blackout in CE and also to help CE recover from a blackout if this unlikely event were to occur.

Great Britain reported a combination of different effects during the solar eclipse. In comparison with a normal day, there was a demand suppression due to people stopping their activities to be able to watch the event. There was also a demand increase due to lighting that extended beyond the eclipse. There was a loss of wind generation in addition to the loss of PV generation because solar eclipses typically reduce wind speeds. The balancing in real time by the system operated mainly relied on pumped hydro storage.

In Continental Europe, the impact was expected to be the greatest. The installed solar PV capacity in the CE synchronous area in 2015 was estimated at around $89 \mathrm{GW}$. As a protection measure, some TSOs had increased their balancing reserves. The additional balancing costs during the event ranged from $€ 40000$ for France to $€ 3.6$ million for Germany. The Italian TSO Terna had proactively removed 4400 MW of planned solar PV production from the day-ahead market. TSOs had raised awareness and informed market players of the responsibilities they had during the eclipse. Extra training of control room operators had been organized. 
During the eclipse, some TSOs strategically used pumped hydro storage plants. Teleconferences among CE TSOs were held and continuous communication took place between control rooms in $\mathrm{CE}$ and the Nordics. Ex post analysis showed that the frequency quality during the event was high. In Continental Europe, the frequency never deviated more than $48 \mathrm{mHz}$ from the set point of $50 \mathrm{~Hz}$. In Great Britain, the frequency only briefly exceeded operational targets at the very beginning of the solar eclipse at 08.00.

Second, the cruise ship. ${ }^{2}$ The story starts with the Norwegian Pearl. This ship needed to pass beneath a high-voltage line in the north of Germany during the evening of 4 November 2006. For security reasons, the line was manually disconnected by the TSO responsible. What should have been a regular operational task that had been done several times during the previous years, on this day triggered the tripping of several high-voltage lines from the north to the south of Continental Europe within a number of seconds. Lines that disconnected included interconnection lines between the German TSOs E.ON Netz and RWE, internal E.ON Netz lines (DE), internal APG lines (AT), interconnection lines between HEP (HR) and MAVIR (HU), internal HEP lines (HR) and internal MAVIR lines (HU). Finally, the interconnection lines between Morocco and Spain also tripped due to low frequency. The final report by UCTE on the system disturbance concluded that the system was operated close to its security limits and coordination and communication among the TSOs had been insufficient.

During this incident, the CE grid was split into three areas. Each experienced significant power imbalances with a frequency drop in two of the areas and an increase in the third. The TSOs completed full re-synchronization of the CE system 38 minutes after the splitting and were able to re-establish a normal situation in all European countries in less than two hours. Figure 6.1 illustrates the frequency deviations in the three $\mathrm{CE}$ areas, and the tripping of generation and shedding of load that followed.

The western area was composed of Spain, Portugal, France, Italy, Belgium, Luxemburg, the Netherlands, a part of Germany, Switzerland, a part of Austria, Slovenia and a part of Croatia. This area was facing a significant imbalance due to missing imports from the east, which led to a quick drop in frequency down to about $49.0 \mathrm{~Hz}$. At this frequency, larger generator units synchronously connected to the transmission grid were expected to stay connected. In many

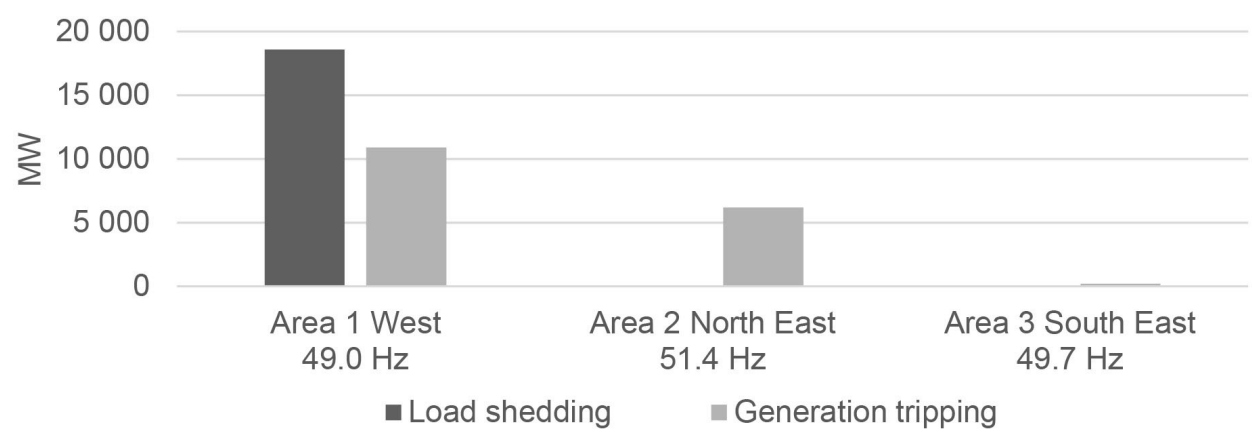

Source: Own illustration based on the UCTE (2007) report.

Figure 6.1 Capacities lost at the frequencies reached in the three areas during the split of the Continental European system on 4 November 2006 
countries, however, smaller generation units only connected to distribution grids had to be able to withstand a drop to $49.5 \mathrm{~Hz}$. In the western area, $10900 \mathrm{MW}$ of generation disconnected, mainly wind and combined heat and power (CHP) generation connected to the distribution grid. Except for one $700 \mathrm{MW}$ thermal generation unit in Spain, none of the generation that tripped was connected to the TSO networks. The load shedding that followed was aimed at solving the initial imbalance in the western area plus the increased imbalance from the generation that disconnected. In total, about $1600 \mathrm{MW}$ of pumps and $17000 \mathrm{MW}$ of consumption were shed.

The north-eastern area was composed of a part of Austria, the Czech Republic, a part of Germany, a part of Hungary, Poland, Slovakia and Ukraine. In this area, the frequency rose to $51.4 \mathrm{~Hz}$ due to a generation surplus of more than $10000 \mathrm{MW}$. Automatic predefined actions and automatic tripping of generation sensitive to high frequency values followed, mainly of wind power connected to the distribution grid, which reduced the frequency to $50.3 \mathrm{~Hz}$. The tripping of wind generation was estimated at around $6200 \mathrm{MW}$ and played a crucial role in decreasing the frequency during the first seconds of the disturbance.

The south-eastern area was composed of North Macedonia, Montenegro, a part of Croatia, Greece, Bosnia and Herzegovina, Serbia, Albania, a part of Hungary, Bulgaria and Romania. This area only faced a slight under-frequency due to a lack of power of around $770 \mathrm{MW}$, but no automatic actions or load shedding took place during the event.

The three main lessons learned can be summarized as follows. First, the cruise ship incident was a wake-up call that there are many smaller units, like wind power plants, CHP and PV, connected to the system that made the problem worse because they simply disconnected to protect their own equipment. These units also caused challenges during frequency restoration, as they automatically reconnected to the grid without any control by TSOs or DSOs when the voltage and frequency conditions were in the acceptable range. In the new decentralized system, it is not enough to manage the technical requirements of the larger units; the small ones also have a technical responsibility that needs to be defined more clearly. This responsibility cannot be limited to the national level because it will have consequences across borders. Second, an understanding emerged that system operation needs to be regionalized. The cruise ship incident was indeed the start of regional security coordination initiatives (RSCIs), which were introduced to avoid this happening again. By sharing information and having a centre that monitors different control areas, the national TSOs are better informed when taking action. Third, the preparation for the first eclipse in a power system with a significant amount of solar power worked out. Its ad hoc organization, however, triggered a debate on how such coordination can be improved in the future.

\subsection{HOW TO ORGANIZE REGIONAL SYSTEM OPERATION?}

In Chapter 3, we showed how regional system operation evolved from RSCIs to regional security coordinators (RSCs) to regional coordination centres (RCCs) following the cruise ship incident discussed here. In this section, we first discuss in more detail the tasks of these regional entities, which go beyond the capacity calculation task we focused on in Chapter 3. We then introduce the Risk Preparedness Regulation (EU) 2019/941, which is part of the Clean Energy Package (CEP) and was a response to the solar eclipse incident. 


\subsubsection{Regional System Operation Tasks}

Figure 6.2 shows how regional system operation tasks have evolved since voluntary initiatives were launched in 2008. The voluntary RSCIs offered regional coordination services and provided TSOs with an overview of electricity flows at the European regional level to complement the TSOs' own system data. The System Operation Guideline (SO GL) later formalized TSO coordination by setting out common requirements for the establishment of RSCs and for their tasks.

RSCs deliver five core operational services to support national TSO decision-making, namely coordinated capacity calculation, coordinated security analysis, delivery of the common grid model, outage planning coordination, and short- and medium-term adequacy. In addition, they are required to review the relevant TSO's system defence and restoration plans for consistency and to provide a technical report to all the TSOs involved, which in turn transmit it to the relevant regulatory authorities and to ENTSO-E to monitor implementation. RSCs also provide critical grid situation (CGS) support to TSOs, a responsibility that was introduced with the cold spell in winter 2017/2018. ${ }^{3}$ This includes support to identify the risk level at an early stage and to organize communication in advance and during the operational planning phase if a CGS is expected and appropriate remedial actions needing to be prepared. Furthermore, the SO GL defines certain annual reporting duties of RSCs to ENTSO-E.

The RCCs were created within the geographical scope of system operation regions (SORs), a new concept introduced in the CEP. A SOR spans several established concepts, including TSOs, bidding zones, bidding zone borders and capacity calculation regions. A SOR covers at least one capacity calculation region and the TSOs in a SOR are required to participate in that region's RCC. All TSOs of a SOR are required to forward a proposal for the establishment of RCCs to the relevant national regulatory authority (NRA) for approval by 5 July 2020. The proposal should include the Member State in which the RCC will be located, the TSOs participating, arrangements regarding the RCC's organization, financing, operations and liability together with an implementation plan for the RCC's entry into operation. Following approval by the NRAs, the RCCs will replace the RSCs and enter into operation by 1 July 2022.

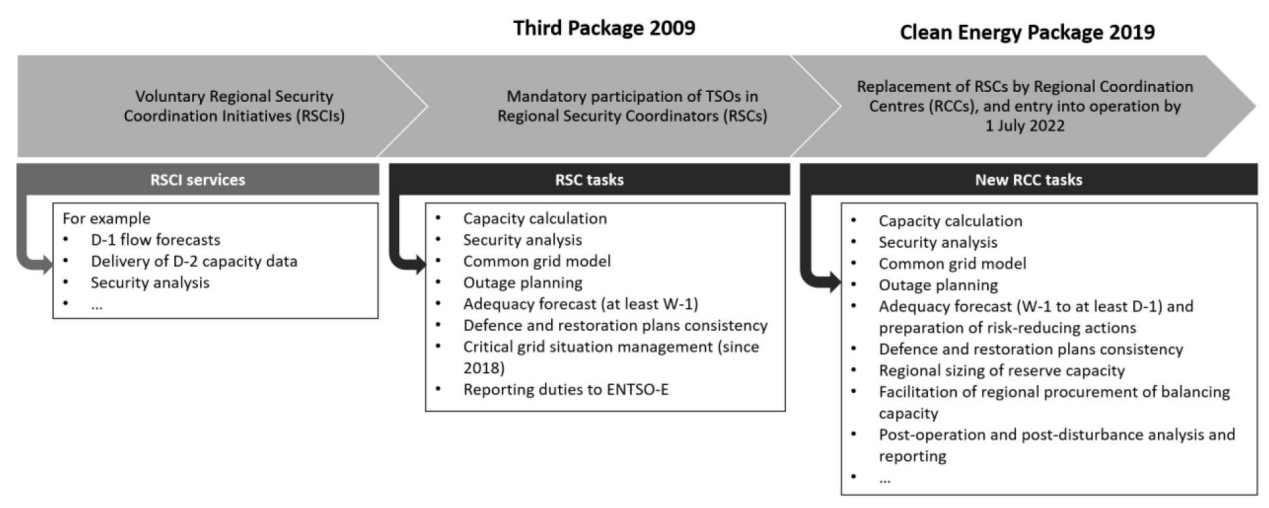

Figure 6.2 Evolution of RSCIs into RSCs and then RCCs and a selection of their tasks 
The five core operational services and the supporting tasks to ensure consistency of the TSOs' defence and restoration plans and manage CGSs will be transferred from the RSCs to the RCCs. In addition, the portfolio of RCC tasks will include new tasks listed in the CEP. In total, the CEP lists 16 tasks for RCCs. Some of the additional tasks are set by default, for example post-operation and post-disturbance analysis and reporting, regional sizing of reserve capacity and facilitation of regional procurement of balancing capacity. Other tasks to be performed by RCCs are subject to a request from TSOs - for example, support for coordination and optimization of regional restoration - or subject to delegation from ENTSO-E - for example, identification of regional electricity crisis scenarios or carrying out seasonal adequacy assessments. RCCs are to remain open to also extending their portfolio to potential future needs for TSO regional coordination.

RCCs issue coordinated actions (for capacity calculation and security analysis) and recommendations (for all other tasks) to the TSOs. The TSOs will implement coordinated actions except where this would result in the violation of security limits. In such cases, the TSO is required to file a report to the RCC and the other TSOs in the SOR. The RCC will assess the impact of the decision on the other TSOs in the SOR and may propose a different set of coordinated actions. If a TSO decides to deviate from a recommendation, it needs to submit a justification to the RCC and the other TSOs in the SOR. Note that under certain conditions the Member States in a SOR may jointly decide to grant their RCCs competence to issue coordinated actions for one or more tasks for which currently only recommendations are given.

\subsubsection{Risk Preparedness}

The Risk Preparedness Regulation (EU) 2019/941, which was adopted as part of the Clean Energy Package, sets out a common framework of rules on how to prevent, prepare for and manage electricity crises. It considers that a regional approach brings significant benefits in terms of the effectiveness of the measures implemented and the optimal use of resources, and so requires Member States to cooperate in the regional context. Regulation (EU) 2019/941 was inspired by the above solar eclipse incident.

As mentioned, RCCs are required to perform the tasks of regional relevance assigned to them in accordance with both the Risk Preparedness Regulation (EU) 2019/941 and the Electricity Regulation (EU) 2019/943. ENTSO-E can delegate to RCCs tasks relating to seasonal adequacy assessment and to the identification of regional electricity crisis scenarios. Note that delegated tasks are to be performed under the supervision of ENTSO-E. On the basis of these regional electricity crisis scenarios, Member States will establish and update their national electricity crisis scenarios, in principle every four years. These scenarios then provide the basis for the national risk-preparedness plans that each Member State is required to develop. In this regard, the geographical scope of SORs is relevant in the identification of regional electricity crisis scenarios and risk assessments.

\subsection{HOW TO INTRODUCE MINIMUM TECHNICAL STANDARDS?}

This section provides a high-level overview of the various requirements that are set out in the connection network codes (CNCs). The CNCs have their basis in the network code areas 
referred to in Regulation (EC) No 714/2009. We first discuss the types of grid user and then describe the types of requirement that apply to these grid users.

\subsubsection{Different Types of Grid User}

The two CNCs we cover in this chapter are the Requirements for Generators Network Code (RfG NC) and the Demand Connection Network Code (DC NC). They refer to different types of grid user: on the one hand power-generating modules (PGMs), which include synchronous power-generating modules (SPGMs), power park modules (PPMs) and offshore power park modules (OPPMs); on the other hand transmission-connected demand facilities, transmission-connected distribution facilities, distribution systems, including closed distribution systems, and demand units which are used by a demand facility or a closed distribution system to provide demand response services to relevant system operators. The different types of grid user are explained in Annex 6A.1. Note that in this book we do not cover the third connection code, the High Voltage Direct Current Network Code (HVDC NC).

The RfG NC applies to new PGMs which are considered significant, unless otherwise provided. PGMs that are considered significant need to comply with the requirements of the RfG NC according to the voltage level of their connection point and their maximum capacity (in MW). As Table 6.1 shows, the RfG NC differentiates between four categories of PGMs (types A to D). It only sets the upper limits ('upper limit minimum capacity threshold') of the capacity thresholds used to divide the PGMs into different types, and these limits differ across the synchronous areas. The final thresholds for the different types are set at the national level and can be lower than the maximum threshold, except for type A PGMs. It is important to note that the final thresholds chosen at the national level are also strongly dependent on national practices before the entry into force of the RfG NC.

Generally, all the RfG NC requirements for lower category PGMs (e.g. PGM type A) need to be fulfilled by those in a higher category (e.g. PGM type B). Note in this context that, despite exceptions, the thresholds are generally lower in 'smaller' synchronous areas (with a lower annual net electricity generation). This means that there are relatively more PGMs in the higher classes $(\mathrm{C}$ and $\mathrm{D})$, which generally have more stringent requirements to satisfy. Furthermore, specific requirements apply to SPGMs of types B to D, PPMs of types B to D, and AC-connected OPPMs. Last, the requirements can also differ between system operators (DSOs or TSOs) when the specific requirement is to be set by the system operator that a grid user has a grid connection contract with. All the requirements are minimum requirements, which means that PGMs can always have more enhanced capabilities if this does not negatively impact system security.

The DC NC splits the different requirements into two groups: first, requirements for transmission-connected demand facilities, transmission-connected distribution facilities and distribution systems, including closed distribution systems; second, requirements for demand units used by a demand facility or a closed distribution system to provide demand response services to relevant system operators. Depending on the voltage level of the connection, the requirements can differ within these two groups. 
Table 6.1 Limits for thresholds for different types of power-generating modules

\begin{tabular}{|c|c|c|c|c|c|}
\hline Type & Threshold & & & & \\
\hline \multirow[t]{2}{*}{ A } & $\geq 0.8 \mathrm{~kW}$ & & & & \\
\hline & Continental Europe & Nordic & Great Britain & Ireland & Baltic \\
\hline B & $1 \mathrm{MW}$ & $1 \mathrm{MW}$ & $1.5 \mathrm{MW}$ & $0.1 \mathrm{MW}$ & $0.5 \mathrm{MW}$ \\
\hline $\mathrm{C}$ & $50 \mathrm{MW}$ & $50 \mathrm{MW}$ & $10 \mathrm{MW}$ & $5 \mathrm{MW}$ & $10 \mathrm{MW}$ \\
\hline $\mathrm{D}^{*}$ & $75 \mathrm{MW}$ & $75 \mathrm{MW}$ & $30 \mathrm{MW}$ & $10 \mathrm{MW}$ & $15 \mathrm{MW}$ \\
\hline
\end{tabular}

Note: $\quad *$ PGMs with a connection point $\geq 110 \mathrm{kV}$ are categorized as type D.

Source: $\quad$ RfG NC, Art. 5.

\subsubsection{Different Types of Requirement}

The technical requirements in the $\mathrm{CNCs}$ are divided into mandatory and non-mandatory requirements, each of which can be either exhaustive or non-exhaustive. Exhaustive requirements do not need further national specification, while non-exhaustive requirements need further specification at the national level for their entire application either in general or as a site-specific choice, and within the boundaries set at the regional level. In other words, non-exhaustive requirements do not provide for a full harmonization. Mandatory requirements are to be applied in all EU Member States and other countries which implement the CNCs, while for non-mandatory requirements countries can decide whether they want to introduce such a requirement either in general at the national level or as a site-specific choice. ${ }^{4}$

Most of the requirements described in the RfG $\mathrm{NC}$ and $\mathrm{DC} \mathrm{NC}$ are non-exhaustive requirements. The specification of non-exhaustive requirements at the national level may require updating and amending technical specifications, such as existing national grid codes. Therefore, a transition period from the date of entry into force of the CNCs to their application is foreseen, as is illustrated in Box 6.1.

\section{BOX 6.1 RfG NC AND DC NC TIMELINES AND NATIONAL IMPLEMENTATION PROCESSES}

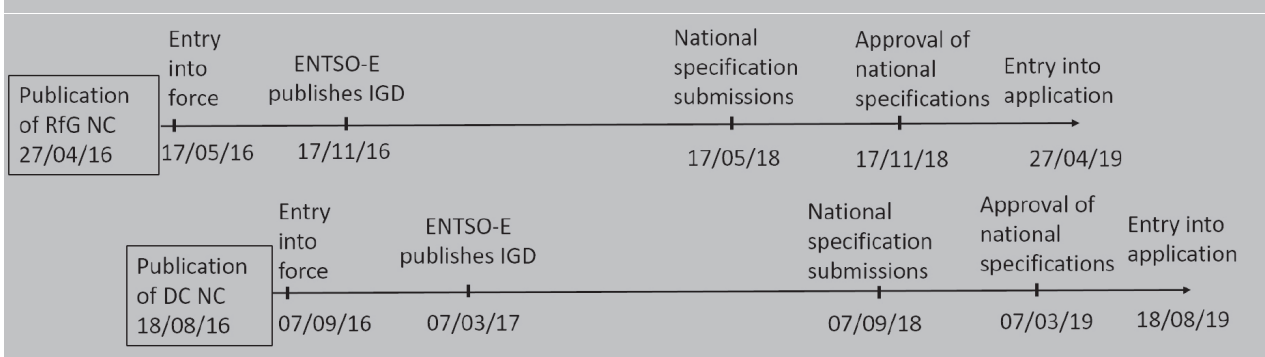

Figure 6.3 Timelines from publication to entry into application of RfG NC and DC NC

The Member States had the obligation to implement the CNCs at the national level no later than three years after they were published, as is shown in Figure 6.3. Within this timeframe, the relevant system operator, which in most cases was the TSO in coordination with the 
DSOs, had two years to define and submit a national specification of the non-exhaustive requirements for approval by the competent entity. In order to support implementation at the national level and in line with the legal requirements in the CNCs, ENTSO-E had an obligation to provide non-binding implementation guidance documents (IGDs). For reasons of transparency, ENTSO-E monitored the CNC implementation process across the Member States. Three years after the publication of the CNCs, all the parties affected had to comply with the regulations. The CNC implementation process did not end with the entry into application of the individual codes. On the contrary, all the relevant stakeholders have to continually analyse the technical details of the codes and monitor whether the requirements need to be revised in the light of system needs in future grid scenarios with increased penetration of renewable energy sources.

Below we introduce the different types of non-exhaustive requirements related to frequency issues, voltage issues, robustness, system restoration and general system management. ${ }^{5}$

First, there are three types of frequency-related requirements. The first type is related to system inertia. As was explained in Chapter 1, the inertia of a system relates to the magnitude of frequency deviations due to sudden imbalances between load and generation. If the system inertia is low, a small sudden difference between load and generation causes a high frequency deviation, and vice versa. Therefore, the RfG NC gives the relevant TSOs the right to specify that PPMs of types C and D must be capable of providing synthetic inertia during very fast frequency deviations to replace the effect of the inertia traditionally provided by SPGMs. The level of inertia influences the frequency gradient (rate of change of frequency, RoCoF) and therefore the stability of the power system. The RfG NC states that all types of PGM must be capable of staying connected to the network and operating at RoCoFs up to a value specified by the relevant TSO. In relation to this, the RfG NC and the SO GL address ramping constraints. The DC NC states that demand units offering demand response must have the withstand capability to not disconnect from the system under a RoCoF up to a value specified by the relevant TSO.

A second type of frequency-related requirement specifies certain frequency ranges within which PGMs, transmission-connected demand facilities, transmission-connected distribution facilities, distribution systems and demand units providing demand response services should be able to withstand frequency disturbances for a certain period of time without disconnecting from the grid, as is shown in Table 6.2. This is important to avoid a sudden loss of a large group of generators which could then initiate a cascading failure. The trade-off here is that if PGMs or demand facilities are exposed to over-frequency or under-frequency for too long their equipment can be damaged. Frequency ranges and duration of connection requirements are defined by synchronous area. The RfG NC foresees that the relevant system operator in coordination with the owner of the PGM may agree on wider frequency ranges, longer minimum times for operation or specific requirements for combined frequency and voltage deviations. The DC NC states that the owner of a transmission-connected demand facility or the DSO may agree with the relevant TSO on wider frequency ranges or minimum times for operation.

A third type of frequency-related requirement relates to the ability of PGMs and demand units providing demand response services to contain or compensate for a frequency drop or rise by regulating the active power output or input. This last type is related to the balancing 
Table 6.2 Frequency ranges and duration of connection requirements by synchronous area for PGMs of all types and transmission-connected demand facilities, transmission-connected distribution facilities, distribution systems and demand units providing demand response services

\begin{tabular}{|c|c|c|c|c|c|}
\hline Frequency range & $\begin{array}{l}\text { Continental } \\
\text { Europe }\end{array}$ & Nordic & Great Britain & Ireland & Baltic \\
\hline $47.0-47.5 \mathrm{~Hz}$ & - & - & $20 s$ & - & - \\
\hline $47.5-48.5 \mathrm{~Hz}$ & $\begin{array}{l}\text { Specified by each } \\
\text { TSO, >=30 min }\end{array}$ & $30 \mathrm{~min}$ & $90 \mathrm{~min}$ & $90 \mathrm{~min}$ & $\begin{array}{l}\text { Specified by each } \\
\text { TSO, }>=30 \mathrm{~min}\end{array}$ \\
\hline $48.5-49.0 \mathrm{~Hz}$ & $\begin{array}{l}\text { Specified by each } \\
\text { TSO, >=period for } \\
47.5-48.5 \mathrm{~Hz}\end{array}$ & $\begin{array}{l}\text { Specified by each } \\
\text { TSO, }>=30 \mathrm{~min}\end{array}$ & $\begin{array}{l}\text { Specified by each } \\
\text { TSO, }>=90 \mathrm{~min}\end{array}$ & $\begin{array}{l}\text { Specified by each } \\
\text { TSO, >=90 min }\end{array}$ & $\begin{array}{l}\text { Specified by each } \\
\text { TSO, >=period for } \\
47.5-48.5 \mathrm{~Hz}\end{array}$ \\
\hline $49.0-51.0 \mathrm{~Hz}$ & Unlimited & Unlimited & Unlimited & Unlimited & Unlimited \\
\hline $51.0-51.5 \mathrm{~Hz}$ & $30 \mathrm{~min}$ & $30 \mathrm{~min}$ & $90 \mathrm{~min}$ & $90 \min$ & $\begin{array}{l}\text { Specified by each } \\
\text { TSO, }>=30 \mathrm{~min}\end{array}$ \\
\hline $51.5-52.0 \mathrm{~Hz}$ & - & - & $15 \mathrm{~min}$ & - & - \\
\hline
\end{tabular}

Source: $\quad$ RfG NC, Art. 13(1.a.i); DC NC, Art. 28(2.a), Art. 29(2.a) and Annex I.

mechanism (see Chapter 5) and includes requirements for both for operation under normal conditions and for operation in emergency situations, such as operation in frequency sensitivity mode. Frequency sensitive mode is the PGM operating mode in which the active power output changes in response to a change in the system frequency so as to assist with recovery to the target frequency.

Second, there are three types of voltage-related requirements. An important difference with respect to frequency is that voltage issues have to be dealt with locally, although they can also have a cross-border impact if not dealt with properly. Frequency can be controlled by adjusting active power consumption or generation, while voltage is controlled by reactive power consumption or generation. A first type of voltage-related requirements is reactive power requirements. The DC NC specifies these for transmission-connected demand facilities and transmission-connected distribution systems. A second type specifies certain voltage ranges within which PGMs of type D, transmission-connected demand facilities, transmission-connected distribution facilities and transmission-connected distribution systems should remain connected to the grid for certain time periods. As with frequency ranges and their duration, the time period chosen for remaining connected during a voltage deviation should be long enough for the TSO to take the necessary mitigating actions and short enough to limit constraints on grid user equipment. A third type of voltage-related requirements is reactive power capabilities of PGMs of types B to D and demand units providing demand response services to contain or compensate for voltage deviations from the reference values. As with frequency, this last type covers both actions taken under normal system operation and actions taken in emergency situations.

Third, there are robustness-related requirements. Robustness or resilience can be defined as the ability to cope with disturbances without loss of proper functioning. In the context of the $\mathrm{CNCs}$, this means the ability to cope with disturbances and to help prevent any major disruption or to facilitate restoration of the system after a collapse. More specifically, generation and 
Table 6.3 Compliance of different types of power-generating modules with a selection of technical requirements as described in the RfG NC

\begin{tabular}{lllll}
\hline & Type A & Type B & Type C & Type D \\
\hline Frequency ranges & $\mathrm{x}$ & $\mathrm{x}$ & $\mathrm{x}$ & $\mathrm{x}$ \\
Fault-ride-through capability & & $\mathrm{x}$ & $\mathrm{x}$ & $\mathrm{x}$ \\
Operation in frequency sensitivity mode & & $\mathrm{x}$ & $\mathrm{x}$ \\
Voltage ranges & & & $\mathrm{x}$ \\
\hline
\end{tabular}

demand units are required to remain connected to the grid after a sudden voltage dip to help prevent any major disruption or to facilitate restoration of the system after a collapse. Voltage dips in high-voltage transmission grids are caused by switching activities which result in a redistribution of energy flows happening as a result of a short circuit or a planned disconnection. The RfG NC sets out requirements for PGMs of types B to D to remain connected to the network and operate through periods of low voltage at the connection point caused by secured faults. This is the so-called fault-ride-through capability. Moreover, SPGMs of types B to D are required to contribute to minimizing the spread of a voltage dip by recovering their active power output quickly following a voltage disturbance. Similar specifications exist for PPMs of types B to D. Relevant in this regard are also the requirements set out in the DC NC for transmission-connected demand facilities and transmission-connected distribution systems to withstand high short-circuit currents to avoid a potential cascading disconnection of grid users.

Fourth, there are system-restoration-related requirements. In Section 6.2, we introduced the system defence and restoration plans that TSOs are required to establish. It is important to have PGMs that do not need any external supply of electrical energy to restart after a blackout takes place. This is referred to as black start capability. Most PGMs do not have this capability. The RfG NC does not mandate black start capability for PGMs but refers to the right of Member States and TSOs to require owners of type C and D PGMs to equip their PGMs with a black start capability under certain conditions. Next to black start capability, the RfG NC also includes system-restoration-related requirements as regards island operation, reconnection and re-synchronization. For all three types of requirements related to system restoration, the $\mathrm{CNCs}$ set out some obligations while other requirements are to be defined by the relevant system operator.

Fifth, there are general system management related requirements. These include requirements related to information exchange with the relevant system operator, the settings of control and protection schemes, instrumentation needed to provide fault recording and monitor dynamic system behaviour and simulation models needed to test PGM compliance with the different technical requirements. These requirements can be different for different types of PGMs and for generation and demand units.

Note that the higher the classification of the PGM, the more requirements it has to satisfy, and the more stringent these requirements are, which is illustrated in Table 6.3. We will come back to this when we discuss open issues. 


\subsection{HOW TO PROCEED WITH THE IMPLEMENTATION OF TECHNICAL STANDARDS?}

In this section, we first discuss ongoing $\mathrm{CNC}$ implementation issues and then look at the case of energy storage.

\subsubsection{Implementation Issues}

Here we discuss four implementation issues regarding CNCs: the compliance by existing versus new connections, multiple connections versus a single connection, derogations at the national level and requirements versus markets.

A first open issue is compliance by new versus existing connections. The DC NC applies to new transmission-connected demand facilities, new transmission-connected distribution facilities, new distribution systems, including closed distribution systems, and new demand units used by a demand facility or a closed distribution system to provide demand response services to relevant system operators. As mentioned in Section 6.3.1, the RfG NC applies to PGMs that are new and significant. Significant means a PGM capacity larger than or equal to $0.8 \mathrm{~kW}$. PGMs and transmission-connected demand facilities, transmission-connected distribution facilities, distribution systems and demand units used to provide demand response services are considered new if the final and binding contract for the purchase of the main generating plant, demand equipment or demand unit is not finalized by two years after the entry into force of the relevant regulation. However, the RfG and the DC NC can also exceptionally apply to existing connections. A first exception is that TSOs can propose to the relevant regulatory authority to make existing PGMs, existing transmission-connected demand facilities, existing transmission-connected distribution facilities, existing distribution systems or existing demand units subject to all or some of the requirements of the relevant regulation. Such retroactive action can be done if the TSO deems that it faces significant factual changes in circumstances, such as an evolution of system requirements (including the penetration of renewable energy sources, smart grids, distributed generation or demand response), and the regulator agrees with it. A second exception is that, after notification by the system operator, the relevant regulatory authority can decide that existing PGMs of types $\mathrm{C}$ or D, existing transmission-connected demand facilities, existing transmission-connected distribution facilities, existing distribution systems or existing demand units have been modernized substantially and therefore need a revised or new connection agreement. How this will be handled at the Member State level remains to be seen.

A second open issue is multiple connections versus a single connection. As Table 6.3 shows, the classification of different types of PGMs impacts on how stringent the requirements are that the PGM has to comply with. A key question is whether a project can request multiple connections. Consider a wind park with ten $3.5 \mathrm{MW}$ wind turbines. If the project is treated as a single $35 \mathrm{MW}$ connection, it will be classified as a type C or even type D generation unit, depending on the control area. If it is treated as ten 3.5 MW connections, they will be classified as ten type B generation units. In the second scenario, the project will have to comply with less stringent requirements. The RfG NC states that classification should be based on size and the effect on the overall system. Differences exist between synchronously and non-synchronously connected generation units. For synchronous generators, the RfG NC 
states that the PGM capacity should be based on machine size and include all the components of a generating facility that normally run indivisibly. This means that one large turbine equals one generation unit. For non-synchronous generation units, the RfG NC is less clear. It states that non-synchronously connected PGMs should be assessed on their aggregated capacity where they are collected together to form an economic unit and where they have a single connection point. It all comes down to the definition of economic unit and single connection point, which is left to Member States, so how this will be handled in detail is an open issue. Note that the DC NC does not define different categories with different technical requirements, so this issue does not apply to demand connections. However, the DC NC clarifies that demand connections with more than one demand unit are to be considered as one demand unit if they cannot be operated independently from each other or can reasonably be considered in a combined manner.

A third open issue is derogations at the national level. Three aspects of derogations are worth noting. First, the criteria for granting derogations are defined by the NRAs. The European Commission may require an NRA to amend the criteria if they are not in line with the CNC. Additionally, if an NRA deems that it is necessary due to a change in circumstances relating to an evolution of system requirements, it may review and amend the criteria for granting derogations at most once a year. Second, two types of derogations exist depending on who files the request. Derogations can be requested by a PGM or demand facility owner or prospective owner. They can also be requested by a system operator for classes of PGMs or for multiple demand facilities. In such a case, the system operator would consider the need for more stringent requirements than those provided by the $\mathrm{CNC}$ to guarantee secure system operation. Third, all decisions regarding derogations granted or refused are notified to ACER and kept in a regularly updated register. ACER and the European Commission both have the possibility of issuing a reasoned recommendation to a regulatory authority to revoke a derogation due to a lack of justification. It remains to be seen to what extent derogations will be used.

A fourth open issue is requirements versus markets. Non-frequency ancillary services may follow a similar path to frequency ancillary services. As was discussed in Chapter 5, frequency ancillary services, or balancing, evolved from technical mechanisms into markets. As discussed in this chapter, non-frequency ancillary services can be treated as technical requirements in connection agreements, but they can also evolve into services that are procured in markets. In some countries, TSOs have already started to define and procure services such as black start capabilities and voltage control. The power system of the future might also require the definition of new requirements and/or services. Inertia might also become a scarce resource in larger synchronous systems as we move towards a power system with more non-synchronous generation units. Regulation (EU) 2019/943 foresees a second generation of network codes which will include rules on the non-discriminatory transparent provision of non-frequency ancillary services, including rules on voltage control, inertia, black start capability and others. To what extent these rules will lead to new requirements or markets is an open issue. ${ }^{6}$

\subsubsection{The Case of Energy Storage}

Two aspects of current discussions around energy storage are worth noting. First, with the exception of pump-storage power-generating modules, which were included in the RfG NC, the first generation of network codes does not cover energy storage. Member States are 
therefore free to follow one of three paths. They can treat storage under one of the existing asset classes of generation or demand and apply the relevant requirements of the relevant connection code; they can create a new asset class and create a separate grid code for energy storage; or they can also do something in between by starting from one of the existing codes and making a few adaptations to reflect the specificities of storage technologies.

Second, Regulation (EU) 2019/943 foresees a second generation of network codes to specify rules in relation to demand response, including rules on aggregation, energy storage and demand curtailment. We do not yet know whether these rules will be more like market guidelines alongside the existing CACM GL, FCA GL and EB GL or whether they will become grid connection network codes alongside the RfG NC, DC NC and HVDC NC.

\subsection{CONCLUSION}

In this chapter on how to organize system operation and connection requirements we have answered four questions. First, why pay attention to detailed technicalities? The technical requirements of grid connections came to the attention of the general public when we had a near-blackout experience triggered by a cruise ship in Germany. The first lesson learned was that system operation needs to be regionalized. This was indeed the start of voluntary initiatives that were later formalized in the SO GL and raised to the next level with the Clean Energy Package. The second lesson learned was that we need stricter requirements for new smaller units connected to the power system. The preparations for the first solar eclipse in a power system with significant amounts of solar power also inspired a more formal risk impact assessment process at the European level.

Second, how to organize regional system operation? TSOs remain the only system operators at the transmission level, but the roles of regional entities have been increasing with the changes from RSCIs to RSCs and RCCs. The Risk Preparedness Regulation, which was adopted as part of the Clean Energy Package, introduced a regional approach for preventing, preparing for and managing electricity crises, such as solar eclipses.

Third, how to introduce minimum technical standards? The connection network codes set out technical requirements for connecting different users and technologies to the grid. The Member States were obliged to implement the connection network codes at the national level no later than three years after their publication. Many non-exhaustive technical requirements had to be defined and tough choices had to be made. The requirements will continue to evolve with the power system.

Fourth, how to proceed with the implementation of technical standards? The new technical requirements mainly apply to new connections, unless the TSO successfully argues that the system needs a retroactive intervention. TSOs and grid users can also apply for derogations from the requirements that have been set, and grid users might try to escape some of the requirements by applying for multiple connections instead of a single bigger connection for a certain project. Requirements could also be at least partly replaced by markets remunerating grid users for the non-frequency ancillary services they provide. These are all open issues. The second generation of network codes might also play a role, especially in energy storage, which has not yet been addressed by the first generation of codes. 


\section{NOTES}

1. This account of the solar eclipse is mostly based on the impact analysis by ENTSO-E (2015) and a report by ENTSO-E and SolarPower Europe (2015).

2. The incident is discussed in detail in UCTE (2007). See also the report in German by the German national regulatory authority Bundesnetzagentur (2007). Researchers from the Ecole Centrale de Lille (FR) published a video of the event, which is available on YouTube under the title 'System Disturbance in EUROPE (2006)'.

3. The RSC task of critical grid situation management is not mandated by the network codes but was introduced by ENTSO-E $(2018,2019)$ to better tackle cold spells during winter.

4. ENTSO-E (2016a) explains the differentiation and the relationship between mandatory/ non-mandatory and exhaustive/non-exhaustive requirements in a guidance document for national implementation of the CNCs.

5. Note that we do not differentiate between mandatory and non-mandatory non-exhaustive requirements. In its guidance document, ENTSO-E (2016b) gives an overview of non-exhaustive requirements in the CNCs and specifies which parameters are mandatory and which are non-mandatory.

6. For a long time there has been a debate in academia on whether in the presence of voltage constraints reactive power prices should also be determined in addition to active power prices. For example, Hogan (1993) claims that reactive power prices complementing active power prices are needed, while Kahn and Baldick (1994) state that 'reactive power is cheap', and that reactive power pricing can be very hard in practice. Anaya and Pollitt (2018) explore the international experience of system operators procuring reactive power in different jurisdictions, including Australia, the United States and Great Britain.

\section{REFERENCES}

Anaya, K. L. and M. G. Pollitt (2018), 'Reactive power procurement: Lessons from three leading countries', Cambridge Working Papers in Economics: 1854.

Bundesnetzagentur (2007), 'Bericht der Bundesnetzagentur für Elektrizität, Gas, Telekommunikation, Post und Eisenbahnen über die Systemstörung im deutschen und europäischen Verbundsystem am 4. November 2006' ['Court of Justice of the European Communities for Electricity, Gas, Telecommunications, Post and Electricity Transmission Systems in the European Union and in the European Union on 4 November 2006'].

ENTSO-E (2015), 'Solar Eclipse 2015. Impact Analysis'.

ENTSO-E (2016a), 'Making Non-Mandatory Requirements at European Level Mandatory at National Level. ENTSO-E Guidance Document for National Implementation for Network Codes on Grid Connection'.

ENTSO-E (2016b), 'Parameters of Non-Exhaustive Requirements. ENTSO-E Guidance Document for National Implementation for Network Codes on Grid Connection'.

ENTSO-E (2018), 'Annual Report 2017'.

ENTSO-E (2019), 'Enhanced TSO Regional Coordination for Europe: Act Locally, Coordinate Regionally, Think European'.

ENTSO-E and SolarPower Europe (2015), 'Solar eclipse March 2015: The successful stress test of Europe's power grid - more ahead', Policy Brief, 15 July.

Hogan, W. W. (1993), 'Markets in real electric networks require reactive prices', Energy Journal, 14 (3), 171-200.

Kahn, E. and R. Baldick (1994), 'Reactive power is a cheap constraint', Energy Journal, 15 (4), 191-201.

Netbeheer Nederland (2019), 'DCC Compliance Verification. Transmission Connected Demand Facilities, Transmission Connected Distribution Facilities and Distribution Systems. Version 1.0. Valid from 18 August 2019'.

UCTE (2007), 'Final Report - System Disturbance on 4 November 2006'. 


\section{A.1 ANNEX: TYPES OF GRID USERS IN THE RfG AND DC NC}

\section{Types of Grid Users in the RfG NC}

The RfG NC is applicable to power-generating modules, which means either synchronous power-generating modules or power park modules. An offshore power park module is a type of power park module that is specified on the basis of its location. According to the definitions in Article 2 of the RfG NC,

- A power-generating module (PGM) means 'either a synchronous power-generating module or a power park module.'

- A synchronous power-generating module (SPGM) means 'an indivisible set of installations which can generate electrical energy such that the frequency of the generated voltage, the generator speed and the frequency of network voltage are in a constant ratio and thus in synchronism.'

- A power park module (PPM) means 'a unit or an ensemble of units generating electricity, which is either non-synchronously connected to the network or connected through power electronics, and that also has a single connection point to a transmission system, distribution system including closed distribution system or HVDC system.'

- An offshore power park module (OPPM) means 'a power park module located offshore with an offshore connection point.'

A conventional power plant falls under the definition of an SPGM. An asynchronously connected wind power plant is treated as a non-synchronously connected PPM. Solar photovoltaic or electricity storage devices connected through an inverter are treated as PPMs connected through power electronics. An AC-connected offshore wind power plant is treated as an OPPM. Note, however, that an AC-connected onshore wind power plant is treated as a PPM. Note also that an offshore wind power plant that is connected through an HVDC system is treated as a DC-connected PPM in the HVDC NC.

\section{Types of Grid Users in the DC NC}

The DC NC is applicable to what are defined in its Article 2 as

- Transmission-connected demand facilities, which means 'a demand facility which has a connection point to a transmission system', with a demand facility being defined as 'a facility which consumes electrical energy and is connected at one or more connection points to the transmission or distribution system. A distribution system and/or auxiliary supplies of a power generating module do not constitute a demand facility.'

- Transmission-connected distribution facilities, which means 'a distribution system connection or the electrical plant and equipment used at the connection to the transmission system.'

- Distribution systems, including closed distribution systems, with closed distribution systems being defined as 'a distribution system classified pursuant to Article 28 of Directive 2009/72/EC as a closed distribution system by national regulatory authorities or by other competent authorities, where so provided by the Member State, which distributes 
electricity within a geographically confined industrial, commercial or shared services site and does not supply household customers, without prejudice to incidental use by a small number of households located within the area served by the system and with employment or similar associations with the owner of the system.'

- Demand units used by a demand facility or a closed distribution system to provide demand response services to relevant system operators and relevant TSOs, with a demand unit being defined as an 'indivisible set of installations containing equipment which can be actively controlled by a demand facility owner or by a CDSO [closed distribution system operator], either individually or commonly as part of demand aggregation through a third party.' The relevant system operator is defined in the RfG NC as 'the transmission system operator or distribution system operator to whose system a power-generating module, demand facility, distribution system or HVDC system is or will be connected.'

It is important to note that the DC NC differentiates between 'system', 'facility' and 'unit'. Figure 6A.1 illustrates the use of the terms 'system' and 'facility' in the DC NC.

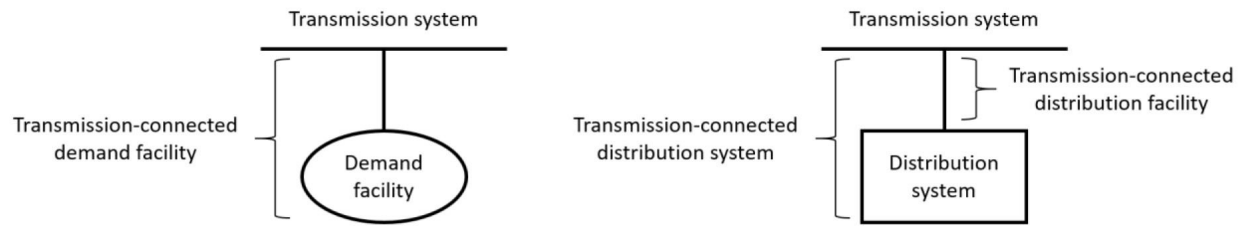

Source: $\quad$ Modified from Netbeheer Nederland (2019).

Figure 6A.1 Illustration of the terms 'demand facility', 'distribution facility' and 'distribution system' as used in the DC NC 


\section{A.2 ANNEX: REGULATORY GUIDE}

\section{Table 6A.1 Regulatory guide}

Section of this chapter, topic and relevant regulation

\section{Section 6.2}

The SO GL formalized TSO coordination by setting out common requirements for the establishment of RSCs and for their tasks.

RSCs deliver five core operational services to support national TSO decision-making.

RSCs are required to review the relevant TSO's system defence and restoration plans for consistency and to provide a technical report to all the TSOs involved.

The SO GL defines the annual reporting duties of RSCs to ENTSO-E.

RCCs are created within the geographical scope of system operation regions (SORs), a new concept introduced in the CEP.

All the TSOs in an SOR were required to forward a proposal for the establishment of RCCs for approval to the relevant NRAs by 5 July 2020.

Following approval by the NRAs, the RCCs will replace the RSCs and will enter into operation by 1 July 2022
Relevant articles

\author{
Relevant articles
}

Recital 6 states that the rules set out in the SO GL require an institutional framework for enhanced coordination between TSOs, including mandatory participation of TSOs in RSCs. Furthermore, the common requirements for the establishment of RSCs and for their tasks constitute a first step towards further regional coordination and integration of system operation.

Art. 77(3) lists four tasks for RSCs: (a) regional operational security coordination; (b) building a common grid model; (c) regional outage coordination; and (d) regional adequacy assessment. A fifth task, coordinated capacity calculation, is indirectly mentioned in the CACM GL. Recital 6 of the CACM GL states that 'capacity calculation for the day-ahead and intraday should be coordinated at least at regional level.'

Art. 6 of the ER NC states that TSOs shall consult with RSCs to assess the consistency of measures defined in the system defence and restoration plans within the entire synchronous area concerned. It states furthermore that within three months of the submission of the measures by each TSO to the relevant RSC(s) the RSC(s) shall produce a technical report on the consistency of the measures based on the criteria set out in paragraph 2 of Art. 6. The report is to be transmitted without delay to all the TSOs involved, who will in turn transmit it to the relevant regulatory authorities and ENTSO-E.

Art. 17 states that 'By 1 March, each regional security coordinator shall prepare an annual report and submit it to ENTSO for Electricity', providing information on the tasks it performs.

Art. 36 of Regulation (EU) 2019/943 states that 'By 5 January 2020 the ENTSO for Electricity shall submit to ACER a proposal specifying which transmission system operators, bidding zones, bidding zone borders, capacity calculation regions and outage coordination regions are covered by each of the system operation regions.' Furthermore, the 'transmission system operators of a system operation region shall participate in the regional coordination centre established in that region.'

Art. 35 of Regulation (EU) 2019/943 states that 'By 5 July 2020, all transmission system operators of a system operation region shall submit a proposal for the establishment of regional coordination centres to the regulatory authorities concerned ...'

Art. 35 of Regulation (EU) 2019/943 states that 'Following approval by regulatory authorities of the proposal in paragraph 1, the regional coordination centres shall replace the regional security coordinators established pursuant to the system operation guideline ... and shall enter into operation by 1 July 2022.' 


\begin{tabular}{l} 
Section of this chapter, topic and relevant \\
regulation \\
\hline The CEP lists 16 tasks for RCCs. \\
RCCs shall remain open to extending their \\
portfolio to potential future needs for TSO \\
regional coordination.
\end{tabular}

RSCs issue coordinated actions to the TSOs.

ENTSO-E can delegate tasks relating to seasonal adequacy assessment and the identification of regional electricity crisis scenarios to RCCs.

On the basis of these regional electricity crisis scenarios, Member States shall establish and update their national electricity crisis scenarios, in principle every four years.

\section{Section 6.3}

The RfG NC applies to new PGMs which are considered significant, unless otherwise provided. PGMs that are considered significant need to comply with the requirements of the RfG NC according to the voltage level of their connection point and their maximum capacity (in MW).
Relevant articles

Art. 37 of Regulation (EU) 2019/943 lists the tasks for regional coordination centres, which are set out in more detail in Annex I of the same regulation.

Art. 37 of Regulation (EU) 2019/943 states that 'On the basis of a proposal by the Commission or a Member State, the Committee established by Art. 68 of Directive (EU) 2019/944 shall issue an opinion on the assignment of new advisory tasks to regional coordination centres. Where that Committee issues a favourable opinion on the assignment of new advisory tasks, the regional coordination centres shall carry out those tasks on the basis of a proposal developed by the ENTSO for Electricity and approved by ACER in accordance with the procedure set out in Art. 27.' In this respect, Art. 68 of Directive (EU) 2019/944 sets out the committee procedure, in which the 'Commission shall be assisted by a committee [composed of representatives of the Member States and chaired by a representative of the Commission] within the meaning of Regulation (EU) No 182/2011.'

Art. 42 of Regulation (EU) 2019/943 states that 'Regional coordination centres shall issue coordinated actions to the transmission system operators ...'

Art. 42 also sets out the procedures described in Subsection 6.2.1 regarding the implementation of coordinated actions issued by the RSCs.

Art. 6 of the Risk Preparedness Regulation (EU) 2019/941 states that ENTSO-E ' may delegate tasks relating to the identification of regional electricity crisis scenarios to the regional coordination centres.' Art. 9 states that ENTSO-E 'may delegate tasks relating to the [seasonal] adequacy assessments to regional coordination centres.'

Art. 7 of the Risk Preparedness Regulation (EU) 2019/941 states that national electricity crisis scenarios shall be identified on the basis of at least the risks listed in Art. 5 of the same regulation for the identification of regional electricity crisis scenarios. Furthermore, 'Member States shall update the national electricity crisis scenarios every four years, unless circumstances warrant more frequent updates.'

Art. 3 states that 'the connection requirements set out in this Regulation shall apply to new power-generating modules which are considered significant in accordance with Art. 5, unless otherwise provided.' Art. 5 states that 'The power-generating modules shall comply with the requirements on the basis of the voltage level of their connection point and their maximum capacity according to the categories set out in paragraph 2' - types A to D. 


\begin{tabular}{l} 
Section of this chapter, topic and relevant \\
regulation \\
\hline The RfG NC only sets the upper limits ('upper \\
limit minimum capacity thresholds') for the \\
capacity thresholds used to divide the PGMs \\
into different types, which differ by synchronous \\
area. The final thresholds for the different types \\
are set at the national level and can be lower \\
than the maximum threshold, except for PGMs \\
of type A.
\end{tabular}

All the RfG NC requirements for lower categories (e.g. PGM type A) need to be fulfilled by a higher category PGM (e.g. PGM type B).

Furthermore, specific requirements shall apply to SPGMs of types B to D, PPMs of types B to D and AC-connected OPPMs.

All the requirements are minimum requirements, which means that PGMs can always have more enhanced capabilities if this does not impact system security negatively.

Member States have the obligation to implement the $\mathrm{CNCs}$ at the national level no later than three years after their publication.

The relevant system operators have two years to define and submit national specifications for non-exhaustive requirements for approval by the competent entity.

In order to support implementation at the national level and in line with the legal requirements for the CNCs, ENTSO-E has an obligation to provide non-binding implementation guidance documents.

For reasons of transparency, ENTSO-E has been monitoring the implementation process of connection network codes across Member States. The RfG NC gives the relevant TSOs the right to specify that PPMs of types C and D shall be capable of providing synthetic inertia during very fast frequency deviations to replace the effect of inertia traditionally provided by SPGMs.
Relevant articles

Art. 5 sets out the limits for thresholds for types B, C and D power-generating modules. It states that 'Proposals for maximum capacity thresholds for types $B, C$ and D power-generating modules shall be subject to approval by the relevant regulatory authority or, where applicable, the Member State.'

This is specified in Art. 14 for type B PGMs, Art. 15 for type C PGMs and Art. 16 for type D PGMs.

Specific requirements are set out in Arts. 17 to 19 for SPGMs of types B to D, Arts. 20 to 22 for PPMs of types B to D, and Arts. 23 to 28 for AC-connected OPPMs.

Recital 2 refers to Art. 5 of Directive 2009/72/EC of the Third Package, which requires that 'Member States or, where Member States have so provided, regulatory authorities ensure, inter alia, that objective and non-discriminatory technical rules are developed which establish minimum technical design and operational requirements for the connection to the system.'

Art. 72 states that the SO GL 'shall enter into force on the twentieth day following that of its publication in the Official Journal of the European Union. Without prejudice to Arts. 4(2)(b), 7, 58, 59, 61 and Title VI, the requirements of this Regulation shall apply from three years after publication.'

Art. 7(4) of the RfG NC and Art. 6(4) of the DC NC state that 'The relevant system operator or TSO shall submit a proposal for requirements of general application, or the methodology used to calculate or establish them, for approval by the competent entity within two years of entry into force of this Regulation.'

Art. 58 of the RfG NC and Art. 56 of the DC NC state that 'No later than six months after the entry into force of this Regulation, the ENTSO for Electricity shall prepare and thereafter every two years provide non-binding written guidance to its members and other system operators concerning the elements of this Regulation requiring national decisions. The ENTSO for Electricity shall publish this guidance on its website.'

This is in accordance with Art. 59 of the RfG NC and Art. 57 of the DC NC.

Art. 21(2.a) states that 'the relevant TSO shall have the right to specify that [type C] power park modules be capable of providing synthetic inertia during very fast frequency deviations.' Art. 22 states that such requirements are also applicable to type D PPMs. 


\begin{tabular}{l} 
Section of this chapter, topic and relevant \\
regulation \\
\hline The RfG NC states that all PGM types shall be \\
capable of staying connected to the network and \\
operating at RoCoFs up to a value specified by \\
the relevant TSO.
\end{tabular}

The RfG NC and the SO GL address ramping constraints.

The DC NC states that demand units offering demand response shall have the withstand capability to not disconnect from the system due to RoCoFs up to a value specified by the relevant TSO.

The RfG NC and the DC NC set out frequency ranges within which PGMs, transmission-connected demand facilities, transmission-connected distribution facilities, distribution systems and demand units providing demand response services should be able to withstand frequency disturbances for a certain period of time without disconnecting from the grid.
Relevant articles

Art. 13(1.b) states that ' With regard to the rate of change of frequency withstand capability, a power-generating module [of type A] shall be capable of staying connected to the network and operate at rates of change of frequency up to a value specified by the relevant TSO, unless disconnection was triggered by rate-of-change-of-frequency-type loss of mains protection.' As mentioned previously, this is also applicable to PGMs of types B to D.

Art. 15(6.e) of the RfG NC states that 'the relevant system operator shall specify, in coordination with the relevant TSO, minimum and maximum limits on rates of change of active power output (ramping limits) in both an up and down direction of change of active power output for a power-generating module, taking into consideration the specific characteristics of prime mover technology.' Art. 137(4.a) of the SO GL states that all TSOs in an LFC block shall have the right to determine obligations regarding ramping periods and/ or maximum ramping rates for PGMs and/or demand units in the LFC block operational agreement.

Art. 28(2.k) states that 'Demand units with demand response active power control, demand response reactive power control, or demand response transmission constraint management shall comply with the following requirements, either individually or, where it is not part of a transmission-connected demand facility, collectively as part of demand aggregation through a third party ... (k) have the withstand capability to not disconnect from the system due to the rate-of-change-of-frequency up to a value specified by the relevant TSO.'

Art. 13(1.b) of the RfG NC specifies that a PGM of type A 'shall be capable of remaining connected to the network and operate within the frequency ranges and time periods' specified in that article by synchronous area. Art. 12 of the DC NC states that 'Transmission-connected demand facilities, transmission-connected distribution facilities and distribution systems shall be capable of remaining connected to the network and operating at the frequency ranges and time periods specified in Annex I.' Art. 29(2.a) states that demand units with demand response system frequency control shallbe able to operate across frequency ranges specified in Art. 12 'either individually or, where it is not part of a transmission-connected demand facility, collectively as part of demand aggregation through a third party.' Annex I of the DC NC includes a table with the frequency ranges and time periods specified by synchronous area. 


\begin{tabular}{l} 
Section of this chapter, topic and relevant \\
regulation \\
\hline The RfG NC foresees that the relevant system \\
operator, in coordination with the relevant TSO \\
and the owner of the PGM, may agree on wider \\
frequency ranges, longer minimum times for \\
operation or specific requirements for combined \\
frequency and voltage deviations. The DC NC \\
states that the owner of a transmission-connected \\
demand facility or the DSO may agree with \\
the relevant TSO on wider frequency ranges or \\
minimum times for operation.
\end{tabular}

A set of requirements relate to the capability of PGMs and demand units providing demand response services to contain or compensate for a frequency drop or rise by regulating the active power output or input. They include requirements both for operation under normal conditions and for operation in emergency situations.

The DC NC specifies the reactive power requirements for transmission-connected demand facilities and transmission-connected distribution systems.

The RfG NC and DC NC set out voltage ranges within which PGMs of type D, transmission-connected demand facilities, transmission-connected distribution facilities and transmission-connected distribution systems should remain connected to the grid for certain time periods.
Relevant articles

Art. 13(1.a.ii) states that 'the relevant system operator, in coordination with the relevant TSO and the power-generating facility owner may agree on wider frequency ranges, longer minimum times for operation or specific requirements for combined frequency and voltage deviations to ensure the best use of the technical capabilities of a power-generating module, if it is required to preserve or to restore system security.' Art. 12(2) of the DC NC states that 'The transmission-connected demand facility owner or the DSO may agree with the relevant TSO on wider frequency ranges or longer minimum times for operation. If wider frequency ranges or longer minimum times for operation are technically feasible, the consent of the transmission-connected demand facility owner or DSO shall not be unreasonably withheld.'

Under normal operating conditions, the relevant requirements relate to the operation of PGMs of types C and D in frequency sensitive mode as set out in Art. 15(2.d) and Art. 16(1). Art. 28(2), Art. 29(2) and Art. 30(2) of the DC NC set out provisions for demand units with demand response active power control, demand response system frequency control and demand response very fast active power control respectively.

The relevant requirements in emergency situations are related to the capability of all PGMs to run in limited frequency sensitive mode as specified in Art. 13(2) of the RfG NC. Art. 15(2.c) of the RfG NC adds specific requirements for types C and D. In addition, Art. 15(2.f) states that PGMs of types C and D which are capable of acting as a load shall be capable of disconnecting their load. Finally, Art. 19(1) of the DC NC covers demand disconnection and reconnection.

This is in accordance with the provisions in Art. 15. Art. 15(1) states that 'Transmission-connected demand facilities and transmission-connected distribution systems shall be capable of maintaining their steady-state operation at their connection point within a reactive power range specified by the relevant TSO' in accordance with conditions specified in this article.

Art. 16(2) of the RfG NC sets out requirements with regard to voltage ranges for PGMs of type D. Art. 13(1) of the DC NC states that 'Transmission-connected demand facilities, transmission-connected distribution facilities and transmission-connected distribution systems shall be capable of remaining connected to the network and operating at the voltage ranges and time periods specified in Annex II.' Annex II of the DC NC includes tables with voltage ranges and time periods specified by synchronous area. 


\begin{tabular}{l} 
Section of this chapter, topic and relevant \\
regulation \\
\hline A set of requirements relate to the reactive \\
power capabilities of PGMs of types B to D \\
and demand units providing demand response \\
services to contain or compensate for voltage \\
deviations from the reference value.
\end{tabular}

The RfG NC sets out requirements for PGMs of types B to D to remain connected to the network and operate through periods of low voltage at the connection point caused by secured faults.

SPGMs of types B to D are required to contribute to minimizing the spread of a voltage dip by quickly recovering their active power output following a voltage disturbance. Similar specifications exist for PPMs of types B to D.

The DC NC sets out requirements for transmission-connected demand facilities and transmission-connected distribution systems to withstand high short-circuit currents to avoid a potential cascading disconnection of grid users. The RfG NC does not mandate black start capability for PGMs but refers to the right of Member States and TSOs to require owners of types $\mathrm{C}$ and D PGMs to equip their PGMs with a black start capability under certain conditions. In addition to black start capability, the RfG NC also includes system-restoration-related requirements as regards island operation and reconnection and re-synchronization.
Relevant articles

Under normal operating conditions, the relevant requirements are related to the right of system operators to specify reactive power capabilities of SPGMs as set out in Art. 17(2.a) and reactive power capabilities at maximum and below maximum capacity as set out in Art. 18(2.a-c) and Art. 19(1) of the RfG NC. Art. 17(2.b), Art. 18(1) and Art. 19(2) of the RfG NC set out provisions for PGMs to be equipped with a voltage control system. Arts. 20(2.a), 21(3.a-c) and 22 set out requirements for reactive power capabilities of PPMs. Art. 21(3.d) and Art. 22 define reactive power control modes for PGMs of types C and D. Art. 28(2) of the DC NC includes provisions for demand units providing reactive power control. Art. 15(3-4) states that the relevant TSO may require a transmission-connected distribution system to actively control the exchange of reactive power at the connection point. The relevant requirements in emergency situations are related to the capability of PGMs to automatically disconnect as set out in Arts. 15(3) and 16(2.c) of the RfG NC. Art. 13(6) and Art. 19(2) of the DC NC set out requirements for the automatic disconnection of a transmission-connected demand facility, a transmission-connected distribution facility and a transmission-connected distribution system, if required by the relevant TSO. Art. 28(3) of the DC NC sets out requirements for demand units providing demand response services related to voltage control with disconnection and reconnection.

This is in accordance with Arts. 14(3), 15(1) and (4) and 16(1) and (3) for PGMs of types B to D.

Art. 17 of the RfG NC states that "type B synchronous power-generating modules shall be capable of providing post-fault active power recovery. The relevant TSO shall specify the magnitude and time for active power recovery.' Art. 18(1) and Art. 19(1) cover the applicability for SPGMs of types C and D respectively. Regarding PPMs, Art. 20(3) states that 'the relevant TSO shall specify the post-fault active power recovery that the power park module is capable of providing' and related parameters.

Art. 14 sets out short-circuit requirements. Art. 14(1) states that 'Based on the rated short-circuit withstand capability of its transmission network elements, the relevant TSO shall specify the maximum short-circuit current at the connection point that the transmission-connected demand facility or the transmission-connected distribution system shall be capable of withstanding.' Art. 15(5.a.i) states that 'black start capability is not mandatory [for type C PGMs] without prejudice to the Member State's rights to introduce obligatory rules in order to ensure system security.' Art. 16(1) refers to the applicability for type D PGMs.

Art. 15(5) and Art. 16(1) specify that PGMs of types C and D shall be capable of taking part in island operation if required by the relevant system operator in coordination with the TSO. Art. 14(4), Art. 15(1) and (5.c) and Art. 16(1) set out reconnection and re-synchronization requirements for PGMs of types $\mathrm{B}, \mathrm{C}$ and $\mathrm{D}$. 


\begin{tabular}{l} 
Section of this chapter, topic and relevant \\
regulation \\
\hline The CNCs also include requirements related to \\
general system management.
\end{tabular}

\section{Section 6.4}

The scope of application of the DC NC.

PGMs and transmission-connected demand facilities, transmission-connected distribution facilities, distribution systems and demand units used to provide demand response services are considered new if the final and binding contract for the purchase of the main generating plant, demand equipment or demand unit is not finalized by two years after the entry into force of the relevant regulation.

The RfG and the DC NC can also exceptionally apply to existing connections.

The RfG NC states that the significance of PGMs, and therefore their classification, should be based on their size and their effect on the overall system. Differences exist between synchronously and non-synchronously connected generation units.

The DC NC states that demand connections with more than one demand unit shall be considered to be one demand unit if they cannot be operated independently from each other or can reasonably be considered in a combined manner.
Relevant articles

The RfG NC specifies general system management requirements in Arts. 14(5), 15(1) and (6) and 16(1) and (4) for PGMs of types B to D and in Art. 28 for AC-connected OPPMs.

Art. 3(1) states that 'the connection requirements set out in this Regulation shall apply to: (a) new transmission-connected demand facilities; (b) new transmission-connected distribution facilities; (c) new distribution systems, including new closed distribution systems; (d) new demand units used by a demand facility or a closed distribution system to provide demand response services to relevant system operators and relevant TSOs.'

Art. 4(2) of the RfG NC specifies when a PGM shall be considered to be existing. Art. 4(2) of the DC NC specifies when a transmission-connected demand facility, a transmission-connected distribution facility, a distribution system and a demand unit that is, or can be, used by a demand facility or a closed distribution system to provide demand response services shall be considered to be existing.

Art. 4(1,3-5) of the RfG NC and Art. 4(1,3-5) of the DC NC specify the circumstances under which existing PGMs, transmission-connected demand facilities, transmission-connected distribution facilities, distribution systems and demand units that are or can be used by a demand facility or a closed distribution system to provide demand response services to a relevant system operator or relevant TSO are subject to the requirements of the respective regulation.

Recital 9 states that 'The significance of power-generating modules should be based on their size and their effect on the overall system. Synchronous machines should be classed on the machine size and include all the components of a generating facility that normally run indivisibly, such as separate alternators driven by the separate gas and steam turbines of a single combined-cycle gas turbine installation. For a facility including several such combined-cycle gas turbine installations, each should be assessed on its size, and not on the whole capacity of the facility. Non-synchronously connected power-generating units, where they are collected together to form an economic unit and where they have a single connection point, should be assessed on their aggregated capacity.'

This is specified in Art. 3(3) of the DC NC. 


Section of this chapter, topic and relevant Relevant articles
regulation

The criteria for granting derogations is defined by the NRA.

Two types of derogations exist depending on who files the request.

All decisions regarding derogations granted or refused will be notified to ACER and maintained in a regularly updated register.

ACER and the European Commission both have the possibility of issuing a reasoned recommendation to a regulatory authority to revoke a derogation due to a lack of justification.

Regulation (EU) 2019/943 foresees a second generation of network codes.

The first generation of network codes does not cover energy storage, with the exception of pump-storage power-generating modules, which were included in the RfG NC.
Art. 61(1) of the RfG NC states that 'Each regulatory authority shall specify, after consulting relevant system operators and power-generating facility owners and other stakeholders whom it deems affected by this Regulation, the criteria for granting derogations pursuant to Articles 62 and 63.' Similar provisions are specified in Art. 51 of the DC NC.

Art. 60 of the RfG NC states that 'Regulatory authorities may, at the request of a power-generating facility owner or prospective owner, relevant system operator or relevant TSO, grant power-generating facility owners or prospective owners, relevant system operators or relevant TSOs derogations from one or more provisions of this Regulation for new and existing powergenerating modules in accordance with Articles 61 to 63.' Similar powers to grant derogations are specified in Art. 50 of the DC NC.

Art. 64 of the RfG NC and Art. 54 of the DC NC state that 'Regulatory authorities shall maintain a register of all derogations they have granted or refused and shall provide the Agency with an updated and consolidated register at least once every six months, a copy of which shall be given to ENTSO for Electricity.'

Art. 65(2) of the RfG NC and Art. 54(2) of the DC NC state that 'The Agency may issue a reasoned recommendation to a regulatory authority to revoke a derogation due to a lack of justification. The Commission may issue a reasoned recommendation to a regulatory authority or relevant authority of the Member State to revoke a derogation due to a lack of justification.'

Art. 59 of Regulation (EU) 2019/943 describes the establishment of network codes. Art. 59(1) lists areas where the 'Commission is empowered to adopt implementing acts in order to ensure uniform conditions for the implementation of this Regulation by establishing network codes.' Art. 59(2) lists areas where the 'Commission is empowered to adopt delegated acts in accordance with Article 68 supplementing this Regulation with regard to the establishment of network codes.' Art. 68 refers to the power to adopt delegated acts that is conferred on the Commission.

Art. 3 states that the RfG NC shall not apply to '(d) storage devices except for pump-storage power-generating modules in accordance with Article 6(2).' Art. 6(2) refers to the application of the RfG NC and states that 'Pump-storage power-generating modules shall fulfil all the relevant requirements in both generating and pumping operation mode.' 


\section{How to ensure adequate investment in power plants?}

\section{Leonardo Meeus with Athir Nouicer}

In this chapter, we answer three questions. First, why did some countries introduce a capacity mechanism? Second, what is the best capacity mechanism? Third, how to limit the (ab)use of capacity mechanisms?

\subsection{WHY DID SOME COUNTRIES INTRODUCE A CAPACITY MECHANISM?}

Capacity mechanisms were introduced to ensure adequate investment in power plants. Today we talk about resource adequacy rather than generation adequacy because we also have demand and storage solutions that can compete with power plants in these mechanisms. However, in some parts of this chapter, we still focus on power plants or generation because that is how we used to talk about this issue. The mechanisms are called capacity mechanisms because they provide payment for capacity (MW) in addition to wholesale markets that remunerate energy (MWh). Electricity markets without capacity mechanisms are sometimes referred to as energy-only markets. This is misleading because electricity markets without capacity mechanisms also include capacity components. Retail contracts typically include capacity components, and the same is true for balancing capacity markets. In what follows, we focus on the main arguments that have been used in favour of capacity mechanisms. First, we explain how the economic arguments in favour of capacity mechanisms are evolving from missing money to missing markets. Second, we argue that the real reason that most countries go for capacity mechanisms is political rather than economical.

First, the evolution from the missing money argument in favour of capacity mechanisms to the missing markets argument. ${ }^{1}$ Electricity demand is relatively inflexible and electric energy storage capacities are still limited, so prices can go up and down depending on the availability of renewable energy sources and the demand for electricity. The California crisis in the early 2000s showed that companies can sometimes abuse their market power by driving up electricity prices. ${ }^{2}$ Around that time, most US electricity markets introduced price caps to limit this market power abuse. However, this caused some power plants to lose money, typically the plants that were only needed to cover peak demand. These so-called peakers ran for a limited number of hours a year. In these hours, they not only had to recover their fuel and other operating costs, but they also needed to earn a margin that was large enough to cover their capital costs. If not, they would go out of business. As the price caps were applied equally to all periods of the year, they also reduced the peakers' income in times of scarcity. This resulting loss of income was termed 'the missing money problem'. Note that the initial focus was on 
price caps, but later it was realized that missing money in wholesale and balancing markets can also be caused by other interventions. For instance, in Chapter 5 we discussed how capacity payments to reserve balancing services can distort the scarcity price signal close to real time. The missing money problem was the main reason why most US wholesale markets introduced a capacity mechanism at the beginning of this century. The situation in Europe was somewhat different, and we will come back to it in the next section.

The counter-argument is that capacity mechanisms are not needed. It is simply necessary to fix the interventions that cause the missing money. For instance, structural measures can be applied to improve competition so that price caps can be removed and balancing markets can be reformed. However, there is also a missing market problem in electricity markets. In Chapter 2, we discussed cross-border hedging in the forward timeframe. The contract length for transmission rights goes up to a year, while companies typically want to hedge with longer-duration contracts. In Chapter 6, we referred to technical requirements in connection agreements that could become markets for system services. Another missing market is the market for reliability. If there is a shortage in the electricity market, rationing is applied. Certain districts are disconnected for a few hours, and then other districts for a few hours, so the pain is spread with what is referred to as a rolling blackout. Unlike a real blackout, this one is planned and scheduled. In Box 7.1 we discuss a controversy in Belgium around a rationing plan when the country came close to having to use it. The problem with the rationing approach is that those who caused the shortage are not held accountable. If retailers knew that their customers would be cut off if they do not secure enough supply, they would have more incentives to enter into long-term contracts with investors in power plants. As long as this is not fixed, it is another argument in favour of a capacity mechanism to ensure that we have adequate investment.

Second, the politics of capacity mechanisms. ${ }^{3}$ Capacity mechanisms have often been lobbied for by incumbents. These mechanisms are also appealing to risk-averse policymakers who do not want to be blamed for electricity shortages. In Europe, the number of countries that have introduced a capacity mechanism increased after the global financial and economic crisis that started in 2008. Most of the big utilities in Europe had invested substantially in new gas-fired power plants. Many of these plants did not run in the years following the crisis because electricity demand stopped growing or even reduced, and renewable energies had grown faster than expected. In this context, capacity mechanisms became controversial. Some argued they are simply state aid to national champions that have made the wrong investment decisions, while others argued they keep alive the gas plants that we desperately need as backup capacity for renewable energy sources.

\section{BOX 7.1 RATIONING OR LOAD-SHEDDING PLANS AND CONTROVERSIES}

In Belgium, a load-shedding plan led to controversy in the media and in court in 2014. In the winter of 2014-2015 several nuclear plants were unavailable, so the country risked having to use the plan. The general public learned about the plan from the media, which started to publish maps in six different colours indicating which regions would be cut off first.

Load-shedding plans organize controlled power outages. They make it possible to avoid a much more serious situation, such as a general blackout of a region. The rationing is usu- 
ally limited in time. Some sites, such as hospitals, are classified as priority and are never cut. The Belgian plan also avoided city centres and communities with more than 50000 inhabitants as well as capitals of provinces.

The main controvesy arose in the port of Ghent and the airports of Liège and Charleroi, which were included in or were close to blue zones - the zones that were first to be cut off. Ghent demanded that the port area be excluded from the load-shedding plan. The City of Ghent and the company responsible for managing the port (Havenbedrijf Gent) launched a court case against the parties involved: the Ministers of Economy and Energy, the transmission system operator (TSO) Elia and the distribution system operator (DSO) IMEWO. The City asked for $€ 10$ million compensation in the case of load shedding. The airports of Liège and Charleroi also had similar concerns.

Note: Commission de l'économie (2015) summarizes the debate that took place in 2015 regarding load-shedding plans in Belgium. CREG (2016) presents the modifications in the load-shedding plans that were decided on following the incident.

\subsection{WHAT IS THE BEST CAPACITY MECHANISM?}

There are many ways to implement a capacity mechanism, and the relative popularity of the different options clearly evolved with experience. In what follows, we discuss the experiences of Spain, Sweden, Great Britain and Ireland, which together nicely illustrate what Europeans think about capacity mechanisms. We present a taxonomy of capacity mechanisms in Annex 7A.1.

First is the case of Spain, which has been well-documented and commented on by our colleagues. ${ }^{4}$ Spain introduced a capacity mechanism as early as 1997 . The capacity price was administratively set by the regulator and the government. In 2007, the mechanism included two components: investment incentives and availability payments. The investment subsidy was then $€ 28000 / \mathrm{MW} /$ year. In 2012, the price was reduced from $€ 28000$ to $€ 23000 / \mathrm{MW} /$ year. In 2013, it was further reduced to $€ 10000$, but the period over which the capacity payments applied was extended from 10 years to 20 years. The investment incentives were only for generation capacity installed between 1998 and 2016. In 2018, availability payments for capacity rewarding combined cycle gas turbines (CCGTs), natural gas, fuel-oil, coal-fired and hydropower generators were suppressed. The Spanish government's reason was to be in line with the Clean Energy Package and the energy transition objectives. This Spanish mechanism is called capacity payments. A few more countries like Ireland, Italy and Greece also tried out this mechanism, but it is being abandoned by all of them in favour of mechanisms that set the price in a market for capacity.

Second is the case of Sweden. Since 2004, it has been possible for power plants to be strategically reserved in Sweden. There is an administrative decision to reserve a certain amount of capacity, and the price of that capacity is set in an auction. Power plants that would otherwise be taken offline can then stay on the system and be used in times of shortages. This mechanism became the most popular mechanism in Europe, even though it received much criticism. The fear was that governments or regulators would be tempted to use their strategic reserves to reduce price peaks. This would then act as a de facto price cap in wholesale markets and cause a missing money problem for the other power plants that did not receive a capacity payment 
from the strategic reserve fund. In Sweden, reserve activation only happens if there is a curtailment situation in Sweden or Finland. TSOs in both countries decide together which resources to use in the case of shortages. Note that today a large part of the Swedish strategic reserve is demand response from load-heavy industry.

Third is the case of Great Britain. Since 2014, Great Britain has had a US-style capacity auction, often referred to as a capacity market. There is an administrative decision to procure a certain amount of capacity, and the price of that capacity is set in an auction. The capacity market applies to all the power plants or resources able to provide capacity. The problem with such a mechanism is that it distorts the wholesale market. The wholesale market is a European market in which power plants from different countries compete, as was explained in Chapter 2 , but some of them are now supported by national capacity mechanisms while others are not. Within a national market with a capacity mechanism, the mechanism also distorts the level playing field between different players and technologies. In the past these mechanisms focused on supporting power plants, while today supply solutions are wanted to compete with demand and energy storage solutions. It has proven to be very difficult to design capacity mechanisms that are technology-neutral. The so-called Tempus case illustrates the controversies around these mechanisms (Box 7.2).

\section{BOX 7.2 THE TEMPUS CASE}

Tempus, a demand response provider, argued that the capacity market scheme in Great Britain discriminated against demand response. The mechanism had been approved by the European Commission, which was challenged by Tempus. In 2018 the General Court of the European Union issued a judgment in case T-793/14 'Tempus Energy Ltd and Tempus Energy Technology Ltd v Commission' overruling the Commission's decision to approve the state aid scheme establishing a capacity market in the United Kingdom (UK). The UK government suspended the capacity market to comply with the judgment. This led to an immediate stopping of the existing capacity payments and the cancelling of 2019 auctions.

The European Commission appealed against the decision and conducted a state aid investigation. The UK government supported the Commission's appeal. After an in-depth investigation, in October 2019 the Commission again approved the mechanism. It confirmed that it complied with the EU state aid rules and that it did not distort competition in the single market. The investigation did not find evidence that the capacity market scheme would put demand response providers at a disadvantage. At the same time, the UK government committed to improving the scheme, considering recent market and regulatory developments and other issues identified in the UK government's 2019 five-year review of the capacity market. This includes, for instance, revisiting the minimum capacity size to participate in the auction and the rules on participation by new types of players. Tempus can still challenge the re-approval, and other related proceedings are still ongoing.

Note: $\quad$ Before the Clean Energy Package was adopted, the European Commission instruments to control the implementation of capacity mechanisms were the EU state aid rules. Our colleagues Hancher et al. (2015) are experts on state aid and provide a detailed discussion of experiences with capacity mechanisms. 
Fourth is the case of Ireland. Ireland started with Spanish-style capacity payments but became the first country in Europe to introduce reliability options. This is a mechanism that has been advocated by academics as superior to capacity markets because it pays for the availability of capacity at times of shortages rather than paying for capacity. Reliability options are based on the concept of a call options contract, and capacity providers enter into an option contract with a counterparty (a TSO or a large consumer or supplier). This contract offers the counterparty the option of procuring electricity at a predetermined strike price. In return for the premium paid - the price of the option contract - the counterparty gets insurance against high prices. This premium then replaces the capacity remuneration. The mechanism incentivizes power plants or other players to have resources available when prices go up. If they do not, they will have to buy energy at the high prices in the market and sell it at the lower strike price that has been agreed when entering the insurance scheme. In addition, regulators may apply further safeguards with a penalty for non-compliance and/or by requiring a certain level of physical capacity for all options sold. By design, this mechanism is less distorting for the wholesale market than capacity markets. However, when we looked into the implementation details, we found that many parameters are still set administratively. These include who can offer which amount of reliability options, the length of the contract and many other factors that are known to favour some solutions over others. ${ }^{5}$

In other words, there is no best design for capacity mechanisms. If a country is fully convinced its electricity market cannot survive without a capacity mechanism, reliability options are the most elegant design option, but it will need to keep a close eye on the implementation details. If it is not convinced but political reality pushes it towards an intervention to safeguard the availability of capacity in the system, strategic reserves will be its preferred option. They are easier to implement and the Clean Energy Package includes provisions that remedy the main risks associated with strategic reserves, as we will discuss in the next section.

\subsection{HOW TO LIMIT THE (AB)USE OF CAPACITY MECHANISMS?}

The Clean Energy Package goes a long way towards limiting the (ab)use of capacity mechanisms. Regulation (EU) 2019/943 introduced two steps to check if capacity mechanisms are really needed and also includes provisions to guide the design of these mechanisms.

\subsubsection{Is a Capacity Mechanism Really Needed?}

Here, we introduce the European resource adequacy assessment and the national implementation plan for market reforms, both of which will be used to check whether a certain country needs a capacity mechanism.

First, the European resource adequacy assessment. Following Regulation (EU) 2019/943, this assessment will be used to check if there is a need for concern. The assessment is to be carried out every year by ENTSO-E based on data provided by national TSOs and cover a period of ten years. A European assessment can avoid over-reaction if a certain country has an issue which can be solved by its neighbours. It can also avoid under-reaction if a number of countries are counting on the same neighbour and/or over-estimate the capacity of their neighbours to help in certain situations. Member States can also continue to do national assess- 
ments, which they can use to complement the European assessment with additional sensitivity analysis. If this leads to disputes, a process has been foreseen with a role for the Agency for the Cooperation of Energy Regulators (ACER).

Regulation (EU) 2019/943 introduced a process to come up with a methodology that will be used in these assessments. The role of the Member States or a competent authority designated by them is to define a reliability standard. The reliability standard is the level of risk countries want to take to face shortages, which is expressed as the 'expected energy not served' (EENS), or the 'loss of load expectation' (LOLE). The role of the European Network of Transmission System Operators for Electricity (ENTSO-E), with oversight from ACER, is to integrate this standard into a methodology that also considers the cost of new entry of generation, or demand response, and the cost people face when they do not have electricity, which is expressed as the value of lost load (VoLL). Scenarios with demand and supply projections will also need to be agreed upon to be able to perform this assessment. In December 2019, ENTSO-E launched two public consultations to collect inputs from stakeholders on the proposal for the EU resource adequacy assessment methodology and on the VoLL, the cost of a new entry and the reliability standard calculation methodology.

Second, the national implementation plan for market reforms. As discussed in the previous sections, much can be done to reduce the need for capacity mechanisms. Price caps can be removed in wholesale markets and retail markets, more investment can be made in the transmission network and balancing markets can be reformed, as was discussed in Chapter 5. Following Regulation (EU) 2019/943, Member States with identified resource adequacy concerns need to develop and publish an implementation plan with a timeline for adopting measures to eliminate any identified market distortions. The plans will be reviewed by the European Commission, which shall issue an opinion within four months. Member States also have to monitor the application of their plans and publish the results of the monitoring in an annual progress report.

Regulation (EU) 2019/943 refers to capacity mechanisms as measures of last resort to eliminate residual resource adequacy concerns. Member States are to carry out a study of the possible effects of capacity mechanisms on neighbouring countries before they are implemented. They are also to prioritize assessment of the potential of a strategy reserve mechanism to address residual resource adequacy concerns. Only if strategic reserves cannot address them may Member States implement other types of capacity mechanisms.

Capacity mechanisms are also to be temporary and to be approved by the European Commission for a maximum of ten years. Then they are to be phased out, or the amount of committed capacity is to be reduced according to the national market reform implementation plan. Member States are to continue the application of the implementation plan after the introduction of the capacity mechanism. They need to include a provision allowing for an efficient administrative phase-out in the case that no new contracts are concluded for three consecutive years. Member States are to review capacity mechanisms that are already in place. If the resource adequacy assessments have not identified concerns, no new contracts under these mechanisms are to be concluded. 


\subsubsection{Design Principles for Capacity Mechanisms}

Regulation (EU) 2019/943 provides guidance to Member States regarding the design of capacity mechanisms. Below, we discuss the design principles that apply to all mechanisms, and specific ones that apply to strategic reserves.

First is technology neutrality. Capacity mechanisms need to be open to participation by all capable resources, including demand and storage solutions and decentralized energy resources. Resources should be selected through a transparent non-discriminatory competitive process. The mechanisms must also provide incentives for participants to be available in times of system stress when they are most needed. Appropriate penalties should be applied for providers who are not available during such times.

Second are strategic reserves. Strategic reserves are only to be dispatched in the case that TSOs are likely to exhaust their balancing resources. During imbalance settlement periods in which resources in the strategic reserve are dispatched, the imbalances in the market are to be settled at least at the VoLL or at a higher value than the intraday technical price limit, whichever is higher. Following the dispatch, the strategic reserve's output is to be attributed to balance responsible parties (BRPs) through the imbalance settlement mechanism. In addition, the resources participating in the strategic reserve mechanism shall not receive any remuneration from wholesale or balancing markets. They are to be held outside the market at least during the contractual period.

Third are $\mathrm{CO} 2$ emission limits. Capacity mechanisms cannot be abused to subsidize the most polluting coal power plants. A grandfathering clause was introduced for capacity mechanism contracts that were concluded before 31 December 2019. Since 4 July 2019, a CO2 emission limit of $550 \mathrm{~g}$ of $\mathrm{CO} 2$ of fossil fuel origin per $\mathrm{kWh}$ has been applied for new generation capacity. Additionally, from 1 July 2025, an emission limit of $350 \mathrm{~kg}$ of CO2 of fossil fuel origin on average per year per installed $\mathrm{kWe}$ for existing capacity is applied, that is, generation capacity that started commercial production before 4 July 2019. In December 2019, ACER published an opinion providing technical guidance related to the calculation of the values of $\mathrm{CO} 2$ emission limits for capacity mechanisms. It clarifies the scope of application of the emission limits and sets out the calculation formulae and the related specifications.

Fourth is cross-border participation. Capacity mechanisms other than strategic reserves must be open to explicit cross-border participation to limit distortions to cross-border trade and competition and to provide incentives for interconnection investment to ensure the EU security of electricity supply at the least cost. Cross-border participation in strategic reserves is to be open where technically feasible. With ACER oversight, ENTSO-E needs to develop a methodology to calculate the maximum entry capacity for cross-border participation. TSOs are then to set the maximum entry capacity for foreign capacity on the basis of a recommendation by the regional coordination centre. Many more details will be worked out to enable cross-border participation in capacity mechanisms.

\subsection{CONCLUSION}

In this chapter on how to ensure adequate investment in power plants, we have answered three questions. First, why did some countries introduce a capacity mechanism to ensure adequate investment in power plants? The arguments in favour of capacity mechanisms are evolving 
from missing money to missing markets. The missing money problem was first identified in the US, where price caps had led to a reduction in generation unit incomes, especially those of peakers. Missing markets include longer-term hedging across borders and the market for reliability. We also showed that the real reason behind capacity mechanisms is often political rather than economical.

Second, what is the best capacity mechanism? We discussed the experiences of Spain with capacity payments, Sweden with strategic reserves, GB with capacity markets and Ireland with reliability options. We cannot say that there is an absolute winner. Nevertheless, there is a trend towards strategic reserves, which is reflected in the Clean Energy Package framework for capacity mechanisms.

Third, how to limit the (ab)use of capacity mechanisms? We presented the new regulatory framework introduced in the Clean Energy Package. It includes EU resource adequacy assessment and national implementation plans for market reforms. Member States need to check whether it is sufficient to introduce strategic reserves, and detailed design principles for these reserves are provided. The new framework also encompasses other design principles for capacity mechanisms, such as technology neutrality, $\mathrm{CO} 2$ emission limits and rules on cross-border participation.

\section{NOTES}

1. Shanker (2003) used the missing money concept in his reaction to the standard market design proposals by the Federal Energy Regulatory Commission (FERC) in the US. Cramton and Stoft (2006) have also been influential in their study of the issue. Joskow (2008) went a step further and argued that the missing money is not only caused by price caps but there are other market interventions that have the same effect. Examples include actions by system operators to ensure system reliability. Newbery (1989) discusses the missing market problem when revenue is adequate but not perceived, that is, the commodity being sold is considered a public good. Bhagwat et al. (2016) present a survey of US experts regarding capacity mechanisms. The answers are in favour of energy-only markets. Cretì and Fontini (2019) highlight the pros and cons of the different capacity mechanisms. They provide an alternative tool to capacity mechanisms: the operating reserve demand curve, which complements energy-only markets. This tool is also discussed in Hogan (2013), who argues that it can complement both energy-only markets and markets with capacity mechanisms. We referred to this approach in Chapter 5.

2. The California crisis in 2000-2001 is one of the most iconic electricity market crises. Several academics from the US have analysed the California crisis including Borenstein (2002), Borenstein et al. (2003, 2008), Joskow $(2001,2008)$ and Wolak (2003). In 1998, the state had introduced competitive wholesale and retail markets for electricity. It was the first fully decentralized market arrangement, with a power exchange (CALPX) and an independent system operator (CAISO), in the US. CAISO operated the transmission networks owned by the three major utilities and ran various energy-balancing, ancillary services and congestion management markets, while CALPX ran both a voluntary day-ahead and hourly hour-ahead public wholesale markets for energy. Note that the three largest utilities had a (largely unhedged) obligation to trade on the day-ahead and real-time markets operated by the PX and the ISO. Wholesale market prices were deregulated, while retail prices were fixed for up to four years. The reforms assumed that wholesale prices would be lower than the administrative cap set for the retail price. As it turned out, markets appeared to be quite competitive in periods with low and moderate demand. However, demand had been increasing rapidly in the previous years, while there had been little new investment. As a result, in periods of high demand a combination of tight supplies and inelastic demand created opportunities for individual generators to exercise market power. Between May 2000 and June 2001, California experienced an explosion in wholesale power prices, followed by supply shortages and rolling blackouts with 
physical rationing by the ISO. In January 2001, CALPX declared itself bankrupt after it had been unable to implement mitigation measures imposed by the regulator. California responded to the crisis with costly long-term contracts of up to 20 years negotiated by the state, long-term obligations for procurement, a freeze on retail competition and, overall, by taking some step backs from a fully decentralized market model. The California crisis even made it into the documentary on the Enron bankruptcy The Smartest Guys in the Room.

3. Thomas-Olivier Léautier (2019) argues that capacity mechanisms owe more to the political economy than to microeconomics. He argues that elected officials prefer a zero-blackout criterion irrespective of the costs incurred. He also argues that most system operators, regulators and government employees are in favour of an increase in their scope of intervention through the design and monitoring of capacity mechanisms. These employees are the first to be blamed by politicians in the case of blackouts.

4. In Batlle et al. (2007) and Batlle and Pérez-Arriaga (2008) our colleagues share their views on the Spanish and international experiences with capacity mechanisms.

5. The concept of reliability option was first outlined by Pérez-Arriaga (1999). Vázquez et al. (2002) discuss the experience of Colombia with this mechanism. Oren (2005) also promotes the concept. In Bhagwat and Meeus (2019) we discuss the implementation of reliability options in Ireland and Italy.

\section{REFERENCES}

ACER (2013), 'Capacity Remuneration Mechanisms and the Internal Market for Electricity'.

Batlle, C. and I. J. Pérez-Arriaga (2008), 'Design criteria for implementing a capacity mechanism in deregulated electricity markets', Utilities Policy, 16 (3), 184-93.

Batlle, C., C. Vázquez, M. Rivier and I. J. Pérez-Arriaga (2007), 'Enhancing power supply adequacy in Spain: Migrating from capacity payments to reliability options', Energy Policy, 35 (9), 4545-54.

Bhagwat, P. and L. Meeus (2019), 'Reliability options: Can they deliver on their promises?', Electricity Journal, 32 (10).

Bhagwat, P. C., L. J. de Vries and B. F. Hobbs (2016), 'Expert survey on capacity markets in the US: Lessons for the EU', Utilities Policy, 38, 11-17.

Borenstein, S. (2002), 'The trouble with electricity markets: Understanding California's restructuring disaster', Journal of Economic Perspectives, 16 (1), 191-211.

Borenstein, S., J. Bushnell, C. R. Knittel and C. Wolfram (2008), 'Inefficiencies and market power in financial arbitrage: A study of California's electricity markets', Journal of Industrial Economics, 56 (2), 347-78.

Borenstein, S., J. Bushnell and F. A. Wolak (2003), 'Measuring market inefficiencies in California's restructured wholesale electricity market', American Economic Review, 92 (5), 1376-405.

Commission de l'économie (2015), 'Débat Sur Le Plan de Délestage' ['Debate on the Shedding Plan'], accessed at https://www.dekamer.be/doc/CCRI/pdf/54/ic044x.pdf.

Cramton, P. and S. Stoft (2006), 'The Convergence of Market Designs for Adequate Generating Capacity', Report for California Electricity Oversight Board, accessed at https://doi.org/10.1007/ s13398-014-0173-7.2.

CREG (2016), 'Rapport Annuel 2015' [Annual Report 2015'].

Cretì, A. and F. Fontini (2019), 'Investing in power generation', in Economics of Electricity: Markets, Competitions and Rules, Cambridge: Cambridge University Press, pp. 259-98.

EP (2017), 'Capacity Mechanisms for Electricity', accessed at http://www.europarl.europa.eu/RegData/ etudes/BRIE/2017/603949/EPRS_BRI(2017)603949_EN.pdf.

Hancher, L., A. de Hauteclocque and M. Sadowska (ed.) (2015), Capacity Mechanisms in the EU Energy Market: Law, Policy, and Economics, Oxford: Oxford University Press.

Hogan, W. W. (2013), 'Electricity scarcity pricing through operating reserves', Economics of Energy and Environmental Policy, 2 (2).

Joskow, P. (2001), 'California's electricity crisis', Oxford Review of Economic Policy, 17 (3), 365-88.

Joskow, P. (2008), 'Lessons learned from electricity market liberalization', Energy Journal, 29 (Special Issue \#2), 9-42. 
Léautier, Thomas-Olivier (2019), 'The highly visible hand: Capacity mechanism', in Imperfect Markets and Imperfect Regulation, Cambridge, MA: MIT Press, pp. 325-59.

Newbery, D. M. (1989), 'Missing markets: Consequences and remedies', in F. H. Hahn (ed.), The Economics of Missing Markets, Information, and Games, Oxford: Clarendon Press, pp. 211-42.

Oren, S. S. (2005), 'Generation adequacy via call options obligations: Safe passage to the promised land', Electricity Journal, 18 (9), 28-42.

Pérez-Arriaga, I. J. (1999), 'Reliability and generation adequacy', in W. S. Read, W. K. Newman, I. J. Pérez-Arriaga, H. Rudnick, M. R. Gent and A. J. Roman (1999), 'Reliability in the new market structure (Part 1) ', IEEE Power Engineering Review, 19 (12), 4-5.

Shanker, R. (2003), 'Comments on Standard Market Design: Resource Adequacy Requirement. Federal Energy Regulatory Commission', accessed at http://elibrary.ferc.gov/idmws/common/opennat.asp ?fileID $=9619272$.

Vázquez, C., M. Rivier and I. J. Pérez-Arriaga (2002), 'A market approach to long-term security of supply', IEEE Transactions on Power Systems, 17 (2), 349-357.

Wolak, F. A. (2003), 'Diagnosing the California electricity crisis', Electricity Journal, 16 (7), 11-37. 


\section{A.1 ANNEX: TAXONOMY OF CAPACITY MECHANISMS}

\section{Table 7A.1 Taxonomy of capacity mechanisms}

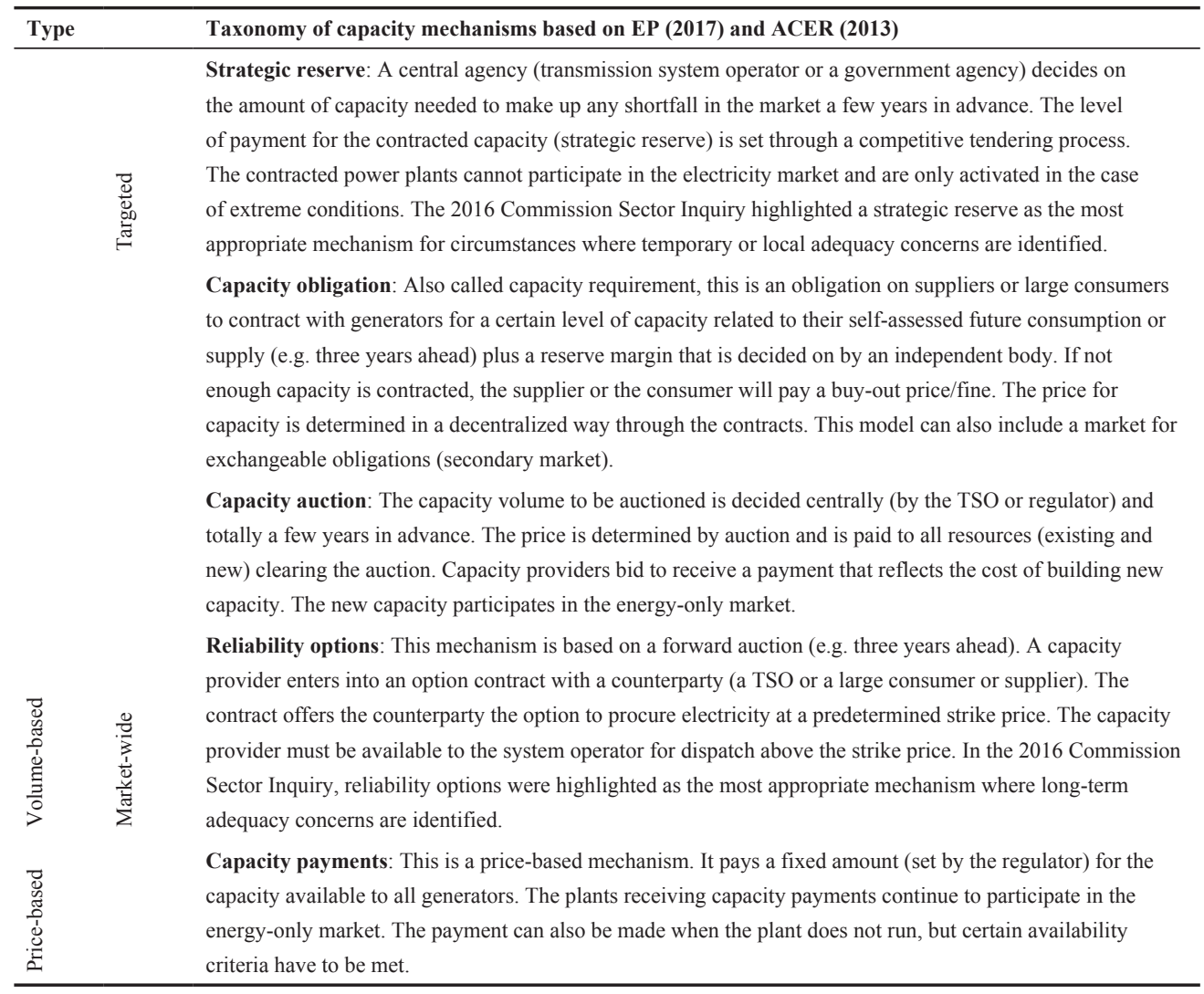




\section{A.2 ANNEX: REGULATORY GUIDE}

\section{Table 7A.2 Regulatory guide}

Section of this chapter, topic and relevant regulation

\section{Section 7.3.1}

Regulation (EU) 2019/943 introduces a binding EU resource adequacy assessment. It can be complemented with national assessments.

Regulation (EU) 2019/943 sets the coverage and duration of the EU resource adequacy assessment together with ENTSO-E's role in its conduct.

Regulation (EU) 2019/943 provides a development process for the draft methodology for the EU resource adequacy assessment and the principles underlying it.

Regulation (EU) 2019/943 requires the development of a methodology for VoLL, cost of new entry and reliability standards.
Relevant article

\author{
Rever
}

Art. 20(1) states that 'Member States shall monitor resource adequacy within their territory on the basis of the European resource adequacy assessment referred to in Article 23. For the purpose of complementing the European resource adequacy assessment, Member States may also carry out national resource adequacy assessments pursuant to Article 24.'When a resource adequacy concern is identified in an assessment, Art. 20(2) states that '... the Member State concerned shall identify any regulatory distortions or market failures that caused or contributed to the emergence of the concern.'

Art. 23(1) states that 'the European resource adequacy assessment shall identify resource adequacy concerns by assessing the overall adequacy of the electricity system to supply current and projected demands for electricity at Union level, at the level of the Member States, and at the level of individual bidding zones, where relevant. The European resource adequacy assessment shall cover each year within a period of 10 years from the date of that assessment.' Art. 23(2) adds that 'the European resource adequacy assessment shall be conducted by the ENTSO for Electricity.'

Art. 23(3) states that 'by 5 January 2020, the ENTSO for Electricity shall submit to the Electricity Coordination Group set up under Article 1 of Commission Decision of 15 November 2012 and ACER a draft methodology for the European resource adequacy assessment based on the principles provided for in paragraph 5 of this Article.'

Among the principles underlying the EU adequacy assessment which are to be ensured by the transparent methodology, Art. 23(5) states that the assessment is to be carried out at each bidding zone level. It is to be based on appropriate central reference scenarios of projected demand and supply. In addition, the methodology must ensure that the assessment 'appropriately takes account of the contribution of all resources including existing and future possibilities for generation, energy storage, sectoral integration, demand response, and import and export and their contribution to flexible system operation.' Moreover, the assessment should apply at least the 'expected energy not served' (EENS) and the 'loss of load expectation' (LOLE) indicators, which are referred to in Art. 25 .

Art. 23(6) states that 'by 5 January 2020, the ENTSO for Electricity shall submit to ACER a draft methodology for calculating:

(a) the value of lost load;

(b) the cost of new entry for generation, or demand response; and

(c) the reliability standard referred to in Article 25 .

The methodology shall be based on transparent, objective and verifiable criteria.' 


\begin{tabular}{l} 
Section of this chapter, topic and relevant \\
regulation \\
\hline According to Regulation (EU) $2019 / 943$, the \\
reliability standard aims to reflect the level of \\
the security of supply of the Member States. \\
Regulation (EU) $2019 / 943$ sets principles for \\
the calculation of the reliability standard.
\end{tabular}

Regulation (EU) 2019/943 provides a guide for the development and publication of national implementation plans for market reforms.
Relevant article

Art. 25(1) states that 'when applying capacity mechanisms Member States shall have a reliability standard in place. A reliability standard shall indicate the necessary level of security of supply of the Member State in a transparent manner. In the case of cross-border bidding zones, such reliability standards shall be established jointly by the relevant authorities.'Art. 25(2) adds that 'the reliability standard shall be set by the Member State or by a competent authority designated by the Member State, following a proposal by the regulatory authority ...' In addition the reliability standardis to be '... calculated using at least the value of lost load and the cost of new entry over a given timeframe and shall be expressed as "expected energy not served" and "loss of load expectation"'(Art. 25(3)).

Art. 20(3) lists the principles that are to be taken into account when addressing adequacy concerns. It states that 'Member States with identified resource adequacy concerns shall develop and publish an implementation plan with a timeline for adopting measures to eliminate any identified regulatory distortions or market failures as a part of the State aid process. When addressing resource adequacy concerns, the Member States shall in particular take into account the principles set out in Article 3 and shall consider:

(a) removing regulatory distortions;

(b) removing price caps in accordance with Article 10;

(c) introducing a shortage pricing function for balancing energy as referred to in Article 44(3) of Regulation (EU) 2017/2195;

(d) increasing interconnection and internal grid capacity with a view to reaching at least their interconnection targets as referred in point (d)(1) of Article 4 of Regulation (EU) 2018/1999;

(e) enabling self-generation, energy storage, demand side measures and energy efficiency by adopting measures to eliminate any identified regulatory distortions;

(f) ensuring cost-efficient and market-based procurement of balancing and ancillary services;

(g) removing regulated prices where required by Article 5 of Directive (EU) 2019/944.'

Regulation (EU) 2019/943 sets out a process for the submission and review of implementation plans.
Art. 20(4) states that the Member States concernedshall 'submit their implementation plans to the Commission for review.'Then, 'within four months of receipt of the implementation plan, the Commission shall issue an opinion on whether the measures are sufficient to eliminate the regulatory distortions or market failures that were identified pursuant to paragraph 2, and may invite the Member States to amend their implementation plans accordingly' (Art 20(5)). The application of the implementation plans shall be monitored by the Member States concerned, as is stated in Art. 20(6). An annual report on the results of the monitoring is to be published by the Member States concerned and submitted to the Commission, which 'shall issue an opinion on whether the implementation plans have been sufficiently implemented and whether the resource adequacy concern has been resolved'(Art. 20(7)). Finally, Art. 20(8) states that 'Member States shall continue to adhere to the implementation plan after the identified resource adequacy concern has been resolved.' 


\begin{tabular}{l} 
Section of this chapter, topic and relevant \\
regulation \\
\hline Regulation (EU) 2019/943 allows the \\
implementation of a capacity mechanism as \\
a measure of last resort.
\end{tabular}

Regulation (EU) 2019/943 requires Member States to conduct a study of the effect on neighbouring Member States.

Regulation (EU) 2019/943 gives priority to strategic reserves implementation.

Regulation (EU) 2019/943 includes a provision on the phasing-out of capacity mechanisms.

Regulation (EU) 2019/943 specifies that capacity mechanisms are temporary.

Regulation (EU) 2019/943 includes measures on already existing capacity mechanisms.

\section{Section 7.3.2}

Regulation (EU) 2019/943 provides general design principles for capacity mechanisms.
Relevant article

Art. 21(1) states that 'to eliminate residual resource adequacy concerns, Member States may, as a last resort while implementing the measures referred to in Article 20(3) of this Regulation in accordance with Article 107, 108 and 109 of the TFEU, introduce capacity mechanisms.'

Art. 21(2) states that 'before introducing capacity mechanisms, the Member States concerned shall conduct a comprehensive study of the possible effects of such mechanisms on the neighbouring Member States by consulting at least its neighbouring Member States to which they have a direct network connection and the stakeholders of those Member States.'

Art. 21(3) requires that Member States give priority to capacity mechanisms in the form of strategic reserves. It states that 'Member States shall assess whether a capacity mechanism in the form of strategic reserve is capable of addressing the resource adequacy concerns. Where this is not the case, Member States may implement a different type of capacity mechanism.'

Art. 21(7) states that "when designing capacity mechanisms Member States shall include a provision allowing for an efficient administrative phase-out of the capacity mechanism where no new contracts are concluded under paragraph 6 during three consecutive years.'

Art. 21(8) states that capacity mechanisms are to be temporary.It adds that 'they shall be approved by the Commission for no longer than 10 years. They shall be phased out or the amount of the committed capacities shall be reduced on the basis of the implementation plans referred to in Article 20. Member States shall continue to apply the implementation plan after the introduction of the capacity mechanism.'

Regarding capacity mechanisms already in place, Art. 21(6) says that "where a Member State applies a capacity mechanism, it shall review that capacity mechanism and shall ensure that no new contracts are concluded under that mechanism where both the European resource adequacy assessment and the national resource adequacy assessment, or in the absence of a national resource adequacy assessment, the European resource adequacy assessment have not identified a resource adequacy concern or the implementation plan as referred to in Article 20(3) has not received an opinion by the Commission as referred to in Article 20(5).'

Art. 22(1) enumerates design principles for capacity mechanisms. It states that 'any capacity mechanism shall:

(a) be temporary;

(b) not create undue market distortions and not limit cross-zonal trade; 
Section of this chapter, topic and relevant regulation
Regulation (EU) 2019/943 provides specific design principles for strategic reserves.
Relevant article

(c) not go beyond what is necessary to address the adequacy concerns referred to in Article 20;

(d) select capacity providers by means of a transparent, non-discriminatory and competitive process;

(e) provide incentives for capacity providers to be available in times of expected system stress;

(f) ensure that the remuneration is determined through the competitive process;

(g) set out the technical conditions for the participation of capacity providers in advance of the selection process;

(h) be open to participation of all resources that are capable of providing the required technical performance, including energy storage and demand side management;

(i) apply appropriate penalties to capacity providers that are not available in times of system stress.'

Art. 22(2) specifies design principles for strategic reserves. It states that 'the design of strategic reserves shall meet the following requirements:

(a) where a capacity mechanism has been designed as a strategic reserve, the resources thereof are to be dispatched only if the transmission system operators are likely to exhaust their balancing resources to establish an equilibrium between demand and supply;

(b) during imbalance settlement periods where resources in the strategic reserve are dispatched, imbalances in the market are to be settled at least at the value of lost load or at a higher value than the intraday technical price limit as referred in Article 10(1), whichever is higher;

(c) the output of the strategic reserve following dispatch is to be attributed to balance responsible parties through the imbalance settlement mechanism; (d) the resources taking part in the strategic reserve are not to receive remuneration from the wholesale electricity markets or from the balancing markets;

(e) the resources in the strategic reserve are to be held outside the market for at least the duration of the contractual period.

The requirement referred to in point (a) of the first subparagraph shall be without prejudice to the activation of resources before actual dispatch in order to respect the ramping constraints and operating requirements of the resources. The output of the strategic reserve during activation shall not be attributed to balance groups through wholesale markets and shall not change their imbalances.' 


\begin{tabular}{ll}
\hline $\begin{array}{l}\text { Section of this chapter, topic and relevant } \\
\text { regulation }\end{array}$ & Relevant article \\
\hline $\begin{array}{l}\text { Regulation (EU) 2019/943 provides design } \\
\text { principles for mechanisms other than strategic }\end{array}$ & $\begin{array}{l}\text { For mechanisms other than strategic reserves, Art. 22(3) lists additional design } \\
\text { principles to those included in Art. 22(1). It states that' capacity mechanisms } \\
\text { reserves. }\end{array}$ \\
& $\begin{array}{l}\text { (a) be constructed so as to ensure that the price paid for availability } \\
\text { automatically tends to zero when the level of capacity supplied is expected to } \\
\text { be adequate to meet the level of capacity demanded; } \\
\text { (b) remunerate the participating resources only for their availability and } \\
\text { ensure that the remuneration does not affect decisions of the capacity provider } \\
\text { on whether or not to generate; } \\
\text { (c) ensure that capacity obligations are transferable between eligible capacity } \\
\text { providers.' }\end{array}$
\end{tabular}

Regulation (EU) 2019/943 sets emission limits for generation units to participate in capacity mechanisms. It differentiates between existing and new generation capacity and requires ACER to provide technical guidance on the emission limit values.

Regulation (EU) 2019/943 includes a grandfathering clause for capacity mechanism contracts concluded before 31 December 2019.

Regulation (EU) 2019/943 requires that capacity mechanisms are open for cross-border participation.
Art. 22(4) includes two limits on the $\mathrm{CO} 2$ emissions of generating units participating in capacity mechanisms. This is with regard to the start date of their commercial production. It states that 'capacity mechanisms shall incorporate the following requirements regarding $\mathrm{CO} 2$ emission limits: (a) from 4 July 2019 at the latest, generation capacity that started commercial production on or after that date and that emits more than $550 \mathrm{~g}$ of $\mathrm{CO} 2$ of fossil fuel origin per $\mathrm{kWh}$ of electricity shall not be committed or to receive payments or commitments for future payments under a capacity mechanism; (b) from 1 July 2025 at the latest, generation capacity that started commercial production before 4 July 2019 and that emits more than $550 \mathrm{~g}$ of CO2 of fossil fuel origin per $\mathrm{kWh}$ of electricity and more than $350 \mathrm{~kg} C O 2$ of fossil fuel origin on average per year per installed $k W e$ shall not be committed or receive payments or commitments for future payments under a capacity mechanism. The emission limit of $550 \mathrm{~g} \mathrm{CO} 2$ of fossil fuel origin per $\mathrm{kWh}$ of electricity and the limit of $350 \mathrm{~kg} C O 2$ of fossil fuel origin on average per year per installed $k$ We referred to in points (a) and (b) of the first subparagraph shall be calculated on the basis of the design efficiency of the generation unit meaning the net efficiency at nominal capacity under the relevant standards provided for by the International Organization for Standardization. By 5 January 2020, ACER shall publish an opinion providing technical guidance related to the calculation of the values referred in the first subparagraph.'

Art. 22(5) says that 'Member States that apply capacity mechanisms on 4 July 2019 shall adapt their mechanisms to comply with Chapter 4 without prejudice to commitments or contracts concluded by 31 December 2019.'

Art. 26(1) states that 'capacity mechanisms other than strategic reserves and where technically feasible, strategic reserves shall be open to direct cross-border participation of capacity providers located in another Member State, subject to the conditions laid down in this Article.' Art. 26(3) adds that 'Member States shall not prevent capacity which is located in their territory from participating in capacity mechanisms of other Member States.' 


\begin{tabular}{|c|c|}
\hline $\begin{array}{l}\text { Section of this chapter, topic and relevant } \\
\text { regulation }\end{array}$ & Relevant article \\
\hline $\begin{array}{l}\text { Regulation (EU) } 2019 / 943 \text { sets out the process } \\
\text { for the calculation of the maximum entry } \\
\text { capacity for participation by foreign capacity in } \\
\text { capacity mechanisms and the roles of the RCCs } \\
\text { and the TSOs. }\end{array}$ & $\begin{array}{l}\text { Art. 26(7) states that'for the purposes of providing a recommendation to } \\
\text { transmission system operators, regional coordination centres established } \\
\text { pursuant to Article } 35 \text { shall calculate on an annual basis the maximum entry } \\
\text { capacity available for the participation of foreign capacity. That calculation } \\
\text { shall take into account the expected availability of interconnection and } \\
\text { the likely concurrence of system stress in the system where the mechanism } \\
\text { is applied and the system in which the foreign capacity is located. Such } \\
\text { a calculation shall be required for each bidding zone border. } \\
\text { Transmission system operators shall set the maximum entry capacity available } \\
\text { for the participation of foreign capacity based on the recommendation of the } \\
\text { regional coordination centre on an annual basis.' }\end{array}$ \\
\hline $\begin{array}{l}\text { Regulation (EU) } 2019 / 943 \text { sets the } \\
\text { methodologies, rules and terms related } \\
\text { to cross-border participation in capacity } \\
\text { mechanisms. }\end{array}$ & $\begin{array}{l}\text { Art. 26(11) lists the different methodologies, common rules and terms to be } \\
\text { developed by ENTSO-E and submitted to ACER. It states that 'by } 5 \text { July } 2020 \\
\text { the ENTSO for Electricity shall submit to ACER: } \\
\text { (a) a methodology for calculating the maximum entry capacity for } \\
\text { cross-border participation as referred to in paragraph 7; } \\
\text { (b) a methodology for sharing the revenues referred to in paragraph 9; } \\
\text { (c) common rules for the carrying out of availability checks referred to in point } \\
\text { (b) of paragraph 10; } \\
\text { (d) common rules for determining when a non-availability payment is due; } \\
\text { (e) terms of the operation of the registry as referred to in point (a) of } \\
\text { paragraph } 10 \text {; } \\
\text { (f) common rules for identifying capacity eligible to participate in the capacity } \\
\text { mechanism as referred to in point (a) of paragraph 10.' }\end{array}$ \\
\hline
\end{tabular}




\section{PART III}

How to put the citizen at the centre of the energy transition? 


\section{How to put the citizen at the centre of the energy transition?}

\section{Leonardo Meeus with Athir Nouicer}

In this chapter we answer two questions. First, why did we start this new paradigm? Second, how is this change of paradigm being implemented?

\subsection{WHY DID WE START THIS NEW PARADIGM?}

In this section, we discuss the extent to which the markets for electricity have delivered their promise of better service and cheaper prices. We examine electricity bills, the energy transition and the political issues around the energy transition. ${ }^{1}$

First, electricity bills. The main components of electricity bills are the energy component, the network component, and taxes and levies. The energy component is the wholesale market price plus a retail margin. On average, EU wholesale prices have been steadily decreasing. However, this is not always translated into a decrease in retail prices as not all countries have well-functioning retail markets. The average EU household electricity bill increased by 28.2 per cent during the period 2008-2018. Other components of the electricity bill have been increasing too. The network component increase reflects investments in networks necessary for the integration of renewable energy resources. The taxes and levies, on top of value-added tax, form the component that has increased the most. This has been in order to recover the subsidies that have been provided to support the energy transition. These include support for the large-scale deployment of renewable energy projects and energy efficiency measures. They may also include the costs of social measures against energy poverty. On average in the EU, the three main components of household electricity bills each make up about a third of the total bill. In the same period, the average price for industrial customers only increased by 1.4 per cent. These customers have often contributed less or have been exempted from the taxes and levies that drove up household bills. They have also had more opportunities to benefit from the support mechanisms for renewable energy. Many industrial consumers invested in the co-generation of heat and power, and in solar and wind parks. Some even own and operate private distribution networks on their industrial sites. Until recently, households had fewer opportunities to invest in the energy transition, and the opportunities were often limited to privileged households with PV rooftops.

Second, the energy transition. The EU energy and climate targets for 2030 are more ambitious than those for 2020. The greenhouse gas emission target increases from 20 per cent to 40 per cent (reduction from the 1990 level), the renewable energy target increases from 20 per cent to 32 per cent (energy from renewable sources in the gross final consumption) and the energy efficiency target increases from 20 per cent to 32.5 per cent (savings against 
a baseline energy consumption scenario established in 2007). The new European Commission (2019-2024) has the ambition to achieve climate neutrality by legislating for a net zero greenhouse gas emission target for 2050, and it might even bring forward this ambition to 2030. The electricity sector is one of the sectors that has been partly decarbonized to achieve the 2020 targets. To achieve the 2030 and 2050 targets, this decarbonization will need to accelerate so that other sectors can switch to electricity to decarbonize. The transport sector can then be decarbonized with electric vehicles and other competing technologies, while the building sector can be decarbonized with heat pumps as well as other competing technologies. A combination of carbon pricing and subsidies will need to be used to push this forward, which will put additional pressure on electricity bills.

Third, political issues. Increasing electricity bills for households, and bigger household bills in general, have already created unrest in several countries. The unrest that has attracted the most media attention is the Gilet Jaunes movement in France, which is voicing the frustration of those that feel left behind. At the other end of the spectrum, there is a growing movement of climate activists who are concerned that we are not going fast enough. School strikes and climate marches initiated by young activists in several European countries have been all over the media. The Clean Energy Package was developed and negotiated in the period up to 2019 and speaks to both forces in society. Citizens are invited to take ownership of the energy transition. Putting citizens at the centre of the energy transition is the new paradigm.

\subsection{HOW IS THIS CHANGE OF PARADIGM BEING IMPLEMENTED?}

In this section, we explain how the new paradigm has been translated into an enabling regulatory framework. We first discuss individual and collective consumer rights, and then focus on the actors that will play a key role in helping consumers exercise their rights and opportunities.

\subsubsection{Individual and Collective Consumer Rights}

Below, we discuss the concepts of self-consumption and collective self-consumption through energy communities, and then the consumer's entitlement to a smart meter with a dynamic retail contract. $^{2}$

First, self-consumption. It is true that in most countries consumers can already generate and store electricity and easily manage their energy consumption. Nevertheless, there are still some barriers in the current design of the retail market that may prevent consumers from fully benefiting from such opportunities. Directive (EU) 2019/944 states that consumers should be allowed to become active customers, or 'prosumers'. They should be able to self-consume what they produce to the extent that their production is aligned with their consumption, and if it is not aligned they should be able to sell their production at wholesale prices or at prices offered by retailers. This was already the case in most countries in Europe, but not all of them. Directive (EU) 2019/944 calls for a phase-out of net metering. In countries with net metering, consumers could deduct their production from their consumption even if the two were not aligned. It meant that they were not paying for the network while they were still using it by injecting energy in some periods and taking it back in others. Abolishing net metering is a very first step towards more cost-reflective distribution network tariffs (see Chapter 4). No new 
rights for schemes that do not account separately for the electricity fed into and consumed from the grid are to be granted after 31 December 2023.

Second, collective self-consumption through energy communities. Not every household has the necessary time, knowledge, financial means or space to become a prosumer. Energy communities can help households access all or at least some of the prosumer benefits. Directive (EU) 2018/2001, better known as the revised Renewable Energy Directive (RED II), requires all countries to develop a regulatory framework for renewable energy communities (RECs). These communities can be set up by consumers in the same apartment building, block, street, neighbourhood or region to jointly invest in renewable energy projects. Countries can choose how they define these communities in terms of proximity, but they should enable collective self-consumption within a renewable energy community. Some form of energy cooperative already existed in most countries, but a clear regulatory framework was often lacking. Directive (EU) 2019/944 requires countries to develop a regulatory framework for citizen energy communities (CECs). These communities can mobilize citizens in joint initiatives that go beyond jointly investing in renewable energy projects. They can take over the role of other market parties, such as retailers and aggregators. CECs can be local, like RECs, but they can also be national. Many countries already have green retailers that are organized as cooperatives of citizens operating at the national level.

Third is consumer entitlement to a smart meter with a dynamic retail contract. The target of reaching an 80 per cent roll-out of smart meters by 2020 will not be achieved in all the countries in Europe. Having a smart meter enables dynamic retail contracts, but such contracts have not always been available in countries with smart meters. Directive (EU) 2019/944 continues to encourage a smart meter roll-out, but it is not explicitly required. Countries that decide not to go forward with a roll-out after conducting a cost-benefit assessment must in any case ensure that consumers that want a smart meter can get one within a few months of requesting it and at a reasonable price determined by the energy regulator. National regulatory frameworks are to ensure that consumers with a smart meter are then entitled to a dynamic retail price contract. Dynamic retail contracts have been defined as retail contracts with a temporal granularity at least equal to the market settlement period. Following Regulation (EU) 2019/943, the settlement period is converging towards 15 minutes. Directive (EU) 2019/944 also defines minimum functionalities for smart meters in accordance with Commission Recommendation 2012/148/EU. These include the provision of information on actual times of use, cyber security and consumer privacy protection, consumption data availability on consumer request and remote-control functionalities. At the time of writing, remote-control functionalities are only available in five countries. By giving market parties or the system operator remote-control over their meter or appliances, consumers can earn money for the flexibility they can provide to the system.

\subsubsection{Actors Expected to Enable the New Paradigm}

In what follows, we show why distribution system operators (DSOs), transmission system operators (TSOs), retailers and aggregators have a key role to play in enabling the new paradigm.

First, DSO and TSOs. These will increasingly compete for the use of flexibility between balancing and congestion management, which will require coordination. With the introduction 
of rooftop PVs, batteries, electric vehicles and heat pumps, flexibility is increasingly available in distribution grids and can be aggregated in so-called virtual power plants of decentralized energy resources. In Chapter 5, we showed that TSOs started to change balancing markets to create a level playing field between the traditional and new sources of flexibility. Following Directive (EU) 2019/944, countries also have to create an enabling regulatory framework for DSOs to procure flexibility services from so-called flexibility service providers. DSOs have to develop multi-annual investment plans that consider flexibility as an alternative to network expansion. Some DSOs have already started to procure flexibility services in newly established flexibility markets. Others have started to countertrade locally in intraday markets. Note that this is very similar to redispatching actions by TSOs. Coordination is therefore needed between TSO balancing actions, TSO congestion management actions in transmission networks and DSO congestion management actions in distribution networks. How this will work is an open issue. ${ }^{3}$

Second, retailers and aggregators. Retailers can become aggregators that help their customers valorize their flexibility as balancing service providers for TSOs and/or flexibility service providers for DSOs and TSOs. Retailers did not always do this because it conflicted with their interests as commodity suppliers. Helping customers valorize flexibility can indeed imply selling less volume. New players have therefore emerged that focus on the aggregation business. They either had to become retailers themselves or ask existing retailers to access their clients. Directive (EU) 2019/944 requires all countries to develop an enabling regulatory framework for independent aggregators to operate next to retailers. This includes the possibility of operating without consent from the retailer and an arrangement to organize compensation between the retailer and the aggregator when one inflicts costs on the other. Similar to the provisions for retailers, aggregators also have to provide data to their customers, enable switching and provide clear terms and conditions in their contracts.

The future of retail markets is very much an open issue. There used to be one retailer active at each connection point. Next to the traditional commodity retailer there will now be independent aggregators interacting with the same customers. Retailers risk becoming backup solutions for the supply of a commodity. Energy communities are alternative suppliers, and peer-to-peer supply solutions are also emerging. Peer-to-peer platforms allow consumers to source their energy from producers or prosumers of their choice. How the competition between new and existing players in the retail market will be organized in the future is an open issue.

\subsection{CONCLUSION}

In this chapter about how to put the citizen at the centre of the energy transition, we have answered two questions.

First, why did we start this new paradigm? Households electricity bills have increased more than industrial ones. The energy transition is accelerating, with 2030 and 2050 targets that are more ambitious than the 2020 targets were. Decarbonizing the electricity sector will also help to decarbonize other sectors that could partly electrify, such as the transport sector with electric vehicles and the building sector with heat pumps. Some citizens feel left behind, while others want to accelerate the energy transition. The new paradigm is an answer to these concerns. It increases opportunities for households to benefit from the energy transition. 
Second, how is this change of paradigm being implemented? New individual and collective consumer rights through energy communities have been introduced. The actors that are expected to enable the new paradigm are TSOs, DSOs, retailers and aggregators. Prosumers and energy communities will increasingly participate in balancing markets and flexibility markets to valorize their flexible resources. Aggregators can help them access these markets. The future of retail is uncertain, with competition from energy communities and peer-to-peer trading.

\section{NOTES}

1. ACER and CEER (2019a) provide a decomposition of household and industry electricity bills. The EU average level for the different components is reported together with figures for country capitals over the period 2008-2018. These figures are updated every year in the annual market monitoring report.

2. CEER (2019) gives new and developing practices for collective self-consumption and energy communities and analyses their regulatory implications. ACER and CEER (2019b) provide more information on the status of smart meter roll-outs and the availability of dynamic retail contracts in Europe.

3. In Nouicer and Meeus (2019) we list the different flexibility pilot projects and European initiatives that are being implemented. In Schittekatte and Meeus (2020) we analyse four pioneering flexibility market projects and show that they give a different answer to six key questions: Is the flexibility market integrated in the existing sequence of EU electricity markets? Is the flexibility market operator a third party? Are there reservation payments? Are the products standardized? Is there TSO-DSO cooperation over the organization of the flexibility market? Is there DSO-DSO cooperation over the organization of the flexibility market? The market design options for TSO-DSO coordination are being discussed at the EU level. CEDEC et al. (2019) provide different options for coordination between system operators.

\section{REFERENCES}

ACER and CEER (2019a), 'Market Monitoring Report 2018 - Electricity and Gas Retail Markets Volume'.

ACER and CEER (2019b), 'Market Monitoring Report 2018 - Consumer Empowerment Volume'.

CEDEC, ENTSO-E, GEODE, E.DSO and EURELECTRIC (2019), 'TSO-DSO Report: An Integrated Approach to Active System Management'.

CEER (2019), 'Regulatory Aspects of Self-Consumption and Energy Communities', Ref: C18-CRM9 DS7-05-03.

Nouicer, A. and L. Meeus (2019), ‘The EU Clean Energy Package (Ed. 2019)', FSR Technical Report.

Schittekatte, T. and L. Meeus (2020), 'Flexibility markets: Q\&A with project pioneers', Utilities Policy, 63, 101017. 


\section{A.1 ANNEX: REGULATORY GUIDE}

\section{Table 8A.1 Regulatory guide}

Section of this chapter, topic and relevant regulation

\section{Section 8.2.1}

Directive (EU) 2019/944 defines the concept of active customers and gives final customers rights to act as active customers.

Directive (EU) 2019/944 requires a phasing out of net metering.
Relevant articles

Art. 2(8) defines an active customer as 'a final customer, or a group of jointly acting final customers, who consumes or stores electricity generated within its premises located within confined boundaries or, where permitted by a Member State, within other premises, or who sells self-generated electricity or participates in flexibility or energy efficiency schemes, provided that those activities do not constitute its primary commercial or professional activity.'

Art. 15(1) states that 'Member States shall ensure that final customers are entitled to act as active customers without being subject to disproportionate or discriminatory technical requirements, administrative requirements, procedures and charges, and to network charges that are not cost-reflective.'

Art. 15(2) lists the rights that shall be ensured to active customers. It states that 'Member States shall ensure that active customers are:

(a) entitled to operate either directly or through aggregation,

(b) entitled to sell self-generated electricity, including through power purchase agreements;

(c) entitled to participate in flexibility schemes and energy efficiency schemes;

(d) entitled to delegate to a third party the management of the installations required for their activities, including installation, operation, data handling and maintenance, without that third party being considered to be an active customer,

(e) subject to cost-reflective, transparent and non-discriminatory network charges that account separately for the electricity fed into the grid and the electricity consumed from the grid, in accordance with Article 59(9) of this Directive and Article 18 of Regulation (EU) 2019/943, ensuring that they contribute in an adequate and balanced way to the overall cost sharing of the system;

(f) financially responsible for the imbalances they cause in the electricity system; to that extent they shall be balance responsible parties or shall delegate their balancing responsibility in accordance with Article 5 of Regulation (EU) 2019/943.'

Art. 15(4) states that 'Member States that have existing schemes that do not account separately for the electricity fed into the grid and the electricity consumed from the grid, shall not grant new rights under such schemes after 31 December 2023. In any event, customers subject to existing schemes shall have the possibility at any time to opt for a new scheme that accounts separately for the electricity fed into the grid and the electricity consumed from the grid as the basis for calculating network charges.' 


\begin{tabular}{ll}
\hline $\begin{array}{l}\text { Section of this chapter, topic and } \\
\text { relevant regulation }\end{array}$ & Relevant articles \\
\hline $\begin{array}{l}\text { Directive (EU) 2018/2001 provides } \\
\text { a definition of a renewable energy }\end{array}$ & A REC is defined in Art. 2(16) as '... a legal entity: \\
community (REC). & (a) which, in accordance with the applicable national law, is based on open and \\
& voluntary participation, is autonomous, and is effectively controlled by shareholders \\
& or members that are located in the proximity of the renewable energy projects that are \\
& owned and developed by that legal entity; \\
& (b) the shareholders or members of which are natural persons, SMEs or local \\
& authorities, including municipalities; \\
& (c) the primary purpose of which is to provide environmental, economic or social \\
community benefits for its shareholders or members or for the local areas where it & operates, rather than financial profits.'
\end{tabular}

Directive (EU) 2019/944 provides a definition of a citizen energy community (CEC).

Directive (EU) 2019/944 provides a definition of a dynamic electricity price contract.

Directive (EU) 2019/944 ensures that customers are offered a dynamic electricity price contract.

Directive (EU) 2019/944 includes a provision to inform consumers of the costs and risks of dynamic electricity contracts.

Following Regulation (EU) 2019/943, the market settlement period is converging towards 15 minutes.
A CEC is defined in Art. 2(11) as'... a legal entity that:

(a) is based on voluntary and open participation and is effectively controlled by members or shareholders that are natural persons, local authorities, including municipalities, or small enterprises;

(b) has for its primary purpose to provide environmental, economic or social community benefits to its members or shareholders or to the local areas where it operates rather than to generate financial profits; and

(c) may engage in generation, including from renewable sources, distribution, supply, consumption, aggregation, energy storage, energy efficiency services or charging services for electric vehicles or provide other energy services to its members or shareholders.'

A dynamic electricity price contract is defined in Art. 2(15) as ' ... an electricity supply contract between a supplier and a final customer that reflects the price variation in the spot markets, including in the day-ahead and intraday markets, at intervals at least equal to the market settlement frequency.'

Art. 11(1) states that 'Member States shall ensure that the national regulatory framework enables suppliers to offer dynamic electricity price contracts. Member States shall ensure that final customers who have a smart meter installed can request to conclude a dynamic electricity price contract with at least one supplier and with every supplier that has more than 200000 final customers.'

Art. 11(2) says that 'Member States shall ensure that final customers are fully informed by the suppliers of the opportunities, costs and risks of such dynamic electricity price contracts, and shall ensure that suppliers are required to provide information to the final customers accordingly, including with regard to the need to have an adequate electricity meter installed. Regulatory authorities shall monitor the market developments and assess the risks that the new products and services may entail and deal with abusive practices.'

Art. 8(4) states that 'by 1 January 2021, the imbalance settlement period shall be 15 minutes in all scheduling areas, unless regulatory authorities have granted a derogation or an exemption. Derogations may be granted only until 31 December 2024. From 1 January 2025, the imbalance settlement period shall not exceed 30 minutes where an exemption has been granted by all the regulatory authorities within a synchronous area.' 
Section of this chapter, topic and Relevant articles

relevant regulation

Directive (EU) 2019/944 continues to encourage a smart meter roll-out, but it is not explicitly required.

Directive (EU) 2019/944 requires Member States proceeding with a smart metering system roll-out to adopt and publish the minimum functional and technical requirements of these systems, in accordance with Art. 20 and Annex II of the same Directive.
Art. 19(1) states that 'in order to promote energy efficiency and to empower final customers, Member States or, where a Member State has so provided, the regulatory authority shall strongly recommend that electricity undertakings and other market participants optimise the use of electricity, inter alia, by providing energy management services, developing innovative pricing formulas, and introducing smart metering systems that are interoperable, in particular with consumer energy management systems and with smart grids, in accordance with the applicable Union data protection rules.'

Art. 19(2) states that 'Member States shall ensure the deployment in their territories of smart metering systems that assist the active participation of customers in the electricity market. Such deployment may be subject to a cost-benefit assessment which shall be undertaken in accordance with the principles laid down in Annex II.'

Art. 19(5) adds that "where the deployment of smart metering systems has been negatively assessed as a result of the cost-benefit assessment referred to in paragraph 2, Member States shall ensure that this assessment is revised at least every four years, or more frequently, in response to significant changes in the underlying assumptions and in response to technological and market developments. Member States shall notify to the Commission the outcome of their updated cost-benefit assessment as it becomes available.'

Art. 19(3) states that 'Member States that proceed with the deployment of smart metering systems shall adopt and publish the minimum functional and technical requirements for the smart metering systems to be deployed in their territories, in accordance with Article 20 and Annex II. Member States shall ensure the interoperability of those smart metering systems, as well as their ability to provide output for consumer energy management systems. In that respect, Member States shall have due regard to the use of the relevant available standards, including those enabling interoperability, to best practices and to the importance of the development of smart grids and the development of the internal market for electricity.'

Art. 20 includes requirements on the functionalities of smart metering systems to be followed in accordance with European standards and Annex II of Directive (EU) 2019/944. Among these requirements, smart meters ' ... shall accurately measure actual electricity consumption and shall be capable of providing to final customers information on actual time of use ...' 


Section of this chapter, topic and $\quad$ Relevant articles
relevant regulation

Commission Recommendation 2012/148/EU sets common minimum functional requirements for smart metering systems.

Directive (EU) 2019/944 entitles customers to request smart metering systems in Member States where they are negatively assessed.

\section{Section 8.2.2}

Directive (EU) 2019/944 requires Member States to define the regulatory framework under which DSOs may acquire flexibility services. This will be through a market-based process, unless the regulatory authorities establish that it is not economically efficient.
In addition, validated historical consumption data will be made available to final customers on request and at no additional cost. Also, non-validated near real-time consumption data will be made available at no additional cost through a standard interface or through remote access in a secure and easy way. The aim is to support, inter alia, energy efficiency and demand response programmes. The smart metering system security, data communication and privacy shall comply with Union security rules. Smart meter operators will ensure that their devices account for the electricity fed into the grid by active customers. Data related to the electricity injected will be made available on request to the corresponding customers. They have the right to then transmit their data to another party at no additional cost. Moreover, at the time of the smart meter roll-out, final customers will receive appropriate advice and information concerning their full potential, in accordance with Art. 20(f). Art. 20(g) adds that 'smart metering systems shall enable final customers to be metered and settled at the same time resolution as the imbalance settlement period in the national market.' Section $42(\mathrm{~g})$ states that every smart metering system shall 'allow remote on/off control of the supply and/or flow or power limitation. This functionality relates to both the demand side and the supply side. It provides additional protection for the consumer by allowing grading in the limitations. It speeds up processes such as when moving home - the old supply can be disconnected and the new supply connected quickly and simply. It is needed for handling technical grid emergencies. It may, however, introduce additional security risks which need to be minimised.'

Art. 21(1) states that "where the deployment of smart metering systems has been negatively assessed as a result of the cost-benefit assessment referred to in Article $19(2)$ and where smart metering systems are not systematically deployed, Member States shall ensure that every final customer is entitled on request, while bearing the associated costs, to have installed or, where applicable, to have upgraded, under fair, reasonable and cost-effective conditions, a smart meter that:

(a) is equipped, where technically feasible, with the functionalities referred to in Article 20, or with a minimum set of functionalities to be defined and published by Member States at national level in accordance with Annex II;

(b) is interoperable and able to deliver the desired connectivity of the metering infrastructure with consumer energy management systems in near real-time.'

Art. 32(1)states that' Member States shall provide the necessary regulatory framework to allow and provide incentives to distribution system operators to procure flexibility services, including congestion management in their areas, in order to improve efficiencies in the operation and development of the distribution system. In particular, the regulatory framework shall ensure that distribution system operators are able to procure such services from providers of distributed generation, demand response or energy storage and shall promote the uptake of energy efficiency measures, where such services cost-effectively alleviate the need to upgrade or replace electricity capacity and support the efficient and secure operation of the distribution system. 
Section of this chapter, topic and Relevant articles

relevant regulation

Directive (EU) 2019/944 requires DSOs to establish flexibility service specifications in a process including all relevant stakeholders. The Directive invites DSOs and TSOs to coordinate over efficient, reliable and secure operation of their network. They should exchange data and information to ensure optimal use of the resources connected to their networks.

Directive (EU) 2019/944 requires DSOs to develop distribution network development plans, with a possible derogation for small DSOs. These plans are to include a trade-off between system expansion and the use of flexibility services. DSOs will consult all relevant system users during the development process. congestion.'
Distribution system operators shall procure such services in accordance with transparent, non-discriminatory and market-based procedures unless the regulatory authorities have established that the procurement of such services is not economically efficient or that such procurement would lead to severe market distortions or to higher

Art. 32(2) states that 'Distribution system operators, subject to approval by the regulatory authority, or the regulatory authority itself, shall, in a transparent and participatory process that includes all relevant system users and transmission system operators, establish the specifications for the flexibility services procured and, where appropriate, standardised market products for such services at least at national level. The specifications shall ensure the effective and non-discriminatory participation of all market participants, including market participants offering energy from renewable sources, market participants engaged in demand response, operators of energy storage facilities and market participants engaged in aggregation ...'

RegardingDSO-TSO coordination, Art. 32(2) adds that ' ... Distribution system operators shall exchange all necessary information and shall coordinate with transmission system operators in order to ensure the optimal utilisation of resources, to ensure the secure and efficient operation of the system and to facilitate market development. Distribution system operators shall be adequately remunerated for the procurement of such services to allow them to recover at least their reasonable corresponding costs, including the necessary information and communication technology expenses and infrastructure costs.'

Art. 32(3) states that 'the development of a distribution system shall be based on a transparent network development plan that the distribution system operator shall publish at least every two years and shall submit to the regulatory authority. The network development plan shall provide transparency on the medium and long-term flexibility services needed, and shall set out the planned investments for the next five-to-ten years, with particular emphasis on the main distribution infrastructure which is required in order to connect new generation capacity and new loads, including recharging points for electric vehicles ...' Network development plans are to include a trade-off between network development and alternative technologies. Art 32(3) adds that these plans '... shall also include the use of demand response, energy efficiency, energy storage facilities or other resources that the distribution system operator is to use as an alternative to system expansion.'

The development of these plans will involve different relevant stakeholders. Art. 32(4) states that 'the distribution system operator shall consult all relevant system users and the relevant transmission system operators on the network development plan. The distribution system operator shall publish the results of the consultation process along with the network development plan, and submit the results of the consultation and the network development plan to the regulatory authority. The regulatory authority may request amendments to the plan.' 


\begin{tabular}{|c|c|}
\hline $\begin{array}{l}\text { Section of this chapter, topic and } \\
\text { relevant regulation }\end{array}$ & Relevant articles \\
\hline $\begin{array}{l}\text { Directive (EU) } 2019 / 944 \text { establishes } \\
\text { a regulatory framework clarifying } \\
\text { the roles and responsibilities of } \\
\text { (independent) aggregators. It aims to } \\
\text { remove the barriers they may face when } \\
\text { entering the market. }\end{array}$ & $\begin{array}{l}\text { Art. 32(5) allows a derogation from the development of distribution network } \\
\text { development plans, to be decided by Member States, for 'integrated electricity } \\
\text { undertakings which serve less than } 100000 \text { connected customers or which serve small } \\
\text { isolated systems.' } \\
\text { Art. } 17 \text { (3) states, in the framework of demand response through aggregation, that } \\
\text { 'Member States shall ensure that their relevant regulatory framework contains at least } \\
\text { the following elements: } \\
\text { (a) the right for each market participant engaged in aggregation, including } \\
\text { independent aggregators, to enter electricity markets without the consent of other } \\
\text { market participants; } \\
\text { (b) non-discriminatory and transparent rules that clearly assign roles and } \\
\text { responsibilities to all electricity undertakings and customers; } \\
\text { (c) non-discriminatory and transparent rules and procedures for the exchange of } \\
\text { data between market participants engaged in aggregation and other electricity } \\
\text { undertakings that ensure easy access to data on equal and non-discriminatory terms } \\
\text { while fully protecting commercially sensitive information and customers' personal } \\
\text { data; } \\
\text { (d) an obligation on market participants engaged in aggregation to be financially } \\
\text { responsible for the imbalances that they cause in the electricity system; to that } \\
\text { extent they shall be balance responsible parties or shall delegate their balancing } \\
\text { responsibility in accordance with Article } 5 \text { of Regulation (EU) 2019/943; } \\
\text { (e) provision for final customers who have a contract with independent aggregators } \\
\text { not to be subject to undue payments, penalties or other undue contractual restrictions } \\
\text { by their suppliers; } \\
\text { (f) a conflict resolution mechanism between market participants engaged in } \\
\text { aggregation and other market participants, including responsibility for imbalances.' }\end{array}$ \\
\hline
\end{tabular}




\section{Conclusion}

\section{Leonardo Meeus}

In the evolution of electricity markets in Europe, day-ahead markets have received most attention. It took a long time to integrate these markets, but the process is almost complete. What was considered impossible at the start has been achieved. Intraday markets have been slower in their development, but they are becoming more important with the transition to renewable energy. In balancing markets, the definition of standard products and the creation of European platforms to exchange these products across borders is a relatively new ambition, but much has been achieved in a relatively short time. Of course, the devil is in the details, so implementation in the coming years will need to be closely monitored.

Looking back, most of the market integration process so far has required horizontal coordination between transmission system operators in different countries. Transmission constraints were first managed by defining transmission rights and organizing separate markets for these rights. The constraints were then integrated into wholesale markets and balancing markets because this proved to be the best approach. The calculation of transmission constraints has also been reorganized. The main open issues are the availability of transmission capacity across timeframes and the definition of bidding zones. We currently have large bidding zones with structural congestion inside them, and changing them is a sensitive topic.

Looking forward, vertical coordination between transmission and distribution system operators is becoming more important, and this coordination process has only just started. Distribution network constraints have always been avoided by (over-)investing in distribution networks. This approach is becoming too expensive due to the integration of wind, solar, electric vehicles and heat pumps in distribution grids. The trade-off between distribution grid expansion and using flexibility to reduce the need for investment is one of the main challenges. Flexibility can come from smart charging of electric vehicles and batteries, smart heating of homes and the use of many other smart appliances.

To allow for coordination between all the resources at different voltage levels, this flexibility deep inside the grid needs to be priced efficiently. Academics are already thinking of wholesale and balancing markets that incorporate distribution network constraints to produce distribution locational marginal prices. Practitioners in Europe currently do not consider this to be feasible. Other solutions are favoured, such as flexibility markets, smart connection agreements and distribution tariff reforms. We know from experience that these solutions can help, but they have their limitations. It seems inevitable that we will go in the direction of DLMP. The question is how long it will take. 


\section{Index}

access charges $68-9,70,74$

ACER (The (European Union) Agency for the Cooperation of Energy Regulators) 7, 9, $12,13,18-24,30,31,34,35,43-4,46-7$, $52,55-6,58,63,65-7,70,73,75,79$, 81-2, 84-5, 91, 92, 94, 97, 100, 105-7, $122,127-8,134,140,141,146,150-151$, 157

ACER Regulation (recast of) 3, 5, 18, 21-3 active customers $80,154-5,158,161$ aggregation 123, 126, 130, 156, 157, 158, 163 automatic frequency restoration process ( $\mathrm{aFRP}$ ) 93, 101, 107

automatic frequency restoration reserves (aFRR) 84-5, 87, 90, 93-4, 96, 100-102, 106-7, 109

balance responsibility $84-8,89-95,96,110$ balance responsible parties (BRPs) 88-9, 91, 104, $141,149,158,163$

balancing capacity exchange $94-5,108-10$

balancing capacity tenders $90-91,96,105-7$

balancing energy exchange see exchange of balancing energy, European platforms for

balancing energy markets 90-91, 96, 106

balancing markets $33,89,90,91-5,96,136,141$, $149,156,157,164$

balancing pilot projects 97

bidding zones $12,40-41,42-7,50-51,55-6,57$, $60,61,62,63,65-6,67,73-4,88,89,103$, $146-7,151,164$

border trade constraints 48-50, 51-7, 60, 61, $62-7$

Brexit 12-13

BRPs see balance responsible parties (BRPs)

capacity allocation and congestion management guideline (CACM GL) 8, 20, 23, 29-31, $33-4,42-7,51-4,56-7,62-6,102,109$, 127

capacity calculation regions (CCRs) $52,53,57$, 63,66

capacity mechanisms 135-7, 138, 139-40, 141, $142,145-51$
CBCA see cross-border cost allocation (CBCA) agreements

CCRs see capacity calculation regions (CCRs)

CEP see Clean Energy Package (CEP)

CGM see common grid model (CGM)

citizens, placing at centre of energy transition 153-4, 155-6, 157, 158-63

Clean Energy Package (CEP) 3, 4, 5, 9, 13, 18 , 20-23, 31, 44, 52, 56, 57, 115, 123, 127-8, $139,142,154$

clock incident $87-8$

common grid model (CGM) 53-4, 62, 64, 65, 114,127

congestion management 42, 95, 96, 155-6, 162

see also capacity allocation and congestion management guideline (CACM GL)

congestion rent 40-41, 78

congestion revenue 69,79

connection charges $68,69,74$

connection network codes (CNCs) 8, 116-20, $121-3,125-6,127-34$

connection requirements see system operation and connection requirements

consumer rights $154-5$

cost-benefit analysis (CBA) 72, 73, 81

cost-reflective network charges 70-71, 74, 80, 96, 154,158

cost sharing 30

Council of European Energy Regulators (CEER) $14,55,58,63,67,91,97,157$

cross-border cooperation 11-12

cross-border cost allocation (CBCA) agreements $72-5,82$

cross-border intraday market project (XBID) 34, 35

cruise ship incident 112-13, 123

data exchange $52-5,57,65$

day-ahead timeframes 28-35

demand connection network code (DC NC) 8, 24, $116,117-20,121-2,125,126,129-34$

Directive 96/92/EC see First Directive

Directive 2003/54/EC see Second Directive

Directive 2009/72/EC see Third Directive 
Directive (EU) 2018/844 see Energy Performance in Buildings Directive

Directive (EU) 2018/2001 see Renewable Energy Directive (RED II)

Directive (EU) 2018/2002 see Energy Efficiency Directive

Directive (EU) 2019/944 see Electricity Directive (Recast of)

Directorate-General for Competition (DG COMP) $55-6,67$

distribution locational marginal pricing (DLMP) 58,164

distribution system operators (DSOs) 5, 7, 9, 17-18, 21-2, 24, 53, 54-5, 65, 80, 95, $110,113,116,118,126,131,137,155-6$, $162-3$

electricity balancing guideline (EB GL) 8,20 , $23,84-5,87,89,90,91-2,93-4,95,96$, $100-110$

electricity bills $153,154,156$

Electricity Directive (Recast of) 3-4, 5, 79, 90, $105,128,147,154-6,158-60,161-3$

electricity market integration $2,11-13,16-17,25$, $27,35,38-9,54-5,92-5,96,164$

electricity price area differentials (EPADs) 33

Electricity Regulation (recast of) 3, 5, 18, 20-24, $44,52,56,62-7,70,79-80,88,89,90$, 94-5, 101, 103-6, 109, 115, 122-3, 127-8, $134,139-40,141,146-51,155,158-9$, 163

electricity transmission system operation guideline (SO GL) 8, 20, 23-4, 52, 53, $54,57,62-5,84-6,87,94,95,100-102$, $108-10,114,118,123,127,129-30$

emergency and restoration network code (ER NC) $8,24,62,127$

energy communities $155,156,157,159$

Energy Efficiency Directive 5

energy-only markets 135, 142, 145

Energy Performance in Buildings Directive 5

energy storage $70,79,90,105,122-3,134,135$, $138,146,147,149,159,162,163$

ENTSO-E see European Network of Transmission System Operators for Electricity (ENTSO-E)

EU electricity network codes 7-10, 13, 19-21, 22, $23-4,31,34-5,56,64,122-3,134$

EU legislative energy packages 4-7, 13, 16-24

EU resource adequacy assessment 135, 139-40, 142, 146-8

EUPHEMIA (Pan-European Hybrid Electricity Market Integration Algorithm) 29, 30-31
European Network of Transmission System Operators for Electricity (ENTSO-E) 5, 6, $7,9,13,18-22,24,30,53,54,56,64-5$, $67,69,71,72,75,80-81,85,87,92,94$, 96-7, 111, 114, 115, 118, 124, 127-9, $139-40,141,146,151$

European platforms for exchange of balancing energy $93-4,96,100,102,106,107-8$, 110,164

European Single Market 2, 13, 138

European treaties 2,13, 16

exchange of balancing capacity $94-5,108-10$

exchange of balancing energy, European platforms for 93-4, 96, 100, 102, 106, $107-8,110,164$

explicit auctions $25,26-7,32,33-4,47,69$

financial transmission rights (FTRs) 32-3, 46

First Directive 3-4, 16-17, 18, 25, 34, 42

First Energy Package 3-4, 5, 12, 17-18

flexibility markets 95, 96, 155-6, 157, 164

flow-based market coupling (FBMC) 50-51, 52, $55,57,60,61,62,72$

forward capacity allocation guideline (FCA GL) $8,20,23,32-3,34,44-6,52-3,54,57$, $63-5$

frequency containment $85-6,92,95,100,106$, 109

frequency containment reserves (FCR) 85-6, 87, 91, 94, 95, 101, 106, 108-9

frequency-controlled reserves 85,86

frequency restoration 86-7, 92, 113

see also automatic frequency restoration process (aFRP); automatic frequency restoration reserves (aFRR); manual frequency restoration reserves (mFRR)

frequency restoration control error (FRCE) 101-2 frequency restoration process (FRP) 85, 86-7, 96, $101-2,106-7$

frequency restoration reserves (FRR) 87, 90, 93, 94-5, 102, 105, 106, 109

G-component (generator component) 69, 72, 79-80

generation adequacy 80,135, 137, 141, 142

generation and load data provision methodology (GLDPM) 53, 54, 63-4, 65

grid user, different types of 116-17, 125-6

harmonization of network tariffs 69-70, 74

high voltage direct current (HVDC) 74, 125-6

high voltage direct current network code (HVDC NC) $8,24,116,123,125$ 
historical privileges for trade across borders 25-6, 34

IGMs see individual grid models (IGMs) imbalance netting 92-3, 95, 96, 107, 109 imbalance settlement 88-9, 91, 96, 103, 141, 149 imbalance settlement period (ISP) 44, 89, 96, $104-5,106,141,149,159,161$

implicit auctions 27, 32, 34, 41, 47 see also market coupling independent system operators (ISOs) 48, 142-3 individual grid models (IGMs) 53-4, 64

inter-TSO compensation (ITC) scheme 71-2, 74, 75,80

intraday auctions 33-4, 35, 47

intraday capacity calculations $51,54,57,62-3$, 127

intraday common grid models 64

intraday cross-zonal capacity 47

intraday cross-zonal gate closure 46-7, 95, 102, 109-10

intraday cross-zonal pricing 34, 47

intraday markets $30,33-4,35,38,39,42-4,87$, $95,110,156,159,164$

intraday technical price limit 141, 149

intraday trading services 29,42

intraday transmission rights 33-4

Italian blackout 49-50

Italy-Greece case 74

ITC mechanism see inter-TSO compensation (ITC) scheme

Joint Allocation Office (JAO) 32, 44

KORRR methodology 54-5, 65

load frequency control (LFC) 86, 87, 94, 101-2, 108-10, 130

load-shedding plans and controversies 136-7

loop flows 61

manual frequency restoration reserves (mFRR) 84-5, 87, 90, 93-4, 96, 100, 102, 106-7, 109

market-based allocation of transmission rights 26-7, 34

market coupling 27, 28-34, 35, 40-41, 42-3, 78 see also flow-based market coupling

(FBMC)

market coupling operator (MCO) 25, 29-30, 34, $40-41,42-3,60$

market splitting 25-6, 28, 29, 33

missing market problem 136, 142 missing money problem 91, 96, 135-6, 138, 142

$\mathrm{N}-1$ redundancy principle 49,57

national regulatory authorities (NRAs) 5, 7, 8-9, $17-18,20,22,25,31-2,34,43,46-7,52$, $53,56,63,65,71-3,82,100,107-8,114$, $122,125,127,134$

net transfer capacity (NTC) 50-51, 58, 62

network codes see connection network codes

(CNCs); EU electricity network codes

network tariffs 68, 69-70, 71-5, 78, 79-82

nodal pricing 56-7, 58, 88

Nominated Electricity Market Operators (NEMOs) 8, 20-21, 29-31, 42-4, 47

Nordic Cooperation of Electricity Utilities (NORDEL) 84, 85, 86

Norway-Sweden case 73-4

offshore power park module (OPPM) 116, 125, 129,133

Operational Planning Data Environment (OPDE) 54, 64

over the counter (OTC) trading 31, 38

peer-to-peer trading 156, 157

Physical Communication Network (PCN) 54

physical transmission rights (PTRs) 32-3, 46

power exchanges $27,28-33,35-6,38-9,40-41$, 42-3

power-generating modules (PGMs) 116-22, 125, 128-33

power park module (PPM) 116, 118, 120, 125, 129,132

power plants investment see capacity mechanisms power system $10,11,13,53,64,84,87,111,118$, 122,123

priority lists $9,19,22,25-6$

pro-rata rationing $25-6$

proactive balancing 87,96

projects of common interest (PCIs) 72-3, 74-5, 80-82

rationing of supply 136-7

RCCs see regional coordination centres (RCCs)

reactive balancing $87,96,102$

real-time energy pricing 89,105

regional coordination centres (RCCs) 52, 53-4, $57,62,63,64,66,67,94-5,109,114,115$, 127,128

regional security coordination initiatives (RSCIs) 51-2, 62, 113-14, 123

regional security coordinators (RSCs) 51-2, 53, $57,62-3,64,114-15,124,127,128$

regional system operation $113-15,123$ 
Regulation (EC) 713/2009 3, 18, 20-21

Regulation (EC) 714/2009 3, 18-24, 72, 79-80, 116

Regulation (EC) 1228/2003 3-4, 26, 34, 42, 69, $72,79-80$

Regulation (EU) 2018/1999 see Regulation on the Governance of the Energy Union

Regulation (EU) 2019/941 see Regulation on Risk-Preparedness

Regulation (EU) 2019/942 see ACER Regulation (recast of)

Regulation (EU) 2019/943 see Electricity Regulation (Recast of)

Regulation (EU) No 347/2013 see Trans-European Energy Network (TEN-E) Regulation

Regulation on Risk-Preparedness 3, 5, 115, 123, 128

Regulation on the Governance of the Energy Union 5, 147

regulatory guides $16-24,42-7,62-7,79-82$, $100-110,127-34,145-51,158-63$

Renewable Energy Directive (RED II) 5, 155, 159

requirements for grid connection of generators network code (RfG NC) 8, 24, 116, $117-18,120,121-2,125,126,128-34$

reserve products, terminology for $84-5$

reserve replacement $85,87,100,106,108-9$

reserves $11-12,85-6,87,89-92,93,94-5,96$, $101,102,105,106,108-10$

see also automatic frequency restoration reserves (aFRR); frequency containment reserves (FCR); manual frequency restoration reserves (mFRR)

resource adequacy see EU resource adequacy assessment

risk preparedness 115

see also Regulation on Risk-Preparedness

RSCs see regional security coordinators (RSCs)

scarcity pricing $91-2$

Second Directive 3-4, 17, 18

Second Energy Package 3-4, 5, 7, 12, 17-18, 26

security of supply $2,16,105,136-8,141,147$

sharing balance responsibility between system operators $84-8,95-6$

sharing network investment costs between countries $72-5$

sharing of reserves $11-12,94-5,108-10$

single day-ahead coupling (SDAC) 28-9, 31, 34, 43-4

single energy market 12,16

Single European Act 1986 2, 16 single intraday coupling (SIDC) 34, 42-4, 47

solar eclipse incident 111-12, 115, 123

solidarity mechanism 10-11, 85-6, 95-6, 101

synchronous power-generating module (SPGM) $116,118,120,125,129,132$

system disturbance 111-12

system inertia 10,11,13,118, 122

system operation and connection requirements $111-13,115-20,121-3,125-6,127-34$

system operation guideline (SO GL) $8,20,23-4$, $52,53,54,57,62-5,85,86,87,94,95$, 100-102, 108-10, 114, 118, 123, 127, $129-30$

tandem bicycle analogy 10-11

technical standards $115-20,121,122-3,125-6$

Tempus case 138

Ten-Year Network Development Plan (TYNDP) $72,75,80$

Terms and Conditions or Methodologies (TCM) 8-9

Third Directive 3-4, 17-18, 104, 125-6, 129

Third Energy Package 3-4, 5, 7, 8-9, 17-23, 129

trade across borders $25-6,28-31,33-4,35,38-9$, $40-41,42-7$

see also border trade constraints; transmission rights

Trans-European Energy Network (TEN-E) Regulation 72-3, 74, 80-82

transit charges $71-2,74,80$

transit flows $61,71-2$

transmission lines 48-9, 55, 57, 72, 80, 95, 109

transmission planning $48-9,57$

transmission rights $25-7,32,33-5,42,44-6,50$, $69,94,78,136,164$

transmission system operators (TSOs) 5-7, 8, 9, $11,13,17-18,20-21,25,26,28,30,32-3$, $34-5,38-9,42-7,48-52,53-5,56,57$, $60,62-7,68-9,71-2,73,74,78,79-80$, $82,84,86-8,89,90,92-5,96,100-110$, 111-13, 114-15, 118-20, 121-2, 123, 126, $127-34,137,138,141,145,151,155-6$, 157,162

TSOs see transmission system operators (TSOs)

Union for Coordination of Transmission of Energy (UCTE) 49-50, 84, 85, 86, 112

virtual border calculations see border trade constraints

volume coupling $28-9,35$

zonal congestion pricing approach 50 